$$
\begin{gathered}
\text { UNIVERSIDADE DE SÃO PAULO } \\
\text { ESCOLA DE ENGENHARIA DE SÃO CARLOS }
\end{gathered}
$$

MAURICIO FRANCISCO CALIRI JUNIOR

MODELOS DE MATERIAL PARA ESPUMAS POLIMÉRICAS APLICADAS A ESTRUTURAS AERONÁUTICAS EM MATERIAL COMPÓSITO SANDUÍCHE 


\title{
MODELOS DE MATERIAL PARA ESPUMAS POLIMÉRICAS APLICADAS A ESTRUTURAS AERONÁUTICAS EM MATERIAL COMPÓSITO SANDUÍCHE
}

\begin{abstract}
Dissertação apresentada à Escola de Engenharia de São Carlos, da Universidade de São Paulo, como parte dos requisitos para obtenção do título de Mestre em Engenharia Mecânica. Área de concentração: Aeronaves.
\end{abstract}

Orientador: Prof. Dr. Volnei Tita

São Carlos 
AUTORIZO A REPRODUÇÃO E DIVULGAÇÃO TOTAL OU PARCIAL DESTE TRABALHO, POR QUALQUER MEIO CONVENCIONAL OU ELETRÔNICO, PARA FINS DE ESTUDO E PESQUISA, DESDE QUE CITADA A FONTE.

Ficha catalográfica preparada pela Seção de Tratamento da Informação do Serviço de Biblioteca - EESC/USP

\footnotetext{
Caliri Junior, Mauricio Francisco
C154m Modelos de material para espumas poliméricas aplicadas a estruturas aeronáuticas em material compósito sanduíche / Mauricio Francisco Caliri Junior ; orientador Volnei Tita. - São Carlos, 2010.

Dissertação (Mestrado-Programa de Pós-Graduação em Engenharia Mecânica e Área de Concentração em Aeronaves) - Escola de Engenharia de São Carlos da Universidade de São Paulo, 2010 .

1. Estrutura de aeronaves. 2. Espuma polimérica.

3. Modelos de material. 4. Ensaios experimentais.

5. Estruturas sanduíche. 6. Material anisotrópico.

7. Elementos finitos. 8. Correlação de imagens.

I. Título.
} 


\section{FOLHA DE JULGAMENTO}

Candidato: Engenheiro MAURICIO FRANCISCO CALIRI JUNIOR.

Dissertação defendida e julgada em 08/07/2010 perante a Comissão Julgadora:

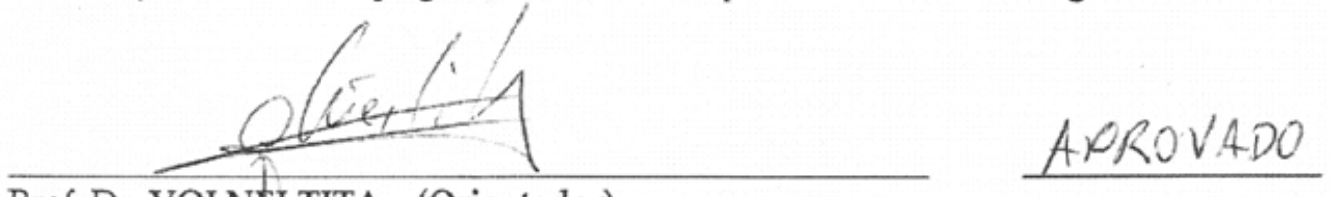

Prof. Dr. VOLNEI TITA - (Orientador)

(Escola de Engenharia de São Carlos/USP)

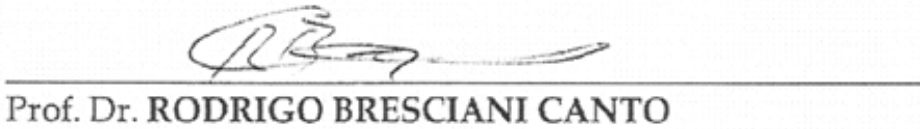

APROL'ADO

(Universidade Federal de São Carlos/UFSCar)

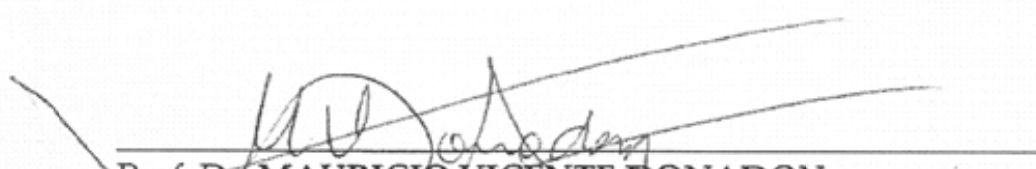

Prof.DH.MAURICIO VACENTE DONADON

APROVACO

(Instituto Teenorogico de Aeronáutica/ITA)

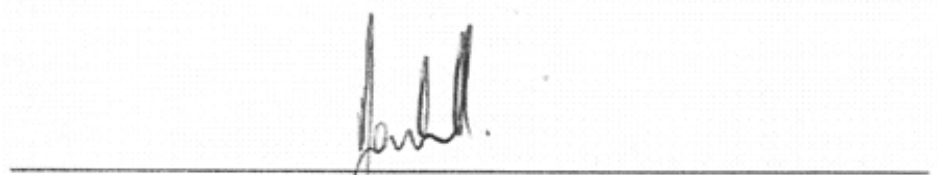

Prof. Associado JONAS DE CARVALHO

Coordenador do Programa de Pós-Graduação em

Engenharia Mecânica

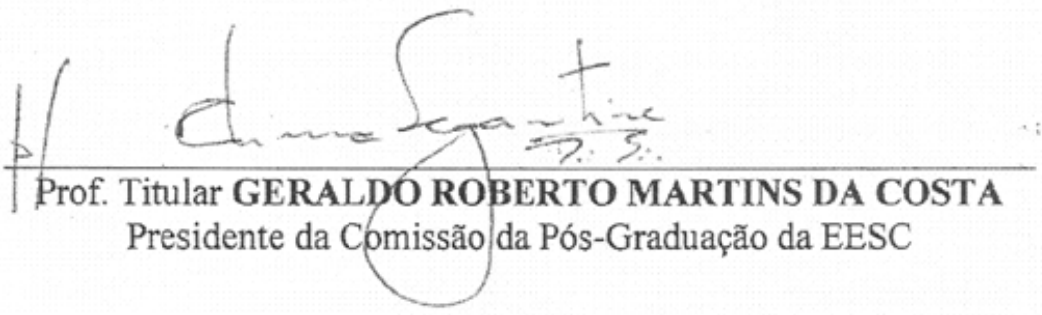


Aos meus Pais

Maurício e Maria 


\section{AGRADECIMENTOS}

Agradeço a todos aqueles que me auxiliaram neste período de pesquisas e colaboraram para a conclusão deste trabalho de Mestrado:

Ao Conselho Nacional de Desenvolvimento Científico e Tecnológico (CNPq) pelo suporte financeiro.

Aos meus Pais, por toda sua ajuda e apoio às minhas decisões pessoais.

Ao Prof. Dr. Volnei Tita, meu orientador e amigo, que me proporcionou essa oportunidade de fazer pesquisa e evoluir profissionalmente.

A todos os colegas do Grupo de Estruturas Aeronáuticas e de outros grupos de pesquisa que contribuíram de alguma forma para a realização das tarefas práticas deste trabalho.

Ao Prof. Tit. Waldek Wladimir Bose Filho por gentilmente ceder à máquina de ensaios EMIC.

Ao Prof. Assoc. Reginaldo Teixeira Coelho pelo uso da licença do programa ABAQUS.

Ao centro de pesquisa LMT-Cachan pelo uso do programa Correli ${ }^{\mathrm{Q} 4}$. 
"Os problemas significativos que enfrentamos não podem ser resolvidos no mesmo nível de pensamento em que estávamos quando os criamos."

Albert Einstein

"A frase mais excitante de ouvir na Ciência, a que anuncia novas descobertas, não é 'Eureka' (Descobri!) mas 'Que engraçado...','

Isaac Asimov 


\section{RESUMO}

\section{CALIRI JR., M. F. Modelos de Material para Espumas Poliméricas Aplicadas a}

Estruturas Aeronáuticas em Material Compósito Sanduíche. 2010. 168 f. Dissertação (Mestrado) - Escola de Engenharia de São Carlos, Universidade de São Paulo, São Paulo, 2010 .

Estruturas aeronáuticas são em sua grande parte fabricadas em material compósito para que sejam atendidas as especificações de projeto. Entre essas estruturas destaca-se a estrutura sanduíche. A utilização desse tipo de estrutura requer estudos extensos em novos materiais, bem como na aplicação dos mesmos. Uma atenção especial para o núcleo dessas estruturas é necessária, pois este material é na verdade uma estrutura celular, como as espumas poliméricas. Esta dissertação busca concatenar a literatura com a prática ao estudar a calibração de modelos de material para descrever o comportamento mecânico de espumas poliméricas, bem como avaliar suas potencialidades e limitações. Estas espumas são estruturas celulares cujos mecanismos de falha consistem em respostas micro e macroscópicas. A identificação e quantificação desses comportamentos podem ser feitas através da investigação de modelos de material micro-mêcanicos ou fenomenológicos (macromecânicos) associados a ensaios e análises experimentais tanto do material celular quanto da estrutura na qual este material é utilizado. Cada abordagem, micro ou macro-mecânica, possui vantagens e desvantagens que no presente trabalho são discutidas para o material estudado (espuma polimérica rígida de PVC, poli-cloreto de vinila, com estrutura de células fechada e densidade de $60 \mathrm{~kg} / \mathrm{m}^{3}$ ). Uma série de ensaios experimentais com bases em normas é realizada e os dados coletados são comparados com dados obtidos simultaneamente através de uma técnica de correlação de imagens. Todas as informações experimentais são confrontadas e associadas aos mecanismos de falha da espuma polimérica. Finalmente, os dados experimentais são utilizados nas identificações de parâmetros de modelos de material disponíveis em um programa comercial de elementos finitos - ABAQUS. Com os modelos de material calibrados, o presente trabalho investiga a representatividade e as limitações dos mesmos quando aplicados a estruturas aeronáuticas submetidas a cargas localizadas, monotônicas ou não. Observou-se que há uma forte dependência da resposta macroscópica da espuma com sua estrutura celular quando submetida a cargas localizadas e/ou não- 
monotônicas. Ademais, o uso de modelos de material simplificados, e/ou com hipóteses de implementação, gera resultados duvidosos quando estes modelos são aplicados a materiais celulares com respostas complexas (mecanismos micro-mecânicos, anisotropia, viscosidade, etc.). Todavia, o presente trabalho mostra que uma calibração estratégica relevando as hipóteses de implementação e as limitações do modelo de material, fornece bons resultados macroscópicos que são fortemente influenciados pelos mecanismos de falha micromecânicos.

Palavras chave: Estrutura de aeronaves. Espuma polimérica. Modelos de material. Ensaios experimentais. Estrutura sanduíche. Material anisotrópico. Elementos finitos. Correlação de imagens. 


\section{ABSTRACT}

CALIRI JR, M. F. Material Models for Polymeric Foams applied to Aircraft Structures in Sandwich Composite Materials. 2010. 168 f. Dissertation (Master of Science) - Escola de Engenharia de São Carlos, Universidade de São Paulo, São Paulo, 2010.

Aircraft structures are mostly made of composite material in order to achieve the specifications of a project. Among these structures one highlights the sandwich structure. The usage of this structure requires extensive studies on new materials as well as on the application of these very materials. A special attention for the core's material of these structures is needed because it is in fact a cellular structure, as the polymeric foams. This dissertation seeks to concatenate the literature and practice, studying the calibration of material models to describe the mechanical behavior of polymeric foams, as well as to analyse their potentials and limitations. These foams are cellular structures whose failure mechanisms comprise micro and macro responses. The identification and quantification of these behaviors can be done through micro-mechanical or phenomenological (macro-mechanical) material models along with experimental tests and analyses of both the cellular material and the structure in which this material is used. Each approach, micro or macro, has advantages and disadvantages that in the present work are discussed for the studied material (PVC, polyvinyl-chloride, rigid closed-cell polymeric foam with a density of $60 \mathrm{~kg} / \mathrm{m}^{3}$ ). A series of experimental tests based on standard procedures are carried out and the data collected are compared with data obtained simultaneously through an image correlation technique. All the experimental information are confronted and associated to the failure mechanisms of the polymeric foam. Finally, the experimental data are used for the identification of material models parameters, currently available in the commercial finite elements software ABAQUS. With the material models calibrated, the present work investigates the representativeness and the limitations of these very models when applied to aircraft structures submitted to monotonic or not localized loads. One has observed that there is a strong dependence of the foam's macroscopic response with its cellular structure when it is submitted to localized and/or non-monotonic loads. Moreover, the usage of simplified material models, and/or with some implementation hypotheses, renders doubtful results when these models are applied to cellular materials with complex responses (micro-mechanical 
mechanisms, anisotropy, viscosity, etc.). Nevertheless, the present work shows that a strategic calibration taking into account the implementation hypotheses and the limitations of the material model, yields good macroscopic results that are strongly influenced by the micromechanical failure mechanisms.

Keywords: Aircraft structures. Polymeric foam. Material models. Experimental tests. Sandwich structure. Anisotropic material. Finite elements. Image correlation. 


\section{LISTA DE FIGURAS}

Figura 1. Estruturas equivalentes com esforços genéricos de força normal (F) e momentos fletores (M): a) Estrutura sanduíche; b) Viga de seção "I". 2

Figura 2. Comparação entre materiais para o núcleo. a) Estrutura genérica tipo colméia, honeycomb; b) Espuma polimérica rígida de Policloreto de Vinila (PVC)............. 5

Figura 3. Diagrama simplificado de forças externas em um ensaio de flexão em 3 pontos..... 12 Figura 4. Diagrama de esforços solicitantes para uma seção genérica da estrutura sanduíche em um ensaio de flexão em 3 pontos.

Figura 5. Estruturas celulares: a) cortiça; b) balsa; c) esponja; d) estrutura celular de célula fechada; e) estrutura celular bidimensional tipo colméia; f) estrutura celular de célula aberta. 20

Figura 6. Curva tensão-deformação típica de materiais celulares em compressão . 22

Figura 7. Representação simplificada das células para modelagem micro-mecânica do material celular: a) Estrutura de células abertas; b) Estrutura de células fechadas25

Figura 8. Micrografias da espuma polimérica. a) Variação da área da seção das bordas ao longo do comprimento; b) Detalhe da região de conexão de 3 bordas ou mais, formando um nó.

Figura 9. Exemplos de superfícies de escoamento/falha fenomenológicas classificadas em classes (C1-C4) de acordo com Abrate (2008) 34

Figura 10. Deformação heterogênea em espumas rígidas de PVC sob compressão: a) Formação das frentes de plastificação em regime elástico; b) Aplicação de cargas de esmagamento.

Figura 11. Comportamento mecânico local generalizado para uma célula polimérica sob compressão.

Figura 12. Amostras da espuma H60 em forma de placas. O plano das placas é indicado pelas direções 1 e 2 e a direção normal é a direção 3 .

Figura 13. Micrografias exibindo a anisotropia da espuma de PVC: a) Destaque para as células alongadas na direção 3; b) Tendência para padrões circulares no plano 1-2 
Figura 14. Mecanismos de falha em compressão para a espuma polimérica de PVC: a) Células esmagadas sob compressão; b) e c) Flambagem das arestas e faces em detalhe; d) Rompimento das células fechadas em diferentes planos

Figura 15. Configuração da estrutura sanduíche investigada.

Figura 16. Estrutura sanduíche investigada sob ensaio de flexão em três pontos: a) Configuração do ensaio; b) Região central em detalhe onde ocorre a endentação na estrutura .50

Figura 17. Exemplo de uma superfície pintada para uso da técnica DIC .54

Figura 18. Equipamentos para a realização dos ensaios convencionais e obtenção de imagens para análises via técnica DIC, dispostos de maneira ilustrativa

Figura 19. Formato dos corpos-de-prova para compressão uniaxial e direção 55

Figura 20. Perfis dos corpos-de-prova utilizados nos ensaios de tração uniaxial: a) Direção no plano 1-2; b) Direção normal - 3 . .56

Figura 21. Geometria do corpo-de-prova em tração: a) Perfil recortado da espuma PVC; b) Cotas .57

Figura 22. Formato dos corpos-de-prova para os ensaios de endentação e direções .58

Figura 23. Endentador utilizado: a) Fotografia do dispositivo utilizado; b) Geometria do endentador em detalhe. .58

Figura 24. Ensaios Hidrostáticos: a) Formato dos corpos-de-prova; b) Prensa 60

Figura 25. Tensões cisalhantes atuantes na espuma 61

Figura 26. Superfície de escoamento com potencial de encruamento isotrópico associativo $(\alpha=\beta)$ ou não $(\alpha \neq \beta)$

Figura 27. Superfície de escoamento genérica com potencial de encruamento volumétrico (misto). 75

Figura 28. Variação do coeficiente de Poisson com deformação Logarítmica para os ensaios de compressão uniaxial: a) direção normal 3; b) direção no plano 1-2 .84

Figura 29. Variação do coeficiente de Poisson com deformação Logarítmica para os ensaios de tração uniaxial: a) direção normal 3 ; b) direção no plano 1-2 ..... 84

Figura 30. Curvas experimentais para os ensaios de compressão uniaxial na direção normal 3

Figura 31. Curvas experimentais para os ensaios de compressão uniaxial para uma direção no plano 1-2 .88

Figura 32. Identificação da tensão de escoamento para a direção normal 89

Figura 33. Identificação da tensão de escoamento para uma direção no plano. .90 
Figura 34. Surgimento e propagação das frentes de plastificação. a) Formação de uma ou mais frentes de plastificação; b) Propagação das frentes de plastificação

Figura 35. Encontro das frentes de plastificação para os ensaios de compressão na direção normal

Figura 36. Tensão de escoamento para diferentes taxas de deformação para a direção normal. Em destaque vê-se a influência do encontro das frentes de plastificação 92

Figura 37. Ajuste exponencial para a variação da tensão de escoamento na direção normal com a taxa de deformação

Figura 38. Flambagem macroscópica da espuma polimérica para a direção normal: a) Plano de um CDP, aparentemente, sem flambagem macroscópica; b) Mesmo CDP rotacionado mostrando a flambagem macroscópica.

Figura 39. Curvas experimentais para os ensaios de tração uniaxial para a direção normal 3.95

Figura 40. Curvas experimentais para os ensaios de tração uniaxial para uma direção no plano $1-2$ 95

Figura 41. Curvas experimentais para os ensaios de endentação na direção normal 3 97

Figura 42. Curvas experimentais para os ensaios de endentação em uma direção no plano 1-2

Figura 43. Ensaio de endentação da espuma polimérica na direção normal 3 . .98

Figura 44. Imagens do programa Correli ${ }^{\text {LMT }}$ para ensaio de compressão do CDP5 na direção normal 3: De a) à d) tem-se a evolução do campo de deformação nominal $\varepsilon_{33} \mathrm{e}$ de e) à h) a evolução da malha virtual correspondente 99

Figura 45. Imagens do programa Correli ${ }^{\mathrm{LMT}}$ para ensaio de compressão do CDP5 na direção 1 no plano 1-2: De a) à d) tem-se a evolução do campo de deformação nominal $\varepsilon_{11} \mathrm{e}$ de e) à h) a evolução da malha virtual correspondente.

Figura 46. Campos de deslocamento (medido em pixels) via Correli ${ }^{\mathrm{LMT}}$ para a tração uniaxial do CDP2 na direção normal: a) Configuração inicial; b) Configuração pré ruptura; c) Região com carregamento próximo ao uniaxial 102

Figura 47. Campos de deslocamento (medido em pixels) via Correli ${ }^{\mathrm{LMT}}$ para a de tração uniaxial do CDP1 na direção do plano: a) Configuração inicial; b) Configuração pré ruptura; c) Região com carregamento próximo ao uniaxial 102

Figura 48. Imagens do programa Correli ${ }^{\mathrm{LMT}}$ para a endentação do CDP2 na direção normal: De a) à c) tem-se a evolução do campo de deformação $\varepsilon_{13}$ e de d) à f) a evolução da malha virtual correspondente 
Figura 49. Imagens do programa Correli ${ }^{\mathrm{LMT}}$ para a endentação do CDP3 para uma direção no plano: De a) à c) tem-se a evolução do campo de deformação $\varepsilon_{12}$ e de d) à f) a evolução da malha virtual correspondente

Figura 50. Detalhe da ruptura da espuma H60 no ensaio de endentação para a direção no plano 105

Figura 51. Compressão hidrostática: Deformação volumétrica plástica 106

Figura 52. Curvas de encruamento real para as compressões uniaxiais: a) Direção no plano; b) Direção normal

Figura 53. Composição da deformação elástica total em compressão para a espuma polimérica

Figura 54. Curvas de encruamento teórico para as compressões uniaxiais: a) Direção no plano; b) Direção normal...... 108

Figura 55. Curvas de encruamento real para as trações uniaxiais: a) Direção no plano; b) Direção normal

Figura 56. Curvas de encruamento teórico para as trações uniaxiais: a) Direção no plano; b) Direção normal

Figura 57. Sensibilidade da curva de encruamento com o tipo de carregamento para a espuma H60

Figura 58. Mecanismos de falha na espuma H60 sob compressão hidrostática: a) Carregamento no plano 3-1(2); b) Deformação plástica no plano 3-1(2); c) Carregamento no plano 1-2; b) Deformação plástica no plano 1-2.....

Figura 59. Deformação volumétrica real: Enrijecimento do material na direção normal: a) Plano 3-1(2); b) Plano 1-2

Figura 60. Comparações das deformações, para uma das compressões na direção normal, calculadas pelas duas metodologias adotadas

Figura 61. Comparações das deformações, para uma das compressões na direção do plano, calculadas pelas duas metodologias adotadas 112

Figura 62. Comparações das deformações para tração na direção normal, calculadas pelas duas metodologias adotadas 115

Figura 63. Comparações das deformações para tração na direção do plano, calculadas pelas duas metodologias adotadas 115

Figura 64. Comparação da variação dos campos de deformação (paralela à direção de carregamento) com a direção do material para os ensaios de tração: a) Direção no plano 1-2; b) Direção normal 3 
Figura 65. Ciclo de carregamento e descarregamento na fase linear elástica dos ensaios de compressão uniaxial via EMIC: a) Direção normal; b) Direção no plano 117

Figura 66. Superfície inicial de escoamento I 122

Figura 67. Superfície inicial de escoamento II. 122

Figura 68. Evolução da superfície de falha III para a direção normal. A elipse mais interna corresponde à superfície de escoamento inicial.

Figura 69. Evolução da superfície de falha IV para a direção no plano. A elipse mais interna corresponde à superfície de escoamento inicial.

Figura 70. Modelo computacional para compressão uniaxial na direção normal: malha e condições de contorno

Figura 71. Comparação entre resultado experimental e modelo computacional de compressão com curvas de encruamento teórica e real para uma direção no plano 125

Figura 72. Comparação entre resultado experimental e modelo computacional de compressão com curvas de encruamento teórica e real para a direção normal

Figura 73. Geometrias para a direção no plano: a) Análise com dados da EMIC; b) Análise com dados via Correli ${ }^{\mathrm{LMT}}$ 127

Figura 74. Geometrias para a direção normal: a) Análise com dados da EMIC; b) Análise com dados via Correli ${ }^{\mathrm{LMT}}$

Figura 75. Identificação ilustrativa da malha útil em a) e da respectiva altura $h_{u}$ e o deslocamento $\Delta \mathrm{lem}$ b) 128

Figura 76. Comparação entre resultado experimental e modelo computacional de tração na direção no plano.

Figura 77. Comparação entre resultado experimental e modelo computacional de tração na direção normal

Figura 78. Resultados para uma análise de tração com modelo de material isotrópico: a) Deformação logarítmica na direção do carregamento; b) Distorção no plano 1-2

Figura 79. Superfícies de escoamento inicial para a Tabela 19: a) V; b) VI; c) VII; d) VIII. 132

Figura 80. Modelos de endentação: Condições de contorno e discretização 133

Figura 81. Tensão equivalente de von Mises (MPa): a) Superfície III para o plano 3-1(2); b) Superfície IV para o plano 1-2

Figura 82. Modelo de endentação para o plano 1-2 135

Figura 83. Modelo de endentação para o plano 3-1(2). 136 
Figura 84. Comparação da deformação nominal na direção do carregamento via Correli ${ }^{\mathrm{LMT}} \mathrm{e}$ EF: a) e b) Resultados para o plano 3-1(2); c) e d) Resultados para o plano 1-2 137

Figura 85. Condições de contorno e deslocamento aplicado à estrutura sanduíche sob flexão em 3 pontos.

Figura 86. Discretização da estrutura sanduíche e configuração do ensaio de flexão em três pontos.

Figura 87. Curvas força-deslocamento para os 8 modelos computacionais da estrutura sanduíche estudada

Figura 88. Curvas força-deslocamento para os modelos ii e vii.

Figura 89. Tensão equivalente de von Mises para as lâminas mais próximas da espuma (modelo vii): a) Deslocamento de $1.6 \mathrm{~mm}$ do endentador; b) Deslocamento de $2.0 \mathrm{~mm}$ do endentador

Figura 90. Deslocamento máximo (na direção 3) do endentador (12mm) para a estrutura sanduíche 144

Figura 91. Deformação logarítmica para a estrutura sanduíche para deslocamento máximo do endentador: a) Modelo iii; b) Modelo viii

Figura 92. Ensaio de flexão em três pontos: a) Deslocamento $u_{3} \sim 3 \mathrm{~mm}$; b) Deslocamento $\mathrm{u}_{3} \sim$ $5-6 \mathrm{~mm}$.

Figura 93. Metodologia de seleção e calibração de modelos de material para análises computacionais

Figura 94. Variação da deformação logarítmica de compressão na direção normal com o tempo

Figura 95. Variação da deformação logarítmica de compressão na direção do plano com o tempo 166

Figura 96. Variação da deformação logarítmica de tração na direção normal com o tempo.167

Figura 97. Variação da deformação logarítmica de tração na direção do plano com o tempo

Figura 98. Relaxamento da espuma polimérica H60. 168 


\section{LISTA DE TABELAS}

Tabela 1 - Modelos micro-mecânicos desenvolvidos por Gibson e Ashby (1988) para espumas de células abertas ou fechadas em compressão uniaxial 25

Tabela 2. Propriedades mecânicas para a espuma polimérica Divinycell H60 fornecidas pelo fabricante 46

Tabela 3 - Especificações geométricas da estrutura sanduíche investigada. .50

Tabela 4 - Definição das variáveis dependentes e independentes para os problemas direto e inverso

Tabela 5 - Dimensões dos corpos-de-prova para os ensaios de compressão uniaxial. 55

Tabela 6 - Dimensões dos corpos-de-prova para os ensaios de tração uniaxial. .57

Tabela 7 - Dimensões dos corpos-de-prova para endentação de acordo com a direção de carregamento

Tabela 8 - Propriedades mecânicas para espumas de PVC de célula fechada 62

Tabela 9 - Matriz de ensaios.

Tabela 10 - Tensões médias de escoamento em compressão uniaxial para a espuma polimérica rígida $\mathrm{H} 60$

Tabela 11 - Variação da Tensão de escoamento com as taxas de deformação calculadas........93

Tabela 12 - Tensões médias de escoamento e resistência para os ensaios de tração 97

Tabela 13 - Propriedades mecânicas para a espuma polimérica H60 de PVC obtidas pelo equipamento da máquina EMIC

Tabela 14 - Propriedades mecânicas para a espuma polimérica H60 de PVC obtidas pela técnica de correlação de imagens e o programa Correli ${ }^{\mathrm{LMT}}$ 118

Tabela 15 - Propriedades mecânicas para o material compósito da estrutura sanduíche investigada 118

Tabela 16 - Parâmetros para a determinação das superfícies de escoamento iniciais. 121

Tabela 17 - Parâmetros k, $\mathrm{k}_{\mathrm{t}} \mathrm{e} \mathrm{v}_{\mathrm{pl}}$ para as superfícies de escoamento inicial 121

Tabela 18 - Parâmetros para a determinação das novas superfícies de escoamento iniciais.. 132

Tabela 19 - Parâmetros k, kt e $v_{\mathrm{pl}}$ para das novas superfícies de escoamento inicial 132

Tabela 20 - Propriedades mecânicas e geometrias para os modelos computacionais da estrutura sanduíche 140 


\section{LISTA DE SÍMBOLOS}

$\hat{\sigma}_{v}=\sqrt{3 J_{2}}=$ Tensão equivalente de von Mises $=\sigma_{v}$

$d \sigma_{i j}{ }^{J}=$ Incremento de tensão (Operador Jaumann)

$d \varepsilon_{i j}=\dot{\varepsilon}_{i j}=$ Incremento de deformação

$D_{i j k l}=$ Tensor constitutivo de rigidez

$\hat{\varepsilon}=$ Deformação equivalente

$\varepsilon_{i j}^{p l}=$ Deformação plástica

$\varepsilon_{\log }=$ Deformação Logarítmica

$\varepsilon_{n}=$ Deformação nominal

$E=$ Módulo de elasticidade

$f=$ Superfície de escoamento

$F=$ Índice de falha

$g=$ Potencial de escoamento

$H^{\prime}=$ Matriz Hessiana

$H, h_{u}, h_{p}=$ Módulos de encruamento

$I_{1}=$ Primeiro Invariante do tensor de tensões

$J_{2}=$ Segundo Invariante do tensor desviador de tensões

$J_{3}=$ Terceiro Invariante do tensor desviador de tensões

$p=-\sigma_{k k} / 3=$ tensão média $=\sigma_{m}$

$p_{c}^{0}=$ Primeira tensão de escoamento em compressão triaxial

$p_{t}=$ Tensão de escoamento em tração triaxial

$S_{i j}=$ Tensor desviador de tensões

$\delta_{i j}=$ Delta de Kronecker

$\hat{\sigma}=$ Tensão equivalente "genérica"

$\sigma_{c}=$ Tensão de Cauchy

$\sigma_{c}^{0}=$ Primeira tensão de escoamento em compressão uniaxial

$\sigma_{y}=$ Tensão de escoamento em ensaios uniaxiais $=\hat{\sigma}_{v}$

$v_{e l}=$ Coeficiente de Poisson elástico

$v_{p l}=$ Coeficiente de Poisson plástico

$W_{p l}=$ Trabalho de deformação plástica 


\section{SUMÁRIO}

1. INTRODUÇÃO, JUSTIFICATIVAS E OBJETIVOS .................................................1

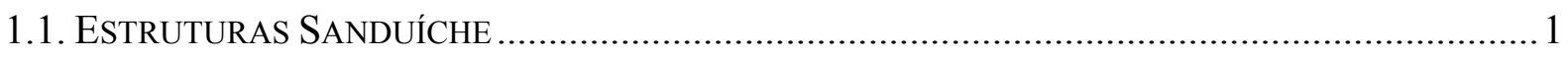

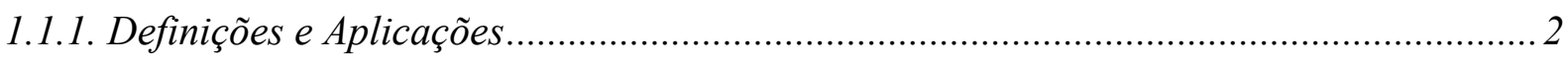

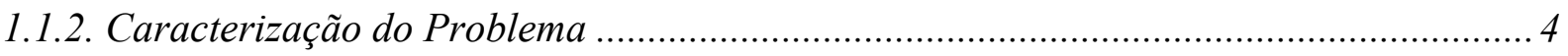

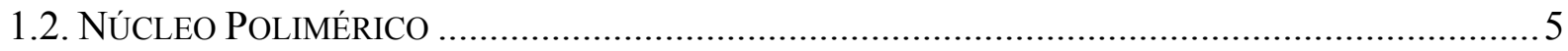

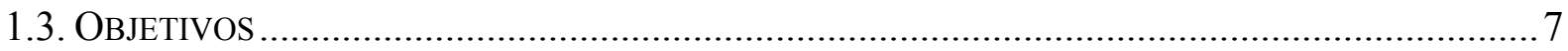

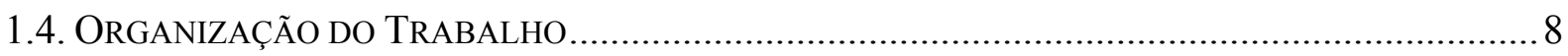

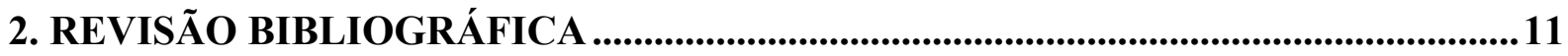

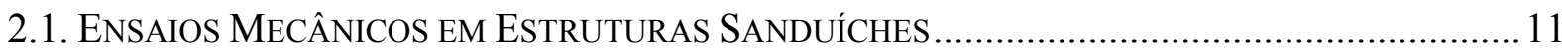

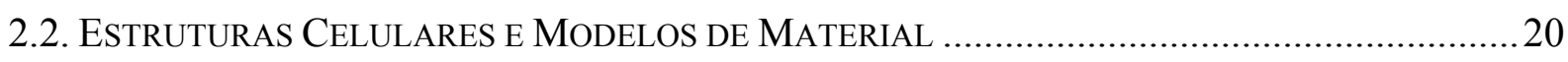

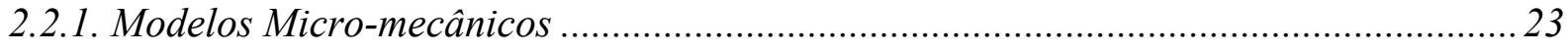

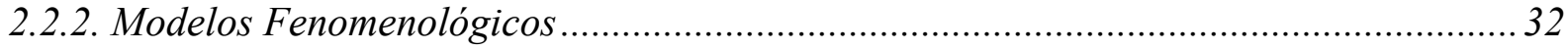

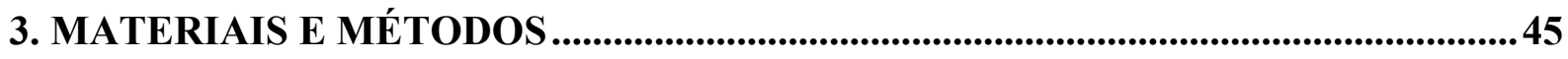

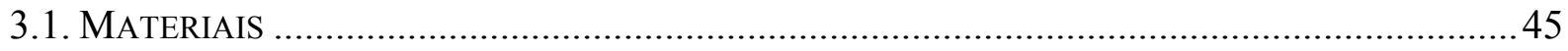

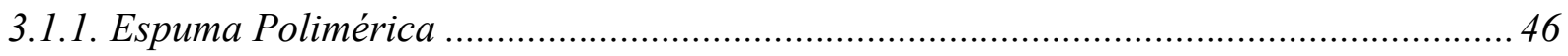

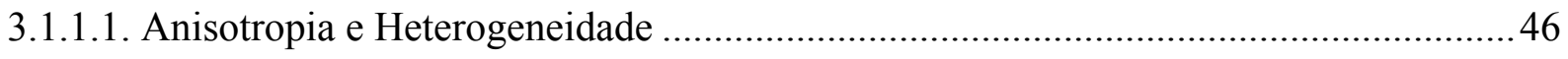

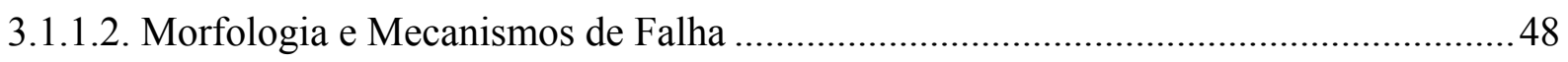

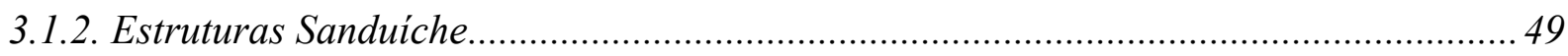

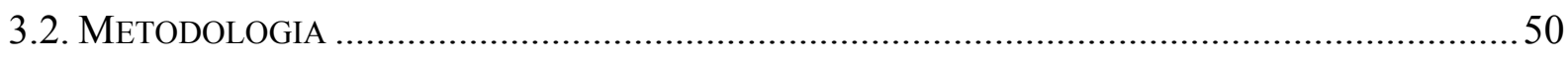

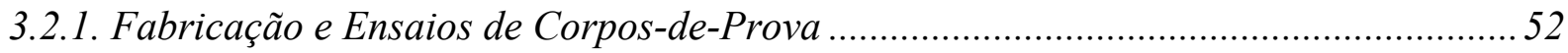

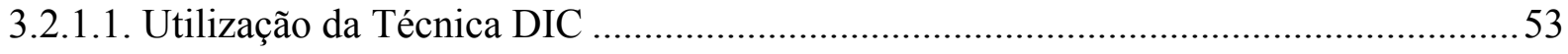

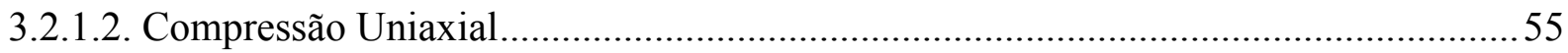

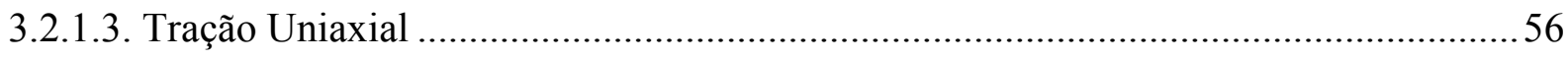

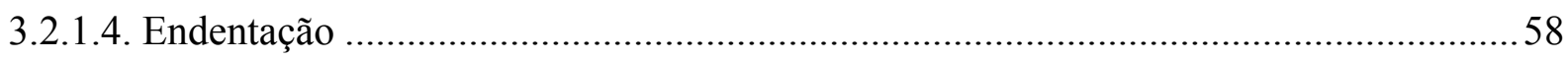

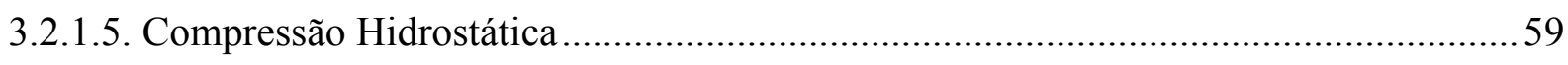

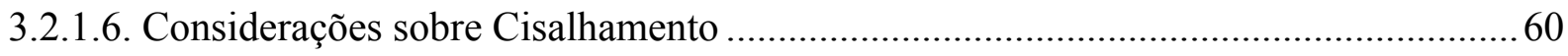

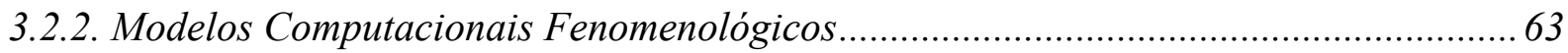

3.2.2.1. Modelo de Material com Encruamento Isotrópico .....................................................63

3.2.2.2. Modelo de Material com Encruamento Misto .............................................................. 74 


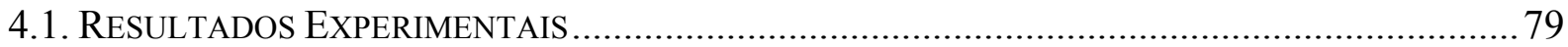

4.1.1. Cálculo das Tensões e Deformações para a Espuma Polimérica ...................................81

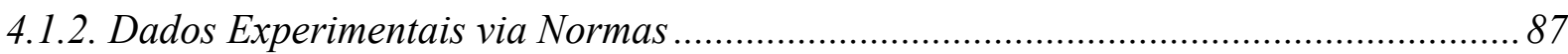

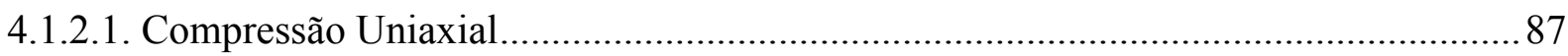

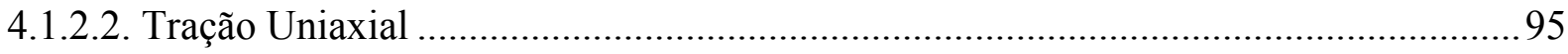

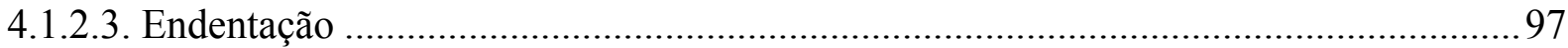

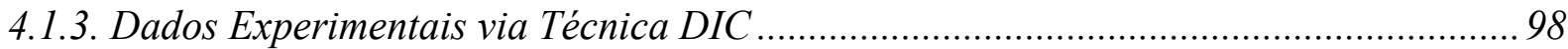

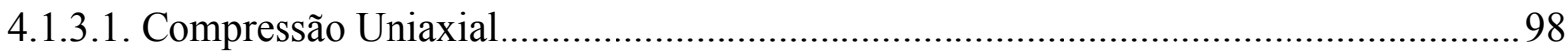

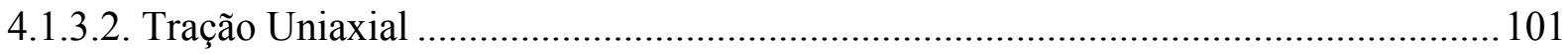

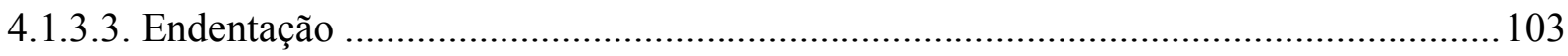

4.1.4. Compressão Hidrostática e Curvas de Encruamento .................................................... 105

4.1.5. Comparação e Discussão dos Resultados Experimentais ........................................... 111

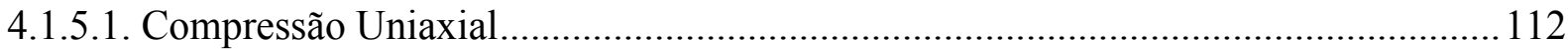

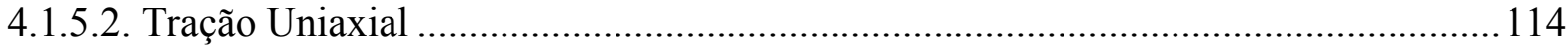

4.1.5.3. Propriedades Mecânicas da Espuma H60 ...................................................................... 117

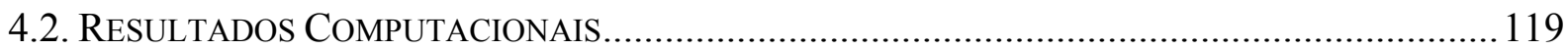

4.2.1. Modelos Computacionais para a Espuma Polimérica …............................................. 119

4.2.1.1. Modelos Computacionais para Compressão Uniaxial............................................. 124

4.2.1.2. Modelos Computacionais para Tração Uniaxial ...................................................... 126

4.2.1.3. Calibração dos Modelos de Material via Endentação ............................................... 131

4.2.2. Modelos Computacionais para a Estrutura Sanduíche ............................................. 138

4.3. Metodologia de Seleção e Calibração de Modelos de Material ........................ 146

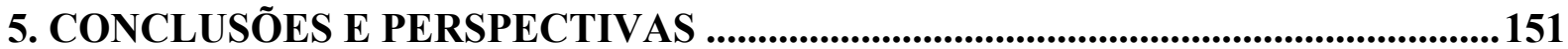

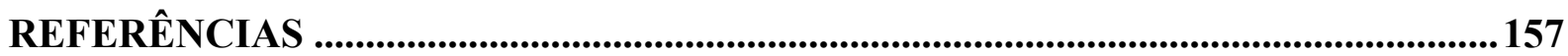

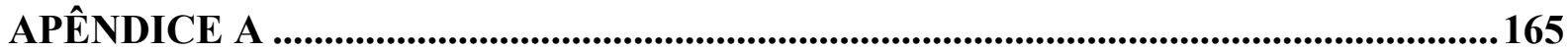

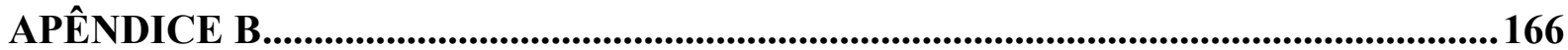

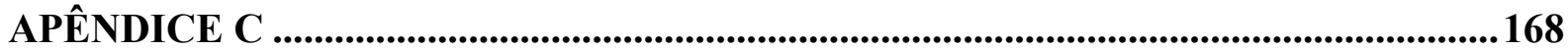





\section{Capítulo I}

\section{INTRODUÇÃO, JUSTIFICATIVAS E OBJETIVOS}

\subsection{Estruturas Sanduíche}

As estruturas sanduíche podem ser formadas de diversas formas, combinando dois ou mais tipos de materiais. No entanto, as referidas estruturas possuem classicamente um núcleo (constituído por um tipo de material mais leve) aderido a duas faces laminadas (constituídas por um tipo de material mais rígido). No presente trabalho, estas faces são formadas por compósitos poliméricos reforçados e o núcleo é fabricado a partir de uma espuma polimérica.

Existem muitas definições para materiais compósitos, mas uma segundo Mendonça (2005) é muito clara quanto à aplicação e ao propósito desses materiais: "Um material composto é um conjunto de dois ou mais materiais diferentes, combinados em escala macroscópica, para funcionarem como uma unidade, visando obter um conjunto de propriedades que nenhum dos componentes individualmente apresenta". O termo macroscópico é o que diferencia esses materiais de ligas metálicas ou co-polímeros onde a interação dos constituintes é em escala atômica ou molecular.

Os materiais compósitos, juntamente com as estruturas sanduíche, foram aplicados em diversos setores da indústria, notadamente a aeronáutica, onde aviões como o modelo civil 787 da Boeing e o militar F-18 possuem missões só alcançadas com aplicação desses materiais. Outro excelente exemplo é a aeronave comercial A380 da Airbus, chamada de superjumbo, que pesa cerca de 250 toneladas podendo decolar com um peso máximo de quase 600 toneladas. Sem a aplicação de materiais compósitos tais projetos, que são frutos da evolução da engenharia, não existiriam. No entanto, vale ressaltar que projetar, analisar e fabricar estruturas em material compósito trouxe muitos desafios para engenheiros e pesquisadores. 


\subsubsection{Definições e Aplicações}

As estruturas sanduíche como mencionado anteriormente, possuem basicamente 3 diferentes constituintes: faces (ou cascas) laminadas, adesivos e núcleo (Fig. 1). O emprego dessas estruturas é motivado pela redução de custo e peso, todavia tal emprego pode ocasionar uma elevação substancial dos custos dependendo da aplicação. Esse aumento nos custos ocorre, pois as faces e o núcleo devem ser compatíveis fisicamente e o adesivo requer também uma compatibilidade físico-química com as faces e o núcleo. Ademais, o ajuste de todos esses componentes requer estudos e procedimentos cautelosos, mas ainda assim, as aplicações das estruturas aeronáuticas sanduíches tem se mostrado viáveis e lucrativas frente ao uso de materiais convencionais (ligas metálicas).

Por outro lado, muita atenção é necessária no estudo dessas estruturas. Fazendo um paralelo com uma viga de seção "I" (Fig. 1), por exemplo, sabe-se que a resistência a flexão é fornecida pela alma da viga, na região central da seção. Porém, na estrutura sanduíche, esta região central é composta pelo núcleo que apesar de sua localização similar à da alma, não fornece a resistência necessária a flexão, tal função compete às faces da estrutura sanduíche localizadas nas extremidades da respectiva seção. Nota-se então que a combinação de geometrias e materiais diferentes na fabricação de estruturas sanduíche gera perfis, que podem e/ou devem ser diferentes dos perfis das estruturas equivalentes para as quais foram projetadas para substituir.

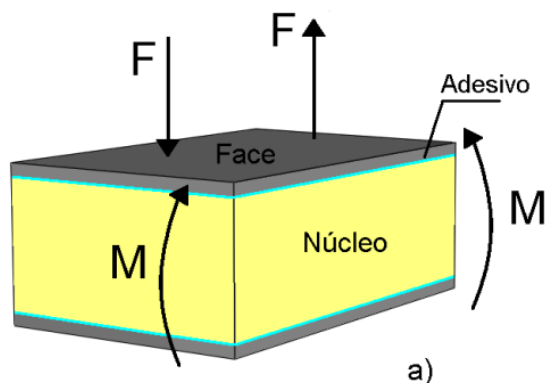

a)

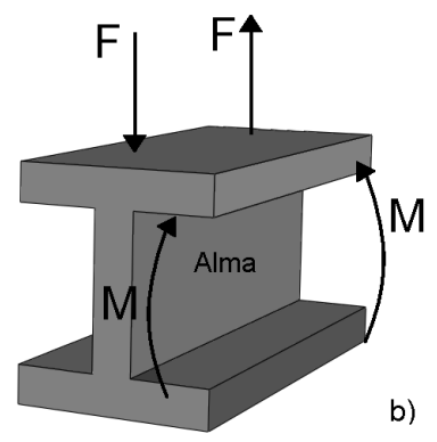

b)

Figura 1. Estruturas equivalentes com esforços genéricos de força normal (F) e momentos fletores (M): a) Estrutura sanduíche; b) Viga de seção "I"

Em uma estrutura sanduíche as funções mecânicas de cada um de seus componentes são bem definidas. As faces, como mencionadas anteriormente, para o presente trabalho serão constituídas por um laminado (tipicamente fabricado a partir de lâminas de compósitos 
poliméricos reforçados - CPR s- por fibras) e cada lâmina (camada) tem espessura desprezível em uma comparação direta com suas dimensões de comprimento e largura.

A principal função das faces é fornecer resistência a carregamentos normais e cisalhantes no plano das faces, gerados em um carregamento de flexão da estrutura sanduíche. Uma caracterização detalhada desses CPRs e seus mecanismos de falha podem ser encontrados no trabalho de Tita (2003).

Os adesivos, como comentado acima, devem ter uma ótima compatibilidade química para fornecer uma forte aderência entre as superfícies uma vez que essas camadas estarão sujeitas principalmente a carregamentos de cisalhamento. Sua espessura é geralmente a menor dentre os três componentes de uma estrutura sanduíche, contudo, ao trabalhar-se com uma espessura mínima para esses adesivos, novas complicações somam-se ao projeto. Como exemplo, camadas de adesivo muito finas são sensíveis a impurezas físicas durante sua utilização, como particulados rígidos em geral, que se misturados ao adesivo podem eliminar pontualmente o contato das superfícies, o que fragiliza a junta. Similarmente, bolhas de ar no adesivo diminuem a resistência do mesmo. Acoplado a este problema, tem-se a necessidade da minimização do peso da estrutura que influencia muitos fatores, dentre os quais pode-se mencionar a qualidade da planicidade/curvatura das regiões coladas. Quanto maior a curvatura (menor a planicidade), maior tende a ser a espessura do adesivo.

O núcleo é composto geralmente por um material com densidade específica bem menor que as faces laminadas, porém sua espessura é muito superior a do adesivo e as das faces laminadas, visando assim aumentar a propriedade de inércia transversal da estrutura sanduíche, além de transmitir os carregamentos transversais de uma face à outra através de sua resistência. O material do núcleo deve ser resistente o suficiente para evitar um esmagamento precoce do mesmo de maneira que a estrutura sanduíche se comporte como uma única peça rígida e estável. Dessa forma, opta-se muitas vezes por ter um núcleo construído a partir de materiais celulares, tais como: 1) estruturas metálicas em forma de colméia (honeycomb); 2) espumas fabricadas a partir de polímeros expandidos; 3) madeiras, que são estruturas celulares encontradas na natureza.

Com relação às aplicações, o emprego das estruturas sanduíche vem crescendo e se diversificando nos últimos anos com o aumento da precisão nos processos de fabricação, especialmente os processos para CPRs, devido à difusão e evolução das tecnologias de automação. Essas estruturas são aplicadas visando alto desempenho em estruturas como pás de rotor de helicópteros, radômes de aeronaves, estruturas de interior de aeronaves, painéis de asas e fuselagens, estruturas para absorção de impacto e cascos de barcos. 
Dessa forma, observa-se que materiais antes não utilizados em determinadas estruturas, devido seu baixo desempenho mecânico, são agora reavaliados como potenciais substitutos em componentes de alto desempenho sob o conceito de estruturas sanduíches.

\subsubsection{Caracterização do Problema}

Verifica-se, portanto, que o emprego de estruturas sanduíche abre um novo leque de oportunidades de como projetar uma estrutura, haja vista que muitos parâmetros podem ser alterados. Por outro lado, o controle desses vários parâmetros, não é uma tarefa convencional, pois os mesmos podem modificar fortemente os modos de falha da estrutura. Em particular, a estrutura sanduíche é susceptível a diversos modos de falha dado a complexidade de seus componentes e sua fabricação. Os principais modos de falha são: 1) escoamento ou ruptura das faces; 2) cisalhamento do núcleo; 3) esmagamento do núcleo; 4) enrugamento das faces (wrinkling); 5) deflexão excessiva; 6) delaminação e 7) flambagem global da estrutura.

De acordo com o material utilizado nas faces, núcleo e adesivo para uma dada geometria específica, alguns dos modos de falha acima são mais característicos que outros e o estudo dessas estruturas torna-se complexo (DANIEL et al., 2002, STEEVES; FLECK, 2004a, b, MENDONÇA, 2005). Com isso, todo e qualquer estudo que vise uma completa previsão de comportamento (por exemplo, através de modelagem computacional) de estruturas sanduíche deve impreterivelmente, em um primeiro passo, focar-se em um dos três componentes principais dessa estrutura e seus modos de falha concernentes. Dessa forma, o presente trabalho irá focar principalmente o estudo do comportamento mecânico do núcleo, mais especificamente, de um núcleo fabricado a partir de uma espuma polimérica. Vale ressaltar que o Grupo de Estruturas Aeronáuticas (GEA) da Escola de Engenharia de São Carlos (USP) também possui estudos sobre o comportamento mecânico das faces (laminados) como mostra o trabalho de Tita (2003) e Angélico (2009), bem como, de junções entre partes unidas por adesivos, como demonstra o trabalho de Ribeiro (2009). 


\subsection{Núcleo Polimérico}

Todos os componentes de uma estrutura sanduíche são desafiadores no que tange a previsão do seu respectivo comportamento mecânico através de modelos computacionais. Os regimes não-lineares dessas estruturas somados às falhas progressivas e combinadas requerem modelos de materiais que muitas vezes mostram-se insuficientes para uma representação mais realística e abrangente dos fenômenos observados.

Os núcleos das estruturas sanduíches por muito tempo têm sido compostos majoritariamente por pequenas estruturas do tipo colméia (Fig. 2a). Essas pequenas estruturas por apresentarem uma regularidade dimensional em sua estrutura, seu comportamento macroscópico pode ser previsto através de modelos via análise micro-mecânica da colméia sem grandes dificuldades. Todavia, os custos do processo e do material dessas colméias, levaram os engenheiros a procurar novos materiais para substituir tais núcleos. Um dos materiais mais bem sucedidos têm sido os núcleos poliméricos fabricados a partir da expansão de polímeros, ou seja, as espumas poliméricas (Fig. 2b).

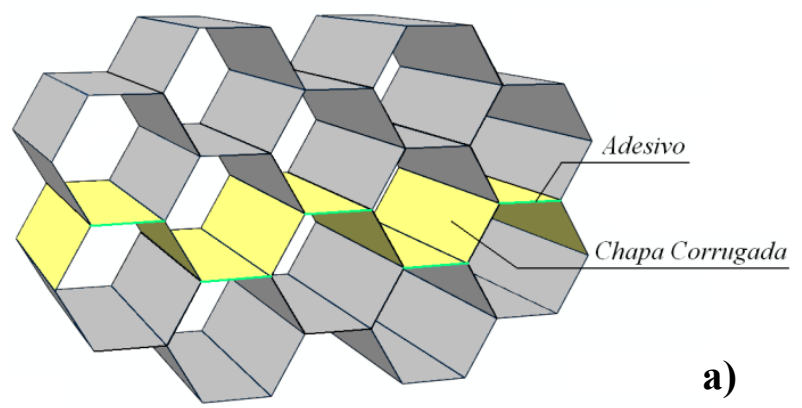

Figura 2. Comparação entre materiais para o núcleo. a) Estrutura genérica tipo colméia, honeycomb; b) Espuma polimérica rígida de Policloreto de Vinila (PVC)

Parte desse sucesso está na substituição do uso de ligas metálicas de alto custo por materiais poliméricos econômicos, sendo que em outra parte está na redução de custos na fabricação das espumas. O processo em si é tão complexo quanto o das colméias, mas as variáveis do processo são controladas com maior facilidade. Isso porque a fabricação dessas espumas requer o monitoramento da temperatura, pressão e da qualidade e quantidade dos reagentes durante a fabricação da espuma (QUÍMICA, 2010), ou seja, não há muitas variáveis associadas à geometria para se controlar. Ao contrário da fabricação das colméias, (MENDONÇA, 2005) onde existe todo um controle rigoroso de alinhamento e sincronização 
das máquinas para que os perfis base, a chapas metálicas corrugadas, de uma colméia sejam obtidos e na sequência montados com expressiva precisão utilizando-se adesivos. Este processo faz com que a produtividade das espumas poliméricas seja superior ao das colméias ocasionando um impacto direto na economia de energia durante o processo. Em contrapartida, as espumas poliméricas podem possuir uma estrutura celular com níveis de irregularidade que afetam significativamente a resposta mecânica do material (CHEN; LU; FLECK, 1999). De uma maneira geral, as propriedades mecânicas das estruturas celulares poliméricas possuem forte dependência com a densidade relativa desses materiais (GIBSON; ASHBY, 1988), que é a razão entre a densidade do material celular, $\rho$, com a do material sólido base, $\rho_{s}$ :

$$
\bar{\rho}=\frac{\rho}{\rho_{s}}
$$

Este parâmetro, assim como muitos outros advindos dos polímeros, dos reagentes e do processo de fabricação são os que definem a estrutura celular da espuma e suas propriedades mecânicas macroscópicas.

É importante ressaltar que os núcleos poliméricos não somente são aplicados visando uma redução de peso, mas também com outros propósitos, tais como: 1) absorvedores de energia de impacto, dado sua grande variação de volume característica após impacto ou aplicações de esforços elevados; 2) como isolantes térmicos e elétricos devido ao gás que ocupa mais de $95 \%$ do volume aparente dessas estruturas; 3) para o controle de vibrações se aplicados como atenuadores de ondas mecânicas (som).

Entretanto, há uma grande dificuldade em projetar o núcleo adequado para cada tipo de aplicação, ou seja, selecionar o tipo de espuma polimérica, bem como, a geometria a ser empregada. Para tal, tem-se assim, a necessidade de se fazer uma previsão do comportamento mecânico da mesma. Uma das abordagens mais empregadas combina análises experimentais com análises computacionais para se prever tanto o comportamento mecânico da estrutura sanduíche como um todo, mas principalmente, do seu núcleo. Neste escopo vários pesquisadores têm desenvolvidos trabalhos, tais como: Gibson e Ashby (1988), Zhang et al. (1998), Deshpande e Fleck (2000, 2001), Gong e Kyriakides (2005), Gong, Kyriakides e Jang (2005), Rizov (2006a, b), Abrate (2008), Oliveira et al. (2008) e outros. Dentro desse contexto é que será desenvolvido o presente trabalho, ou seja, serão empregados modelos computacionais e ensaios experimentais para se prever o comportamento de espumas poliméricas e de estruturas sanduíche. 


\subsection{Objetivos}

O presente trabalho tem como principal objetivo avaliar as potencialidades e limitações de modelos de material utilizados para simular o comportamento de espumas poliméricas empregadas em estruturas sanduíche para aplicações aeronáuticas. Dessa forma, parâmetros associados a esses modelos serão criteriosamente investigados utilizando ensaios experimentais e simulações computacionais via Método dos Elementos Finitos (MEF). Sendo assim, o objetivo geral do presente trabalho pode ser dividido nos seguintes objetivos parciais:

1) Realizar uma revisão bibliográfica visando compreender os trabalhos científicos mais relevantes bem como os mais recentes que foram desenvolvidos nas áreas de estruturas sanduíche, com foco em modelagem de espumas poliméricas;

2) Fabricar e realizar ensaios experimentais em corpos-de-prova (CDPs) de espumas poliméricas seguindo orientações de normas de ensaios, a fim de entender o comportamento micro e macro mecânico, bem como, visando obter os parâmetros associados aos modelos constitutivos;

3) Identificar os parâmetros associados aos modelos constitutivos, com base em resultados provenientes de ensaios experimentais, bem como, empregando a técnica de correlação de imagens, e também, recorrendo a simulações computacionais via MEF;

4) Avaliar as potencialidades e limitações dos modelos constitutivos investigados, analisando problemas de compressão, de tração e de endentação em espumas poliméricas e problemas de flexão em estruturas sanduíche;

5) Propor uma metodologia de modelagem computacional com base nos resultados obtidos para materiais celulares, de forma que muitos dos modelos de materiais existentes e/ou já implementados sejam utilizados de forma mais criteriosa. Com isso, pretende-se minimizar as limitações desses modelos, potencializando o emprego dos mesmos; 


\subsection{Organização do Trabalho}

Dessa forma o presente trabalho visa contribuir para a previsão do comportamento mecânico de núcleos poliméricos de estruturas sanduíche, através do emprego de simulações computacionais e ensaios experimentais, sendo que o mesmo é constituído pelos seguintes capítulos:

Capítulo I: Constitui-se de uma contextualização e motivação para o presente trabalho ao ressaltar a importância de um estudo mais detalhado de modelos de materiais utilizados na modelagem de estruturas sanduíche.

Capítulo II: Apresenta uma revisão bibliográfica com foco em estruturas sanduíche e em núcleos poliméricos. São abordados trabalhos referentes à estrutura sanduíche de forma mais ampla e um aprofundamento do tema segue-se com a discussão dos modelos de material existentes com aplicação em estruturas celulares. As potencialidades das diferentes abordagens indicadas e dos respectivos modelos de material são evidenciadas e comparadas.

Capítulo III: São agrupados e descritos os materiais e métodos pertinentes à abordagem do presente trabalho. Através de ensaios com base em normas ASTM (American Society for Testing and Materials), assim como micrografias obtidas via MEV (Microscopia de Varredura Eletrônica), as principais características mecânicas e geométricas da estrutura celular da espuma polimérica em questão são exibidas. Também nesse tópico são apresentados e discutidos os procedimentos experimentais normalizados ou não. Uma técnica auxiliar de coleta de dados é utilizada para embasar e dar consistência aos procedimentos adotados. Esta técnica é conhecida como técnica de correlação de imagens (DIC), através da qual propriedades mecânicas do material são obtidas com auxílio de um equipamento fotográfico e um programa para o tratamento das respectivas fotografias das quais algumas propriedades do material são identificadas.

Capítulo IV: Todo o tratamento dos dados experimentais, assim como as particularidades da espuma polimérica são mostrados neste capítulo. A forte influência da anisotropia do material é investigada com base na metodologia proposta e, a partir dos respectivos resultados experimentais, o modelo de material em estudo é calibrado, ou seja, seus parâmetros são identificados. Uma grande contribuição desse trabalho reside num estudo parcial da sensibilidade da espuma polimérica com o modelo de material adotado e sua implementação. Os conceitos de critério de falha e superfície de escoamento são confrontados 
com o intuito de aumentar a precisão na calibração dos modelos de material. Este estudo é pertinente, pois nem sempre o modelo de material em questão representa satisfatoriamente o material estudado. No entanto, o presente trabalho vem confirmar que um bom tratamento de dados experimentais é decisivo na escolha do modelo de material utilizado, bem como na opção por implementar outro modelo de material mais representativo. Lembra-se aqui que determinados modelos de material podem requerer a implementação de um modelo elastoplástico com encruamento que considere carregamentos multiaxiais e que muitas vezes precisam descrever um amolecimento (softening) na resposta do material e/ou ciclos de carregamentos e descarregamentos na estrutura. Por isso, um estudo quanto à sensibilidade, no caso, da resposta da estrutura sanduíche ou mesmo da espuma, deve ser realizado para que o modelo de material em questão seja devidamente explorado antes de se optar por um novo modelo. As análises da estrutura sanduíche indicam que as propriedades da espuma e as geometrias dos laminados das faces influenciam de maneira similar na resposta da estrutura sanduíche quanto a sua resistência e rigidez. Portanto, uma determinação correta da superfície de escoamento para a espuma polimérica em questão é fundamental para que as contribuições geométricas não sejam confundidas com as propriedades mecânicas do material celular. Por fim as conclusões obtidas até o Capítulo IV são utilizadas para a determinação de uma metodologia de análise computacional.

Capítulo V: Para finalizar o presente texto, as principais conclusões sobre a escolha de modelos de material para espumas poliméricas são apresentadas, discutindo sua calibração, implementação e limitações, tanto para análises computacionais da espuma quanto para a estrutura sanduíche. É enfatizada a necessidade de um bom tratamento dos dados experimentais para que os modelos computacionais sejam representativos, principalmente, em modelos com uso de compósitos. Neste caso há uma necessidade ainda maior na precisão dos dados experimentais quanto à geometria do laminado, pois estes são em geral muito mais rígidos que os demais materiais envolvidos na estrutura em questão. 


\section{Capítulo II}

\section{REVISÃO BIBLIOGRÁFICA}

Para entender o comportamento mecânico do núcleo polimérico utilizado em estruturas sanduíches, é necessário que sejam investigados criteriosamente os mecanismos de falha provenientes de carregamentos uniaxiais, biaxiais e multiaxiais.

\subsection{Ensaios Mecânicos em Estruturas Sanduíches}

Os ensaios do tipo flexão em 3 pontos e os de endentação em estruturas sanduíche contribuem fortemente na investigação dos núcleos poliméricos, uma vez que esses carregamentos geram concentrações de tensões na região logo abaixo do aplicador de carga. Essas tensões causam um esmagamento localizado do material do núcleo que posteriormente contribui de maneira decisiva para a falha da estrutura sanduíche como um todo. Essas análises localizadas são necessárias, pois em aplicações estratégicas (como por exemplo: absorvedores de impacto) as estruturas sanduíches requerem modelos de material cada vez mais precisos e realísticos de maneira a evitar a previsão errônea de seu comportamento mecânico e assim, comprometer sua aplicação em estruturas primárias e mesmo secundárias. Além disso, a aplicação em estruturas sanduíches é a principal motivação do estudo mais detalhado de núcleos poliméricos contido no presente trabalho que vem complementar uma investigação realizada por Oliveira (2007) sobre essas estruturas.

Tomando como exemplo um ensaio de flexão em 3 pontos de uma estrutura sanduíche (Fig. 3), pode-se verificar essa concentração de carga ao se aplicar os conceitos básicos de uma viga de Timoshenko, bem como, a Teoria Clássica dos Laminados e a Homogeneização de Laminados (MENDONÇA, 2005). 


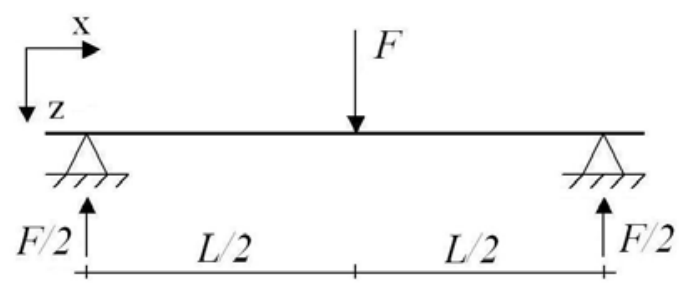

Figura 3. Diagrama simplificado de forças externas em um ensaio de flexão em 3 pontos

A deflexão máxima no centro da estrutura sanduíche é a soma das contribuições das deflexões causadas pela flexão da viga, $w_{f}$, e pelo cisalhamento transversal do núcleo, $w_{c}$ (eq. 2).

$$
\begin{gathered}
w_{\max }(x=L / 2)=w_{f}(L / 2)+w_{c}(L / 2) \\
w_{f}\left(\frac{L}{2}\right)=\frac{F L^{3}}{48 D_{s}} ; \quad w_{c}\left(\frac{L}{2}\right)=\frac{F L}{4\left(G_{x z}\right)_{n} A \kappa} ;
\end{gathered}
$$

onde $F$ é a força aplicada no centro da estrutura sanduíche, $L$ é a distância entre os apoios (span), $D_{s}$ é a rigidez a flexão da estrutura sanduíche, $\left(G_{x z}\right)_{n}$ é a rigidez ao cisalhamento do núcleo, $A$ é a área da seção transversal (plano $y-z$ ) e $\kappa$ é um fator de correção para o cisalhamento (transversal) interlaminar utilizado em teorias mais elaboradas de vigas e placas laminadas (tipicamente $\kappa=5 / 6$ ).

Nas equações (2) e (3) demonstra-se a concentração de carga no centro da viga sanduíche e quantifica-se a sensibilidade da rigidez da estrutura sanduíche às propriedades do núcleo e das faces.

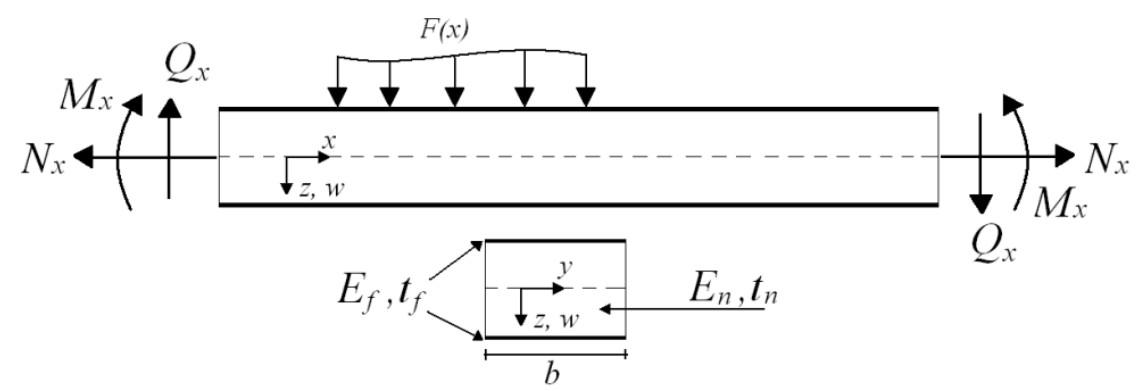

Figura 4. Diagrama de esforços solicitantes para uma seção genérica da estrutura sanduíche em um ensaio de flexão em 3 pontos

Verifica-se que quanto menor o span, $L$, menor é a diferença entre $w_{c}$ e $w_{f}$, logo, mais dependente fica a resposta da estrutura sanduíche com o comportamento mecânico do núcleo, mais especificamente, sua deformação. Analisando o diagrama de esforços solicitantes para uma seção da estrutura sanduíche, na Figura 4, é possível definir a rigidez $D_{s}$ (eq. (4)) bem 
como as tensões de cisalhamento no núcleo, $\tau_{n}$, e nas faces, $\tau_{f}$ (eqs. (5) e (6) respectivamente), para que seja avaliada a resistência da estrutura sanduíche. Segue-se:

$$
\begin{gathered}
D_{s}=\int_{-t / 2}^{t / 2} E(z) z^{2} d A=\frac{E_{t} t_{f}^{3} b}{6}+\frac{E_{f} t_{f}\left(t_{f}+t_{n}\right)^{2} b}{2}+\frac{E_{n} t_{n}^{3} b}{12} \\
\tau_{n}(z)=\frac{Q_{x}}{D_{s}}\left[\frac{E_{f} t_{f}\left(t_{f}+t_{n}\right)}{2}+\frac{E_{n}}{2}\left(\frac{t_{n}^{2}}{4}-z^{2}\right)\right],|z|<\frac{t_{n}}{2} \\
\tau_{f}(z)=\frac{Q_{x} E_{f}}{2 D_{s}}\left[\left(\frac{t_{n}}{2}+t_{f}\right)^{2}-z^{2}\right], \frac{t_{n}}{2}<|z|<\frac{t_{n}}{2}+t_{f}
\end{gathered}
$$

onde os índices $f$ e $n$ em $E$ e $t$, indicam as rigidezes e espessuras das faces e do núcleo, respectivamente.

Considerando que a viga laminada em questão é uma estrutura sanduíche típica $\left(E_{n} \ll E_{f}\right.$ e $\left.t_{f} \ll t_{n}\right)$ as tensões normais e as cisalhantes no núcleo $\left(\sigma_{n}\right.$ e $\left.\tau_{n}\right)$ e nas faces $\left(\sigma_{f}\right.$ e $\left.\tau_{f}\right)$ são:

$$
\sigma_{n}(z) \cong 0 ; \quad \tau_{n}(z) \cong \frac{Q_{x}}{\left(t_{f}+t_{n}\right) b} ; \sigma_{f}(z) \cong \pm \frac{M_{x}}{t_{f}\left(t_{f}+t_{n}\right) b} ; \tau_{f(z)} \cong 0
$$

A formulação descrita nas equações acima para o ensaio de flexão em três pontos aponta a dependência dos modos de falha da estrutura sanduíche com a rigidez e a resistência do material do núcleo. Igualmente, é possível exibir um desenvolvimento para a resposta dessa mesma estrutura sob endentação e demonstrar como a resposta da estrutura sanduíche depende das propriedades do material do núcleo além de definir explicitamente as expressões de cargas críticas de falha em função da resistência do núcleo. Todavia, não é foco deste trabalho modelar analiticamente estruturas sanduíches sob diferentes carregamentos e por isso, os comportamentos mecânicos provenientes de abordagens analíticas, numéricas e experimentais da estrutura sanduíche, importantes para o estudo do núcleo polimérico, são obtidas a partir da vasta bibliografia existente para o tema.

Como foi evidenciado anteriormente, o comportamento mecânico da estrutura sanduíche depende fortemente do comportamento do núcleo polimérico, ou seja, dos estados de deformações apresentados pelo núcleo. Essas deformações localizadas nos núcleos, bem como nas faces da estrutura sanduíche, decorrentes de carregamentos concentrados, foram 
trabalhados por muitos pesquisadores que buscaram novas soluções experimentais numéricas e/ou analíticas para esses e outros problemas recorrentes nessas estruturas.

Iniciando a investigação do presente trabalho sobre estruturas sanduíche através de trabalhos sobre flexão em 3 pontos, o estudo analítico-experimental de Soden (1996) apresenta uma abordagem interessante. Nesse trabalho o autor estuda e modela analiticamente as falhas localizadas (esmagamento das células) em ensaios de endentação, sendo que os principais fenômenos de falha também foram observados nos carregamentos de flexão em 3 pontos de estruturas sanduíche com núcleos poliméricos. Embora seu modelo subestime alguns resultados experimentais, ele demonstra significativa coerência com a realidade física devido à simplicidade e a lógica da formulação.

Essas falhas por esmagamento, observadas em ensaios de endentação e em ensaios de flexão em 3 pontos, foram posteriormente estudadas com maior rigor analítico por Steeves e Fleck (2004a). As formulações neste artigo consideram o núcleo rígido ou flexível e em ambos os casos o comportamento é tido como plástico perfeito, ou seja, não há presença de encruamento, portanto, as deformações evoluem sem que haja incremento de tensão. A riqueza desta formulação está no elevado grau de parametrização das equações que inclui geometria e cargas críticas. Além disso, os pesquisadores aplicam sua formulação no projeto e minimização do peso de estruturas sanduíches considerando os principais modos de falha para um estudo de caso com núcleo polimérico, dentre os quais, tem-se: cisalhamento ou esmagamento do núcleo e micro flambagem das faces. Comparando as formulações desenvolvidas com resultados experimentais e análises via MEF (Método dos Elementos Finitos) para diferentes estruturas sanduíches com núcleos de espuma PVC (Poli Cloreto de Vinila) (STEEVES; FLECK, 2004b), os autores também identificaram a dependência dos modos de falha mais pertinentes para a estrutura sanduíche com a densidade do núcleo e com as geometrias de seus constituintes. Os modelos em MEF foram elaborados no programa ABAQUS via UMAT (User Material Subroutine - sub-rotina contendo um modelo de material especificado pelo usuário) considerando um modelo de material isotrópico e com visco-plasticidade sendo que a calibração deste modelo foi realizada com base em ensaios de tração, cisalhamento e compressão.

Uma variação desta abordagem teórica também foi proposta por Tagarielli, Fleck, e Deshpande (2004) para o mesmo carregamento de endentação. A proposta foi descrever vigas engastadas e comparar os modos de falha destas com os de vigas simplesmente apoiadas. Verificou-se que para diferentes geometrias, cada viga sob uma dada restrição apresentou uma resposta diferente pós-escoamento. A viga simplesmente apoiada tem um incremento de 
tensão devido à micro flambagem das faces e depois essa tensão se reduz devido a um tipo de “encruamento negativo" (amolecimento - softening). Por outro lado, a engastada tem forte encruamento positivo devido à rigidez das faces, e não apresentam micro-flambagem devido à condição de contorno de engastamento. Neste trabalho, novamente o núcleo é modelado através de uma UMAT baseada em um modelo de material isotrópico. As faces são modeladas de acordo com a restrição (condição de contorno) em questão para descrever com maior precisão a resposta observada após o início da falha das faces. As formulações analíticas são validadas com base em análises numéricas e experimentais, verificando-se uma boa concordância entre os resultados obtidos, e com isso, mapas de falha e critérios para otimização de peso são definidos a partir das mesmas.

Os mapas de falha construídos nos trabalhos supracitados foram desenvolvidos para auxiliar no projeto de estruturas sanduíche que de acordo com seus constituintes, geometrias e carregamentos, podem exibir diversos e/ou combinados modos de falha os quais dificultam a aplicação dessas estruturas. Daniel et al. (2002) também identificaram a necessidade desses mapas e estudaram, detalhadamente, os modos de falha específicos de estruturas sanduíches fabricadas com faces reforçadas com fibra de carbono e núcleos poliméricos de PVC ou alumínio (honeycomb). Para cada modo de falha foi proposto um critério: 1) Para as faces, utiliza-se um critério clássico para compósitos (Critério de Tsai-Wu); 2) Para o adesivo, podese usar o critério da máxima tensão de cisalhamento; 3) Para o núcleo, verifica-se a falha por densificação local quando o mesmo atinge uma tensão crítica ou quando as cargas de flexão local e global geram tensões críticas de compressão sobre as faces; 4) Também para o núcleo, a falha do mesmo pode ser identificada por critérios de falha de compósitos e novamente propõe-se o modelo de Tsai-Wu; 5) Para o enrugamento (wrinkling) das faces, considera-se que o referido fenômeno ocorre quando a tensão nas faces atinge a tensão crítica de flambagem local. Esses modos de falha e os respectivos limites de resistência foram discutidos e determinados com auxílio de strain gages e técnicas ópticas baseadas nos padrões das envoltórias de Moiré.

Outro trabalho extenso e representativo sobre endentação e caracterização dessas estruturas sanduíches é o de Berthelot e Lolive (2002a). Neste artigo, os autores caracterizaram os materiais de sua estrutura sanduíche de fibra de vidro e PVC, empregando ensaios de tração, compressão e cisalhamento. Através de uma incrementação linear das curvas experimentais de tensão-deformação, determinaram-se incrementos de módulo de elasticidade para o material, sendo que estes incrementos foram utilizados como dados de entrada em um modelo bidimensional de elementos finitos sob carregamentos de endentação. 
Neste modelo, a falha progressiva das faces, a anisotropia do núcleo assim como o contato do endentador com a estrutura foram contabilizados, visando uma modelagem mais representativa. A precisão dos dados experimentais e a calibração dos modelos numéricos com base nos ensaios proporcionam resultados fisicamente consistentes.

Para avaliar o algoritmo proposto, esses pesquisadores realizaram ensaios de endentação para endentadores de diferentes tamanhos e estruturas sanduíches com diferentes empilhamentos para os laminados das faces e diferentes densidades para o núcleo. De uma maneira geral, os pesquisadores verificaram uma concordância razoável entre os valores numéricos e experimentais, sendo que os desvios observados nas curvas foram atribuídos às falhas abruptas das faces juntamente com a não uniformidade dos poros dos núcleos. Também foram realizados ensaios de flexão em 3 pontos e os limites elásticos teóricos para as estruturas sanduíche foram calculados e comparados com a modelagem proposta e com os ensaios. Observou-se que os modelos teóricos divergem um pouco da realidade, sendo que o erro foi associado a não-linearidade local do material, que não foi contabilizada no modelo analítico clássico empregado. Além disso, diferentes distâncias entre apoios (spans) foram usadas, bem como diferentes laminados para as faces a fim de se verificar a validade do algoritmo proposto. Os ensaios mostraram que os efeitos de carregamentos locais geram discrepâncias nos resultados que por sua vez comprometeram a modelagem via MEF empregada (BERTHELOT; LOLIVE, 2002b).

Analisando os resultados obtidos nos trabalhos acima é possível concluir que uma representação realística de estruturas sanduíches com núcleos poliméricos será obtida com base em extensas análises experimentais dos materiais constituintes, mais especificamente, análises dos núcleos poliméricos. Recentemente, Russo e Zuccarello (2007) observaram essa tendência nas modelagens do comportamento mecânico de tais estruturas e fizeram uma contribuição. Mostraram que os modelos teóricos clássicos indicam valores críticos de carregamentos bem acima ou abaixo dos valores reais para os quais os modos de falha de delaminação ou cisalhamento do núcleo ocorrem. Para tal demonstração, os autores realizaram ensaios experimentais de flexão em quatro pontos em estruturas sanduíches (com faces reforçadas com fibra de vidro e núcleos poliméricos de PVC ou poliéster) bem como efetuaram modelagens computacionais. Para obter dados mais realísticos, os componentes das estruturas sanduíches foram ensaiados separadamente para se obter as propriedades elásticas e as resistências dos mesmos. Mostrou-se também que os limites em mapas de falhas, no caso o limite entre delaminação e cisalhamento do núcleo, podem chegar a erros de mais de $100 \%$. Além disso, os pesquisadores concluíram que os critérios de falha são altamente dependentes 
dos materiais estudados, das resistências ao cisalhamento e à tração. Dessa forma, foram propostos critérios de falha sensíveis ao principal modo de falha de cada material. Para o poliéster, indica-se um critério para cisalhamento do núcleo (eq. (8)) e, ao passo que para o PVC, um critério de delaminação (eq. (9)).

$$
\begin{gathered}
\frac{\tau_{x z}}{\tau_{c}}+\frac{\sigma_{z}}{\sigma_{t}}=1 \\
\left(\frac{\tau_{x z}}{\tau_{d}}\right)^{2}+\left(\frac{\sigma_{z}}{\sigma_{t}}\right)^{2}=1
\end{gathered}
$$

Sendo $\tau_{x z}$ e $\sigma_{z}$ são tensões médias ao longo do span no plano médio da estrutura sanduíche em ensaios de flexão em 3 ou 4 pontos com carregamento na direção $z$. Os subíndices $c, t$ e $d$ indicam as resistências em cisalhamento puro, tração e delaminação respectivamente.

Este trabalho mostrou que a modelagem da falha em estruturas poliméricas celulares é extremamente dependente da geometria e de seu material base, e, consequentemente, a obtenção de modelos de material genéricos para materiais celulares representa assim, uma tarefa desafiadora.

O aumento no grau de dificuldade na modelagem dessas estruturas incentivou pesquisadores a procurarem abordagens alternativas para o problema de maneira a identificarem outras respostas desses materiais poliméricos que explicassem as divergências entre as previsões computacionais e os dados experimentais, sempre buscando modelos de material mais abrangentes. Alguns autores limitaram o estudo dessas estruturas sanduíches ao regime elástico, como Sokolinsky et al. (2003) que trabalharam em uma teoria de ordem superior linear para descrever o regime elástico de estruturas sanduíches com núcleos macios (espuma polimérica de PVC com densidade de $60 \mathrm{~kg} / \mathrm{m}^{3}$ ), focando em cargas localizadas, típicas de testes de flexão em quatro pontos. Esse trabalho ratificou que as teorias clássicas subestimam as deformações elásticas. Sob uma perspectiva diferente, Yang, Shen e Zhang (2001) analisaram um laminado sanduíche sobre um apoio elástico com base em um modelo parametrizado. Foi observada uma forte interação de cisalhamento entre a face carregada e o núcleo, e, portanto, essa iteração deve ser contabilizada no modelo de material. Assim, o modelo contabiliza o comportamento não-linear das placas sanduíche sob ação combinada de cargas transversal e compressiva, que promovem a flambagem do material. Análises analíticas e numéricas foram desenvolvidas para determinar as respostas de flexão e pós flambagem 
para estruturas sanduíche de diferentes materiais. Por fim, os resultados obtidos pelos pesquisadores são coerentes com dados da literatura da época.

Abordagens por impacto e energia absorvida durante a endentação de estruturas sanduíche também fornecem dados de como as resistências e rigidezes das espumas podem ser modificadas mesmo sob impactos localizados de baixa velocidade. Diminuições na resistência, rigidez e carga crítica de flambagem dessas estruturas celulares podem ocorrer e são atribuídas em parte à formação de cavidades na espuma abaixo do local de impacto (SHIPSHA; HALLSTRÖM; ZENKERT, 2003). Ainda com base em testes de impacto à baixa velocidade (de 1 a 5 m/s), Schubel, Luo e Daniel (2007) estudaram estruturas sanduíches de fibra de carbono e núcleo de PVC para avaliar os danos após impactos. Verificou-se que muitas vezes os danos de delaminação podem ser vistos com técnicas mais precisas que a mera inspeção visual, técnicas como as de mapeamento ultra-sônico. Após alguns experimentos, observou-se que ensaios específicos para compressão após impacto (CAI Compression After Impact) são os mais sensíveis às delaminações mínimas geradas pelo impacto do endentador e, portanto, são os mais indicados para a determinação da nova tolerância ao dano da estrutura impactada.

Sadighi, Pouriayevali, e Saadati (2007) analisaram estruturas sanduíche com faces laminadas em fibra de vidro e epóxi e núcleos de Poliuretano (PU) e PVC para diferentes geometrias. Foram feitos ensaios de endentação bem como de flexão em 3 pontos, comparando os resultados obtidos com as formulações teóricas propostas. De uma maneira geral, os resultados teóricos são coerentes, e assim, as formulações analíticas podem ser usadas para o cálculo da energia absorvida em problemas de impacto nos quais quase toda energia de impacto é absorvida pelo núcleo.

Somada às questões supracitadas, são diversos os comportamentos mecânicos dos núcleos poliméricos, tais como o aparecimento de seções e zonas sob diferentes regimes de deformação. Zenkert, Shipsha e Persson (2004) trazem uma formulação analítica para uma estrutura sanduíche sob endentação que leva em consideração algumas regiões do núcleo polimérico esmagadas plasticamente enquanto outras, ainda estão sob deformação elástica. Espumas tradicionais em aplicações náuticas (Divinycell H60, espuma de PVC) e aeroespaciais (Rohacell WF51, espuma de PMI, polimetacrilimida) foram avaliadas. As deformações nas regiões esmagadas são diferenciadas das demais com o auxílio de uma técnica de correlação de imagens (digital speckle photography, DSP). Os ensaios experimentais são comparados com modelos analíticos e modelos em MEF via ABAQUS, cujo modelo de material foi calibrado com ensaios uniaxiais. Os pesquisadores verificaram 
uma boa concordância entre os resultados teóricos e experimentais para condições de carregamento, contudo, para condições de descarregamento, o modelo não foi desenvolvido devido à falta de dados e da complexidade dos efeitos viscosos da zona endentada.

Outra dificuldade quanto à análise de estruturas sanduíche, trata-se da investigação de falhas localizadas, haja vista que o uso de extensômetros nem sempre é possível dado sua capacidade limitada de medir grandes deformações. Sendo assim, o emprego de técnicas óticas de correlação de imagens, como a DSP, torna-se uma alternativa muito razoável. Fazendo uso dessa classe de técnicas, Fan et al. (2002) estudaram a obtenção dos campos de deslocamento e deformação ao longo da espessura de estruturas sanduíche em ensaios de flexão em quatro pontos. As imagens necessárias para a aplicação da técnica foram coletadas em duas câmeras posicionadas em ângulos diferentes de maneira a homogeneizar os resultados. Com auxílio de formulações clássicas, a rigidez à flexão e ao cisalhamento foram computadas com os dados das imagens tratadas.

Percebendo a necessidade de um estudo detalhado para modelagens mais amplas e representativas das estruturas sanduíches sob flexão em 3 pontos, Swanson e Kim (2002) desenvolveram um modelo analítico para uma estrutura sanduíche sob cargas concentradas considerando as dependências das respostas macroscópicas do material com a densidade relativa da estrutura celular (eq. (1)), a fim de otimizar essas estruturas. No cálculo, observouse que o melhor valor para a densidade do material do núcleo é definido com base em um valor de carga aplicado no centro da viga que por sua vez gera uma falha simultânea por compressão e cisalhamento do núcleo com a máxima deformação das faces.

Revisando os artigos citados acima, fica evidente a necessidade de um estudo mais centralizado nos materiais utilizados para o núcleo de estruturas sanduíches, especialmente os núcleos poliméricos que podem ser fabricados a partir de diferentes polímeros (PVC, PU, PMI, Poliestireno expandido-EPS, Polietileno de alta densidade-HDPE, Polipropileno-PP, Poli-metil-metacrilato-PMMA, Poliéster, Epóxi e outros). Esses núcleos formam estruturas celulares cujos mecanismos de falha variam substancialmente com o material polimérico empregado, bem como com os carregamentos aplicados e consequentemente modificam a resposta das estruturas sanduíches. Logo, a necessidade de uma extensa investigação fica evidente para que seja possível definir e calibrar um modelo de material para estruturas poliméricas sob carregamentos multiaxiais que melhor represente o comportamento mecânico observado nas estruturas sanduíche. Assim, uma vez que o modelo de material é definido e ajustado, é possível finalmente rever os conceitos de mapas de falha para determinar rotinas 
de seleção de materiais (PFLUG e VERPOEST, 2006; FERRANTE, 2002) de acordo com características reais de rigidez, resistência, custo e aplicação.

\subsection{Estruturas Celulares e Modelos de Material}

Estruturas celulares são aglomerados de células abertas, fechadas ou uma combinação de ambas interconectadas entre si, sendo que o material e a geometria dessas estruturas são atreladas ao processo de formação das células. Por exemplo, se o processo é controlado artificialmente, tem-se a formação das espumas poliméricas e das estruturas metálicas em forma de colméia. Por outro lado, se o processo ocorre naturalmente, tem-se a cortiça, madeiras em geral ou mesmo os animais denominados esponjas como seus representantes (Fig. 5).

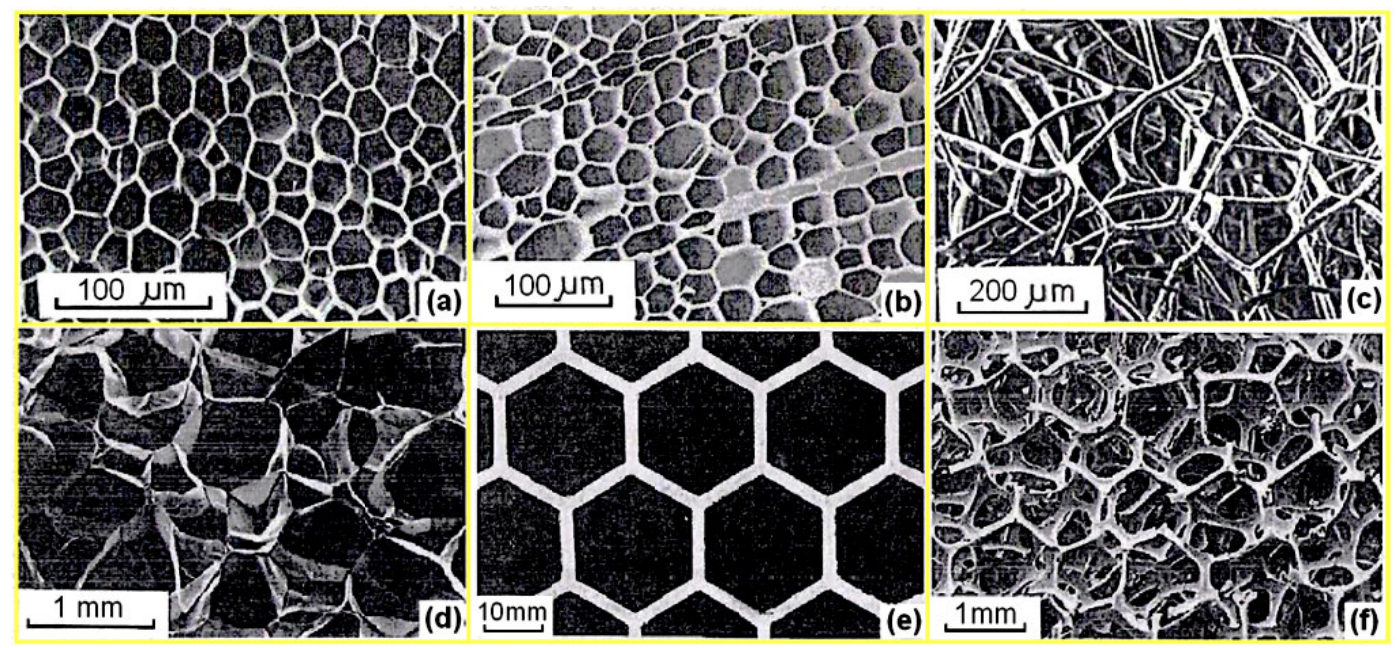

Figura 5. Estruturas celulares: a) cortiça; b) balsa; c) esponja; d) estrutura celular de célula fechada; e) estrutura celular bidimensional tipo colméia; f) estrutura celular de célula aberta.

Adaptado de: Gibson e Ashby (1988)

As estruturas celulares poliméricas são comumente referenciadas por espumas ou esponjas e assume-se também que as espumas podem ser líquidas e as esponjas não. Originalmente o termo em inglês para espumas líquidas (geralmente na superfície de um líquido) é "froth", todavia o termo sem tradução própria para o português foi também traduzido para o termo "espuma" (foam). Dessa forma, toma-se este termo como o mais genérico, pois se refere a um aglomerado de "bolhas" de gás dispostas em um líquido ou sólido com certa regularidade de forma poliédrica e arranjo espacial (WEAIRE; HUTZLER, 
1999). Quando o meio é sólido, esse material configura uma estrutura de células abertas ou fechadas, dependendo do processo de expansão do polímero base (para o caso de espumas poliméricas). Como as estruturas poliméricas de células abertas são geralmente mais flexíveis e possibilitam um maior deslocamento de fluido através de seus poros, elas representam a maior parte das espumas sólidas utilizadas no cotidiano (colchões, buchas de lavar louça ou tomar banho, filtros de água, etc.). Sendo algumas das características dessas estruturas sólidas de célula aberta semelhantes às dos animais aquáticos conhecidos como "esponjas" (sponges), este termo foi associado a essas espumas poliméricas de célula aberta. Resumindo a terminologia, defini-se como:

- Espumas líquidas: espumas/froth;

- Espumas/Estruturas sólidas de célula aberta: espumas/esponjas;

- Espumas/Estruturas sólidas de célula fechada: espumas.

Para diferenciar uma estrutura celular de um sólido poroso, Gibson e Ashby (1988) definiram um valor limite para a densidade relativa do material (eq. (1)) de $\bar{\rho}=0.3$. Valores maiores que 0.3 indicam um sólido poroso e os inferiores apontam as estruturas celulares. Esse valor é baseado nas densidades relativas de estruturas celulares recorrentes na natureza ou obtido artificialmente. Há espumas poliméricas com densidade relativa na faixa de 0.03 a 0.2 e para algumas espécies de madeiras variam entre 0.15 a 0.4 . Portanto, de uma maneira geral, não há estruturas celulares em escala macroscópica (dimensões na ordem de $1 \times 10^{-3}$ à $\left.1 \times 10^{0} \mathrm{~m}\right)$, pois as atuais aplicações dessas estruturas assim como os seus respectivos processos de formação/fabricação envolvem células de tamanho microscópico $\left(1 \times 10^{-6}\right.$ à $1 \mathrm{x}$ $10^{-3} \mathrm{~m}$ ). As estruturas celulares artificiais podem ser obtidas a partir de metais, polímeros ou cerâmicas de acordo com a aplicação em questão. Todas estas aplicações exploram a característica celular do material que permite o seu uso como isolantes acústicos ou térmicos ou ainda, sob o ponto de vista mecânico, como excelentes absorvedores de energia, dado as grandes deformações em compressão desses materiais. Na Figura 6, está representada uma curva de tensão-deformação típica dessas estruturas celulares em compressão que pode ser dividida em três regiões relativamente distintas.

A região "A" corresponde ao regime elástico da estrutura, geralmente assumido como linear; a região "B" é o platô (plateau) onde ocorre a grande absorção de energia característica desses materiais e a região "C" é onde o material sofre densificação devido à compactação das células. Este fenômeno tende a formar um volume de material com porosidade mínima cuja rigidez tende a do material base. 


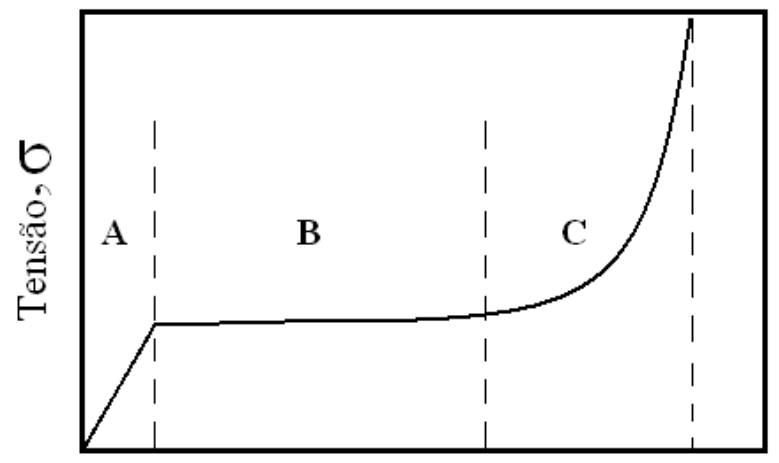

Deformação, $\varepsilon$

Figura 6. Curva tensão-deformação típica de materiais celulares em compressão

Dependendo da geometria, material e tipo das estruturas celulares, as espumas podem apresentar diferentes respostas mecânicas em compressão para os regimes A, B e C delimitados na Figura 6. Não somente em compressão (principal tipo de carregamento de projeto para esses materiais), mas também em tração e mais notadamente em carregamentos multiaxiais, os materiais celulares exibem mecanismos de falha que podem compor respostas fenomenológicas não-lineares, anisotrópicas, hiperelásticas, frágeis, elastoplásticas ou uma combinação desses fenômenos (GIBSON; ASHBY, 1988).

Deve-se destacar que o comportamento mecânico desses materiais dependerá fortemente da estrutura celular e de seu material base. Dessa forma, o presente trabalho exibe uma bibliografia referente a diferentes abordagens dessas espumas que visam prever os complexos mecanismos apresentados por esses materiais. Cada referência traz contribuições significativas para o tratamento mecânico das espumas na determinação dos modelos de material. Algumas buscam se concentrar no estudo dos polímeros base dessas espumas, outras, porém, no arranjo ou no formato das células e existem ainda aquelas que modelam os diferentes mecanismos de falha dessas micro-estruturas.

Em suma, os modelos de material podem ser divididos em dois grandes grupos: modelos fenomenológicos ou micro-mecânicos. O primeiro grupo faz uso de respostas e propriedades macroscópicas, tipicamente obtidas através de ensaios padronizados, para definir o modelo de material, e o segundo grupo aborda o material em escala microscópica, estudando a morfologia das estruturas celulares para definir mecanismos de falha microscópicos que regem as tensões e deformações macroscópicas da respectiva estrutura celular. 


\subsubsection{Modelos Micro-mecânicos}

Classicamente, o estudo microscópico de estruturas ou sólidos celulares inicia-se com a determinação da densidade relativa do material (eq. (1)). Contudo é preciso cautela ao extrapolar ou desconsiderar as contribuições mecânicas advindas dos "vazios" (espaços ocupados por gases) em materiais celulares poliméricos de acordo com a distinção que se faz entre estruturas de células abertas ou fechadas.

Christensen (2000), reconhecendo a amplitude do desafio na modelagem de sólidos celulares, iniciou seu estudo na origem física da formação das espumas poliméricas que tem início no arranjo das bolhas do gás dissolvido no polímero fundido, em forma de poliedros configurando uma espuma seca (WEAIRE; HUTZLER, 1999) que posteriormente se solidifica. Esse procedimento seria o mais indicado na modelagem micro-mecânica das espumas poliméricas, contudo, é necessário que o pesquisador tenha muitas informações sobre o processo de fabricação da espuma e se esta será de célula aberta ou fechada para determinar se o modelo de material é válido para a geometria e arranjo das células em questão. Dentre algumas conclusões obtidas, Christensen pôde afirmar que estruturas poliméricas de célula aberta possuem maior resistência, porém as de célula fechada possuem maior rigidez, mas os problemas de aplicação são muito mais complexos. Muitas aplicações dependem da qualidade e técnica de fabricação dos materiais e das especificações do uso dos mesmos, e isto irá definir o quanto a estrutura celular precisa ser regular e homogênea.

Antes de citar outras referências, algumas definições são necessárias, pois não é uma tarefa trivial desenvolver modelos de material micro-mecânicos que sejam amplos no sentido de serem aplicáveis a estruturas celulares com morfologia e/ou composição distintas e ao mesmo tempo realísticos. O início dessa tarefa é uma análise micrográfica do material celular a ser modelado, associada ao respectivo processo de fabricação dessa espuma. Na sequência deve-se adotar o tipo de abordagem micro-mecânica que será usada na modelagem dessas estruturas. De forma geral, as abordagens podem ser separadas em duas categorias:

i. Modelos de material para células $\rightarrow$ São desenvolvidos com base em um número mínimo de células, geralmente algumas arestas e/ou faces conectadas a um único vértice, sendo uma abordagem tipicamente analítica.

ii. Modelos de material para um volume elementar representativo (VER ou RVE) ou unidade celular representativa $(R U C) \rightarrow$ Nestes modelos, uma grande quantidade de arestas pertencentes a várias células formam um volume para representar o material, sendo uma abordagem tipicamente numérica. 
As vantagens e desvantagens de cada categoria estão no método com que os modelos são desenvolvidos. O primeiro tipo de abordagem tem a vantagem de ser aplicado rapidamente e com precisão teórica, mas apresenta resultados pobres quando as tensões e deformações nos vértices, colunas e paredes da estrutura celular devem ser transferidas à escala macroscópica do material. O segundo tipo de abordagem apresenta melhores resultados, contudo, algumas limitações ocorrem durante a aplicação desses modelos. Naturalmente, por requererem modelagens numéricas, as soluções podem ser demoradas para serem calculadas, além dos parâmetros e hipóteses assumidos na construção do modelo que podem comprometer a obtenção de uma resposta realística.

Definidas as linhas gerais da modelagem, uma metodologia deve ser posta em prática, porém muitas vezes são necessários estudos e investigações paralelas para que a metodologia seja efetivada. Estudos sobre modelos de material para o sólido da espuma e sua sensibilidade a agentes externos como a temperatura ou com a variação nas taxas de deformação devem ser considerados para determinados tipos de aplicação.

Uma das literaturas mais citadas quando se trata de modelos associados ao primeiro tipo de abordagem é o livro de Gibson e Ashby (1988). O texto tornou-se um clássico no estudo de materiais celulares devido ao desenvolvimento micro-mecânico exibido para materiais artificiais e naturais. Os autores fazem uma distinção muito clara entre os comportamentos mecânicos de espumas de células abertas e fechadas na determinação dos modos de falha para cada tipo de espuma de acordo com o material base. É possível resumir os principais resultados para as tensões críticas sob as quais as espumas falham por escoamento, flambagem ou ruptura frágil desse trabalho. Os respectivos mecanismos e modos de falha e suas expressões estão resumidos na Tabela 1. 
Tabela 1 - Modelos micro-mecânicos desenvolvidos por Gibson e Ashby (1988) para espumas de células abertas ou fechadas em compressão uniaxial

\begin{tabular}{|c|c|c|c|}
\hline Célula & Tipo de falha & Mecanismo de falha & Tensões de Falha das espumas (*) \\
\hline \multirow{3}{*}{ Aberta } & Elástica & Flambagem & $\frac{\sigma_{e l}^{*}}{E_{s}} \approx 0.03\left(\frac{\rho}{\rho_{s}}\right)^{2}\left(1+\left(\frac{\rho}{\rho_{s}}\right)^{1 / 2}\right)^{2}$ \\
\hline & Plástica & $\begin{array}{c}\text { Formação de rótulas } \\
\text { plásticas }\end{array}$ & $\frac{\sigma_{p l}^{*}}{\sigma_{y s}} \approx 0.23\left(\frac{\rho}{\rho_{s}}\right)^{3 / 2}\left(1+\left(\frac{\rho}{\rho_{s}}\right)^{1 / 2}\right)^{2}$ \\
\hline & Frágil & Esmagamento frágil & $\frac{\sigma_{c r}^{*}}{\sigma_{f s}} \approx 0.65\left(\frac{\rho}{\rho_{s}}\right)^{3 / 2}$ \\
\hline \multirow{3}{*}{ Fechada } & Elástica & $\begin{array}{c}\text { Flambagem; Diferença } \\
\text { de Pressão }\end{array}$ & $\frac{\sigma_{e l}^{*}}{E_{s}} \approx 0.03\left(\frac{\rho}{\rho_{s}}\right)^{2}\left(1+\left(\frac{\rho}{\rho_{s}}\right)^{1 / 2}\right)^{2}+\frac{\left(p_{\text {int }}-p_{\text {ext }}\right)}{E_{s}}$ \\
\hline & Plástica & $\begin{array}{l}\text { Alongamento plástico } \\
\text { das faces; Flexão } \\
\text { plástica de arestas; } \\
\text { Diferença de Pressão }\end{array}$ & $\frac{\sigma_{p l}^{*}}{\sigma_{y s}} \approx 0.3\left(\phi \frac{\rho}{\rho_{s}}\right)^{3 / 2}+(1-\phi) \frac{\rho}{\rho_{s}}+\frac{\left(p_{i n t}-p_{e x t}\right)}{\sigma_{y s}}$ \\
\hline & Frágil & Esmagamento frágil & $\frac{\sigma_{c r}^{*}}{\sigma_{f s}} \approx 0.65\left(\phi \frac{\rho}{\rho_{s}}\right)^{3 / 2}+(1-\phi) \frac{\rho}{\rho_{s}}$ \\
\hline
\end{tabular}

Onde $\sigma^{*}{ }_{e l}$ é a tensão de falha elástica, $E_{S}$ o módulo elástico e $\rho_{s}$ a densidade do material base. $\sigma_{y s}$ é a tensão de falha plástica, $\sigma_{c r}{ }_{c r}$ é a tensão de falha frágil por esmagamento e $\sigma_{f s}$ é a tensão de ruptura de uma aresta de uma célula em flexão. Por fim o fator $\phi$ representa a fração volumétrica de material nas arestas de uma célula em relação à quantidade de material nas faces. Os demais mecanismos de falha tais como torção e cisalhamento nas células foram desconsiderados no modelo micro-mecânico de Gibson e Ashby cujas arestas homogêneas configuram uma célula em forma de um paralelepípedo ou um cubo, como na Figura 7, caso o material seja isotrópico.
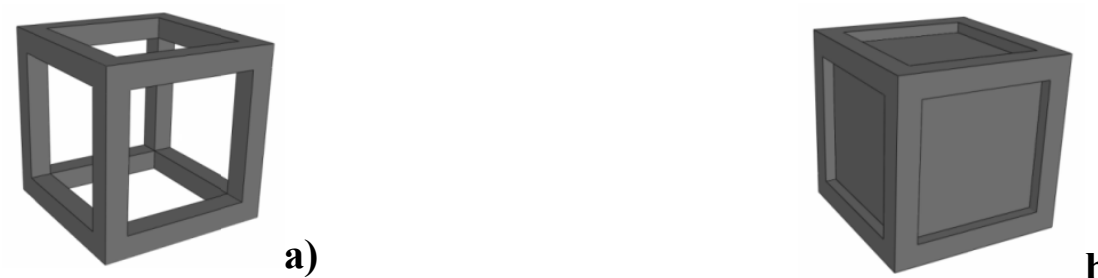

a)

b)

Figura 7. Representação simplificada das células para modelagem micro-mecânica do material celular: a) Estrutura de células abertas; b) Estrutura de células fechadas

Apesar de contemplar as tensões de colapso apenas em compressão, é possível extrapolar os resultados da Tabela 1 para carregamentos de tração sendo que a única mudança 
significativa está na tração de espumas frágeis, pois neste caso é necessária a aplicação de conceitos de mecânica da fratura com propagação de trincas.

A aplicação das equações da Tabela 1 está atrelada à distinção entre os tipos de falha de acordo com o material base, densidade relativa e estrutura da célula. Notadamente para materiais cerâmicos utilizam-se as equações (12) e (15), bem como para todo material que falhe de maneira frágil. Tais materiais são facilmente identificados pela rápida propagação de falhas no material o que resulta na ruptura do mesmo ainda sob pequenas deformações. Infelizmente, a determinação do limite entre as falhas elásticas por flambagem e escoamento plástico do material base pode representar uma variável complexa na determinação dos modos de falha. Ainda no trabalho de Gibson e Ashby (1988) encontra-se um critério para se escolher o tipo de falha, que foi baseado nas equações da Tabela 1. Se válida, a equação (16) indica que o material pode falhar elasticamente, caso contrário deformações plásticas dominam a resposta do material.

$$
\bar{\rho}<36\left(\sigma_{y S} / E_{S}\right)^{3 / 2}
$$

Para pressões externas próximas daquelas no interior dos materiais de células fechadas, os termos na Tabela 1 referentes à diferença entre essas pressões podem ser desconsiderados. Todavia, para espumas elastoméricas, a simples presença de um gás confinado em células de material hiperelástico influencia a resposta do material macroscopicamente. De maneira geral, se a equação (17) for válida para uma espuma elastomérica, a contribuição de pequenas diferenças de pressão pode ser descartada.

$$
\bar{\rho}>0.1
$$

Parte da sensibilidade das espumas à temperatura, taxas de deformação e escoamento do gás no interior das células também foram descritas por Gibson e Ashby, todavia muitos dos resultados obtidos foram calibrados experimentalmente e dependendo da espuma em questão os resultados apresentados para essas variáveis podem divergir significativamente dos valores reais. Deve-se ressaltar que há variações e erros nas equações da Tabela 1, mas para aplicações com carregamentos quase-estáticos à temperatura ambiente, verifica-se uma concordância satisfatória com resultados experimentais. 
Gibson et al. (1989) apresentaram um modelo para carregamentos multiaxiais de estruturas celulares que ficou conhecido como GAZT, referente às iniciais dos nomes dos autores. Neste trabalho, tem-se um equacionamento que leva em consideração a anisotropia do material em questão. Basicamente, uma média das tensões de escoamento nas diferentes direções é proposta para substituir a tensão de escoamento uniaxial $\sigma_{y}$ no critério de GAZT, que é dado por:

$$
\begin{aligned}
\pm\left\{\frac { 1 } { 2 } \left[\left(\frac{\sigma_{11}}{\left(\sigma_{y}\right)_{1}}-\right.\right.\right. & \left.\left.\frac{\sigma_{22}}{\left(\sigma_{y}\right)_{2}}\right)^{2}+\left(\frac{\sigma_{22}}{\left(\sigma_{y}\right)_{2}}-\frac{\sigma_{33}}{\left(\sigma_{y}\right)_{3}}\right)^{2}+\left(\frac{\sigma_{33}}{\left(\sigma_{y}\right)_{3}}-\frac{\sigma_{11}}{\left(\sigma_{y}\right)_{1}}\right)^{2}\right] \\
& \left.+\left[\left(\frac{\tau_{12}}{\left(\tau_{y}\right)_{12}}\right)^{2}+\left(\frac{\tau_{23}}{\left(\tau_{y}\right)_{23}}\right)^{2}+\left(\frac{\tau_{31}}{\left(\tau_{y}\right)_{31}}\right)^{2}\right]\right\}^{1 / 2} \\
& +0.09 \bar{\rho}\left[\frac{\sigma_{11}}{\left(\sigma_{y}\right)_{1}}+\frac{\sigma_{22}}{\left(\sigma_{y}\right)_{2}}+\frac{\sigma_{33}}{\left(\sigma_{y}\right)_{3}}\right]^{2} \leq 1
\end{aligned}
$$

O modelo anterior (eq. (18)) foi investigado para ensaios uni ou multiaxiais por Triantafillou et al. (1989) em espumas cujos mecanismos de falha eram flambagem ou escoamento do sólido base. Espumas rígidas e flexíveis foram escolhidas para observar os diferentes modos de falha, e verificou-se que as flexíveis falhavam por flambagem e as rígidas por escoamento plástico associado a uma flambagem elástica. A discrepância das formulações com os dados experimentais se explica através da complexa anisotropia do material e da difícil identificação dos mecanismos de flambagem nessas espumas.

Resultados parciais para o comportamento de sólidos celulares também foram obtidos em análises similares presentes em Warren e Kraynik (1987) e Warren, Kraynik e Stone (1989). Detalhes sobre a modelagem geométrica dos vértices são algumas das diferenças entre os modelos que incentivam o leitor a examinar os respectivos trabalhos com maior atenção.

A limitada concordância obtida até então motivou outros pesquisadores a desenvolver modelos de material considerando os efeitos da taxa de deformação, encruamento, tempo, temperatura, cristalinidade do polímero base e uma melhor descrição das estruturas celulares. Examinando o artigo de Zhu e Mills (1999), observa-se que os efeitos de altas taxas de deformação e da viscosidade das espumas de PU de baixa densidade são investigados com uma teoria de viscoelasticidade linear. A microestrutura considerada é uma célula de Kelvin (octaedro truncado ou tetracadodecaedro), e a resposta do material não inclui o contato entre as estruturas da célula deformada. Sendo que os mecanismos de deformação considerados sob 
carregamento de flexão, torção e quanto à reorientação das arestas das células foram avaliados para um carregamento em uma direção genérica da célula. $\mathrm{O}$ efeito de anisotropia pode ser incluído na modelagem, contudo, enquanto não se souber ao certo como variam as dimensões das arestas nas diferentes direções da célula, a modelagem da anisotropia da espuma não é possível sob a ótica destes autores. Uma metodologia e formulação semelhante a esta pode ser encontrada no trabalho de Wang e Cuitiño (2000).

Em outro trabalho, Zhu e Mills (MILLS; ZHU, 1999) realizaram análises micrográficas e concluíram que a quantidade de material nas faces das células da espuma estudada além de ser considerável, é também responsável por grande parte da rigidez e resistência da estrutura e precisa ser contabilizada. Assim, os pesquisadores analisaram uma espuma de célula fechada rígida usando um modelo micro-mecânico cuja célula é novamente um octaedro truncado num arranjo cúbico de corpo centrado $(B C C)$. As contribuições das tensões normais e de flexão das arestas são analisadas assumindo que as faces comportam-se como membranas de um material linear-elástico ou que escoa. Eles verificaram que para espumas com arestas mais espessas, as faces do modelo apresentado devem ser modificadas. A análise não envolve efeitos de torção, que estão presentes principalmente em células abertas. Por fim, dentre resultados e conclusões, o modelo pôde prever satisfatoriamente os coeficientes de Poisson elásticos para espumas de PS (poliestireno) e PE (polietileno).

Mais modelos micro-mecânicos podem ser contemplados em Zhang (2008), Segerstad e Toll (2008) e Romero, Zheng e Cuitiño (2008). O primeiro trabalho faz comparações com o modelo de Gibson e Ashby (1998), o segundo trabalho incorpora anisotropias induzidas pela deformação das células e o último trabalho valida a formulação proposta com base num modelo em Elementos Finitos desenvolvido no programa ABAQUS com auxílio de subrotinas para materiais (UMAT-User Material).

Uma abordagem mais ampla visando caracterizar dinamicamente espumas poliméricas é realizada por Pérez e Saja (2000) que selecionam uma coleção de espumas poliméricas com composições químicas diferentes para serem estudas, usando técnicas de microscopia varredura de eletrônica $(M E V)$, técnicas de calorimetria diferencial de varredura $(D S C)$ e análises mecânicas dinâmicas $(D M A)$. O regime não-linear e elástico das espumas foi investigado, considerando a dependência da rigidez do material perante altas temperaturas, morfologia/cristalinidade dos polímeros e taxas de deformação. Essas análises foram feitas principalmente para espumas de baixa densidade de célula fechada onde a pressão exercida pelo gás é fortemente influenciada por esses parâmetros. O amortecimento de vibrações em cargas dinâmicas também foi investigado pelos pesquisadores. 
Em se tratando das análises micro-mecânicas baseadas em Volumes Elementares Representativos, tem-se alguns exemplos descritos no artigo de Linn e Oliveira (2008) ou em Cunda et al. (2008). Linn e Oliveira modelam numericamente espumas de alumínio com células abertas com certa regularidade (marca Duocel®) enquanto Cunda et al. (2008) investigaram uma espuma metálica cuja a estrutura é formada pela adesão de esferas ocas com resina ao invés do uso da injeção de gases inertes para criar os vazios. Um modelo de material para metais porosos presente no programa ABAQUS foi utilizado visando calibrar o material metálico com o qual as estruturas em questão foram modeladas. Linn e Oliveira (2008) analisaram o fenômeno de micro-flambagem da espuma e buscaram a otimização do modelo computacional através do uso de RVE e RUC, porém nenhuma comparação experimental foi efetuada. Por outro lado, os resultados de Cunda et al. (2008) foram comparados com dados experimentais e as diferenças encontradas, em parte, foram atribuídas à modelagem plástica da resina adesiva através do critério de von Mises.

Brydon et al. (2005) exploraram também, o conceito de RVE, mas usaram uma técnica de microtomografia tridimensional via raio-X para estudar estruturas de células abertas sob compressão, visando avaliar o efeito da densificação do material. Esse procedimento foi justificado, pois no uso de modelos micro-mecânicos analíticos é muito difícil separar efeitos estruturais (ex.: propriedades inerciais geométrica da microestrutura) das propriedades do material (ex.: viscosidade do material base). Porém, em modelos numéricos, as altas deformações em análises via MEF produzem erros com a distorção das malhas Lagrangianas ou com as extensivas mudanças nas propriedades do material nas malhas Eulerianas. Ademais, existe o desafio em modelar uma estrutura celular realisticamente, definindo as variações da quantidade de material ao longo de arestas, paredes e vértices. A metodologia proposta por Brydon et al. (2005) não é muito eficiente, pois algumas análises chegaram a demorar 3 semanas rodando em 48 processadores. Todavia a mesma explora as análises do tipo PIC (particle-in-cell) que evitam a construção de malhas como as realizadas via MEF, sujeitas a grandes deformações. Observou-se ao final do trabalho que a densidade relativa do material varia com as taxas de deformação, mas a mesma tende a um valor comum para a densificação máxima do material. Registrou-se, como esperado, que as propriedades do material são altamente dependentes do volume elementar representativo empregado.

Alguns trabalhos merecem certo destaque, como o de Gong, Kyriakides e Jang (2005) que investiga espumas poliméricas de células abertas. Imagens de microscopia eletrônica de varredura (MEV) permitiram a determinação da seção das colunas interconectadas (Fig. 8), 
denominadas "bordas/ligamentos de Plateau", para que o material fosse implementado via MEF com auxílio de modelos micro-mecânicos.

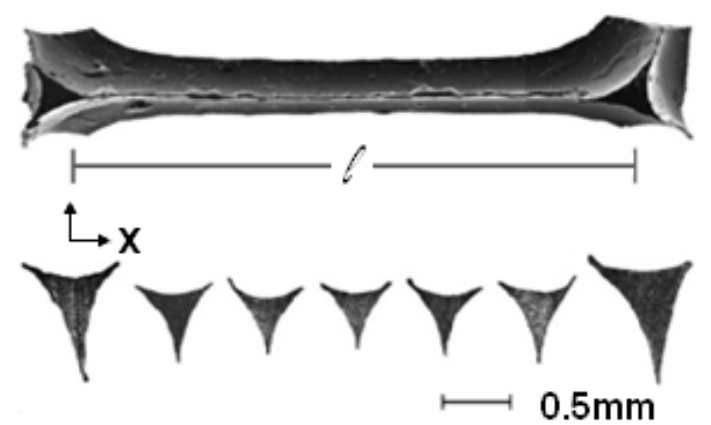

a)

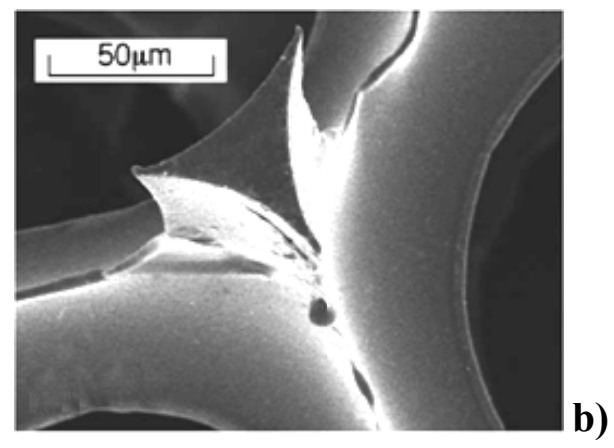

Figura 8. Micrografias da espuma polimérica. a) Variação da área da seção das bordas ao longo do comprimento; b) Detalhe da região de conexão de 3 bordas ou mais, formando um nó. Adaptado de: Gong, Kyriakides e Jang (2005)

Um dos principais resultados das micrografias é a variação da seção de área com a posição relativa normalizada ao longo da borda de Plateau $(A(\xi)$, eq. (19)).

$$
A(\xi)=A_{0}\left(a \xi^{4}+b \xi^{2}+1\right) ; \operatorname{com} \xi=x / l
$$

Sob posse desses dados, o autor utiliza a disposição das arestas em uma célula de Kelvin para construir um modelo em elementos finitos. As células foram modeladas de acordo com a equação (19) e modelos em vigas foram comparados com modelos sólidos e analíticos na determinação das propriedades elásticas. As diferenças observadas nos modelos numéricos foram justificadas com base nas diferentes modelagens dos vértices (Fig. 8). Em publicação associada (GONG; KYRIAKIDES, 2005), os pesquisadores investigaram o esmagamento de espumas poliméricas e o fenômeno de flambagem em escalas macroscópica (dimensões da amostra) e microscópicas (dimensões médias de uma célula). Eles identificaram o comportamento transversalmente isotrópico da espuma, e observaram que a flambagem em escala micro ocorre em ambas as direções do material, todavia a flambagem em escala macro ocorreu somente na direção paralela ao crescimento da espuma, direção geralmente mais rígida e resistente. De acordo com o número de células na direção perpendicular ao plano de crescimento, diferentes modos de flambagem foram observados macroscopicamente. Concluíram que quanto maior o número de células, o modo de flambagem tende para o modo fundamental, ou seja, para uma espessura de amostra suficientemente grande o material passa a exibir somente flambagem do primeiro modo. Este 
fenômeno configura um dos muitos atrelados à definição de um RVEs ou RUCs. Para tal, os autores desenvolveram um modelo bidimensional via MEF contabilizando efeitos de contato intercelular com o esmagamento decorrente da flambagem da estrutura.

De forma geral, o desenvolvimento de uma metodologia para a definição de modelos de material utilizando RVEs inicia na escolha de um modelo de material para o sólido base da estrutura celular e por isso, o presente trabalho apresenta algumas relações constitutivas para polímeros com o intuito de ressaltar algumas características de polímeros para futuras análises micro-mecânicas. Arruda, Boyce e Jayachandran (1995) calcularam a deformação de polímeros com uma relação constitutiva que contempla os efeitos de viscosidade, taxas de deformação, encruamento e evolução de anisotropia (ambos dependentes da temperatura), bem como com a variação de temperatura na superfície do material. O comportamento mecânico previsto no modelo foi avaliado com dados obtidos para carregamento uniaxial de amostras de PMMA (poli-metil-metacrilato). No mesmo ano, Buckley e Jones (1995) modelaram polímeros elastoméricos sob uma temperatura próxima à temperatura de transição vítrea e observaram que alguns desses materiais se comportam como termoplásticos, porém outros, como típicos elastômeros.

Avançando cronologicamente, estudos paralelos permitiram a elaboração de modelos constitutivos mais complexos e representativos. Pesquisadores como Anand e Ames (2006) desenvolveram um novo modelo constitutivo viscoelasto-plástico via análise mecânica das deformações em micro endentações de polímeros amorfos. Eles identificaram que sob temperatura ambiente, polímeros com grandes deformações de compressão exibem encruamento isotrópico e/ou encruamento cinemático, bem como sensibilidade à taxa de deformação e a grandes tensões triaxiais. O modelo é capaz de descrever a resposta viscosa de polímeros amorfos sob tensões abaixo do chamado escoamento macroscópico e relaxamento para deformações abaixo de aproximadamente 30\%. Um modelo mais elaborado foi apresentado por Ghorbel (2008), que modificou modelos clássicos baseados na termodinâmica de processos irreversíveis, para modelar o comportamento mecânico de polímeros. O modelo inclui o terceiro tensor desviador de tensão $\left(J_{3}\right)$ na determinação de uma superfície de escomento para polímeros isotrópicos (eq. (20)), pois este intensifica a sensibilidade do material ao cisalhamento com a introdução de um termo relativo às tensões e deformações de torções.

$$
f=\frac{3 J_{2}}{\sigma_{y t}} \psi\left(J_{2}, J_{3}\right)+\frac{7}{8}\left[(m-1) I_{1}-m \sigma_{y t}\right] \leq 0
$$




$$
\psi\left(J_{2}, J_{3}\right)=\left(1-\frac{27}{32} \frac{J_{3}^{2}}{J_{2}^{3}}\right) ; \quad m=\sigma_{y c} / \sigma_{y t}
$$

Os valores das tensões uniaxiais de escoamento em tração $\left(\sigma_{y t}\right)$ e compressão $\left(\sigma_{y c}\right)$ são tomados na intersecção dos dados experimentais com uma reta construída paralelamente ao regime linear elástico e transladada em 3\% a partir da origem do eixo de deformação. O autor também investiga a viscosidade na fase plástica, o encruamento, fatores de cristalinidade e temperatura de transição vítrea do polímero. O modelo desenvolvido resulta em uma boa concordância com os resultados experimentais, porém, os carregamentos cíclicos não se apresentam tão coerentes e ensaios tridimensionais são propostos.

Avanços nas técnicas de caracterização de materiais e modelagem de estruturas permitiram a construção de modelos de material ainda mais representativos. Liu et al. (2006) conseguiram elaborar um modelo constitutivo para polímeros que acumulam deformações quando submetidos a certas variações de temperatura, esses materiais são chamados "polímeros com memória de forma" (SMP). Li e Buckley (2009) utilizaram o programa ABAQUS e implementaram com o auxílio de uma UMAT, um modelo hiperelástico com efeitos de temperatura, viscosidade, taxa de deformação e encruamento.

\subsubsection{Modelos Fenomenológicos}

Diferentemente dos modelos micro-mecânicos, os modelos de materiais fenomenológicos representam a maior parte das relações constitutivas implementadas programas computacionais comerciais e em uso recentemente. Isso pode ser explicado com base no argumento de que esses modelos são desenvolvidos sob fundamentos termodinâmicos clássicos sob os quais quase a totalidade das teorias de cálculo estrutural e comportamentos mecânicos elásticos e plásticos são derivadas. Ademais, as formulações foram desenvolvidas para serem calibradas com alguns poucos ensaios mecânicos simples. Na prática, isto muito favorece a aplicação desses modelos na indústria, pois além de práticos, os modelos fenomenológicos tornam-se precisos porque são ajustados com dados experimentais de amostras reais do material em questão. Mesmo que algumas vezes os modelos não sejam tão representativos em sua formulação para uma estrutura celular em particular, o seu ajuste experimental garante uma precisão mínima o que torna esses modelos abrangentes e utilizáveis na modelagem de diferentes estruturas celulares. 
Os cálculos estruturais clássicos de tensão e deformação para diferentes materiais e estruturas são baseados na densidade de energia de deformação $(U)$ para sólidos em geral. Sendo que essa densidade de energia para materiais isotrópicos é dada por:

$$
\begin{gathered}
U=\frac{J_{2}}{G}+\frac{1-2 v}{6 E} I_{1}^{2}=\frac{1}{2 \bar{E}}\left[\sigma_{v}^{2}+\zeta^{2} \sigma_{m}^{2}\right]=\frac{1}{2} \sigma_{i j} \varepsilon_{i j} \\
J_{2}=\frac{1}{2} S_{i j} S_{j i} ; \quad I_{1}=\sigma_{k k} ; S_{i j}=\sigma_{i j}-\frac{1}{3} \sigma_{k k} \delta_{i j} \\
\bar{E}=\frac{3 E}{2(1+v)} ; \zeta^{2}=\frac{9}{2} \frac{(1-2 v)}{(1+v)} ; i, j=1 ; 3
\end{gathered}
$$

Examinando as equações acima observa-se que a densidade de energia de deformação é composta por parcelas de energia provenientes de distorções, associadas ao segundo Invariante do tensor desviador de tensões $J_{2}$, e/ou variações de volume representadas pelo primeiro Invariante de tensões $I_{1}$. Isso explica porque os modelos de material são geralmente funções de $J_{2}$ (ou tensão equivalente de von Mises, $\sigma_{v}$ ), e/ou $I_{1}$ (ou tensão média, $\sigma_{m}$ ). $\mathrm{O}$ Terceiro Invariante do tensor desviador de tensões, $J_{3}=S_{i j} S_{j k} S_{k i} / 3$, não é incluído na equação (22), pois este pode ser escrito como uma combinação dos termos $J_{2}$ e $S_{i j}$. Todavia alguns autores o utilizam para aumentar a sensibilidade do modelo a tensões cisalhantes originadas em esforços de torção (GHORBEL, 2008).

$\mathrm{Na}$ atualidade são muitos os modelos fenomenológicos de material em uso ou em estudo, mas existem aqueles que se destacam dado principalmente à sua aplicabilidade. As formulações constitutivas mais representativas, incluindo abordagens micro-mecânicas, foram sintetizadas por Abrate (2008) em uma coletânea de critérios de falha/escoamento para materiais celulares sujeitos a carregamentos multiaxiais. Para materiais celulares considerados isotrópicos, o pesquisador faz uma divisão dos critérios em quatro classes definidas pela dependência desses critérios com solicitações desviadoras e hidrostáticas. As quatro classes e uma superfície de falha/escoamento para cada critério estão evidenciadas nas equações (23)(30).

\section{Classe 1:}

$$
\sqrt{J_{2}}=a_{0}+a_{1} I_{1} \quad \text { ou } \quad \sigma_{v}=b_{0}+b_{1} \sigma_{m}
$$

Ex.: Drucker-Prager

$$
f=\alpha I_{1}+\sqrt{J_{2}}-k \leq 0
$$


Classe 2:

$$
\sqrt{J_{2}}=c_{0}+c_{1} I_{1}^{2} \quad \text { ou } \quad \sigma_{v}=d_{0}+d_{1} \sigma_{m}^{2}
$$

Ex.: Miller

$$
f=\sigma_{v}-\gamma \sigma_{m}+\frac{\alpha}{\beta \sigma_{c}} \sigma_{m}^{2}-\beta \sigma_{c} \leq 0
$$

Classe 3:

$$
J_{2}=e_{0}+e_{1} I_{1}^{2} \quad \text { ou } \quad \sigma_{v}^{2}=f_{0}+f_{1} \sigma_{m}^{2}
$$

Ex.: Deshpande e Fleck

$$
f=\left(\frac{\sigma_{v}^{2}+\alpha^{2} \sigma_{m}^{2}}{1+(\alpha / 3)^{2}}\right)-\sigma_{y}^{2} \leq 0 ; \alpha^{2}=\frac{9}{2} \frac{\left(1-2 v_{p}\right)}{\left(1+v_{p}\right)}
$$

Classe 4:

$$
J_{2}=g_{0}+g_{1} I_{1} \quad \text { ou } \quad \sigma_{v}^{2}=h_{0}+h_{1} \sigma_{m}
$$

Ex.: Raghava, Caddell e Yeh (1973 apud ABRATE, 2008, p. 26)

$$
f=3 J_{2}+I_{1}(C-T)-C T \leq 0
$$

Acima, o termo $\sigma_{c}$ corresponde à tensão de escoamento em compressão uniaxial e o subíndice $p$ no coeficiente de Poisson no terceiro exemplo corresponde à resposta plástica do material. Já os parâmetros $C$ e $T$ são relativos ao início dos escoamentos em compressão e tração, respectivamente. Uma breve comparação entre as superfícies pode ser vista na Figura 9, subsequente.

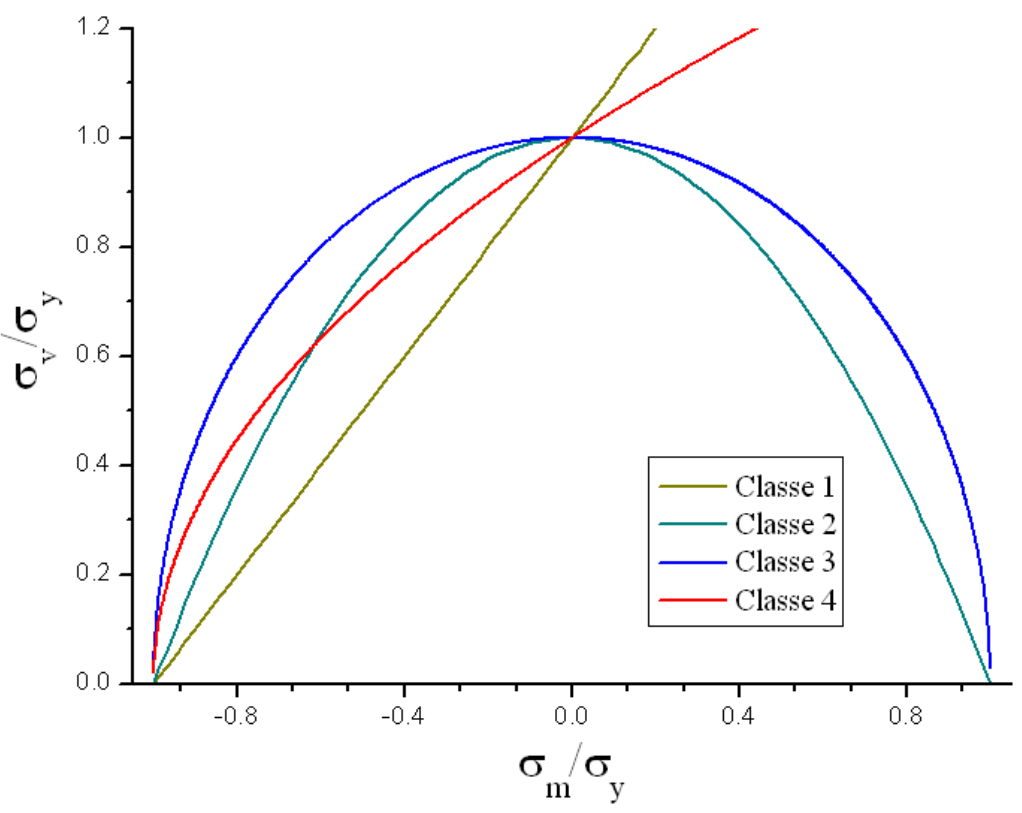

Figura 9. Exemplos de superfícies de escoamento/falha fenomenológicas classificadas em classes (C1-C4) de acordo com Abrate (2008) 
No caso dos materiais considerados anisotrópicos, o autor cita critérios originalmente desenvolvidos para compósitos, que foram considerados frágeis, ou seja, com escoamento desprezível. De todos os critérios para compósitos desenvolvidos e citados pelo autor, o de Tsai-Wu destaca-se por contemplar as diferentes falhas em compressão e tração para materiais anisotrópicos, uma vez que muitos materiais têm comportamento frágil em compressão e dúctil em tração, ou vice-versa. A versão bidimensional do critério de Tsai-Wu (eq. (31)) é a mais utilizada dado à quantidade de materiais transversalmente isotrópicos ou ortotrópicos aplicados na atualidade.

$$
\begin{gathered}
f_{1} \sigma_{1}+f_{3} \sigma_{3}+f_{11} \sigma_{1}^{2}+f_{33} \sigma_{3}^{2}+2 f_{13} \sigma_{1} \sigma_{3}=1-k^{2} \\
f_{1}=\frac{1}{\sigma_{1 T}}-\frac{1}{\sigma_{1 C}} ; f_{3}=\frac{1}{\sigma_{3 T}}-\frac{1}{\sigma_{3 C}} ; f_{11}=\frac{1}{\sigma_{1 T} \sigma_{1 C}} \\
f_{33}=\frac{1}{\sigma_{3 T} \sigma_{3 C}} ; f_{13}=-\frac{1}{2} \sqrt{f_{11} f_{33}} ; k=\frac{\tau_{13}}{\sigma_{13}}
\end{gathered}
$$

Os subíndices numéricos presentes nas equações acima indicam a direção de carregamento ou as diferentes propriedades do material, e as letras $T$ e $C$ nos módulos das resistências diferenciam os valores em tração e compressão respectivamente. Contudo, esse critério não leva em consideração as contribuições hidrostáticas do material e o autor, para eliminar essa deficiência, aponta, por exemplo, uma generalização tridimensional do modelo de Drucker-Prager ou a normalização das resistências nas diferentes direções para serem utilizadas em critérios isotrópicos. Vale ressaltar ainda que o parâmetro $\mathrm{f}_{13}$ do critério de Tsai$\mathrm{Wu}$ é muito difícil de ser determinado por ensaios, sendo a expressão da equação (32) uma alternativa até um tanto quanto grosseira para alguns casos.

Como observações finais, Abrate (2008) ressalta a relevância das taxas de deformação e da temperatura na resposta mecânica dessas estruturas celulares encontrada em trabalhos anteriores e apresenta uma equação genérica (eq. (33)), devidamente fundamentada, para incluir esses parâmetros em um modelo constitutivo unidimensional.

$$
\sigma=H(T) G(\rho) f(\varepsilon)\left(\frac{\dot{\varepsilon}}{\dot{\varepsilon_{0}}}\right)^{b_{1}+b_{2} \varepsilon} ; H(T)=\exp \left[-\frac{C_{1}\left(T-T_{r}\right)}{C_{2}+T-T_{r}}\right]
$$

Dentre as variáveis da equação (33) somente $G$ e $f$ são funções polinomiais, todos os demais parâmetros são constantes ou variáveis independentes. 
Para que seja possível determinar qual das relações constitutivas fenomenológicas tem maior compatibilidade com um material ou uma classe de materiais, o presente trabalho buscou na literatura, trabalhos que detalhassem os modelos citados por Abrate (2008) e outros cujas perspectivas de abordagem permitissem concluir se o respectivo modelo é o ou não representativo para uma aplicação escolhida.

Gioux, McCormack e Gibson (2000) comparam o modelo de material de GAZT com o de Deshpand e Fleck (eq. 27-28) e o de Miller (eq. 25-26). Verificaram que esses dois últimos modelos são melhores que o de GAZT, pois, por serem fenomenológicos, permitem uma calibração com dados experimentais, incluindo a fragilização do material devido às imperfeições originadas no processo de fabricação e desconsiderando os mecanismos microscópicos de falha. O modelo de Deshpande e Fleck (2000) foi baseado no estudo de resultados experimentais para espumas metálicas de alumínio. Os autores propuseram dois modelos constitutivos para carregamentos multiaxiais, ou seja, duas superfícies de escoamento. Cada superfície contempla um tipo de encruamento diferente para o material, a primeira, e mais citada (eq. (34)), é denominada "auto-similar" e incorpora um encruamento isotrópico. Por outro lado, a segunda (eq. (36)), chamada de "modelo de encruamento diferencial", leva em consideração diferentes sensibilidades ao encruamento sob tensões desviadoras e hidrostáticas.

Superfície de Escoamento Isotrópico:

$$
f=\hat{\sigma}^{2}-\sigma_{y}^{2}=\left(\frac{\sigma_{v}^{2}+\alpha^{2} \sigma_{m}^{2}}{1+(\alpha / 3)^{2}}\right)-\sigma_{y}^{2} \leq 0 ; \alpha^{2}=\frac{9}{2} \frac{\left(1-2 v_{p}\right)}{\left(1+v_{p}\right)}
$$

Lei de Evolução das Deformações Plásticas e de Encruamento:

$$
d \varepsilon_{i j}^{p l}=\frac{1}{H} \frac{\partial f}{\partial \sigma_{i j}} \frac{\partial f}{\partial \sigma_{k l}} d \sigma_{k l}^{J} ; H=\frac{d \hat{\sigma}}{d \hat{\varepsilon}}=\left[\frac{\sigma_{v}}{\hat{\sigma}} h_{u}+\left(1-\frac{\sigma_{v}}{\hat{\sigma}}\right) h_{p}\right]
$$

Superfície de Escoamento Diferencial:

$$
f=\left(\frac{\sigma_{v}}{S}\right)^{2}+\left(\frac{\sigma_{m}}{P}\right)^{2}-1 \leq 0
$$

Lei de Encruamento:

$$
\left(\begin{array}{l}
\dot{P} \\
\dot{S}
\end{array}\right)=\left(\begin{array}{ll}
h_{11} & h_{12} \\
h_{21} & h_{22}
\end{array}\right)\left(\begin{array}{l}
\dot{\varepsilon} \\
\dot{\gamma}
\end{array}\right)
$$


A indexação indicada pela sigla $p l$ faz referência ao regime plástico do material. $\hat{\sigma}$ é a tensão equivalente e $\hat{\varepsilon}$ a deformação plástica equivalente conjugada (CHEN; HAN, 1988). Na equação (35), $d \sigma_{k l}^{J}$ é o operador Jaumann de tensão (por exemplo), $\sigma_{y}$ é a tensão de escoamento obtida através de ensaios uniaxiais de tração ou compressão e nas equações (35) e (36), tem-se os respectivos encruamentos definidos através dos parâmetros $H$ e $h$ a serem calibrados experimentalmente.

Ao final da referida publicação, ambos os modelos apresentam-se coerentes com dados experimentais, mas o modelo auto-similar mostrou-se mais prático, de onde se originou sua repercussão. Continuando esse trabalho (DESHPANDE; FLECK, 2001), os autores também compararam seu modelo ao de GAZT, aplicando ambos às espumas de PVC. A partir dos dados experimentais, os mecanismos microscópicos de falha por flambagem e escoamento plástico foram identificados assim como a dependência associada à taxa de deformação, a anisotropia e a visco-plasticidade do material. As comparações foram feitas com os valores das resistências e tensões de escoamento para a direção mais rígida do material, ou seja, a direção do crescimento da espuma. Das curvas obtidas, verificou-se uma concordância maior com os resultados experimentais para o modelo de Deshpande e Fleck (2001).

Por fim, têm-se o trabalho de Miller (2000), representado pela equação (38), que modificou o critério de Drucker-Prager para criar uma superfície de escoamento capaz de prever a alta compressibilidade de espumas, principalmente, as metálicas.

$$
f=\sigma_{v}-\gamma \sigma_{m}+\frac{\alpha}{d} \sigma_{m}^{2}-d \leq 0
$$

A Equação (38) foi estudada paralelamente ao modelo de GAZT, empregando modelos de endentação via MEF com auxílio do programa ABAQUS e a implementação de UMATs. No modelo de Miller (2000), só há encruamento do material a partir da deformação na fase de densificação, cujo valor limite é o proposto por Gibson e Ashby (1988), dado por: $\varepsilon_{D}=\ln (1.4 \bar{\rho})$.

Quando essas superfícies de escoamento evoluem no espaço das tensões desviadoras versus tensões hidrostáticas, elas definem as leis de evolução, que são dadas como função de um potencial plástico, e podem estar relacionadas ao critério de falha com que uma superfície de escoamento em questão foi desenvolvida, definindo as "leis de evolução associativas". Caso o critério de falha difira do potencial de escoamento, defini-se as leis de evolução não 
associativas. Potenciais não associativos permitem com que o encrumento do material se comporte de maneira diferente em seu regime plástico, em relação a diferentes carregamentos combinados (tensão desviadora e tensão hidrostática). Em linhas gerais, uma lei de evolução com potencial associativo significa que o comportamento elástico do material sob carregamentos multiaxais é extrapolado para o regime plástico. Zhang et al. (1998) estudaram três espumas poliméricas (PU, PP e PS) de baixa densidade com diversos ensaios experimentais e notaram diferentes intensidades de encruamento em tração e compressão. Para descrever esse comportamento, os pesquisadores desenvolveram um modelo para espumas poliméricas isotrópicas e rígidas (eq. (39)) com um potencial de encruamento $g$ não associado à superfície de escoamento escolhida.

Superfície de escoamento:

$$
f=\frac{\left[\sigma_{m}-p_{o}\left(\varepsilon_{v p}\right)\right]^{2}}{a\left(\varepsilon_{v p}\right)}+\frac{\sigma_{v}^{2}}{b\left(\varepsilon_{v p}\right)}-1 \leq 0
$$

Potencial de Encruamento:

$$
g=\sqrt{\beta p^{2}+\sigma_{v}^{2}}
$$

Neste caso, o termo $p$ também se refere à tensão hidrostática: $p=-\sigma_{k k} / 3$. O programa LS-DYNA3D foi utilizado juntamente com o modelo de material implementado através de uma sub-rotina. A validação do modelo teórico foi feita com modelos computacionais e ensaios de endentação.

Alguns modelos fenomenológicos, assim como os micro-mecânicos, podem ser propostos para aplicações específicas ou mesmo para comportamentos dominantes. É evidente que o principal comportamento de espumas a ser descrito é o de compressão, com ou sem restrições, como abordado por Subhash e Liu (2004) em seu estudo sobre esmagamento de espumas fabricadas em material epóxi com diferentes densidades. Um ano depois, Liu, Subhash e Gao (2005) investigaram um modelo de material, essencialmente unidimensional, para estas espumas, empregando ensaios experimentais oedométricos, pois alguns pesquisadores julgam que esta seja a principal solicitação desse material. O modelo proposto tem a densidade relativa do material como principal parâmetro (eq. (41)).

$$
\sigma(\rho, \varepsilon)=A(\rho) \frac{e^{\alpha(\rho) \varepsilon}-1}{1+e^{\beta(\rho) \varepsilon}}+e^{C(\rho)}\left(e^{\gamma(\rho) \varepsilon}-1\right)
$$


Onde $\rho$ é a densidade da espuma, $\varepsilon$ é a deformação na direção do carregamento, $A$ refere-se à tensão de escoamento do material em compressão, $C$ e $\gamma$ determinam o início da densificação do material, por fim $\alpha$ e $\beta$ definem o encruamento do mesmo. Uma excelente concordância com resultados experimentais foi obtida até o regime de densificação.

Ao contrário dos modelos micro-mecânicos para os quais relações constitutivas genéricas são difíceis de serem obtidas, os modelos fenomenológicos permitem que essas relações mais abrangentes sejam elaboradas com maior facilidade. Cientes disso, Wang e Pan (2006) apresentaram uma superfície de escoamento não quadrática com ampla parametrização de maneira a representar as diferentes respostas das espumas poliméricas. A equação parametrizada é dada por (eq. (42)):

$$
\begin{gathered}
f=(1-\alpha) f_{1}+\alpha f_{2}-k^{m} \leq 0 \\
f_{1}=\Sigma_{1}^{m}+\Sigma_{2}^{m}+\Sigma_{3}^{m} \\
f_{2}=\left\{\left[\frac{\left(\Sigma_{1}-\Sigma_{2}\right)^{2}+\left(\Sigma_{2}-\Sigma_{3}\right)^{2}+\left(\Sigma_{3}-\Sigma_{1}\right)^{2}}{2}\right]^{1 / 2}\right. \\
\Sigma_{n}=a_{n}\left(\sigma_{n}-b_{n}\right) ; n=1 ; 3
\end{gathered}
$$

Nas equações (42)-(44), a parametrização presente contabiliza os efeitos de anisotropia do material quanto às tensões principais. O parâmetro $m$ é definido pelos autores como um valor acima de 2 , sendo que no caso, empregou-se o valor 8 , para que os extremos da superfície possam representar a alta compressibilidade das espumas sem a necessidade de uma tensão limite de flambagem. Os demais parâmetros controlam a sensibilidade do material quanto a carregamentos desviadores e hidrostáticos. Infelizmente esses modelos requerem muitos ensaios mecânicos para sua calibração, incluindo os de menor frequência como os de tração hidrostática. No caso, são necessários pelo menos cinco ensaios experimentais para que a superfície proposta possa ser identificada. Caso haja graus de anisotropia, mais ensaios deverão ser realizados, sendo que para um material transversalmente isotrópico, tem-se, por exemplo, um ensaio adicional.

Nesse trabalho a superfície da equação (42) mostra-se superior para carregamentos simultâneos de cisalhamento, tração e compressão, todavia para carregamentos dominantes de cisalhamento ou tração outras superfícies como as de Deshpande e Fleck e a de Bikhul, Founas e Nusholtz (1993 apud WANG; PAN, 2006, p. 445), são indicadas por serem mais práticas. Portanto, conclui-se que a simples aplicação de uma superfície de escoamento altamente parametrizada pode não ser prática e assim como os demais modelos, o mesmo, 
também, apresenta deficiências. Uma maior parametrização ou um melhor tratamento estatístico/numérico de dados experimentais são opções naturais para a solução do problema em longo prazo. Porém o presente trabalho acredita que outras abordagens possam fornecer uma nova perspectiva de análise para obter modelos mais viáveis, como o estudo de modelos fenomenológicos calibrados com alguns efeitos microscópicos intrínsecos ao material.

Com base nessa metodologia microscópica, Li, Mines e Birch (2000) investigaram a espuma polimérica rígida Rohacell-51WF através de ensaios mecânicos simples e combinados de compressão e cisalhamento. A dependência das resistências é quantificada com uma expressão semelhante à equação (8), mas o valor da resistência neste caso é para compressão e não mais para tração $\left(\sigma_{t} \rightarrow \sigma_{c}\right)$. Efeitos da taxa de deformação e comparações com os modelos de Gibson e Ashby (1988) e Deshpande e Fleck (2000) são também apresentados. Todavia, é em um trabalho posterior que Li e Mines (LI; MINES, 2002), com o mesmo material, publicaram um resultado interessante e que foi usado, com poucas variações, em outro trabalho mencionado no presente texto (ZENKERT; SHIPSHA; PERSSON, 2004). O resultado em questão constitui-se da identificação de diferentes regimes de deformação ao longo da espessura do material solicitado (Fig. 10).

Observou-se que uma seção de células perpendicular ao carregamento, geralmente a mais fraca, escoa e flamba com a ruptura de paredes, arestas e o surgimento de rótulas plásticas, ocasionando o aparecimento de uma seção esmagada ( $H_{0}$ na Figura $\left.10 \mathrm{~b}\right)$. O limite dessa seção esmagada é definido previamente com a observação da formação de um volume inicial de altura $h_{0}$ que é esmagado primeiramente.

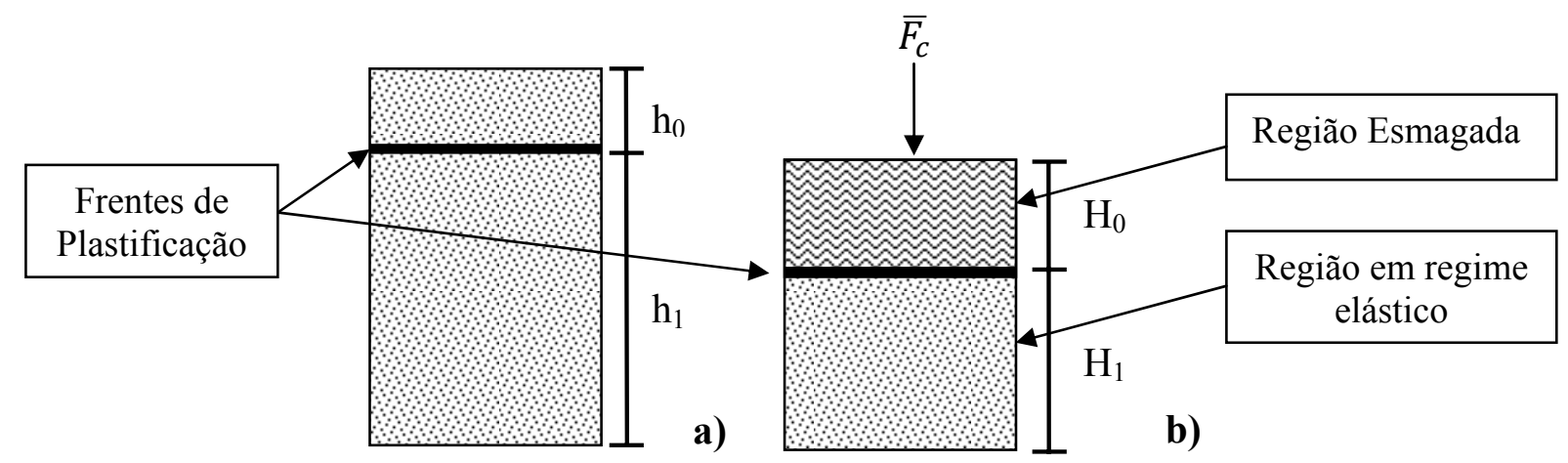

Figura 10. Deformação heterogênea em espumas rígidas de PVC sob compressão: a) Formação das frentes de plastificação em regime elástico; b) Aplicação de cargas de esmagamento.

Adaptado de: Li e Mines (2002) 
Como esta seção torna-se mais resistente com a densificação da mesma, a sua fronteira funciona como uma frente de plastificação que separa as regiões do material em tensão crítica de escoamento e flambagem (sob regime elástico) da região esmagada com deformações plásticas. Assim, a partir desses limites $h_{0}, h_{1}, H_{0}$ e $H_{0}$, os pesquisadores propõem um cálculo para a deformação total da espuma comprimida como função dos diferentes regimes de deformação, considerando ainda os efeitos viscosos de relaxação da espuma.

Além disso, o referido trabalho apresenta uma discussão microscópica dos mecanismos de falha do material esmagado ao estudar uma única célula carregada. Observase que o deslocamento das faces e arestas de uma célula recém flambada, cria um "encruamento negativo" (amolecimento) localizado (região I na Figura 11) e no momento em que esta célula sofre um acréscimo de deformação, a mesma passa a se densificar (região II na Figura 11), enquanto outras células estão apenas começando seu esmagamento com o início na flambagem. Isso é devido à disposição aleatória das células nos vários planos do material ao longo da espessura.

Uma média estatística dessas respostas para todas as células que se somam à seção esmagada $H_{0}$ (Figura 10b) ao longo da compressão do material, faz com que a curva de cargadeslocamento apresente oscilações em torno de 5 a 10\% para o nível de tensão do platô plástico, resultando num comportamento macroscópico que poder ser aproximado ao de um material plástico perfeito.

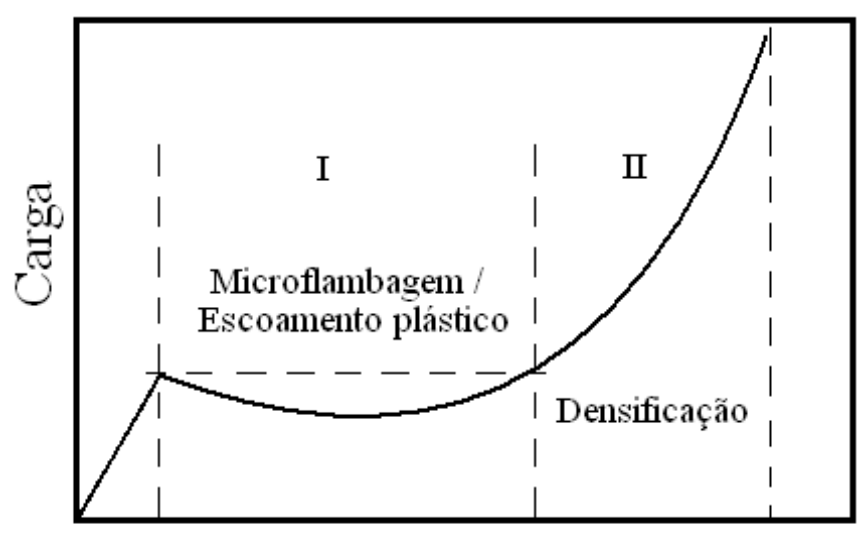

Deslocamento

Figura 11. Comportamento mecânico local generalizado para uma célula polimérica sob compressão. Adaptado de: Shim, Tay e Stronge (1990 apud LI; MINES, 2002, p. 134)

Se o material for mais flexível macroscopicamente e/ou mais homogêneo microscopicamente na direção do esmagamento, faz com que o "encruamento negativo" local das células tenha menor representatividade, pois a frente de plastificação passa a evoluir com 
maior uniformidade, uma vez que a estrutura celular está mais regular. Com isso, a densificação local das células é realçada, fazendo com que um encruamento positivo seja mais evidente macroscopicamente.

Complementando os modelos de material descritos, é importante lembrar algumas complicações que tornam trabalhosos o desenvolvimento de modelos constitutivos fenomenológicos. Em duas classes genéricas, existem os problemas numéricos e os referentes à fabricação do material. Os problemas numéricos foram brevemente discutidos no presente trabalho, porém outras dificuldades são registradas em Hučkot e Faria (1997). Os problemas de processo tratam das imperfeições que os métodos de fabricação geram em materiais celulares, podendo fragilizá-los significativamente. Chen, Lu e Fleck (1999) estudaram a influência de seis tipos de imperfeições presentes em espumas carregadas biaxialmente: 1) estruturas onduladas; 2) não uniformidade da parede das células; 3) células com tamanhos variáveis; 4) paredes das células com fraturas; 5) desalinhamento das células e 6) ausência de células. A superfície de escoamento bidimensional para espumas isotrópicas em função dos tipos de imperfeições apresentada foi dada por:

$$
\begin{gathered}
\bar{\sigma}-Y \leq 0 ; \bar{\sigma}=\sqrt{\sigma_{d}^{2}+\zeta^{2} \sigma_{m}^{2}} ; \zeta=\sqrt{\frac{4 \sigma_{U}^{2}}{4 \sigma_{H}^{2}-\sigma_{U}^{2}}} ; \\
\sigma_{d}=\sqrt{2 S_{\alpha \beta} S_{\alpha \beta}} ; \quad \sigma_{m}=\frac{1}{2} \sigma_{\alpha \beta} ; S_{\alpha \beta}=\sigma_{\alpha \beta}-\delta_{\alpha \beta} \sigma_{m} ; \alpha, \beta=1 ; 2 \\
Y=\zeta \sigma_{H} ; \zeta^{2}=\xi \bar{\rho} ; Y=\sigma_{y} \eta \bar{\rho}^{2}
\end{gathered}
$$

Onde $\sigma_{U}, \sigma_{H}, \bar{\sigma}$ e $\sigma_{y}$ indicam, respectivamente, as tensões de escomento em compressão uniaxial, compressão hidrostática, tensão equivalente e a de escoamento sob tração ou sob compressão dependendo do material. Por outro lado, $\eta$ e $\xi$ são os parâmetros que variam de acordo com as imperfeições do material e foram definidos com base em muitas simulações via MEF, em análises de dados experimentais, bem como em formulações analíticas estudadas. Assim, de acordo com a imperfeição na espuma, a influência nos respectivos valores de resistência foi discutida nesse artigo.

Com base nessa revisão bibliográfica, o presente trabalho irá basear-se em análises fenomenológicas e micro-mecânicas combinadas para alcançar uma relação razoável entre a calibração dos modelos (identificação de parâmetros) e a representatividade dos mesmos para espumas poliméricas. De forma geral, algumas análises microcráficas podem auxiliar na identificação da morfologia celular da espuma escolhida para que os respectivos mecanismos 
de falha sejam definidos. Dessa forma, pode-se determinar como o modelo será calibrado a partir das curvas experimentais e qual modelo constitutivo será utilizado.

A metodologia proposta no presente trabalho para a calibração de um modelo de material para uma espuma polimérica, parte do modelo fenomenológico de Deshpande e Fleck (2000) devido a sua representatividade comprovada com a literatura discutida até então. Além disso, esse modelo faz parte da biblioteca de modelos constitutivos implementados no programa de elementos finitos ABAQUS, denominado Crushable foam model (with isotropic hardening). Esse procedimento contorna a necessidade da implementação de sub-rotinas UMAT, possibilitando um estudo focado na identificação dos parâmetros de modelos e suas avaliações com ensaios experimentais e modelos computacionais via MEF. Contudo, esse modelo será confrontado com outro também presente no programa ABAQUS, cujo encruamento é do tipo "volumétrico" (volumetric hardening, onde a evolução da superfície de escoamento ocorre com incrementos de pressão hidrostática $p=\sigma_{k k} / 3$ ). Esse modelo de material já foi utilizado por Rizov (2006a, b) para estudar uma espuma polimérica de PVC, semelhante à estudada no presente trabalho, em uma estrutura sanduíche sob endentação. Sendo que o mesmo apresentou bons resultados, motivando em parte o uso desse algoritmo comercial. Entretanto, o referido pesquisador não discute nenhuma das particularidades existentes quando tais modelos são calibrados. Ademais, diferentemente de Tagarielli, Fleck, e Deshpande (2004), o presente trabalho busca discutir os erros numéricos presentes nos modelos computacionais em elementos finitos frente ao modelo de material selecionado para o núcleo e a calibração dos respectivos parâmetros para um material não isotrópico

Vale ressaltar que muito pouco foi discutido e mesmo citado, na literatura investigada, sobre a metodologia de calibração desses modelos. Somente Oliveira et al. (2008) exploram essa necessidade de uma identificação de parâmetros mais detalhada ao modelar tautologicamente ensaios em compressão simples e oedométricos com o algoritmo do programa ABAQUS supracitado. Segundo a literatura, acredita-se que os modelos de material devam ser calibrados com resultados padrões de ensaios em tração, compressão e cisalhamento. Contudo, a revisão bibliográfica presente neste tópico mostra que o melhor procedimento para a determinação e calibração de um modelo de material não reside necessariamente no uso de modelos constitutivos complexos. A melhor alternativa constituise de uma calibração cautelosa de um modelo de material que contemple os mecanismos de falha do material em questão. Independentemente se o modelo é micro-mecânico ou fenomenológico, a calibração deve ser feita com dados experimentais micro e macroscópicos 
e estes necessitam ser interpretados de acordo com o material celular e sua aplicação em questão para que resultados coerentes e satisfatórios sejam obtidos. 


\section{Capítulo III}

\section{MATERIAIS E MÉTODOS}

Fundamentado na literatura investigada, o presente trabalho utiliza uma espuma polimérica de uso aeronáutico para demonstrar uma metodologia de identificação de parâmetros e modelos de material que buscam obter o melhor conjunto possível de resultados para o comportamento mecânico do material em foco. Neste trabalho, as modelagens e as calibrações realizadas são para uma espuma polimérica de célula fechada de Policloreto de Vinila (PVC) pertencente à linha de produtos Divinycell ${ }^{\circledR} \mathrm{H}$ do fabricante DIAB. A escolha do material está vinculada a uma estrutura sanduíche que foi fabricada com essa mesma espuma e que foi estudada previamente sob ensaios de flexão em três pontos. Alguns destes resultados experimentais foram registrados na dissertação de Oliveira (2007) e no relatório de Soares (2009) e serão confrontados com os modelos computacionais desenvolvidos no presente trabalho para reproduzir os dados experimentais dessa estrutura sanduíche em seus respectivos ensaios.

\subsection{Materiais}

O presente trabalho utiliza especificamente amostras da espuma polimérica em sua investigação e por isso esta será apresentada com maiores detalhes nas seções subsequentes, enquanto as especificações da estrutura sanduíche em questão são obtidas da dissertação de Oliveira (2007). 


\subsubsection{Espuma Polimérica}

A espuma em estudo no presente trabalho tem densidade nominal de $60 \mathrm{~kg} / \mathrm{m}^{3}$, pertencente à linha Divinycell conhecida como H60 (Fig. 12).

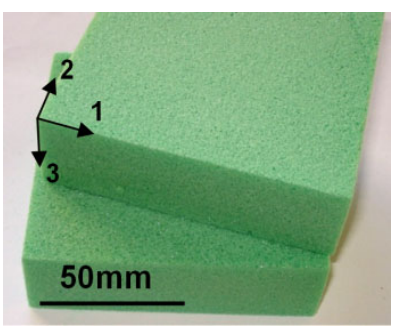

Figura 12. Amostras da espuma $\mathbf{H 6 0}$ em forma de placas. O plano das placas é indicado pelas direções 1 e 2 e a direção normal é a direção 3

As propriedades mecânicas desse material fornecidas pelo fabricante (DIAB, 2010) estão presentes na Tabela 2.

Tabela 2. Propriedades mecânicas para a espuma polimérica Divinycell H60 fornecidas pelo fabricante

\begin{tabular}{|c|c|c|}
\hline Propriedade & Valores em SI & Procedimento Experimental \\
\hline Densidade nominal & $60 \mathrm{~kg} / \mathrm{m}^{3}$ & ISO 845 \\
\hline Resistência à compressão* & $0.9 \mathrm{MPa}$ & ASTM D 1621 \\
\hline Módulo elástico em compressão* & $70 \mathrm{MPa}$ & ASTM D 1621 \\
\hline Resistência à tensão* & $1.8 \mathrm{MPa}$ & ASTM D 1623 \\
\hline Módulo elástico em tensão* & $75 \mathrm{MPa}$ & ASTM D 1623 \\
\hline Resistência ao cisalhamento* & $0.76 \mathrm{MPa}$ & ASTM C 273 \\
\hline Módulo elástico em cisalhamento* & $20 \mathrm{MPa}$ & ASTM C 273 \\
\hline
\end{tabular}

* Valores para a direção perpendicular ao plano da placa (direção 3)

\subsubsection{Anisotropia e Heterogeneidade}

Presente em muitos dos trabalhos citados, uma característica marcante de espumas poliméricas é uma distribuição heterogênea das células em diferentes planos, diferente das estruturas tipo colméia (Fig. 2a), onde é possível definir limites geométricos para a estrutura celular. Além disso, devido ao processo de fabricação associado ao material polimérico, a espuma de PVC apresenta uma anisotropia identificada como transversalmente isotrópica o que se traduz em dois conjuntos de propriedades mecânicas identificadas na literatura e nos ensaios mecânicos do presente trabalho. 
Para entender a origem dessa anisotropia e heterogeneidade, é preciso que o respectivo processo de fabricação seja conhecido. Em QUÍMICA (2010), uma explicação detalhada para alguns desses processos com dados sobre composição química, infra-estrutura, processos, metodologia e várias propriedades e conceitos sobre aplicação, são discutidas para espumas poliméricas de poliuretano (PU). Com as devidas restrições, muitas informações podem ser extrapoladas para outras espumas poliméricas, notadamente as apresentadas nas seções de metodologia e processos. De forma resumida, o material é produzido com a injeção ou criação de gás inerte na mistura de PVC quente e fundido. Com a estabilização (podendo ser química ou física) e crescimento das bolhas, estas tendem a se alongar um pouco mais na direção da espessura, a qual está submetida à força da gravidade. As propriedades viscosas do polímero fundido e seu peso fazem com que este material seja drenado pelas bordas de Plateau a favor da gravidade para a porção inferior do volume de material, enquanto o gás tende a sair pela superfície da mistura. É importante ressaltar que esse mecanismo é uma hipótese, contudo algumas análises micrográficas tendem a confirmá-lo. Mais detalhes sobre espumas líquidas podem ser encontrados em Weaire e Hutzler (1999).

Essas células alongadas resultam em propriedades mecânicas inferiores para o material no plano (indexado pelos algarismos 1-2) perpendicular à direção de crescimento (indexada pelo algarismo 3) da espuma, o que torna o material mais flexível e menos resistente no plano 1-2. Na Figura 13, há uma micrografia, obtida via microscopia eletrônica de varredura, para uma amostra de material. A partir dessas micrografias é possível observar uma anisotropia na geometria da estrutura celular com a constatação de um maior número de células alongadas na direção 3 e a tendência, no plano 1-2, do formato circular.
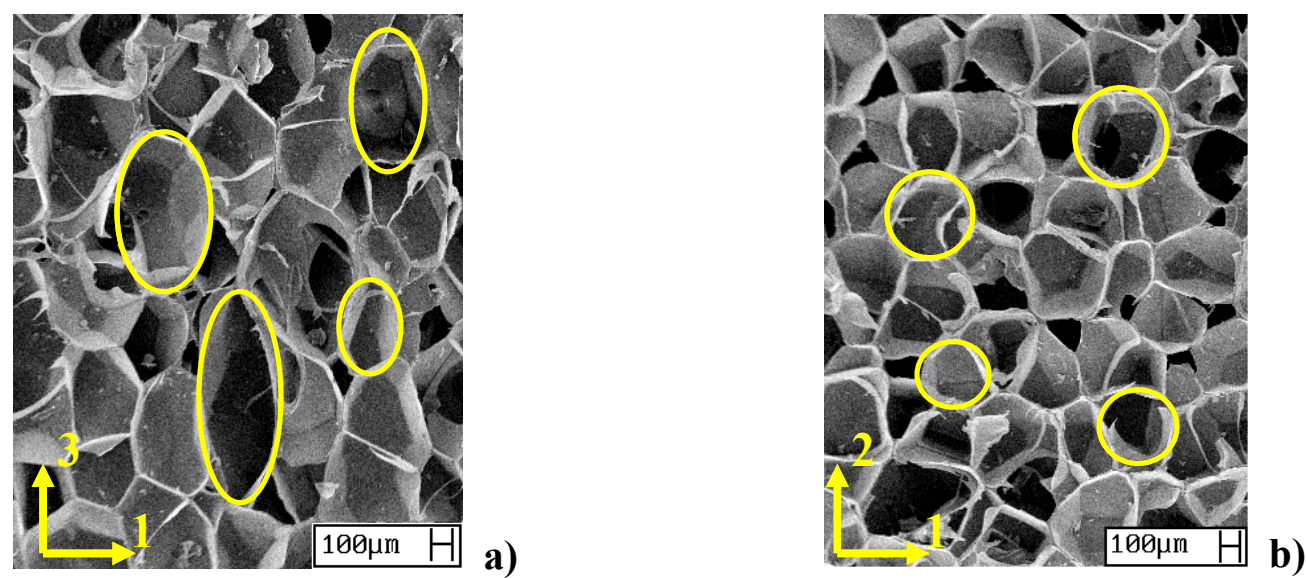

Figura 13. Micrografias exibindo a anisotropia da espuma de PVC: a) Destaque para as células alongadas na direção 3 ; b) Tendência para padrões circulares no plano 1-2 
Os padrões geométricos exibidos nas Figuras 13a e 13b são recorrentes em outras micrografias para outras amostras da mesma espuma polimérica, o que reforça a hipótese de que a fragilização do material no plano 1-2 tem origem na fabricação de um material celular com células anisotrópicas.

\subsubsection{Morfologia e Mecanismos de Falha}

Com a morfologia e material da estrutura celular definidos, pode-se juntamente com base na literatura, inferir os mecanismos de falha para a espuma polimérica de PVC estudada.

A densidade média do policloreto de vinila sólido é de $\rho_{s}=1400 \mathrm{~kg} / \mathrm{m}^{3}$, enquanto que a da espuma é de $\rho=60 \mathrm{~kg} / \mathrm{m}^{3}$, o que resulta em uma densidade relativa de $\bar{\rho}=$ 0.043. Para este material, a literatura recomenda que os efeitos da pressão interna sejam desconsiderados, pois esta diferença de pressão é praticamente nula e o material é essencialmente rígido. Sob carregamento de tração, o material deve escoar plasticamente com a formação de rótulas plásticas nos vértices e o alongamento das faces. Sob carregamento de compressão, o mecanismo de falha não é bem definido, pois a densidade relativa está próxima do valor de transição entre mecanismos de falha por flambagem e escoamento plástico das células. Para auxiliar nessa determinação, uma amostra de material esmagado, e completamente relaxado, foi examinada via MEV e os modos de falha do material ficaram assim melhor evidenciados (Figura 14).

Conclui-se que o material utilizado tem falha iniciada em compressão com a flambagem de algumas arestas e faces e simultaneamente com o escoamento de outras células devido à disposição aleatória das mesmas. Com uma densidade relativa de 0.043 e como as bordas de Plateau não se solidificam com homogeneidade suficiente, não se pode afirmar qual dos dois mecanismos é predominante na região em que se forma a frente de plastificação para a espuma em questão. Este é um dos motivos pelo qual se define essa frente de plastificação como um volume e não uma área no plano perpendicular ao carregamento (Fig. 10).

As taxas de deformação com que o material mostrado na Figura 14 foi ensaiado são relativamente baixas $\left(1 \times 10^{-5}\right.$ à $\left.1 \times 10^{-2} \mathrm{~s}^{-1}\right)$ e com isso a vazão de gás para fora da espuma e o rompimento das paredes (Fig. 14d) das células não é significativo. Contudo, sob taxas bem mais elevadas, em torno de $1000 \mathrm{~s}^{-1}$, essa vazão do gás para fora das células fechadas (com o rompimento das mesmas), e a densificação da estrutura celular ocorrem muito rapidamente. 
Com isso os mecanismos micro-mecânicos de falha da estrutura celular para essas taxas de deformação podem alterar significativamente a resposta macroscópica do material (GIBSON; ASHBY, 1988, OUELLET; CRONIN; WORSWICK, 2006).
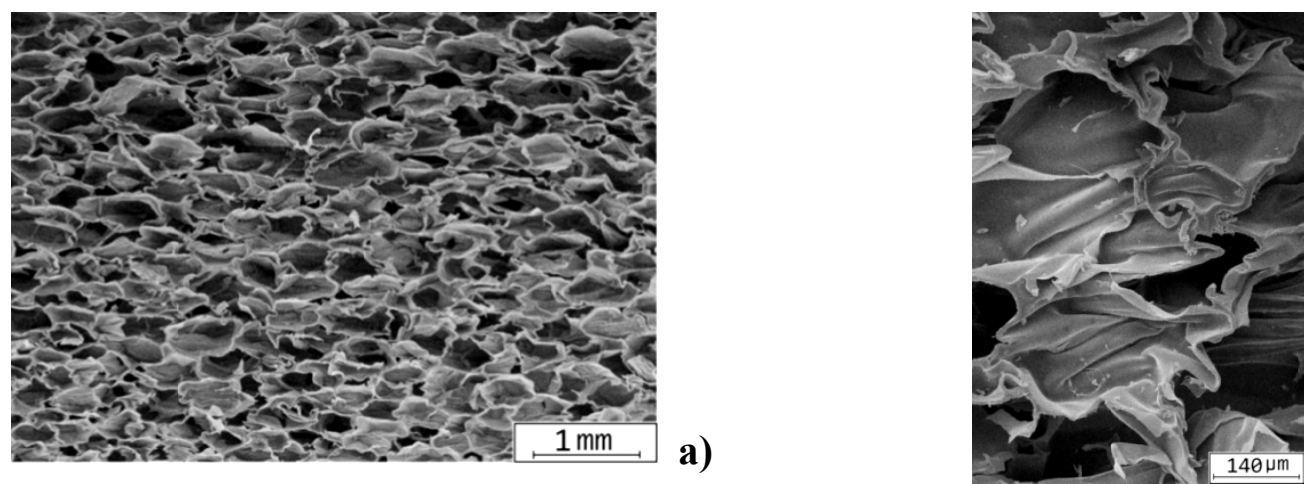

b)

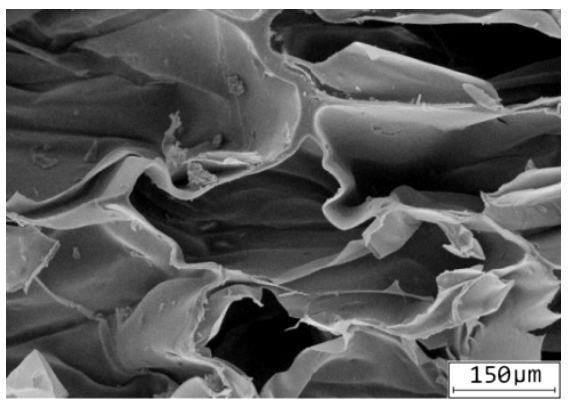

c)

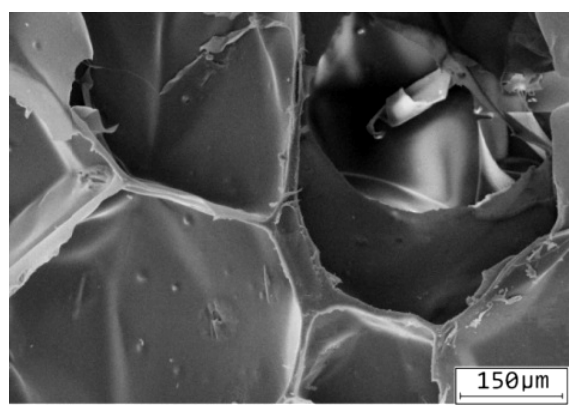

d)

Figura 14. Mecanismos de falha em compressão para a espuma polimérica de PVC: a) Células esmagadas sob compressão; b) e c) Flambagem das arestas e faces em detalhe; d) Rompimento das células fechadas em diferentes planos

\subsubsection{Estruturas Sanduiche}

A estrutura sanduíche que motivou o presente trabalho foi fabricada pelo processo de fabricação manual de compósitos conhecido como hand lay-up. De maneira resumida, nesse processo de construção de laminados, cada camada de tecido reforçador é sobreposta à outra camada de matriz polimérica durante o empilhamento até a obtenção das especificações desejadas para as faces. Dessa forma, foi fabricada uma estrutura sanduíche com material compósito laminado de fibra de vidro e resina epóxi nas faces e um núcleo polimérico com a espuma de PVC H60.

A Tabela 3 traz as especificações da estrutura e as Figuras 15 e 16 exibem, respectivamente, a configuração e uma fotografia da estrutura ensaiada. 
Tabela 3 - Especificações geométricas da estrutura sanduíche investigada

\begin{tabular}{|c|c|c|}
\hline \multirow{2}{*}{ Material } & Núcleo & Face \\
\cline { 2 - 3 } & Espuma Divinycell H60 & Laminado $[0 / 90 / /+45 /-45 / / 0 / 90]_{\mathrm{T}}$ \\
\hline Comprimento $^{*}$ & $250 \mathrm{~mm}$ & $250 \mathrm{~mm}$ \\
\hline Largura $^{*}$ & $29.93 \mathrm{~mm}$ & $29.93 \mathrm{~mm}$ \\
\hline Espessura $^{*}$ & $10 \mathrm{~mm}$ & $0.22 \mathrm{~mm}$ \\
\hline
\end{tabular}

* Valores experimentais segundo Oliveira (2007).

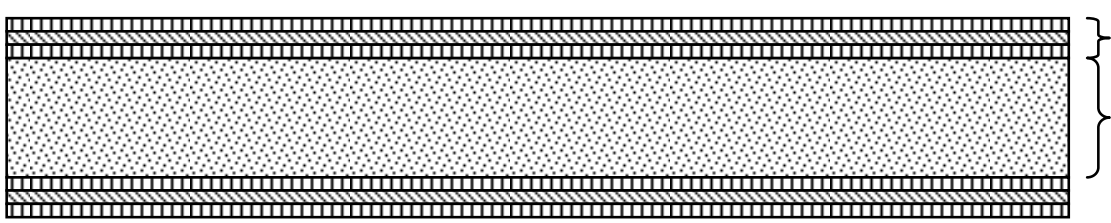

Face (Fibra vidro/Epóxi) $[0 / 90 / /+45 /-45 / / 0 / 90]_{\mathrm{T}}$

Núcleo polimérico

Divinycell H60

Figura 15. Configuração da estrutura sanduíche investigada

O laminado é composto por três tecidos bidirecionais de fibra de vidro embebidos com resina epóxi empilhados na configuração indicada na Figura 15, sendo que cada camada tem espessura média em torno de $0.0073 \mathrm{~mm}$ de acordo com Oliveira (2007).

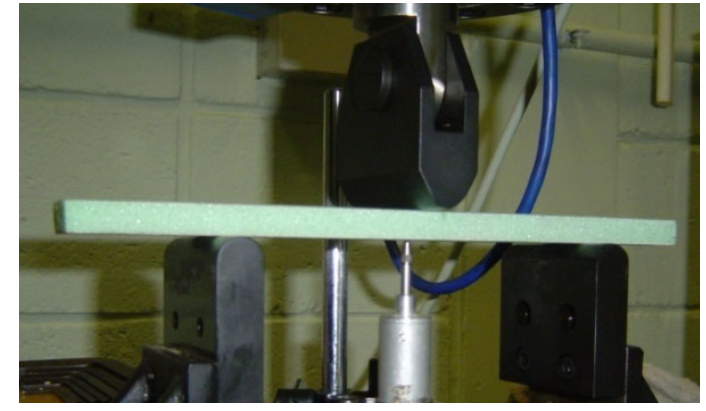

a)

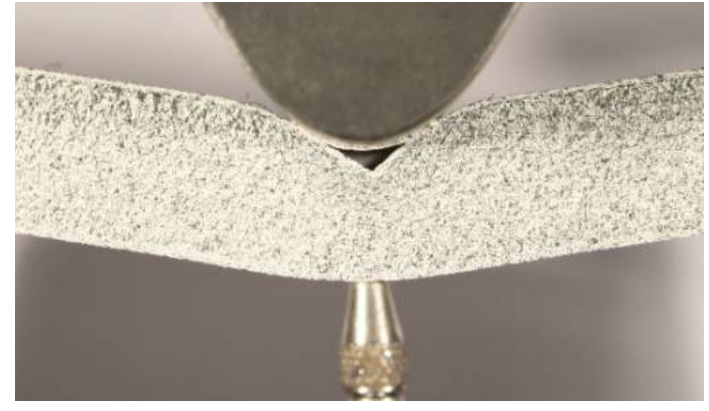

b)

Figura 16. Estrutura sanduíche investigada sob ensaio de flexão em três pontos: a) Configuração do ensaio; b) Região central em detalhe onde ocorre a endentação na estrutura

\subsection{Metodologia}

Foram aplicados, basicamente, dois tipos de procedimentos experimentais para a coleta de dados que são usados na calibração do modelo de material. $O$ primeiro procedimento, e mais convencional, consiste na obtenção dos dados de força e deslocamento dos ensaios usando um computador e os sensores acoplados a uma máquina de ensaios, no caso uma máquina EMIC com uma célula de carga de $10 \mathrm{kN}$. O segundo procedimento, não 
tão comum, baseia-se no emprego de uma técnica de correlação de imagens onde o conceito de "problema inverso" é explorado.

Esse problema inverso consiste na determinação de parâmetros que são conhecidos em análises consideradas "diretas". A Tabela 4 mostra a diferença entre os dois métodos e quais as variáveis dependentes (desconhecidas) e independentes (conhecidas) para cada caso.

Tabela 4 - Definição das variáveis dependentes e independentes para os problemas direto e inverso

\begin{tabular}{|c|c|}
\hline Problema Direto $\rightarrow \boldsymbol{\sigma}_{\boldsymbol{i j}}=\boldsymbol{C}_{\boldsymbol{i j k l}} \boldsymbol{\varepsilon}_{\boldsymbol{k} \boldsymbol{l}}$ & Problema Inverso $\rightarrow \boldsymbol{\sigma}_{\boldsymbol{i} \boldsymbol{j}}=\boldsymbol{C}_{\boldsymbol{i} \boldsymbol{j} \boldsymbol{k} \boldsymbol{l}} \boldsymbol{\varepsilon}_{\boldsymbol{k} \boldsymbol{l}}$ \\
\hline O campo de deslocamentos é desconhecido & As relações constitutivas são desconhecidas \\
\hline$C_{i j k l} \rightarrow$ conhecido & $C_{i j k l} \rightarrow$ desconhecido \\
\hline$\sigma_{i j}=? ; \varepsilon_{k l}=? ; u_{k}=?$ & $\sigma_{i j}=? ; \varepsilon_{k l}=$ conhecido; $u_{k}=$ conhecido \\
\hline
\end{tabular}

Como se pode observar, em ambos os problemas as tensões no material são desconhecidas, porém a determinação dessas tensões pela análise inversa requer uma metodologia muitas vezes iterativa e algumas complicações podem aparecer na aplicação dessa técnica para algumas estruturas e carregamentos, mas no geral a técnica tem se mostrado muito promissora (GRÉDIAC, 2004). Por determinar os campos de deslocamento na superfície do material este método é conhecido como VFM (Virtual Field Method), pois como comentado, esses campos são criados virtualmente. A geração desses campos para carregamentos genéricos, a partir de técnicas óticas, e aplicações são muito bem demonstradas por Grédiac, Toussaint e Pierron em uma sequência de três trabalhos (GRÉDIAC; TOUSSAINT; PIERRON, 2002a, b, GRÉDIAC; TOUSSAINT; PIERRON, 2003). Nesses artigos encontram-se algumas discussões sobre a representatividade dos campos, sua geração, estabilidade e sensibilidade das soluções. Como os artigos não discutem o método de aquisição das deformações, mas somente a identificação e geração dos campos virtuais, essas deformações foram obtidas usando modelos via MEF.

O presente trabalho explora essa teoria VFM indiretamente através de técnicas de correlação de imagens (DIC, Digital Image Correlation). Além de fornecer os campos de deslocamento e deformações, essas técnicas óticas muitas vezes possuem uma interface gráfica para interpretar os respectivos dados. Existem muitas técnicas DIC e cada uma delas utiliza uma formulação própria para abordar o problema indireto. Jin et al. (2007) investigaram uma estrutura celular de poliuretano através de 3 tipos de ensaios onde volumes cúbicos de material foram solicitados unidirecialmente. Os resultados foram tratados com uma técnica de correlação de imagens tridimensional (3D-DIC) e inseridos em um código de 
elementos finitos (SIERRA) para a obtenção de modelos computacionais elastoviscoplásticos, que apresentaram resultados satisfatórios.

No presente trabalho foi utilizada uma versão bidimensional de técnicas DIC implementada na forma de um programa em plataforma MATLAB chamado Correli ${ }^{L M T}$. Tal programa foi desenvolvido por pesquisadores do LMT-Cachan (França) e mais detalhes sobre o mesmo podem ser encontrados no relatório consultado (HILD; ROUX, 2008). O programa Correli $^{\text {LMT }}$ auxiliou na determinação das propriedades elásticas do material e principalmente no estudo das deformações localizadas que a espuma polimérica exibe para ensaios com cargas concentradas. Isso porque essas deformações localizadas somadas a uma grande variação de volume dificultam a determinação das deformações analiticamente. Entretanto, vale ressaltar que os pesquisadores do LMT-Cachan (França) afirmam que os resultados de deslocamento previstos pelo Correli ${ }^{\mathrm{LMT}}$ são bem precisos, não podendo afirmar o mesmo para os resultados de deformação (BESNARD; HILD; ROUX, 2006). Dessa forma, tanto as propriedades elásticas como as plásticas foram determinadas através dos sensores da máquina de ensaios, bem como através do programa Correli ${ }^{\text {LMT }}$, sendo que a calibração dos modelos de material a serem utilizados foi discutida com profundidade, avaliando as potencialidades e limitações dos procedimentos empregados.

\subsubsection{Fabricação e Ensaios de Corpos-de-Prova}

Foram realizados ensaios monotônicos e cíclicos para amostras da espuma polimérica H60 de PVC em compressão uniaxial, tração uniaxial e endentação. Para quantificar a anisotropia identificada no material, os ensaios na direção normal 3 foram repetidos para o plano 1-2. Um breve estudo sobre taxas de deformação, também, foi feito para a direção normal 3 da espuma polimérica em compressão, a fim de verificar a sua respectiva sensibilidade a essas taxas. Deve-se destacar que amostras adicionais não foram ensaiadas para confirmar a dependência do material sob elevadas taxas de deformação, pois como observaram Ouellet, Cronin e Worswick (2006), uma espuma polimérica pode ser insensível para uma dada faixa de taxas de deformação. Isto tende a ocorrer para taxas de deformação inferiores a $10^{3} \mathrm{~s}^{-1}$. Esta conclusão foi baseada no estudo de seis corpos-de-prova de espumas poliméricas diferentes, dentre as quais havia uma de EPS com densidade de $61 \mathrm{~kg} / \mathrm{m}^{3}$ e de célula fechada, ou seja, uma espuma similar a que este trabalho investiga. Dessa forma o estudo do comportamento mecânico da espuma polimérica para altas taxas de deformação não 
foi realizado. Ressalta-se também, que taxas de deformação em torno de $10^{3} \mathrm{~s}^{-1}$, ou superiores, excedem o limite permitido pelo equipamento com o qual os ensaios do presente trabalho foram executados.

Ensaios hidrostáticos também foram realizados, contudo os resultados obtidos foram cautelosamente analisados, pois o equipamento não possuía sensibilidade adequada para determinados níveis de tensão estudados. Mesmo assim, alguns dados para níveis de tensão mais elevados foram obtidos, juntamente com informações qualitativas que auxiliaram os estudos como um todo. Dessa forma, como não se obteve determinados dados quantitativos dos ensaios hidrostáticos, outros ensaios, além de tração e compressão, são necessários para que o modelo de material seja devidamente calibrado. Uma alternativa, então adotada para embasar o procedimento experimental, foi a utilização de valores da literatura, com as devidas ressalvas.

Para todos os ensaios da espuma polimérica, os corpos-de-prova foram cortados manualmente com uma serra e com auxílio de estilete. Os acabamentos foram feitos com lixas, rebolos e esquadros e as medidas foram tomadas com réguas e/ou paquímetros.

\subsubsection{Utilização da Técnica DIC}

Os corpos-de-prova para cada ensaio foram devidamente estocados por poucos dias até a sua preparação para que a técnica DIC, com o programa Correli ${ }^{\mathrm{LTM}}$, fosse utilizada. A preparação das amostras para esta técnica, segundo o guia do usuário do programa, consiste na geração de uma superfície plana em tons de cinza sobre a qual o programa constrói-se uma malha com os mesmos conceitos usados no MEF. Porém, no caso, as coordenadas $x$ e $y$ da malha gerada são representadas pelos pixels originados da escala de cinza. O deslocamento dessa malha é monitorado através de fotografias tomadas ao longo do respectivo ensaio, e o intervalo de tempo $\Delta t$ entre fotos é definido de forma que um número suficiente de fotos capture os principais regimes de deformação no material.

O gradiente de tons de cinza na superfície da amostra (Figura 17) é obtido com uso de duas tintas spray, uma branca e uma preta. Ambas precisam ser foscas para minimizar a difusividade da imagem refletida que é capturada pela câmera fotográfica. Deposita-se assim, uma camada fina de tinta branca, "borrifando" o substrato com o spray várias vezes, para gerar um fundo homogêneo. Na sequência, uma simples "borrifada" de spray preto é suficiente para gerar alguns pontos pretos na amostra que dão o contraste que constitui o 
gradiente de tons cinza na amostra. A qualidade dessa pintura pode ser verificada com o auxílio do programa Correli ${ }^{\mathrm{LTM}}$, cujo manual do usuário indica como a qualidade dos gradientes de cinza deve ser analisada.

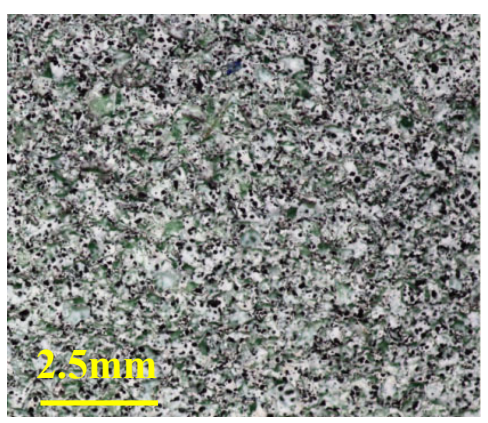

Figura 17. Exemplo de uma superfície pintada para uso da técnica DIC

Para usar uma técnica DIC, o equipamento experimental pode ser constituído por uma máquina fotográfica (com uma lente adequada) rigidamente posicionada com auxílio de um tripé, iluminadores com LED para evitar o aquecimento do polímero, bem como um computador para o controle e armazenamento remoto das fotos que são tomadas automaticamente com o intervalo de tempo $\Delta t$ definido (Figura 18).

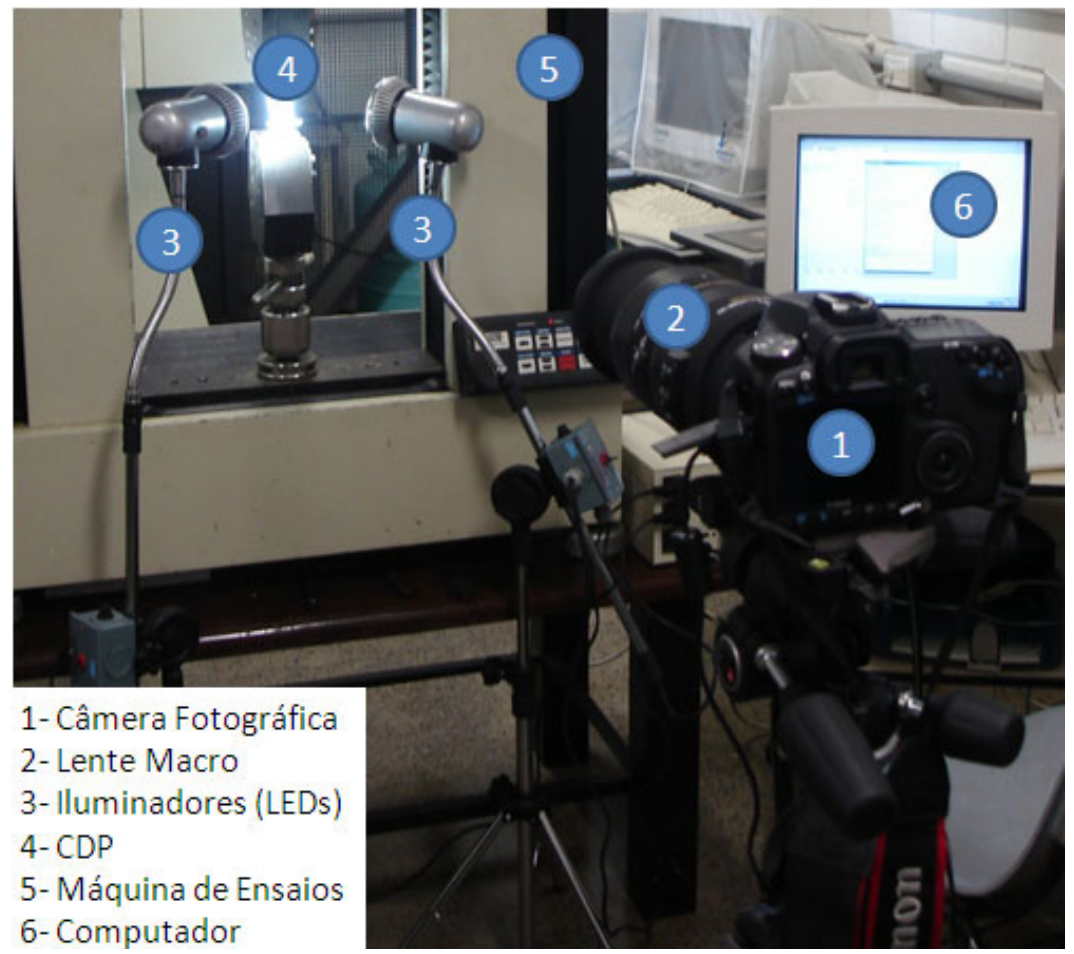

Figura 18. Equipamentos para a realização dos ensaios convencionais e obtenção de imagens para análises via técnica DIC, dispostos de maneira ilustrativa 


\subsubsection{Compressão Uniaxial}

Com base na norma ASTM D1621-04a, foram fabricados cinco corpos-de-prova para direção 3 e para direção 1-2 do material a fim de identificar o comportamento anisotrópico do mesmo. O formato próximo a um cubo (Fig. 19) foi utilizado para ambas às direções no plano (1-2) e normal (3).

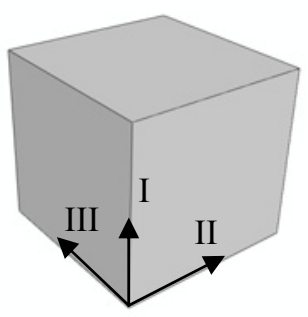

Figura 19. Formato dos corpos-de-prova para compressão uniaxial e direção

A espuma foi adquirida em forma de placas com 40mm de espessura (direção normal 3), sendo que as dimensões para os corpos-de-prova variam um pouco com a direção do carregamento, como mostrado na Tabela 5.

Tabela 5 - Dimensões dos corpos-de-prova para os ensaios de compressão uniaxial

\begin{tabular}{|c|c|c|c|c|c|}
\hline $\begin{array}{c}\text { Direção de } \\
\text { Carregamento I }\end{array}$ & $\begin{array}{c}\text { Direção } \\
\text { II }\end{array}$ & $\begin{array}{c}\text { Direção } \\
\text { III }\end{array}$ & Altura I (mm) & Largura II (mm) & Comprimento III (mm) \\
\hline Normal 3 & $1(2)$ & $2(1)$ & $37.5 \pm 0.5$ & $40.0 \pm 0.5$ & $40.0 \pm 0.5$ \\
\hline Plano 1(2) & $2(3)$ & $3(2)$ & $35.0 \pm 0.5$ & $37.0 \pm 0.5$ & $37.0 \pm 0.5$ \\
\hline
\end{tabular}

Os ensaios cíclicos foram feitos para três dos cinco corpos-de-prova, em ambas as direções normal e planar, contendo quatro ciclos com nível de descarregamento máximo possível a fim de se evitar perda de contato entre o aplicador de carga a amostra sob a velocidade de $1.5 \mathrm{~mm} / \mathrm{min}$.

Utilizando-se do procedimento supracitado, foram também, realizados quatro ensaios de compressão para a direção normal do material, sob diferentes velocidades de deslocamento do aplicador de carga. O propósito desses ensaios foi o de investigar a sensibilidade do material em diferentes taxas de deformação dentro dos limites especificados para o equipamento de ensaios utilizado. Dessa forma, foram investigadas quatro velocidades: $0.1 \mathrm{~mm} / \mathrm{min} ; 1 \mathrm{~mm} / \mathrm{min} ; 5 \mathrm{~mm} / \mathrm{min}$ e $25 \mathrm{~mm} / \mathrm{min}$. 


\subsubsection{Tração Uniaxial}

A norma que orientou os ensaios de tração foi a ASTM D1623-03, porém a geometria das amostras não foram inteiramente copiadas da norma devido à ausência de dispositivos específicos para a realização do ensaio de tração. Sendo assim, o presente trabalho optou pela fabricação de corpos-de-prova, semelhantes aos utilizados por Viana e Carlsson (2002), porém, ligeiramente modificados. Ao estudar a fratura de espumas poliméricas Divinycell H de PVC com densidades de 36 a $400 \mathrm{~kg} / \mathrm{m}^{3}$, os pesquisadores escolheram diferentes corpos-deprova para os ensaios de tração nas direções normal e no plano. Para a direção do plano usaram o perfil de $d o g$ bone e na direção normal usaram serras do tipo copo para cortar amostras em forma cilíndrica. Todavia, uma das questões sempre abordadas para o ensaio de tração consiste em como fixar os corpos-de-prova na máquina de ensaios. A solução adotada no presente trabalho foi vincular os corpos-de-prova em um substrato rígido através de um adesivo, e então, o substrato rígido foi vinculado à máquina de ensaios. $\mathrm{O}$ adesivo escolhido é conhecido comercialmente como Araldite ${ }^{\circledR}$, sendo o mesmo um bicomponente (resina e endurecedor) que uma vez curado apresenta comportamento frágil e tem uma resistência média de aproximadamente $0.5 \mathrm{MPa}$ (CIBA, 2010). Para garantir que esse nível de tensão não fosse atingido durante os ensaios, projetou-se os corpos-de-prova de tal forma que havia uma razão de 3 vezes, entre a área colada e a seção de ruptura (seção mínima). Cabe ressaltar que esta razão é satisfatória para que os perfis escolhidos fossem utilizados em ambas as direções (normal e no plano). De acordo com a geometria das placas de espuma, os corpos-de-prova para as diferentes direções seguiram os perfis da Figura 20, detalhados na Tabela 6.
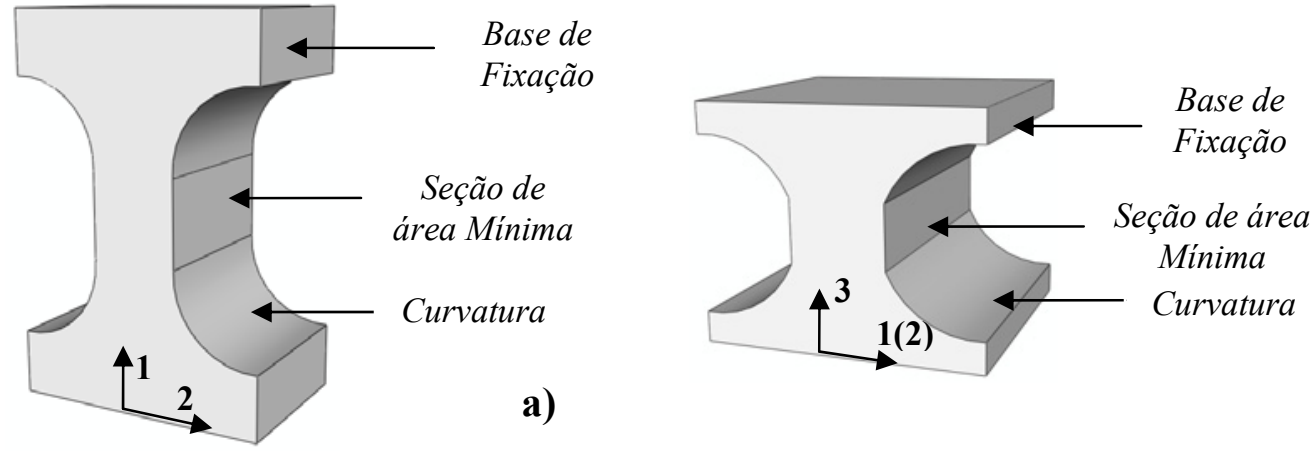

a)

b)

Figura 20. Perfis dos corpos-de-prova utilizados nos ensaios de tração uniaxial: a) Direção no plano 1-2; b) Direção normal - 3 
Tabela 6 - Dimensões dos corpos-de-prova para os ensaios de tração uniaxial

\begin{tabular}{|c|c|c|c|c|}
\hline Região (Direção) & Altura (mm) & Largura (mm) & Espessura (mm) & Raio (mm) \\
\hline Curvatura(Normal) & $9.0 \pm 0.5$ & $\mathrm{n} / \mathrm{d}$ & $43.0 \pm 0.5$ & $20.0 \pm 0.5$ \\
\hline Seção Mínima(Normal) & $10.0 \pm 0.5$ & $15.0 \pm 0.5$ & $43.0 \pm 0.5$ & $\mathrm{n} / \mathrm{d}$ \\
\hline Base de Fixação(Normal) & $5.0 \pm 0.5$ & $45.0 \pm 0.5$ & $43.0 \pm 0.5$ & $\mathrm{n} / \mathrm{d}$ \\
\hline Total & $38 \pm 1$ & $\mathrm{n} / \mathrm{d}$ & $\mathrm{n} / \mathrm{d}$ & $\mathrm{n} / \mathrm{d}$ \\
\hline Curvatura(Plano) & $25.0 \pm 0.5$ & $\mathrm{n} / \mathrm{d}$ & $37.5 \pm 0.5$ & $30.0 \pm 0.5$ \\
\hline Seção Mínima(Plano) & $20.0 \pm 0.5$ & $20.0 \pm 0.5$ & $37.5 \pm 0.5$ & $\mathrm{n} / \mathrm{d}$ \\
\hline Base de Fixação(Plano) & $15.0 \pm 0.5$ & $60.0 \pm 0.5$ & $37.5 \pm 0.5$ & $\mathrm{n} / \mathrm{d}$ \\
\hline Total & $100 \pm 1$ & $\mathrm{n} / \mathrm{d}$ & $\mathrm{n} / \mathrm{d}$ & $\mathrm{n} / \mathrm{d}$ \\
\hline
\end{tabular}

A altura é a medida na direção de carregamento do corpo-de-prova, o raio de curvatura é aquele para o alívio de tensão entre a seção mínima e as bases; a largura define os limites laterais do perfil e a espessura é a profundidade das amostras. A Figura 21 mostra uma fotografia de um corpo-de-prova fabricado para a direção no plano 1-2 e um diagrama das respectivas cotas indicadas.

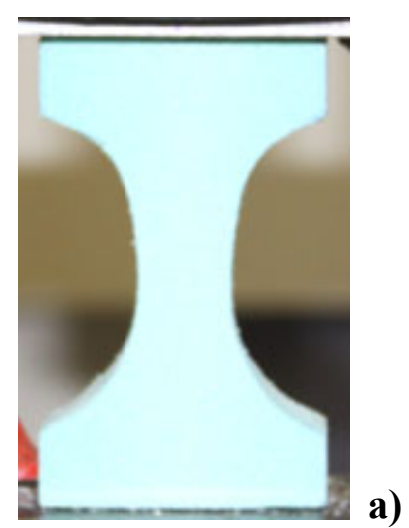

a)

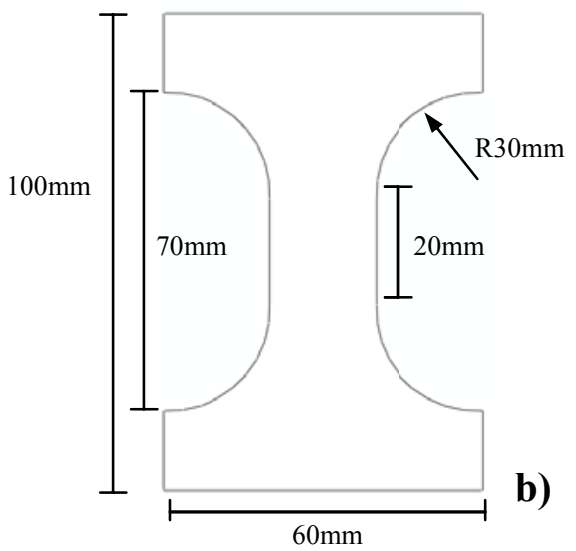

Figura 21. Geometria do corpo-de-prova em tração: a) Perfil recortado da espuma PVC; b) Cotas

Para os ensaios de tração, quatro corpos-de-prova para cada direção foram fabricados sendo que dois corpos-de-prova foram utilizados para ensaios cíclicos e os outros dois para os ensaios monotônicos. Os ensaios cíclicos foram compostos por dois ciclos para o plano 1-2 e três ciclos para a o plano 3-1(2), com o máximo nível de descarregamento possível a fim de se evitar a compressão da amostra. Sendo que todos os ensaios foram executados para uma mesma taxa de deslocamento de $0.2 \mathrm{~mm} / \mathrm{min}$. 


\subsubsection{Endentação}

Esse teste baseou-se na norma ASTM D3574-08 que se refere a espumas poliméricas flexíveis, pois não foi encontrada uma norma específica para a espuma de PVC rígida. Sendo assim, algumas orientações como tamanho, número de amostras e outros parâmetros foram modificados para o material em questão e os equipamentos disponíveis.

O ensaio de endentação foi escolhido para principalmente, avaliar os modelos computacionais, pois neste tipo de ensaio, o endentador pode produzir diferentes estados de tensão na região da espuma polimérica próxima ao mesmo. Para tais ensaios empregou-se um endentador cilíndrico e quatro corpos-de-prova para cada direção com geometria mostrada na Figura 22 e especificada na Tabela 7. Por não ser um típico endentador cilíndrico (Fig. 23b), os dados experimentais foram tomados com atenção para o valor exato do raio do endentador "semi-cilíndrico". Consequentemente a profundidade máxima que configura um típico ensaio de endentação, é menor que $8.0 \mathrm{~mm}$ em torno de $4.0 \mathrm{~mm}$, ou seja, metade do valor do raio.

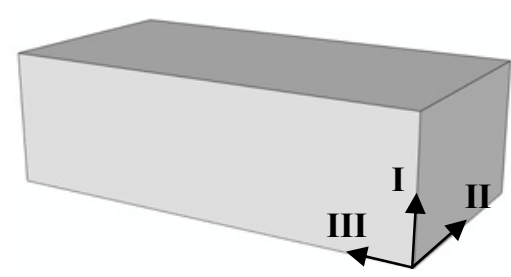

Figura 22. Formato dos corpos-de-prova para os ensaios de endentação e direções

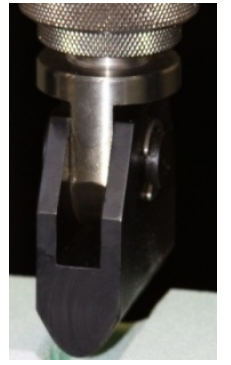

a)

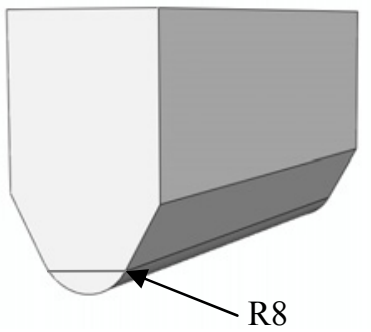

b)

Figura 23. Endentador utilizado: a) Fotografia do dispositivo utilizado; b) Geometria do endentador em detalhe

A escolha desse endentador justifica-se, pois foi o mesmo utilizado por Oliveira (2007) em seus ensaios de flexão 3 pontos da estrutura sanduíche cujos resultados experimentais servirão de base para algumas das comparações neste trabalho. 
Tabela 7 - Dimensões dos corpos-de-prova para endentação de acordo com a direção de carregamento

\begin{tabular}{|c|c|c|c|c|c|}
\hline $\begin{array}{c}\text { Direção de } \\
\text { Carregamento I }\end{array}$ & $\begin{array}{c}\text { Direção } \\
\text { II }\end{array}$ & $\begin{array}{c}\text { Direção } \\
\text { III }\end{array}$ & Altura I (mm) & $\begin{array}{c}\text { Largura II } \\
\text { (mm) }\end{array}$ & $\begin{array}{c}\text { Comprimento III } \\
\text { (mm) }\end{array}$ \\
\hline Normal 3 & $2(1)$ & $1(2)$ & $37.5 \pm 0.5$ & $60.0 \pm 0.5$ & $120 \pm 1$ \\
\hline Plano 1(2) & 3 & $2(1)$ & $26.0 \pm 0.5$ & $36.5 \pm 0.5$ & $120 \pm 1$ \\
\hline
\end{tabular}

Por fim, vale ressaltar que as taxas de deslocamento, assim como a geometria dos corpos-de-prova utilizados são muito próximos aos utilizados por Gimenez et al. (2004) em seus ensaios experimentais de espumas polimérica de PVC com diferentes densidades, sendo uma delas de $60 \mathrm{Kg} / \mathrm{m}^{3}$.

Novamente, dois corpos-de-prova foram submetidos a ensaios cíclicos com quatro ciclos com nível máximo de descarregamento viável a fim de se evitar a perda de contato entre o aplicador e a amostra. Sendo que tanto no carregamento como no descarregamento utilizou-se a mesma taxa de deslocamento de $1.5 \mathrm{~mm} / \mathrm{min}$.

\subsubsection{Compressão Hidrostática}

Ensaios experimentais hidrostáticos consistem em solicitar as amostras em todas as direções com uma mesma carga. São essas múltiplas solicitações iguais que tornam essa classe de ensaios mais complexa do que os usuais ensaios uniaxiais (de tração e compressão) e até mesmo do que os ensaios de cisalhamento. Isso porque os carregamentos devem evoluir simultaneamente, o que requer equipamentos específicos dependendo do material e da análise considerados. Poucos autores citados na revisão bibliográfica desse trabalho (ex.: DESHPANDE; FLECK, 2001 e VIOT, 2009) realizaram ensaios hidrostáticos em espumas, pois a sua alta porosidade gera grande variação de volume e os limites de escoamento desse material são muito pequenos (valores menores que $1 \mathrm{MPa}$ ) o que exige uma precisão do equipamento em torno de pelo menos $0.05 \mathrm{MPa}$.

Uma abordagem comum citada na literatura para efetuar ensaios de compressão hidrostática consiste em envolver a espuma polimérica em um material flexível tipo silicone ou mesmo em invólucros de borracha devidamente conformados e selados. Dessa forma, a espuma pode ser imersa em um fluido armazenado em um vaso de pressão. As máquinas de ensaios hidrostáticos convencionais, então, pressurizam esse fluido (geralmente uma mistura de água e óleo) para este então deformar o material, aplicando a mesma carga em todas as direções. A deformação volumétrica do material é obtida a partir do cálculo da variação do 
volume no interior do vaso de pressão. Verifica-se assim que a aplicação de trações hidrostáticas não é viável usando este método e por isso são raramente executadas.
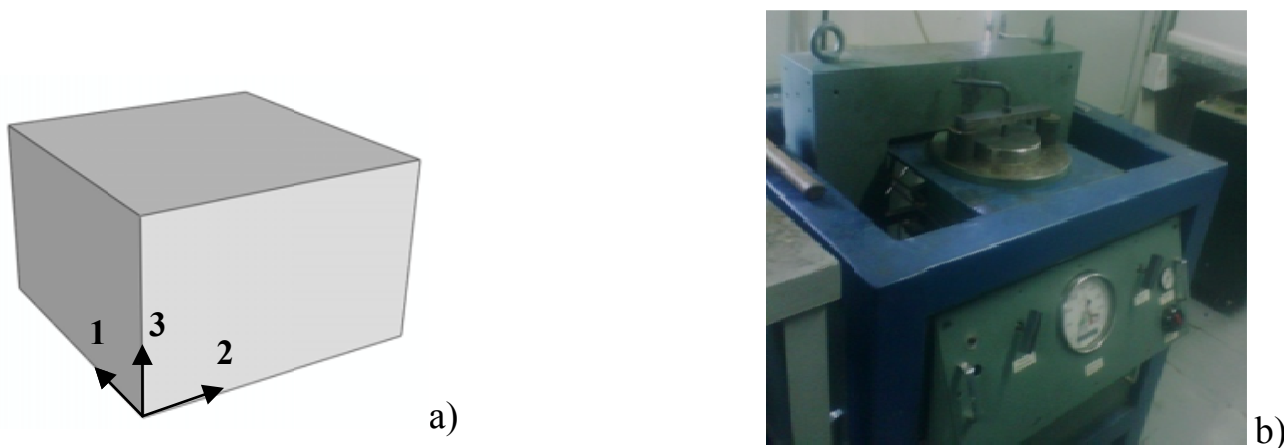

Figura 24. Ensaios Hidrostáticos: a) Formato dos corpos-de-prova; b) Prensa

No presente trabalho foram realizados alguns ensaios hidrostáticos em compressão para amostras com dimensões 38x60x60mm (Fig. 24a). Os ensaios requisitaram o uso de uma prensa hidráulica (Fig. 24b), sendo que os corpos-de-prova selados com balões de borracha que envolveram os CDPs com uma pré-tensão desprezível e foram assim, imersos no vaso de pressão.

Segundo a literatura, é necessária a criação de uma válvula de escape para o ar que está inicialmente contido dentro das células da espuma e que representa a maior parte de seu volume seja expulso. Todavia esse fato foi desconsiderado devido à flexibilidade da borracha pré-tensionada e, portanto, a variação de volume (densificação) não foi elevada.

O maior problema registrado durante os ensaios residiu, principalmente, na sensibilidade do equipamento. Mesmo instalando um manômetro com precisão de 5psi ( $\sim 0.034 \mathrm{MPa})$, o equipamento apresentou dificuldades em sua utilização, porque o sistema foi projetado para altas pressões e sua precisão real fica em torno de $1 \mathrm{MPa}$, ou seja, bem acima do necessário para obter dados quantitativamente representativos para níveis mais baixos de carga. Apesar disso, alguns ensaios foram conduzidos com a máxima precisão possível, obtendo-se dados quantitativos satisfatórios para níveis mais elevados de carga, assim como uma boa análise qualitativa da resposta volumétrica do material como um todo.

\subsubsection{Considerações sobre Cisalhamento}

No presente trabalho optou-se por não realizar ensaios de cisalhamento, haja vista que na literatura consultada tem-se resultados de ensaios de cisalhamento de uma espuma 
semelhante ou até da mesma marca e modelo que a deste trabalho. $\mathrm{O}$ emprego de dados da literatura associado aos dados obtidos, faz-se necessário, pois a investigação de parâmetros na determinação de modelos de material requer uma quantidade mínima de dados experimentais. Alguns modelos mais simples necessitam apenas dados provenientes de um único tipo de ensaio, enquanto outros mais complexos podem requerer dados de inúmeros tipos de ensaios.

Da bibliografia investigada, destacam-se os trabalhos de Gimenez et al. (2004) e o de Juntikka e Hallström (2007) como os mais relevantes. O primeiro consiste em uma análise experimental de espumas em PVC de diferentes densidades, incluindo uma de célula fechada com densidade de $60 \mathrm{~kg} / \mathrm{m}^{3}$. Além de ensaios de cisalhamento, foram realizados ensaios de compressão uniaxial, de flexão em três pontos e de endentação. O trabalho de Juntikka e Hallström (2007) propõe um método para a determinação da resistência ao cisalhamento de espumas de PVC (Divinycell H60 e H100), utilizando ensaios de flexão em 4 pontos e compara seus resultados com os provenientes de um ensaio de cisalhamento puro. A partir de soluções clássicas para as cargas de falha, os apoios dos ensaios de flexão foram dimensionados e posicionados de maneira que o material viesse a falhar por cisalhamento. Considerando os eixos de anisotropia (1-2-3) da espuma no presente trabalho, a Figura 25 evidencia as tensões cisalhantes $\tau_{31}\left(=\tau_{13}\right)$ que atuam nas estruturas sanduíches quando solicitads por uma força de compressão $\overline{F_{C}}=F_{0} \hat{k}$.

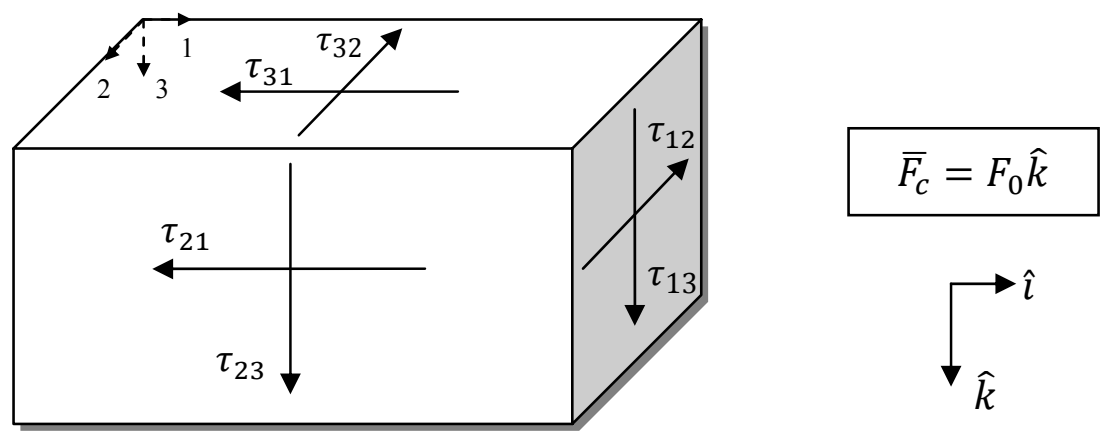

Figura 25. Tensões cisalhantes atuantes na espuma

Assim, conclui-se que as resistências e limites de tensão em cisalhamento obtidos nesses trabalhos supracitados, bem como pelo fabricante são especificados para a direção normal 3 (plano 3-1). A Tabela 8 contém as propriedades mecânicas da espuma de PVC segundo as três referidas referências. 
Tabela 8 - Propriedades mecânicas para espumas de PVC de célula fechada

\begin{tabular}{|c|c|c|c|}
\hline Propriedade & Gimenez et al. (2004) & Juntikka e Hallström (2007) & DIAB (2010) \\
\hline Densidade & $60 \mathrm{~kg} / \mathrm{m}^{3}$ & $62 \mathrm{~kg} / \mathrm{m}^{3}$ & $60 \mathrm{~kg} / \mathrm{m}^{3}$ \\
\hline $\begin{array}{c}\text { Módulo Elástico em } \\
\text { compressão, } E\end{array}$ & $25 \mathrm{MPa}$ & $60 \mathrm{MPa}$ & $60-70 \mathrm{MPa}$ \\
\hline $\begin{array}{c}\text { Módulo Elástico em } \\
\text { cisalhamento, } G\end{array}$ & $22 \mathrm{MPa}$ & $21.54 \mathrm{MPa}$ & $16-20 \mathrm{MPa}$ \\
\hline $\begin{array}{c}\text { Tensão de Escoamento } \\
\text { em cisalhamento }\end{array}$ & $0.7 \mathrm{MPa}$ & $0.45^{*} \mathrm{MPa}$ & $0.63-0.76 \mathrm{MPa}$ \\
\hline $\begin{array}{c}\text { Tensão de Resistência } \\
\text { em cisalhamento }\end{array}$ & $0.8 \mathrm{MPa}$ & $0.55-0.58 \mathrm{MPa}$ & \\
\hline
\end{tabular}

* Valor especificado para o presente trabalho

Desta tabela pode-se observar a variação nos módulos elásticos e nas resistências obtidas pelos pesquisadores e pelo fabricante da espuma H60. É importante notar que o fabricante não disponibiliza em DIAB (2010), a tensão de escoamento do material, mas somente a sua resistência, ou seja, a maior tensão suportada pelo material antes da sua ruptura/falha devido ao comportamento "frágil" do mesmo em tração. Juntikka e Hallström (2007) não fornecem explicitamente uma tensão de escoamento. Todavia, das observações em seu trabalho, pode-se concluir que a tensão de escoamento encontra-se para um nível de deformação de aproximadamente 3\%. É interessante notar que esse nível de deformação foi aproximadamente o mesmo obtido por Gimenez et al. (2004) na determinação do valor de 0.7MPa para a tensão de escoamento em cisalhamento.

Após as devidas considerações sobre os ensaios de cisalhamento feitas neste tópico, os demais ensaios que foram realizados no presente trabalho são agrupados na Tabela 9.

Tabela 9 - Matriz de ensaios

\begin{tabular}{|c|c|c|c|c|}
\hline Ensaio & $\begin{array}{c}\text { Direção de } \\
\text { Carregamento }\end{array}$ & $\begin{array}{c}\text { Tipo de } \\
\text { Carregamento* }\end{array}$ & $\begin{array}{l}\text { Quantidade de } \\
\text { corpos-de prova }\end{array}$ & Geometria \\
\hline \multirow{4}{*}{$\begin{array}{c}\text { Compressão } \\
\text { Uniaxial }\end{array}$} & \multirow{2}{*}{3} & $\mathrm{C}$ & 7 & \multirow{4}{*}{ Figura 19} \\
\hline & & $\mathrm{M}$ & 2 & \\
\hline & \multirow[b]{2}{*}{$1(2)$} & $\mathrm{C}$ & 3 & \\
\hline & & $\mathrm{M}$ & 2 & \\
\hline \multirow{4}{*}{ Tração Uniaxial } & \multirow{2}{*}{3} & $\mathrm{C}$ & 2 & \multirow{4}{*}{ Figura 20} \\
\hline & & $\mathrm{M}$ & 2 & \\
\hline & \multirow{2}{*}{$1(2)$} & $\mathrm{C}$ & 2 & \\
\hline & & $\mathrm{M}$ & 2 & \\
\hline \multirow{4}{*}{ Endentação } & \multirow[b]{2}{*}{3} & $\mathrm{C}$ & 1 & \multirow{4}{*}{ Figura 22} \\
\hline & & $\mathrm{M}$ & 3 & \\
\hline & \multirow{2}{*}{$1(2)$} & $\mathrm{C}$ & 1 & \\
\hline & & $\mathrm{M}$ & 3 & \\
\hline \multirow{2}{*}{$\begin{array}{l}\text { Compressão } \\
\text { Hidrostática }\end{array}$} & \multirow[t]{2}{*}{$1-2-3$} & \multirow{2}{*}{$\mathrm{C}$} & 2 & Figura 19 \\
\hline & & & 2 & Figura 24a \\
\hline
\end{tabular}

* M : Ensaios monotônicos; C: Ensaios cíclicos 


\subsubsection{Modelos Computacionais Fenomenológicos}

Para que seja possível utilizar um modelo para materiais isotrópicos com encruamento isotrópico e ou cinemático em espumas poliméricas anisotrópicas, é preciso que sejam revisados os conceitos que permeiam a elaboração desse modelo, bem como as hipóteses assumidas pelo(s) respectivo(s) autor(es). Assim, o usuário do modelo pode comparar as hipóteses do modelo que foi escolhido com as obtidas a partir dos ensaios experimentais de seu material. Isto possibilita que a aplicação deste modelo forneça um conjunto de resultados o mais coerente possível com as propriedades do material em questão.

Serão discutidos e detalhados na sequência os dois modelos de material que estão implementados no programa comercial de elementos finitos ABAQUS (ABAQUS/CAE User's Manual, 2007). Sem perda de generalidade, é possível, a partir dessa discussão, extrapolar os procedimentos e hipóteses efetuados para esses modelos para outros implementados ou não em outros programas de elementos finitos.

\subsubsection{Modelo de Material com Encruamento Isotrópico}

O modelo em questão é referenciado no programa ABAQUS como Crushable foam model with isotropic hardening. Este modelo é baseado no modelo fenomenológico de Deshpande e Fleck (2000) que apresentaram em sua publicação três modelos de material para espumas metálicas. Um primeiro modelo é o indicado nas equações (34) e (35), o segundo nas equações (36) e (37) e o terceiro, implementado no ABAQUS, consisti na simplificação da relação de encruamento do primeiro modelo, equação (35). A relação de encruamento, então modificada, passou assim, a não possuir sensibilidade aos diferentes "caminhos" de carregamento do plano das tensões desviadoras versus tensões hidrostáticas, sendo dada pela seguinte equação:

$$
H=\left[\frac{\sigma_{v}}{\hat{\sigma}} h_{u}+\left(1-\frac{\sigma_{v}}{\hat{\sigma}}\right) h_{p}\right] \approx h_{u}
$$

Ou seja, o modelo não mais apresenta sensibilidade à taxa de encruamento sob carregamentos de pressão hidrostática $\left(h_{p}\right)$. Essa aproximação faz com que os incrementos 
plásticos de deformação sejam iguais para quaisquer tipos de carregamentos, sendo que essa aproximação na prática nem sempre é aconselhavél ou mesmo possível.

Para detalhar a implementação do modelo em questão, a superfície de escoamento é reescrita e seus parâmetros de calibração $\alpha e v_{p}$ são relacionados aos resultados experimentais e às respectivas hipóteses adotadas.

A superfície de escoamento (eq. (34)) é reescrita como:

$$
f=\hat{\sigma}-\sigma_{y}=\left(\frac{\sigma_{v}^{2}+\alpha^{2} \sigma_{m}^{2}}{1+(\alpha / 3)^{2}}\right)^{1 / 2}-\sigma_{y} \leq 0
$$

Onde $\hat{\sigma}$ e $\sigma_{y}$ são, respectivamente, a tensão equivalente do modelo de material e a tensão de escoamento em compressão (ou tração) uniaxial. $\sigma_{v}$ e $\sigma_{m}$ representam respectivamente:

$$
\begin{gathered}
\sigma_{v}=\sqrt{\frac{3}{2} S_{i j} S_{i j}} \\
\sigma_{m}=-\frac{\sigma_{k k}}{3}
\end{gathered}
$$

O parâmetro $\alpha$ é obtido a partir da relação:

$$
\alpha=\frac{3 k}{\sqrt{9-k^{2}}}
$$

onde o parâmetro $k$ é calculado a partir das tensões de escoamento do material em compressão uniaxial $\left(\sigma_{c}^{0}\right)$ e compressão hidrostática $\left(p_{c}^{0}\right)$ :

$$
k=\sigma_{c}^{0} / p_{c}^{0}
$$

O potencial de encruamento foi definido como:

$$
g=\sqrt{\sigma_{v}^{2}+\beta^{2} \sigma_{m}^{2}}
$$

e o parâmetro $\beta$ é dado por: 


$$
\beta^{2}=\frac{9}{2}\left(\frac{1-2 v_{p}}{1+v_{p}}\right)
$$

onde $v_{p}$ é o coeficiente de Poisson plástico do material.

Por fim, o fator de encruamento do material $\left(H \approx h_{u}\right)$ é inserido na implementação em questão através de uma relação em forma de tabela entre a deformação plástica Logarítmica (abscissa) e a tensão de Cauchy (ordenada) para um ensaio de compressão uniaxial.

Antes de utilizar as relações de (49) a (55), alguns conceitos de plasticidade devem ser revistos de maneira que o fator $\beta$, o potencial de encruamento, a evolução da superfície de escoamento e as demais variáveis sejam devidamente calibradas e aplicadas. Essa revisão é imprescindível à compreensão e ao discernimento dos modelos de material aqui discutidos e que estão implementados no programa ABAQUS.

Através da bibliografia presente neste trabalho é fácil notar que o uso de modelos de material com encruamento pode ser relativamente complexo. O ajuste ou calibração desses modelos com dados experimentais apresenta certa dificuldade, pois os cálculos envolvem diferenciações tensoriais. Para que seja de uso prático, essas superfícies (critérios) de escoamento são normalmente apresentadas em função das respectivas tensões e deformações equivalentes que são indicadas nesse texto pelo símbolo “^”. A proposta de uma tensão equivalente é a de apresentar uma superfície (critério) de escoamento num formato tal que para um ensaio de compressão (tração) uniaxial, a expressão para o escoamento do material se reduza a:

$$
f=F-\sigma_{y}^{2}=C \hat{\sigma}^{n}-\sigma_{y}^{2}
$$

Neste caso, como $F$ na equação (49) já está escrita em função da tensão equivalente $\hat{\sigma}$, o valor de $C$ se resume a 1 e $n$ é igual a 2. Assim, a calibração dos modelos pode ser realizada com base em ensaios uniaxiais, bem como através de expressões e operações algébricas quando se utiliza as tensões e deformações equivalentes.

A determinação da deformação equivalente é um pouco mais trabalhosa que a respectiva tensão equivalente, e pode ser definida como uma combinação de incrementos de deformação volumétrica e/ou de distorções angulares. Há também, a possibilidade do cálculo através dos conceitos de energia plástica $W_{p l}$. Independentemente da abordagem, os incrementos de deformação plástica devem ser investigados previamente para garantir que os modelos de material implementados não violem algumas Leis Termodinâmicas. 
Começando com a deformação volumétrica (CHEN; HAN, 1988), tem-se:

$$
\varepsilon_{v o l}=\varepsilon_{v o l}^{e l}+\varepsilon_{v o l}^{p l}=\ln \left(V / V_{0}\right)=\left[\ln \left(V / V_{0}\right)\right]^{\mathrm{el}}+\left[\ln \left(V / V_{0}\right)\right]^{\mathrm{pl}}
$$

onde $V$ é o volume atual do material e $V_{0}$ o volume inicial. O incremento de deformação total composto pela parcela elástica e plástica é dado por:

$$
d \varepsilon_{i j}=d \varepsilon_{i j}^{e l}+d \varepsilon_{i j}^{p l}
$$

No regime linear elástico, o uso de incrementos não é necessário e a solução é obtida diretamente por (Lei de Hooke generalizada):

$$
\sigma_{i j}=D_{i j k l} \varepsilon_{k l} \rightarrow \varepsilon_{i j}=\left[D_{i j k l}\right]^{-1} \sigma_{k l}
$$

Por outro lado, no regime plástico é necessário o uso de incrementos de deformação plástica que configuram as Leis de Evolução das superfícies de escoamento. Estas leis (CHEN; HAN, 1988) são definidas de forma genérica por:

$$
d \varepsilon_{i j}^{p l}=d \lambda \frac{\partial g}{\partial \sigma_{i j}}=\frac{1}{H} \frac{\partial g}{\partial \sigma_{i j}} \frac{\partial f}{\partial \sigma_{k l}} d \sigma_{k l}^{J}
$$

onde $H$ é o coeficiente de encruamento, $\left(\partial f / \partial \sigma_{k l}\right) d \sigma_{k l}^{J}$ representa o módulo do operador Jaumann de tensão (que pode atuar na tensão de Cauchy) na direção ( $\left.\partial f / \partial \sigma_{k l}\right)$ da superfície de escoamento $f$. Este produto é então projetado na direção $\partial g / \partial \sigma_{k l}$ do potencial de encruamento $g$. É a partir desta projeção que se define então a direção do incremento de deformação segundo o espaço de tensões do potencial $g$ e da superfície $f$. O uso do operador de Jaumann na tensão de Cauchy (por exemplo) visa contabilizar as variações nas tensões provenientes de rotações de corpos rígidos através do uso de um incremento (taxa) objetivo(a). Isso porque uma rotação de corpo rígido escrita em função de um sistema de coordenadas fixo e não rotacionado altera o tensor de Cauchy. Este incremento (no caso associado ao operador Jaumann) pode ser escrito como:

$$
d \sigma_{k l}^{J}=\dot{\boldsymbol{\sigma}}_{J}=\dot{\boldsymbol{\sigma}}-\dot{\boldsymbol{\Omega}} \boldsymbol{\sigma}+\boldsymbol{\sigma} \dot{\boldsymbol{\Omega}}=\left(D_{i j k l}\right)_{t J C} \dot{\varepsilon}_{k l}
$$


sendo:

$$
\frac{1}{d t} \frac{\partial \delta u_{i}}{\partial x_{j}}=\frac{\partial v_{i}}{\partial x_{j}}=\frac{\partial \boldsymbol{v}}{\partial \boldsymbol{x}}=\boldsymbol{L}=\frac{1}{2}\left(\boldsymbol{L}+\boldsymbol{L}^{T}\right)+\frac{1}{2}\left(\boldsymbol{L}-\boldsymbol{L}^{T}\right)=\dot{\boldsymbol{\varepsilon}}+\dot{\boldsymbol{\Omega}}
$$

lembrando que as coordenadas $\boldsymbol{x}$ representam o sistema de coordenadas atual (no qual definise a tensão de Cauchy) e que o incremento de tempo $d t$ não faz, necessariamente, referência a grandeza física tempo, mas é apenas um recurso na utilização e implementação das teorias incrementais elástica e/ou plástica, ou seja, representa uma iteração e/ou um step (passo). É importante lembrar que o tensor anti-simétrico $\dot{\boldsymbol{\Omega}}$, conhecido por spin, contempla as rotações do material/estrutura e o tensor simétrico $\dot{\varepsilon}$ contém as deformações puras (CRISFIELD, 1997).

Retornando à Lei de Evolução (59), as direções de evolução da superfície $f$ dependentes da deformação plástica $\varepsilon_{i j}^{p l}$ variam de acordo com o potencial de encruamento escolhido. Na Figura 26 tem-se uma superfície de falha, um potencial de encruamento e os parâmetros do modelo de material implementado no ABAQUS.

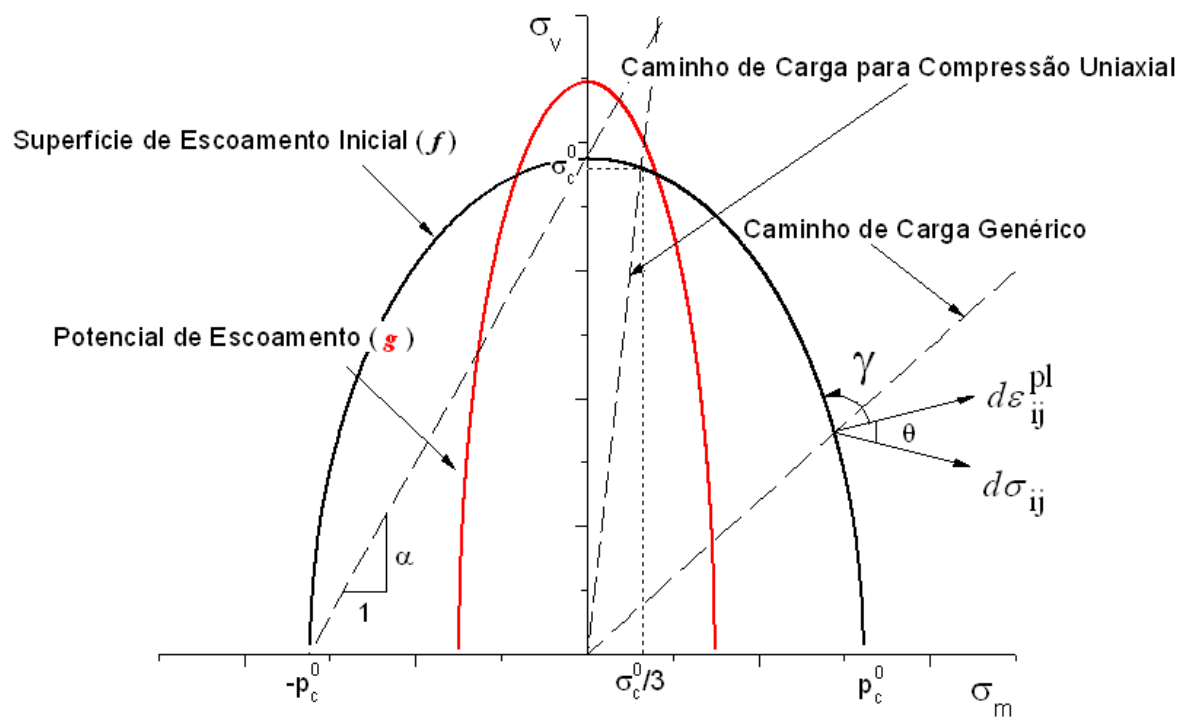

Figura 26. Superfície de escoamento com potencial de encruamento isotrópico associativo $(\alpha=\beta)$ ou não $(\boldsymbol{\alpha} \neq \boldsymbol{\beta})$

Nesta figura, o incremento de deformação plástica $d \varepsilon_{i j}^{p l}$ forma um ângulo $\gamma$ com uma tangente da superfície $f$. Se o potencial de encruamento for associativo, $f=g$, tem-se $\gamma=\pi / 2$. Com $\gamma=\pi / 2$, o ângulo $\theta$ indica se o material está sob carregamento $(\theta<90)$, 
descarregamento $(\theta>90)$ ou estado neutro de carregamento $(\theta=90)$, contudo para $\gamma \neq \pi / 2$ essa análise de carregamento torna-se mais complexa.

Essa perpendicularidade para potenciais associativos é conhecida como condição de normalidade (ou regra da normalidade) para o incremento de deformação plástica, e garante que modelo não viole o Princípio da Irreversibilidade do processo de deformação plástica. Em termos matemáticos, para um incremento de deformação plástica sob um determinado carregamento $\sigma_{i j}$, o incremento de trabalho realizado deve obedecer à seguinte condição:

$$
d W_{p l}=\sigma_{i j} d \varepsilon_{i j}^{p l} \geq 0
$$

Todavia, de modo geral, esse critério de normalidade não se verifica para potenciais de encruamento não associativos, onde $g \neq f$ ou $\gamma \neq \pi / 2$. Contudo é preciso lembrar que esse critério não é necessário para garantir uma solução fisicamente admissível, mas apenas suficiente, juntamente com os critérios de convexidade, continuidade e unicidade das soluções que compõem o Postulado de Estabilidade de Drucker (CHEN; HAN, 1988). Verifica-se que o critério de unicidade das soluções é suficiente para garantir uma estabilidade local do material, pois garante a existência de uma forma inversa única da relação constitutiva local através da utilização de matrizes Hessianas ( $\boldsymbol{H}^{\prime}$, não confundir com o coeficiente de encruamento $H$ ) sempre positivas (ou seja, não há energia negativa sendo gerada):

$$
H_{i j k l}^{\prime p l}=\frac{\partial^{2} W_{p l}}{d \varepsilon_{i j}^{p l} d \varepsilon_{k l}^{p l}} \geq 0
$$

Em outros termos, o critério de unicidade diz que o potencial a partir do qual são calculados os incrementos de deformação deve garantir a conservação de energia do sistema para as deformações elásticas e plásticas. De forma geral, tais potenciais têm a propriedade de gerar campos de tensão (neste caso designados por $E$ ) que podem ser definidos por:

$$
\boldsymbol{E}=\boldsymbol{\nabla} g
$$

Se estes campos gerados forem conservativos, garante-se a unicidade das soluções a partir do potencial $g$. Sendo conservativos, estes campos possuem a propriedade matemática de serem irrotacionais, ou seja: 


$$
\boldsymbol{\nabla} \times \boldsymbol{E}=\left[\begin{array}{ccc}
\widehat{\boldsymbol{x}} & \widehat{\boldsymbol{y}} & \widehat{\mathbf{z}} \\
\partial_{x} & \partial_{y} & \partial_{z} \\
E_{x} & E_{y} & E_{z}
\end{array}\right]=0
$$

Aplicando a equação (64) neste produto vetorial tem-se:

$$
\boldsymbol{\nabla} \times \boldsymbol{\nabla} g=\left[\begin{array}{ccc}
\hat{\boldsymbol{x}} & \hat{\boldsymbol{y}} & \hat{\mathbf{z}} \\
\partial_{x} & \partial_{y} & \partial_{z} \\
g_{x} & g_{y} & g_{z}
\end{array}\right]=0
$$

Para utilizar a relação acima no contexto de plasticidade, os versores $\widehat{\boldsymbol{x}}, \hat{\boldsymbol{y}}$ e $\hat{\boldsymbol{z}}$ são interpretados no espaço das tensões principais como versores $\widehat{\boldsymbol{\sigma}}_{\mathbf{1}}, \widehat{\boldsymbol{\sigma}}_{\mathbf{2}}$ e $\widehat{\boldsymbol{\sigma}}_{\mathbf{3}}$ respectivamente. Usando então a definição do potencial $g$ (eq. (54)) na equação (66) obtem-se os termos $g_{x}, g_{y}$ e $g_{z}:$

$$
\begin{aligned}
& g_{x}=\frac{\sigma_{1}}{\sqrt{\mathrm{g}}}\left[\frac{\beta^{2}}{9}-\left(\sigma_{2}+\sigma_{3}\right)\right] \\
& g_{y}=\frac{\sigma_{2}}{\sqrt{\mathrm{g}}}\left[\frac{\beta^{2}}{9}-\left(\sigma_{1}+\sigma_{3}\right)\right] \\
& g_{z}=\frac{\sigma_{3}}{\sqrt{\mathrm{g}}}\left[\frac{\beta^{2}}{9}-\left(\sigma_{1}+\sigma_{2}\right)\right]
\end{aligned}
$$

Inserindo as equações (67), (68) e (69) em (66) e realizando as devidas diferenciações, torna-se evidente a validade da equação (66), o que garante que o potencial $g$ utilizado pelo algoritmo do ABAQUS é válido fisicamente e que para cada ponto de integração (de cada elemento) existe uma matriz inversa para a relação constitutiva local.

A principal vantagem ao utilizar um potencial não associativo é a de alterar sob regime plástico, a dependência que o material possui com as tensões desviadoras $\left(\sigma_{v}\right)$ e hidrostáticas $\left(\sigma_{m}\right)$ do regime elástico. Infelizmente o uso de potenciais não associativos gera relações constitutivas (tensores) assimétricas que aumentam o custo computacional do modelo implementado. Outra alternativa ao uso de potenciais não associativos para evitar os problemas supracitados e descrever a evolução de superfícies de escoamento consiste em utilizar uma Lei de Encruamento sensível ao caminho de carregamento do material, como foi proposto inicialmente por Deshpande e Fleck (2000) com as equações de (34) à (37). Estes autores evitaram as complicações de potenciais não associativos e propuseram dois modelos 
de material com relações de encruamentos cuja complexidade no uso dessas relações está na sua calibração experimental.

Contudo, o programa ABAQUS adota a estratégia de usar uma Lei de Encruamento não associativa, pois ela torna o modelo mais prático de ser calibrado. Com isso, a determinação do incremento de deformação plástica equivalente apresenta certas dificuldades. Utilizando a Relação de Consistência (relação que garante que os carregamentos plásticos geram tensões e deformações contidas nas superfícies de escoamento subsequentes) para a superfície $f$, equação (49), tem-se que:

$$
d f=0=\frac{\partial f}{\partial \sigma_{i j}} d \sigma_{i j}^{J}+\frac{\partial f}{\partial \sigma_{y}} d \sigma_{y}
$$

Notando que $\partial f / \partial \sigma_{y}=-1$, a equação acima pode ser inserida na lei de evolução em (59), e fornece a seguinte equação:

$$
d \varepsilon_{i j}^{p l}=d \lambda \frac{\partial g}{\partial \sigma_{i j}}=\frac{1}{H} \frac{\partial g}{\partial \sigma_{i j}} d \sigma_{y}
$$

Sabe-se que o módulo de encruamento $H$ é a tangente da curva $\hat{\sigma}(\hat{\varepsilon})$, ou seja:

$$
H=\frac{d \hat{\sigma}}{d \hat{\varepsilon}}
$$

Aplicando (72) em (71), o incremento de deformação plástica é dado por:

$$
d \varepsilon_{i j}^{p l}=\frac{d \hat{\varepsilon}}{d \hat{\sigma}} \frac{\partial g}{\partial \sigma_{i j}} d \sigma_{y}
$$

como a tensão equivalente é definida para um ensaio uniaxial, seu módulo coincide com $\sigma_{y}$, logo:

$$
d \varepsilon_{i j}^{p l}=\frac{\partial g}{\partial \sigma_{i j}} d \hat{\varepsilon}
$$

Para definir explicitamente o incremento de deformação plástica equivalente, algumas considerações são necessárias. Primeiro, aplica-se o conceito de tensão equivalente para o 
potencial de encruamento $g$ obtendo um novo potencial $g$ ' a partir do qual será definido $d \hat{\varepsilon}$. Essa abordagem tem o propósito de tornar o mais genérica possível a expressão para $d \hat{\varepsilon}$

$$
g^{\prime}=\frac{1}{\sqrt{1+(\beta / 3)^{2}}} g
$$

Em seguida, as deformações são obtidas a partir da equação (75), porém a derivação parcial é feita em relação ao carregamento específico. Para as solicitações geradas por componentes desviadoras ("tensões de von Mises") deriva-se $g$ ' em relação à $\sigma_{v}$ e depois, para os carregamentos hidrostáticos, a derivada é em relação à $\sigma_{m}$. Dessa forma obtém-se:

$$
d \varepsilon_{v}^{p l}=\frac{\partial g^{\prime}}{\partial \sigma_{v}} d \hat{\varepsilon}=\frac{\sigma_{v}}{g^{\prime}} \frac{d \hat{\varepsilon}}{\left[1+(\beta / 3)^{2}\right]}
$$

De maneira análoga, o incremento de deformação volumétrica é calculado por:

$$
d \varepsilon_{m}^{p l}=\frac{\partial g^{\prime}}{\partial \sigma_{m}} d \hat{\varepsilon}=\frac{\beta^{2} \sigma_{m}}{g^{\prime}} \frac{d \hat{\varepsilon}}{\left[1+(\beta / 3)^{2}\right]}
$$

Isolando $\sigma_{v}$ em (76) e $\sigma_{m}$ em (77) e aplicando essas equações na definição da tensão equivalente $\hat{\sigma}$ (eq. (49)), obtém-se uma forma explícita para o incremento de deformação plástica equivalente:

$$
d \hat{\varepsilon}=\frac{g^{\prime}}{\hat{\sigma}} \frac{\left[1+(\beta / 3)^{2}\right]}{\sqrt{1+(\alpha / 3)^{2}}}\left[\left(d \varepsilon_{v}^{p l}\right)^{2}+\frac{\alpha^{2}}{\beta^{4}}\left(d \varepsilon_{m}^{p l}\right)^{2}\right]^{1 / 2}
$$

Para um potencial de encruamento associativo $(\alpha=\beta)$, esta expressão se reduz à obtida por Deshpande e Fleck (2000).

Resta agora discutir a evolução da superfície de escoamento implementada. Segundo a implementação do modelo, a evolução ocorre de maneira isotrópica no espaço das tensões $\sigma_{v} x \sigma_{m}$ e é definida pela lei de encruamento que é obtida em função de valores de entrada em forma tabular no programa ABAQUS. Isto deixa implícita a função do limite de escoamento em compressão (ou tração) uniaxial com o incremento de deformação plástica $\sigma_{y}(\hat{\varepsilon})$. Em suma, uma vez devidamente calculada pelo programa, essa função fornece a cada incremento 
de deformação plástica uma nova tensão de escoamento $\sigma_{y}(\hat{\varepsilon})$. É importante destacar que o limite de escoamento $\sigma_{y}$ no espaço das tensões $\sigma_{v} x \sigma_{m}$ é definido como a componente de tensão desviadora $\left(\sigma_{y}\right)_{v}$ para o caminho de carregamento adotado, geralmente, utilizando-se um valor de compressão ou de tração uniaxial, retomando assim o conceito de tensão equivalente.

Após essa comparação de conceitos básicos e definições teóricas sobre plasticidade e encruamento para o modelo de material implementado no programa ABAQUS, os parâmetros $\beta, \alpha, v_{p}$ e $k$ podem ser determinados com maior coerência frente às possíveis variações dos dados experimentais existentes.

Primeiramente, o fator $k$ definido na equação (53), requer que o usuário realize um ensaio de compressão uniaxial e um ensaio hidrostático para que os limites de escoamento iniciais sejam determinados, e, assim, o fator $k$ possa ser calculado. Uma vez que $k$ está calculado, $\alpha$ também estará determinado de acordo com a relação (52). O potencial de encruamento $g$ é parametrizado com o fator $\beta$ que depende do coeficiente de Poisson plástico do material. Este coeficiente revela se o potencial de encruamento é associativo $(\alpha=\beta)$ ou não $(\alpha \neq \beta)$.

O cálculo de $\beta$ parte do incremento de deformação plástica na equação (71). Com as relações (50), (51) e (54) sendo escrito como:

$$
\begin{aligned}
& d \varepsilon_{i j}^{p l}=d \lambda \frac{\partial}{\partial \sigma_{i j}}\left(\sigma_{v}^{2}+\beta^{2} \sigma_{m}^{2}\right)^{1 / 2}=\frac{d \lambda}{2 g}\left(3 S_{i j}-\beta^{2} 2 \sigma_{m}\right) \\
& =\frac{d \lambda}{2 g}\left(3 S_{i j}+\beta^{2} \frac{2}{3} \frac{\sigma_{k k}}{3} \delta_{i j}\right)=\frac{3 d \lambda}{2 g}\left(S_{i j}+\beta^{2} \frac{2}{9} \frac{\sigma_{k k}}{3} \delta_{i j}\right)
\end{aligned}
$$

Para um carregamento de compressão uniaxial na direção $z$, tem-se que os incrementos de deformação nas três direções cartesianas são dados por:

$$
d \varepsilon_{x}^{p l}=d \varepsilon_{y}^{p l}=-v_{p} d \varepsilon_{z}^{p l}
$$

Para a direção do carregamento $\boldsymbol{z}$, a deformação é dada especificamente por:

$$
d \varepsilon_{z}^{p l}=\frac{3 d \lambda}{2 g}\left(S_{z z}+\beta^{2} \frac{2}{9} \frac{\sigma_{k k}}{3}\right)
$$

sendo: 


$$
S_{z z}=-2 \sigma_{m}=\frac{2}{3} \sigma_{k k}
$$

pois $\sigma_{z z}$ representa a tensão de compressão do ensaio uniaxial. Das duas últimas equações obtém-se:

$$
\begin{aligned}
d \varepsilon_{z}^{p l} & =\frac{3 d \lambda}{2 g}\left(\frac{2 \sigma_{k k}}{3}+\beta^{2} \frac{2}{9} \frac{\sigma_{k k}}{3}\right) \\
& =\frac{d \lambda}{g}\left(1+\frac{\beta^{2}}{9}\right) \sigma_{k k}
\end{aligned}
$$

Com a deformação na direção de carregamento calculada, resta determinar a deformação plástica volumétrica, que é dada por:

$$
\begin{gathered}
d \varepsilon_{v o l}^{p l}=d \varepsilon_{x}^{p l}+d \varepsilon_{y}^{p l}+d \varepsilon_{z}^{p l} \\
=\frac{3 d \lambda}{2 g}\left(S_{i i}+3 \beta^{2} \frac{2}{9} \frac{\sigma_{k k}}{3}\right) \\
=\frac{3}{2 g} d \lambda\left(3 \beta^{2} \frac{2}{9} \frac{\sigma_{k k}}{3}\right)=\frac{d \lambda}{g} \beta^{2} \frac{\sigma_{k k}}{3} \\
=\left(1-2 v_{p}\right) d \varepsilon_{z}^{p l}
\end{gathered}
$$

Da equação acima se determina o valor do incremento de deformação plástica na direção $z$ :

$$
d \varepsilon_{z}^{p l}=\frac{d \lambda}{g} \frac{\beta^{2}}{3} \frac{\sigma_{k k}}{\left(1-2 v_{p}\right)}
$$

Aplicando (83) em (85) obtém-se:

$$
\left(1+\frac{\beta^{2}}{9}\right)=\frac{1}{3} \frac{\beta^{2}}{\left(1-2 v_{p}\right)} \rightarrow \beta^{2}=\frac{9}{2}\left(\frac{1-2 v_{p}}{1+v_{p}}\right)
$$

Ficam dessa forma registradas todas as particularidades do modelo Crushable foam model with isotropic hardening implementado no ABAQUS de maneira a aumentar a confiabilidade da aplicação do mesmo, e principalmente, a metodologia de identificação de seus parâmetros. 


\subsubsection{Modelo de Material com Encruamento Misto}

Este modelo é referenciado no programa ABAQUS como Crushable foam model with volumetric hardening. Diferentemente do modelo com encruamento isotrópico, esta implementação possui o chamado encruamento cinemático, que consiste na contabilização de translações da superfície de escoamento durante a deformação plástica nos espaço das tensões, fenômeno conhecido na literatura por Efeito Bauschinger (CHEN; HAN, 1988). Esse modelo é considerado misto, pois também contempla uma forma de evolução que expande os limites da superfície de escoamento, porém não de uma forma isotrópica. A superfície é expandida somente para as contribuições volumétricas de compressão $\sigma_{m}>0$, daí então, o modelo implementado ser conhecido por ter encruamento volumétrico. As equações envolvidas neste modelo de material também têm alguma influência do modelo proposto por Deshpande e Fleck (2000) e estão descritas abaixo. Em ordem similar ao tópico anterior, as equações envolvidas são dadas por:

$$
f=\hat{\sigma}-\sigma_{y}=\left(\frac{\sigma_{v}^{2}+\alpha^{2}\left(\sigma_{m}-\sigma_{0}\right)^{2}}{1+(\alpha / 3)^{2}}\right)^{1 / 2}-\sigma_{y} \leq 0
$$

O parâmetro $\alpha$ na relação acima é obtido a partir de uma relação similar à (52):

$$
\alpha=\frac{3 k}{\sqrt{\left(3 k_{t}+k\right)(3-k)}}
$$

onde o novo parâmetro $k_{t}$ é calculado a partir das tensões de escoamento inicial do material em compressão hidrostática $\left(p_{c}^{0}\right)$ e da tensão em tração hidrostática $\left(p_{t}\right)$ :

$$
k_{t}=p_{t} / p_{c}^{0}
$$

O cálculo de $k$ é o mesmo realizado na seção anterior na equação (53). Contudo, o potencial de encruamento é diferente daquele em (54), pois neste caso, o valor de $\beta=\sqrt{9 / 2}$, é fixo, ou seja, a implementação não permite que se calibre o modelo com potenciais associativos (exceto quando $\alpha=\sqrt{9 / 2}$ ). Ademais, para o valor fixado para $\beta$, assume-se que o material tem coeficiente de Poisson plástico nulo $\left(v_{p}=0\right)$, o que significa que o material 
tem a máxima deformação volumétrica admissivél fisicamente (exceto para estruturas muito particulares onde podem existir valores negativos para o coeficiente de Poisson). Assim, o potencial é dado por:

$$
g=\sqrt{\sigma_{v}^{2}+(9 / 2) \sigma_{m}^{2}}
$$

Novamente os conceitos de tensão e deformação equivalente são utilizados e mais uma vez, a tensão equivalente não precisa ser determinada novamente. Entretanto a deformação equivalente precisa ser revisada e, de maneira análoga, aplica-se a equação (90) na equação (74) para obter:

$$
d \hat{\varepsilon}=\frac{g^{\prime}}{\hat{\sigma}} \frac{[1+(9 / 2)]}{\sqrt{1+(\alpha / 3)^{2}}}\left[\left(d \varepsilon_{v}^{p l}\right)^{2}+\left(\frac{2 \alpha}{9}\right)^{2}\left(d \varepsilon_{m}^{p l}\right)^{2}\right]^{1 / 2}
$$

É preciso agora especificar a Lei de Evolução do material. Acredita-se que o pesquisador que implementou este modelo de material no ABAQUS baseou-se em ensaios experimentais para espumas em compressão e tração, sendo que o comportamento padrão observado é exibido na Figura 27.

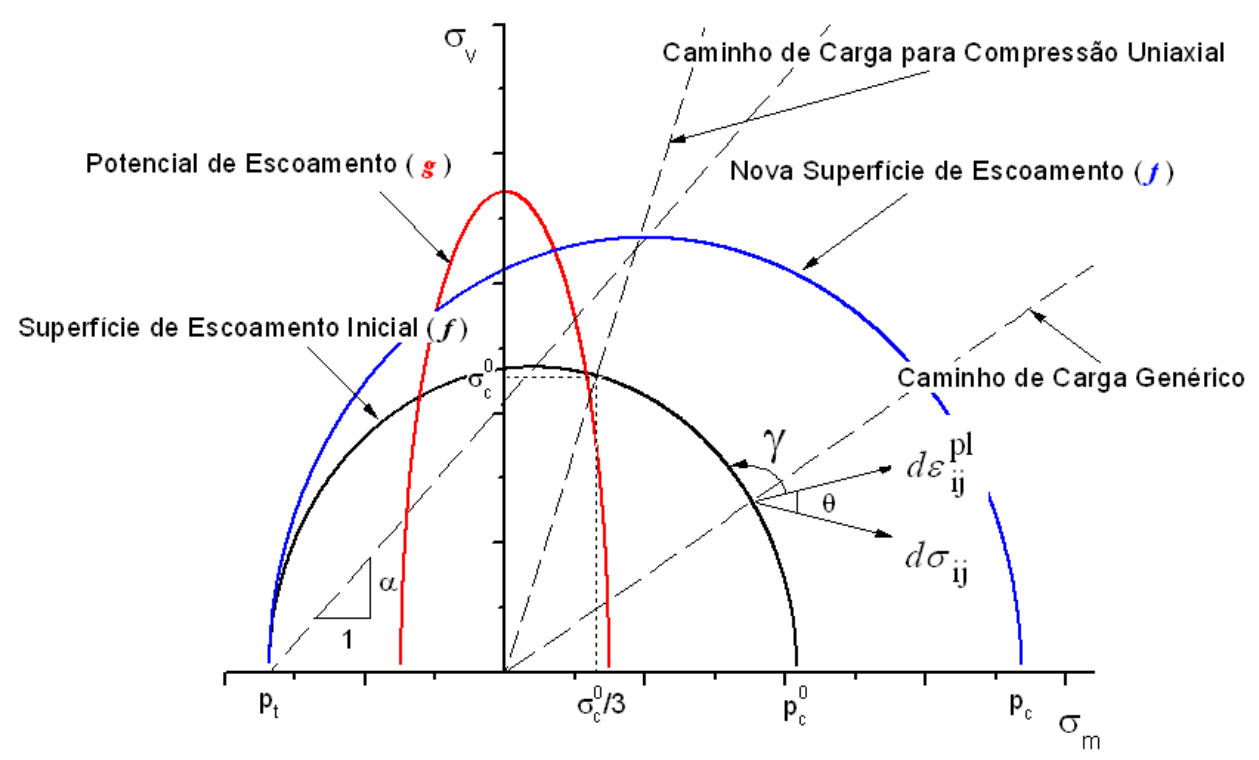

Figura 27. Superfície de escoamento genérica com potencial de encruamento volumétrico (misto)

A evolução da superfície $f$ está baseada em um encruamento misto cuja evolução cinemática pode ser descrita de forma genérica dada por: 


$$
\sigma_{i j}^{c}=\sigma_{i j}^{c 0}+\vartheta_{i j}
$$

onde $\sigma_{i j}^{c}$ é o valor atual do centro da superfície de escoamento no espaço de tensões e $\sigma_{i j}^{c 0}$ é a posição inicial deste centro. $\vartheta_{i j}$ é o tensor de translação do centro da superfície no espaço das tensões. Como o modelo assume uma evolução somente para variações de tensão hidrostática, utiliza-se a equação (51) para simplificar a equação acima gerando:

$$
\sigma_{m}^{c}=-\sigma_{k k}^{c}=-\left(\sigma_{k k}^{c 0}+\vartheta_{k k}\right)
$$

No modelo em discussão $\sigma_{k k}^{c 0}$ é denominado simplesmente por $\sigma_{0}$. Já o tensor $\vartheta_{i j}$ que rege a evolução é mais complicado de ser obtido, pois é este tensor que defini a evolução mista da superfície $f$. Este termo supõe que um dos pontos da superfície de escoamento inicial não é modificado para qualquer carregamento efetuado no material. O ponto escolhido é o limite de escoamento em tração hidrostática $p_{t}$. Logo, a evolução da superfície (e seu centro) é determinada pela evolução de um ponto no eixo das tensões hidrostáticas. No caso, o ponto $p_{c}$ é escolhido e sua evolução é dada pela seguinte expressão (ABAQUS/CAE User's Manual, 2007):

$$
p_{c}\left(\varepsilon_{v o l}^{p l}\right)=\frac{\sigma_{y}\left(\varepsilon_{v o l}^{p l}\right)}{p_{t}+\left[\sigma_{y}\left(\varepsilon_{v o l}^{p l}\right) / 3\right]}\left[\sigma_{y}\left(\varepsilon_{v o l}^{p l}\right)\left(\frac{1}{\alpha^{2}}+\frac{1}{9}\right)+\frac{p_{t}}{3}\right]
$$

Esta expressão é obtida notando que $\sigma_{0}=\left(p_{c}-p_{t}\right) / 2$ e que $\sigma_{y}=\alpha\left(p_{c}+p_{t}\right) / 2$. Basta aplicar as condições de carregamento de compressão ou tração uniaxial na equação (87) juntamente com as definições de $\sigma_{0}$ e $\sigma_{y}$ e isolar $p_{c}$, tem-se o tensor de translação:

$$
\vartheta_{i j}=\vartheta_{k k}=\frac{p_{c}\left(\varepsilon_{v o l}^{p l}\right)-p t}{2}
$$

O procedimento na definição de $\vartheta_{i j}$ é fundamentado em resultados experimentais. Ao contrário do que se observa nos ensaios em compressão, esses materiais celulares tem baixa deformação plástica em tração (se comparado a compressão), chegando a valores menores que $10 \%$ da deformação em compressão. Essa relação é considerada nas curvas de tensãodeformação para o limite de tensão de carregamento para a qual se considera a falha total do 
material (resistência do material). É importante, não confundir a resistência do material com o limite de escoamento. São valores de tensão geralmente distintos e podem ser muito próximos para materiais frágeis, para os quais o encruamento do material pode ser desconsiderado e assim, supor que a superfície não evolui sob cargas de tração. Todavia a implementação desse fenômeno requer uma Lei de Encruamento sensível ao tipo de carregamento $(\sigma>0$ em tração e $\sigma<0$ em compressão), o que aumentaria a complexidade da lei de evolução significativamente e, consequentemente, o uso de tal modelo de material seria, muitas vezes, impraticável. A alternativa proposta no modelo foi a de controlar a evolução da superfície através da equação (94) e do incremento de deformação plástica equivalente, já definido em (74) e que é reescrito para o novo potencial de encruamento $g$ e aplicado para um carregamento uniaxial:

$$
d \hat{\varepsilon}=d \varepsilon_{\text {axial }}^{p l} /\left(\partial g / \partial \sigma_{i j}\right)_{\text {axial }}=\sqrt{2 / 3} d \varepsilon_{\text {axial }}^{p l}
$$

Os incrementos de deformação plástica são definidos a partir da relação do incremento de trabalho plástico realizado:

$$
d W_{p l}=d \varepsilon_{i j}^{p l} \sigma_{i j}=d \hat{\varepsilon} \hat{\sigma}=d \hat{\varepsilon} g
$$

onde a tensão equivalente $\hat{\sigma}$ foi substituida pelo potencial de encruamento $g$ não associativo que determina a direção $\partial g / \partial \sigma_{i j}$ dos incrementos de deformação plástica na superfície $f$.

Das equações (96) e (97) obtém-se uma expressão para o incremento de deformação plástica a partir de um ensaio uniaxial:

$$
d \varepsilon_{i j}^{p l}=\frac{g}{\sigma_{i j}} \sqrt{\frac{2}{3}} d \varepsilon_{a x i a l}^{p l}
$$

Então, têm-se definidos o incremento de deformação plástica e também, a evolução da superfície com a equação (94), sendo que ambos são calibrados com um ensaio de compressão uniaxial. Apesar da evolução da superfície requerer a relação de encruamento de um ensaio hidrostático, que relaciona as respectivas tensões com as deformações volumétricas $p_{c}\left(\varepsilon_{v o l}^{p l}\right)$, o modelo implementado pode ser utilizado com dados provenientes de ensaios uniaxiais, pois é considerado na equação (90), que o coeficiente de Poisson plástico é nulo 
$\left(v_{p}=0\right)$. Tal hipótese também indica que as tensões em uma direção no material não geram tensões em outra direção perpendicular durante a deformação plástica, de onde se conclui que não há deformações plásticas em direções diferentes da do carregamento aplicado. Logo, a deformação axial é função somente da deformação plástica de uma direção, e, portanto, da equação (56) calcula-se:

$$
\begin{gathered}
\varepsilon_{\text {axial }}^{p l}=\varepsilon_{m}^{p l}+\varepsilon_{e}^{p l}=\varepsilon_{m}^{p l}=\varepsilon_{\text {vol }}^{p l} \\
=\left[\ln \left(V / V_{0}\right)\right]^{p l}=\ln \left(\varepsilon_{x}^{p l} \varepsilon_{y}^{p l} \varepsilon_{z}^{p l}\right)=\ln \left(\varepsilon_{x}^{p l}\right)
\end{gathered}
$$

Assim, a evolução da superfície de escoamento é calibrada fornecendo apenas a deformação plástica logarítmica na direção do carregamento de um ensaio uniaxial. Contudo ainda é necessário fornecer, assim como no modelo de material isotrópico da seção anterior, a relação em forma tabular da tensão de Cauchy com a deformação plástica volumétrica.

Há uma limitação imposta nessa implementação do modelo de material com encruamento volumétrico quanto ao seu uso. Segundo o manual do programa ABAQUS, para carregamentos de pressão hidrostática negativa, referentes às tensões de tração, e para carregamentos somente com tensões desviadoras, o modelo é assumido como perfeitamente plástico. Assim o encruamento discutido ocorre somente para carregamentos essencialmente de compressão. Acredita-se que essa restrição tem base no fato de que estruturas celulares, espumas, são aplicadas para carregamentos essencialmente de compressão.

O mesmo manual também restringe a aplicação do respectivo modelo sob carregamentos monotônicos, pois a modelagem de descarregamentos é relativamente complicada tornando os algoritmos de plastificação mais demorados e envolvendo o cálculo de fenômenos viscosos. Estas restrições serão retomadas e mais detalhadas no Capítulo IV. 


\section{Capítulo IV}

\section{RESULTADOS E DISCUSSÕES}

De acordo com a bibliografia contida no presente trabalho, verifica-se que a quantidade de parâmetros experimentais a serem investigados para os modelos de material para espumas poliméricas vão além daqueles obtidos em um simples ensaio de compressão ou tração uniaxial. A identificação da superfície de escoamento e a influência de cada um dos parâmetros requerem uma comparação detalhada dos dados experimentais com as respectivas variáveis.

Somente com ensaios experimentais e modelagens numéricas é possível determinar se os modelos de material investigados, com seus respectivos parâmetros e hipóteses de implementação, são capazes de representar satisfatoriamente o comportamento mecânico da espuma polimérica em questão. Também se identificam quais são as novas hipóteses para o uso desse modelo, caso uma aplicação direta não seja possível devido às características do material não serem representadas pelo modelo escolhido, como por exemplo, a anisotropia da espuma polimérica.

\subsection{Resultados Experimentais}

Como discutido anteriormente, as espumas poliméricas de baixa densidade $\rho$ e baixa densidade relativa $\bar{\rho}$ (eq. (1)) exibem um comportamento macroscópico com características viscosas (referentes ao escoamento ou expulsão dos gases no interior das células associados aos mecanismos de falha micromecânicos (GIBSON; ASHBY, 1988)) e com isso uma dada sensibilidade a diferentes taxas de deformações é esperada. Todavia, essa sensibilidade deve ser investigada com cuidado, pois esta pode variar com o tipo de material e com a estrutura celular em questão, bem como com a faixa de variação da taxa de deformação. 
Para garantir a não influência desses efeitos viscosos nos resultados, os ensaios para identificação de parâmetros foram realizados com baixas taxas de deformação em torno de $10^{3} \mathrm{~s}^{-1}$ ou menores, tratando-se assim, de ensaios quase estáticos. Porém, alguns ensaios foram realizados para verificar a sensibilidade do material com as taxas de deformação possíveis de serem aplicadas pelo equipamento de ensaio disponível como mencionado na metodologia descrita.

A calibração dos modelos fenomenológicos (49) e (87) requerem que o usuário realize ao menos dois ensaios para obter os parâmetros necessários. Um ensaio de compressão uniaxial e um ensaio de compressão hidrostática, para que sejam calculados ou estimados os valores dos parâmetros $k$ e $k_{t}$, bem como a dependência da tensão plástica equivalente com a deformação plástica equivalente. Evitando fazer estimativas para os parâmetros supracitados, o presente trabalho utiliza artifícios matemáticos para obter a mesma superfície de escoamento inicial definida por $k$ e $k_{t}$ através de outro dado adicional, proveniente de um ensaio de tração uniaxial ou somente com tensões desviadoras. Portanto, a determinação da superfície (87) consiste na solução de um sistema não-linear de 3 equações e 3 incógnitas (Apêndice A).

Todavia, como comentado na metodologia, os ensaios de cisalhamento puro não foram realizados e os ensaios hidrostáticos geraram poucos dados quantitativos consistentes, porém foram suficientes para a determinação da superfície (87). Além das dificuldades técnicas, um fator que contribuiu para a não realização dos ensaios de cisalhamento puro foi uma grande anisotropia do material identificada nos ensaios uniaxiais. Uma vez que o modelo de material em questão (equação (49) ou (87)) considera que o material é isotrópico, o uso desse modelo requer uma calibração cautelosa que, em um primeiro momento não requer os dados de todos os ensaios propostos para as duas direções de anisotropia identificada (normal e no plano). Ainda assim, o presente trabalho analisa alguns valores da literatura para as tensões de escoamento e/ou resistência do material sob solicitação de cisalhamento puro, com o intuito de investigar a sensibilidade do modelo fenomenológico estudado em função da intensidade da anisotropia verificada.

Por fim, os ensaios de endentação realizados têm a finalidade de avaliar os modelos de material calibrados com os dados dos demais ensaios. Esses ensaios serão discutidos em detalhes nas seções seguintes junto com a avaliação computacional do modelo de material que foi calibrado com os ensaios de tração e compressão.

É importante lembrar que sob carregamentos de compressão ou deformações localizadas, a espuma polimérica apresenta uma grande variação de volume e as deformações 
plásticas iniciadas e propagadas com a frente de plastificação, tem origem em posições aleatórias no material. Isso torna não recomendável o uso de extensômetros convencionais. Por isso, o uso de uma técnica de correlação de imagens (DIC) foi uma alternativa para se determinar o coeficiente de Poisson e os campos de deformação no material nos ensaios de tração uniaxial, compressão uniaxial e endentação.

A seguir são apresentados os detalhes dos resultados dos ensaios realizados através da "metodologia clássica" com o uso de instrumentos da máquina de ensaios, e através da técnica DIC via programa Correli ${ }^{\mathrm{LMT}}$. Para cada tipo de ensaio, são descritas as respectivas considerações e formulações.

\subsubsection{Cálculo das Tensões e Deformações para a Espuma Polimérica}

Através do equipamento, exibido anteriormente na Figura 18 (Capítulo III), foram coletados dados de força, deslocamento e tempo para todos os corpos-de-prova ensaiados. A utilização desses dados em modelos computacionais requer uma breve revisão sobre conceitos e definições das grandezas tensão e deformação.

O rigor matemático presente nas implementações computacionais requer o uso de grandezas tensoriais e nem sempre as grandezas coletadas nos ensaios são representadas como tensores. No cálculo do trabalho interno da estrutura, utilizam-se tensores de tensão e deformação conjugados. Para a deformação é usual escolher o tensor de deformações de Green-Lagrange $\boldsymbol{E}$ e para a tensão, o Segundo tensor de tensão de Piola-Kirchhoff $\boldsymbol{S}$. Estas grandezas definem o trabalho interno virtual do material $W_{\text {int }}$ como:

$$
W_{\text {int }}=\int \boldsymbol{S}^{T}: \delta \boldsymbol{E}_{v} d V_{0}
$$

onde $V_{0}$ é o volume inicial do material. A expressão acima é uma das formas matemáticas usadas nas implementações, contudo o uso do tensor $\boldsymbol{E}$ torna a interpretação dos resultados experimentais e computacionais um tanto difíceis pois essas deformações estão escritas em relação ao sistema de coordenadas inicial. O tensor de deformação de Green-Lagrange é dado por: 


$$
\boldsymbol{E}=\frac{1}{2}\left(\boldsymbol{D}+\boldsymbol{D}^{T}\right)+\frac{1}{2} \boldsymbol{D}^{T} \boldsymbol{D}
$$

onde $\boldsymbol{D}=\partial \boldsymbol{u} / \partial \boldsymbol{X}, \boldsymbol{u}$ é o deslocamento interno real do material e o vetor $\boldsymbol{X}$ faz referência ao sistema de coordenadas inicial.

Todavia, os dados práticos estão quase sempre no sistema de coordenadas atual, o sistema em que o material está deformado, e por isso o uso de um tensor no sistema de coordenadas atual é mais prático e utilizado na calibração de modelos matemáticos.

A grandeza de deformação mais corrente é a deformação Logarítmica $\varepsilon_{l o g}$, que pode ser calculada a partir da deformação nominal, ou de engenharia $\varepsilon_{n}$. Para o problema unidimensional, estas deformações têm a forma:

$$
\begin{gathered}
\varepsilon_{n}=\frac{l-l_{0}}{l_{0}} \\
\varepsilon_{\log }=\ln \left(\varepsilon_{n}+1\right)
\end{gathered}
$$

sendo $l$ o comprimento atual do material e $l_{0}$ o comprimento inicial. Portanto, para um meio contínuo um incremento de deformação Logarítmica virtual obtém-se:

$$
\delta \boldsymbol{\varepsilon}_{\log }=\frac{1}{2}\left[\frac{\partial \delta \boldsymbol{u}_{v}}{\partial \boldsymbol{x}}+\frac{\partial \delta \boldsymbol{u}_{v}^{T}}{\partial \boldsymbol{x}}\right]
$$

onde o vetor $\boldsymbol{x}$ faz referência ao sistema de coordenadas atual e $\boldsymbol{u}_{v}$ é o campo de deslocamento virtual interno. Estes incrementos em modelagens matemáticas podem ser interpretados como incrementos lineares de deformação no sistema de coordenadas atual e, portanto, não requerem um rigor tensorial. Por isso, essa deformação deve ser acoplada com uma grandeza de tensão correspondente. Uma solução é utilizar a tensão verdadeira ou tensão de Cauchy $\sigma_{c}$, que é relacionada com o segundo tensor de tensão de Piola-Kirchhoff por:

$$
\sigma_{c}=\frac{1}{\operatorname{det}(\boldsymbol{F})} \boldsymbol{F} \boldsymbol{S}^{T}
$$

onde $\boldsymbol{F}=\partial \boldsymbol{x} / \partial \boldsymbol{X}$. Assim, a equação (100) tem uma forma equivalente dada por: 


$$
W_{\text {int }}=\int \boldsymbol{S}^{T}: \delta \boldsymbol{E}_{v} d V_{0}=\int \boldsymbol{\sigma}_{c}: \delta \boldsymbol{\varepsilon}_{v} d V
$$

onde $V$ é calculado por:

$$
d V=J d V_{0}=\operatorname{det}(\boldsymbol{F}) d V_{0}
$$

sendo $J$ conhecido como Jacobiano.

Após explicitar o rigor matemático das grandezas envolvidas, segue-se com o cálculo das tensões e deformação a partir das curvas carga-deslocamento obtidas nos ensaios mecânicos.

A tensão de Cauchy é obtida experimentalmente dividindo o módulo da força aplicada $\boldsymbol{P}$, pela área atual da seção do corpo-de-prova em análise.

$$
\sigma_{c}=\frac{P}{A}=\frac{P}{A\left(v ; l ; l_{0}\right)}
$$

onde $v$ é o coeficiente de Poisson em questão que pode ser elástico ou plástico. Com a devida abordagem matemática, a expressão (108) é reescrita para um ensaio uniaxial típico como:

$$
\sigma_{c}=\frac{P}{A_{0}}\left(\frac{l}{l_{0}}\right)^{2 v}
$$

Normalmente, para o regime elástico da maioria dos materiais, especialmente aços, a deformação elástica é muito reduzida, e por isso desconsidera-se a variação de volume e adota-se $v=0$ em (109). Vale lembrar que tal procedimento é válido para aplicações que não requerem elevada precisão ou que abordem o regime plástico do material.

Contrariamente, no regime plástico, adota-se, por exemplo, que os metais possuem coeficiente de Poisson igual a $1 / 2$, pois se assume que os mesmos não apresentam variação de volume durante a fase plástica, haja vista, que os mecanismos de plastificação deve-se a ação de tensões desviadoras.

Nos ensaios da espuma polimérica H60 do presente trabalho, a identificação do coeficiente de Poisson foi feita através da técnica DIC comentada na metodologia deste trabalho. A técnica identificou diferentes níveis de variação do coeficiente de Poisson com o nível de deformação Logarítmica do material de acordo com a direção de anisotropia e do tipo de ensaio, tração ou compressão. 
Na sequência são mostradas quatro curvas, referentes a ensaios distintos, que exibem a variação do coeficiente de Poisson. As duas primeiras curvas na Figura 28, representam os ensaios de compressão uniaxial para a direção normal e para a direção no plano.
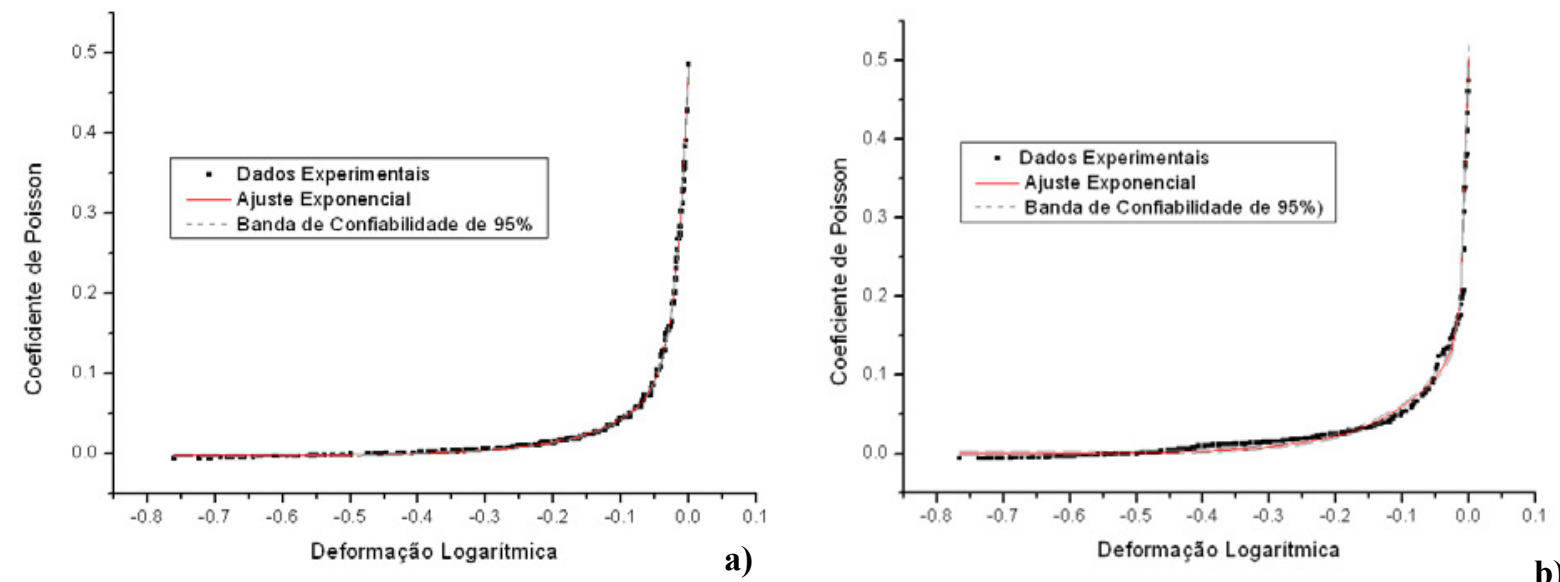

Figura 28. Variação do coeficiente de Poisson com deformação Logarítmica para os ensaios de compressão uniaxial: a) direção normal 3; b) direção no plano 1-2
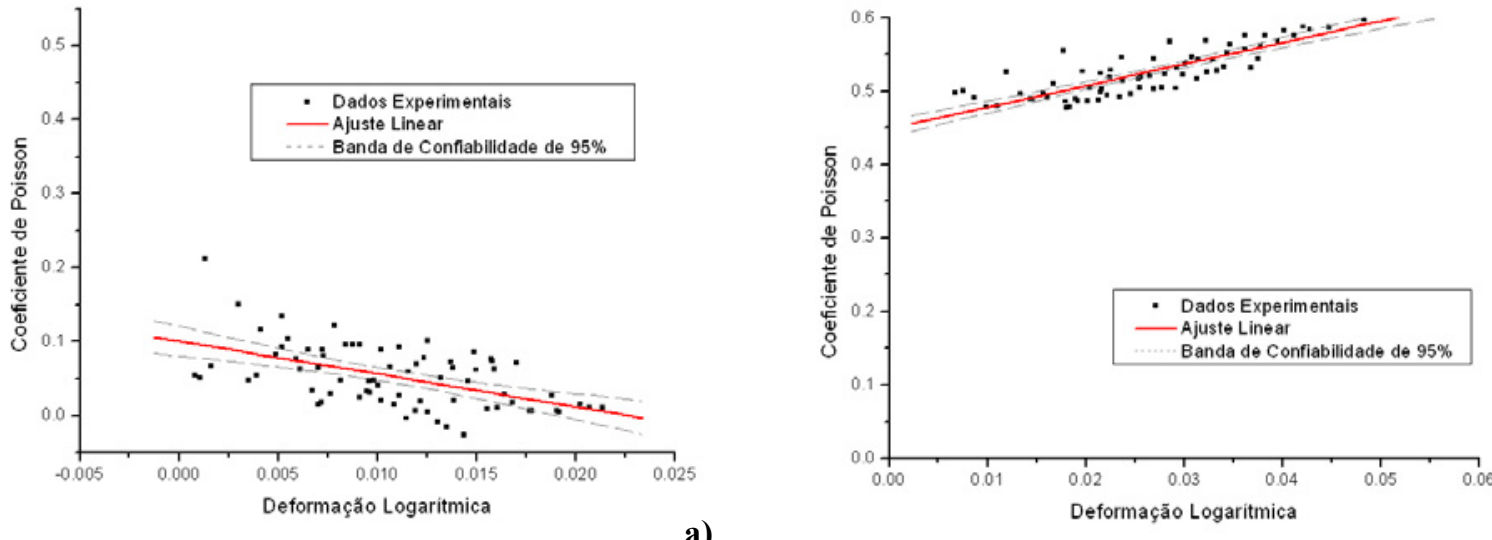

a)

Figura 29. Variação do coeficiente de Poisson com deformação Logarítmica para os ensaios de tração uniaxial: a) direção normal 3; b) direção no plano 1-2

Nas curvas da Figura 28 (para a direção normal e para uma direção no plano) observase um comportamento muito próximo do coeficiente de Poisson e praticamente independente da anisotropia do material. É verificado que sob compressão o parâmetro em questão tende a zero com o colapso das células umas sobre as outras, preenchendo assim, os espaços vazios e mantendo praticamente inalterada a área da seção analisada. Todavia, mesmo com uma resposta seguindo um decaimento exponencial, o coeficiente de Poisson varia significativamente até $20 \%$ de deformação. A partir desse ponto a variação relativa do coeficiente de Poisson é pequena. Isso indica que, diferentemente da implementação apresentada no Capítulo III, o coeficiente de Poisson plástico não é nulo para todo o regime 
de deformação plástica do material. Entretanto, ciente das complicações para uma implementação de tal variação, a aproximação de que $v=0$ será investigada e explorada nesse trabalho.

Enquanto a anisotropia do material não altera de modo significativo a variação do coeficiente de Poisson sob carregamentos de compressão, tem-se que em tração, essa anisotropia tem influência acentuada. Sob compressão não há diferença entre as direções de carregamento, pois neste caso, a espuma sofre grandes deformações e para o respectivo nível de tensão, o material apresenta colapso em regime elasto-plástico. Sendo que o referido fenômeno envolve mais de um plano do CDP, e os resultados são similares.

Analisando as outras duas curvas na Figura 29, observa-se que para a direção normal (Fig. 29a), o coeficiente de Poisson em tração tende a um valor próximo de zero. Por outro lado, na direção 1(2), na Figura 29b, o coeficiente de Poisson tem comportamento inverso e oscila em torno de 1/2 com uma resposta ascendente até o rompimento do corpo-de-prova.

Deve-se lembrar que o material em questão é transversalmente isotrópico, logo, para materiais não hiperelásticos, alguns dos coeficientes de Poisson podem ser superiores à 1/2 desde que essa deformação excessiva seja compensada em outra direção. Vale ressaltar que esta anisotropia será detalhada em tópicos seguintes, mas de modo geral, observou-se que o material é quase duas vezes mais resistente na direção normal 3 em relação às direções contidas no plano 1-2. É exatamente a influência dessa diferença que se observa na Figura 29. Na direção 3, o carregamento de tração gera um coeficiente de Poisson $v_{31}$ que tende a zero, pois além de mais frágil, o material tem uma flexibilidade nas direções do plano 1-2 maior que na direção 3. Dessa forma, a estricção esperada nos ensaios de tração é minimizada ao longo do ensaio, pois a tensão induzida no plano é muito pequena para diminuir a área de seção mínima dos corpos-de-prova. Enquanto a deformação no plano 1-2 permanece reduzida, a deformação na direção 3 aumenta, e, no limite, tem-se um coeficiente de Poisson plástico quase nulo (eq. (110)).

$$
v_{31}=-\frac{\varepsilon_{11}}{\varepsilon_{33}} \rightarrow 0
$$

Por outro lado, na direção 1 ou 2 do plano, o respectivo coeficiente de Poisson $v_{21}$ tende à $1 / 2$, pois o material é mais homogêneo e ao mesmo tempo frágil. Assim, o coeficiente de Poisson plástico tende a um valor próximo ao do polímero base, no caso o PVC. Uma vez que os polímeros são muito sensíveis ao cisalhamento (alguns modelos de material empregam 
até o terceiro tensor desviador de tensão $J_{3}$ para contabilizar o escoamento de polímeros com maior precisão, GHORBEL, 2008), assume-se que o coeficiente de Poisson plástico tende a um valor próximo de $1 / 2$, pois seria o valor para materiais isotrópicos que escoam sob o critério de von Mises. O aumento desse valor é esperado, pois, haja vista que o material é anisotrópico. Quando se carrega o material na direção 1(2), a direção 3 alinhada com a espessura da placa base compõe a área da seção ensaiada juntamente com a outra direção 2(1) do material. Nesta condição de ensaio, o material tem uma estricção maior que o esperado no plano 1-2, pois o material não é isotrópico. Essa estricção resulta em grandes valores de $v_{2 l}$, como os observados na Figura 29b, compensando o fato de que a espuma praticamente não se deforma na direção normal 3 para a tração em uma direção no plano 1-2. Assim, mesmo com um coeficiente de Poisson plástico atribuído igual a $1 / 2$, os resultados obtidos não violam nenhum Princípio Termodinâmico e esse valor $1 / 2$ também não caracteriza um regime hiperelástico. $\mathrm{Na}$ verdade, existe apenas um equilíbrio atualizado das tensões no material anisotrópico que faz com que o coeficiente de Poisson para um carregamento na direção $3\left(v_{31}\right.$ ou $\left.v_{32}\right)$ tenda a zero enquanto os coeficientes para o plano $\left(v_{21}\right.$ ou $\left.v_{12}\right)$ aumentam (eq. (111)).

$$
v_{21}=-\frac{\varepsilon_{11}}{\varepsilon_{22}} \rightarrow \geq \frac{1}{2}
$$

Quantificados os coeficientes de Poisson para o material, calcula-se então a expressão com a qual são construídos os gráficos de tensão-deformação a partir das curvas cargadeslocamento. A deformação escolhida é a Logarítmica (eq. (103)) devido à implementação do modelo de material e às vantagens discutidas anteriormente. Os valores para a tensão são dados pela tensão de Cauchy (eq. (109)). Com base no texto supracitado sobre os coeficientes de Poisson para o material em compressão e tração, tem-se que os mesmos são calculados separadamente. Para compressão adota-se, por motivos práticos, que o coeficiente de Poisson do material seja próximo de zero, logo:

$$
\sigma_{c}=\frac{P}{A_{0}}\left(\frac{l}{l_{0}}\right)^{2 v} \approx \frac{P}{A_{0}}\left(\frac{l}{l_{0}}\right)^{0}=\frac{P}{A_{0}}
$$

Em tração, observou-se um valor quase zero para o coeficiente de Poisson plástico para um carregamento na direção normal 3, e um valor que oscila em torno de $1 / 2$ e eventualmente aumenta durante a tração do material em uma das direções contidas no plano 
1-2. Contudo, as deformações, independente do plano, são pequenas, logo, $l / l_{0} \rightarrow 1$ e a tensão de Cauchy novamente tende a:

$$
\sigma_{c}=\frac{P}{A_{0}}\left(\frac{l}{l_{0}}\right)^{2 v} \approx \frac{P}{A_{0}} 1^{2 v}=\frac{P}{A_{0}}
$$

Vale ressaltar que para aplicações de alta precisão, as aproximações acima precisam ser reavaliadas, mas dado a irregularidade da estrutura celular das espumas poliméricas, dificilmente este tipo de material será aplicado sob critérios de alta precisão. Para isso é necessário um alto controle do processo de fabricação que pode tornar o uso desses materiais não mais vantajoso.

Assim, com o uso das equações (112) e (113), as tensões e deformações para cada tipo de ensaio realizado são apresentadas e discutidas nas respectivas seções separando os dados de acordo com o modo de obtenção das deformações (via célula de carga ou via técnica DIC).

\subsubsection{Dados Experimentais via Normas}

Nas três próximas subseções são apresentados os ensaios de compressão uniaxial, tração uniaxial e endentação. Para os ensaios de compressão e de tração são exibidas curvas de tensão-deformação, enquanto que para a endentação as curvas são apresentadas como força-deslocamento, pois este ensaio tem propósito de avaliação do emprego do modelo de material em questão que foi calibrado com os demais dados experimentais. No entanto, os ensaios de endentação visam principalmente avaliar as limitações e potencialidades do modelo de material implementado.

\subsubsection{Compressão Uniaxial}

Nesta seção são apresentados todos os resultados dos ensaios de compressão na direção 3 normal ao plano e para uma direção no plano 1-2. Como mencionado na metodologia, foram realizados ensaios cíclicos e monotônicos para identificar o comportamento do material sob descarregamento, bem como avaliar possíveis efeitos viscosos. Dessa forma, foi realizado um breve estudo sobre a sensibilidade do material às 
taxas de deformação para registrar os respectivos padrões de resposta para a espuma rígida H60.

De acordo com a metodologia executada, os gráficos de compressão uniaxial são divididos em cíclicos e monotônicos. Em ambas as direções, sendo que os três primeiros corpos-de-prova foram ensaiados ciclicamente. Ao todo, cinco ciclos completos foram executados para os corpos-de-prova numerados de 1 a 3. Na Figura 30 observa-se 4 ciclos completos, pois o primeiro foi feito no regime linear-elástico do material.

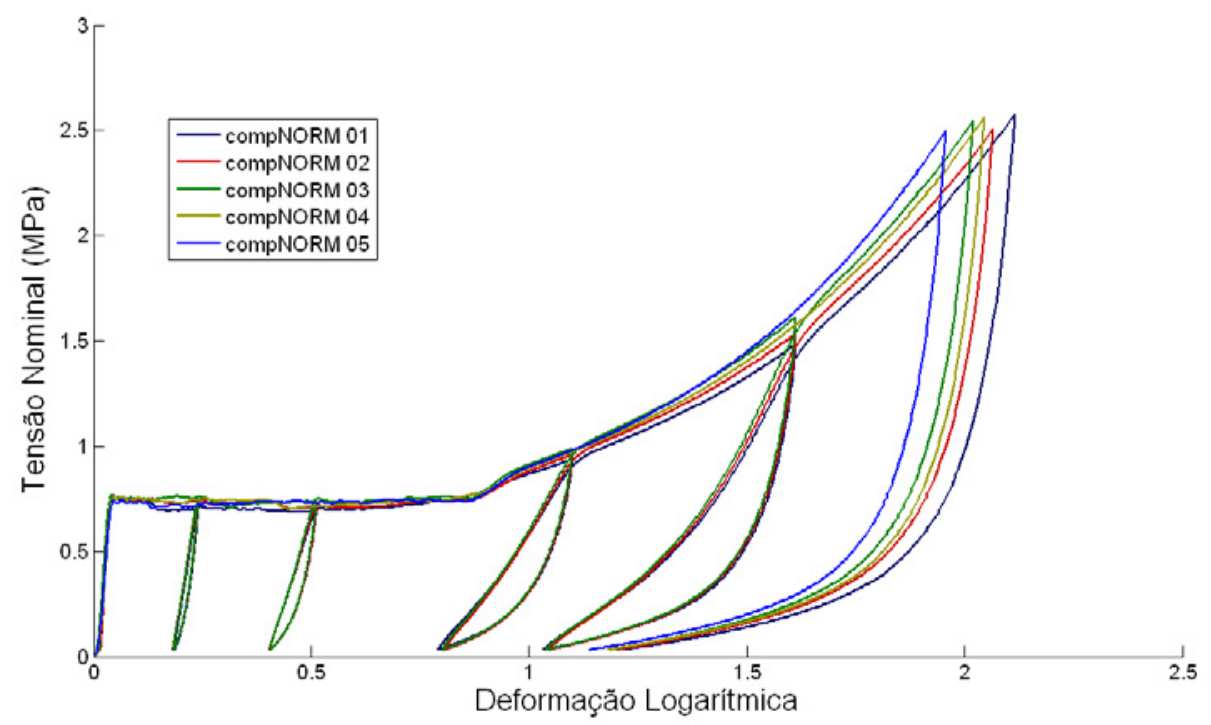

Figura 30. Curvas experimentais para os ensaios de compressão uniaxial na direção normal 3

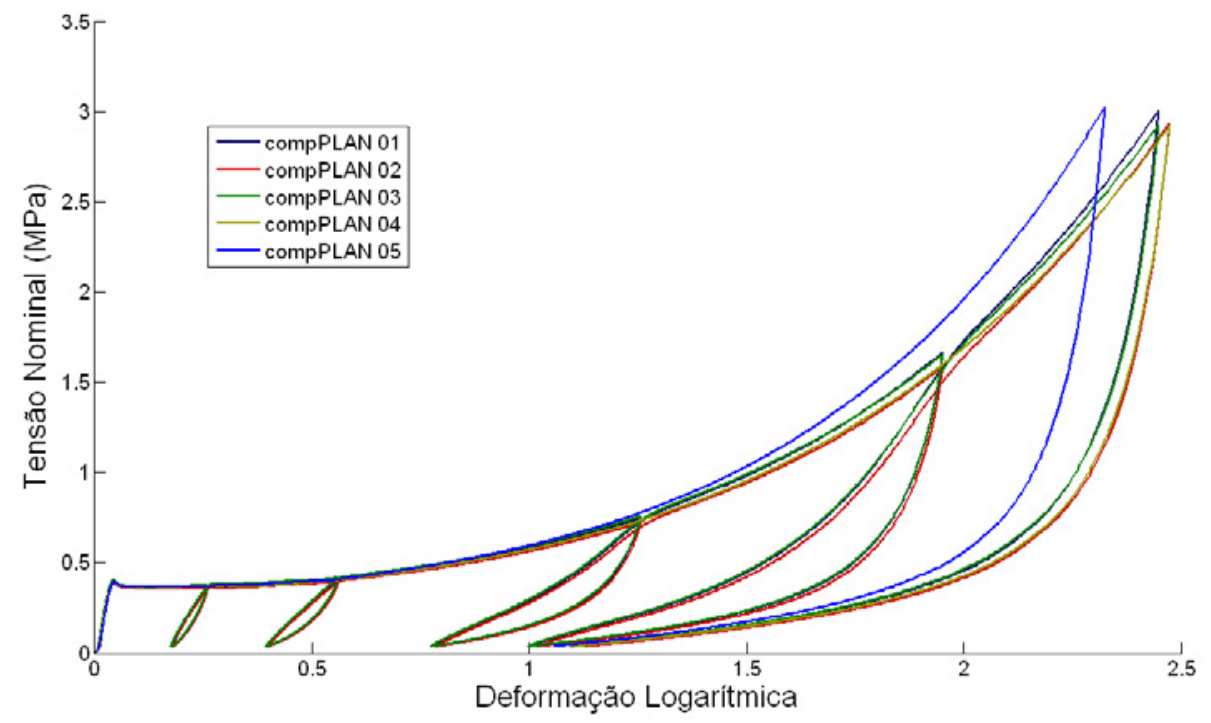

Figura 31. Curvas experimentais para os ensaios de compressão uniaxial para uma direção no plano 1-2

É possível constatar na Figura 30 a densificação do material para níveis de deformação logarítmica acima de $80 \%$. Como visto na bibliografia, esse fenômeno corresponde ao colapso 
elástico e plástico das células que ocupam os espaços vazios das células rompidas. Dos gráficos da figura 30 , também se conclui que o efeito da viscosidade aumenta com a deformação (vide Apêndice B). Isso ocorre, pois quanto maior é o nível de deformação, um maior volume de ar é expelido através das células danificadas, e o retorno desse ar associado com a instabilidade das células flambadas, aumenta a viscosidade aparente do material. Tal fenômeno é mais pronunciado para uma direção no plano 1-2, haja vista que a espuma é mais flexível e homogênea no plano 1-2. As curvas de compressão uniaxial obtidas para a direção no plano estão evidenciadas na figura 31 .

Os efeitos viscosos não são contabilizados no presente trabalho, pois a implementação dessa variável incrementa razoavelmente o nível de complexidade da formulação, adicionando um volume de dados experimentais considerável. Além disso, as formulações implementadas que serão calibradas e avaliadas não contemplam efeitos viscosos. Todavia, esses efeitos serão discutidos ao longo do desenvolvimento do presente trabalho. Ademais, das Figuras 30 e 31 conclui-se que para deformações até $50 \%$, a não inclusão dos efeitos viscosos, não resulta em alterações significativas no descarregamento ou relaxação do material. A partir de 50\% de deformação, tal simplificação precisa ser reavaliada.

De acordo com a norma ASTM D1621-04a, a tensão de escoamento para a espuma polimérica rígida é definida de duas maneiras. Na primeira, para materiais que apresentam na sua resposta um pico de tensão imediatamente após o regime linear elástico; a esse pico atribui-se o valor da tensão de escoamento. Caso não exista a formação desse pico, uma segunda abordagem é escolhida, tomando-se um valor de tensão correspondente a $10 \%$ de deformação absoluta como sendo a tensão de escoamento.

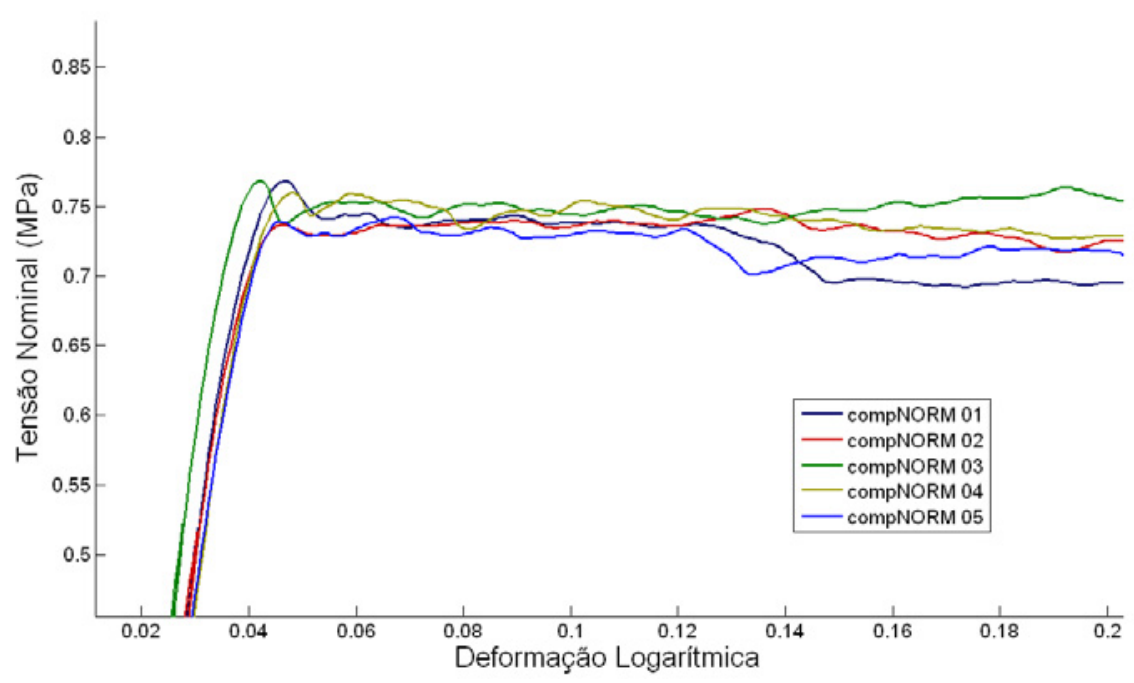

Figura 32. Identificação da tensão de escoamento para a direção normal 
Ao analisar as Figuras 32 e 33, verifica-se uma formação de picos mais consistentes para uma direção no plano 1-2 dado sua maior homogeneidade. Para a direção normal, a maior irregularidade das células impossibilita a identificação dos picos de tensão para todos os corpos-de-prova ensaiados o que implica na determinação das tensões de escoamento pelo segundo método.

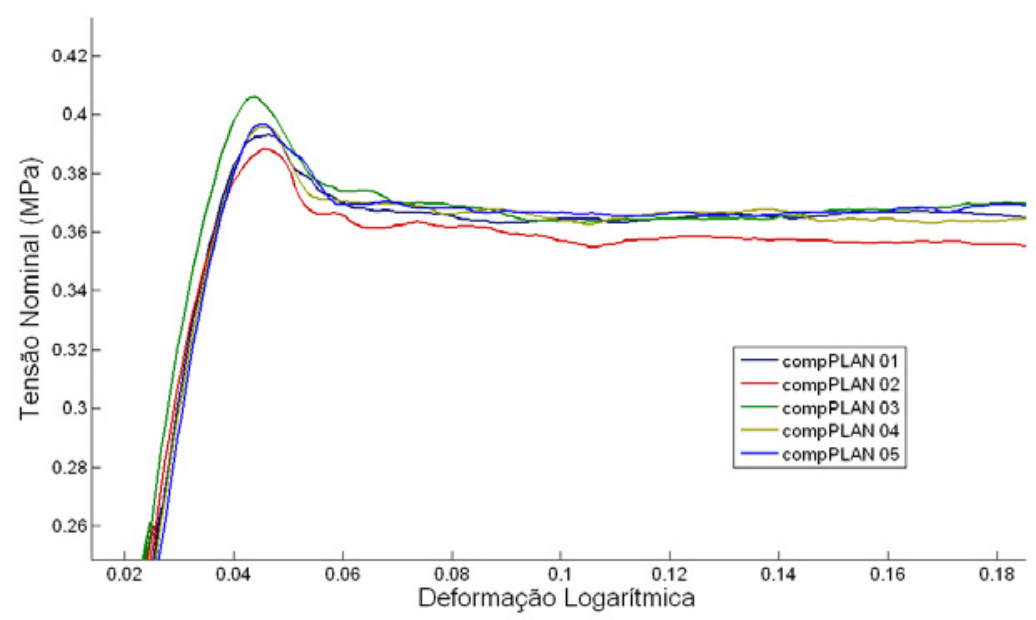

Figura 33. Identificação da tensão de escoamento para uma direção no plano

Para quantificar a anisotropia do material e calibrar modelos numéricos, são exibidas na Tabela 10 as tensões de escoamento, e os erros estatísticos, de acordo com os dois métodos apresentados na norma ASTM D1621-04a para ambas as direções da espuma H60.

Tabela 10 - Tensões médias de escoamento em compressão uniaxial para a espuma polimérica rígida $\mathrm{H60}$

\begin{tabular}{|c|c|c|c|}
\hline Propriedade & Metodologia & Direção Normal & Direção no Plano \\
\hline Tensão de Escoamento $\left(\sigma_{\mathrm{y}}\right)$ & Pico & $0.75 \pm 0.02 \mathrm{MPa}$ & $0.396 \pm 0.006 \mathrm{MPa}$ \\
\hline Tensão de Escoamento $\left(\sigma_{\mathrm{y}}\right)$ & $10 \%$ de deformação total & $0.740 \pm 0.007 \mathrm{MPa}$ & $0.363 \pm 0.004 \mathrm{MPa}$ \\
\hline
\end{tabular}

Com base nas tensões de pico, calcula-se a razão entre tensão no plano e a tensão na direção normal, obtendo um valor de aproximadamente 52\%. Valor este bem acima dos $20 \%$ encontrado por Deshpande e Fleck (2001) quando investigaram as espumas poliméricas H100 e H200 do mesmo fabricante com densidades de 100 e $200 \mathrm{~kg} / \mathrm{m}^{3}$, respectivamente. Estes autores, apesar de identificar a anisotropia do material, focaram seu estudo nos dados obtidos para a direção normal. Acredita-se que espumas poliméricas mais densas, estas sofram menor influência da gravidade em seu processo de fabricação, logo quanto mais denso o material menor o seu grau de anisotropia. 
Discutindo um pouco mais as Figuras 32 e 33, observa-se que formação dos picos de tensão está associada à formação das frentes de plastificação (Fig. 10). Uma vez que a tensão do material atinge o valor máximo, uma seção do material entra em colapso elasto-plástico formando as frentes de plastificação. Foi observado durante os ensaios de compressão, que, diferentemente de Li e Mines (2002), a frente de plastificação é formada logo após a tensão de pico do material e não ocorre sempre na mesma região do corpo-de-prova, bem como pode não ser a única durante o ensaio (Fig. 34). Com base na Figura 32, verifica-se a formação dessa primeira frente de plastificação (indicada pelo pico que é formado) e posteriormente outras frentes de plastificação surgem (oscilações no nível de tensão do platô) até que, certo nível de deformação, tais frentes de plastificação se encontram e o material entra em um regime de densificação mais intensa com uma resposta tendendo à rigidez do PVC.
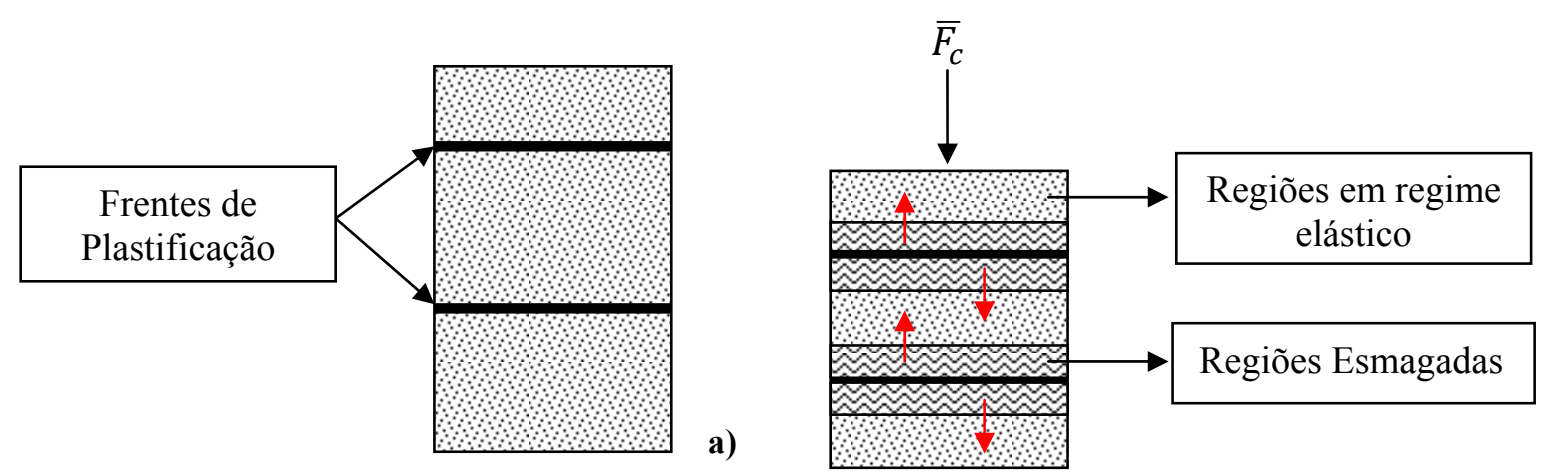

b)

Figura 34. Surgimento e propagação das frentes de plastificação. a) Formação de uma ou mais frentes de plastificação; b) Propagação das frentes de plastificação

O encontro das frentes de plastificação é mais visível nos ensaios para a direção normal, pois dado sua maior irregularidade estrutural, a formação de várias frentes de plastificação em momentos distintos do ensaio é mais frequente que para a direção com maior homogeneidade (plano 1-2). Nas curvas das Figuras 35 e 36, destaca-se o momento em que as frentes de plastificação se encontram. A queda de tensão visualizada, indica o momento em que as últimas seções em regime elástico entram em colapso e flambam, o que ocasiona a diminuição de tensão.

Dessa forma conclui-se que uma contabilização das frentes de plastificação realizadas nos trabalhos de Li e Mines (2002) e de Zenkert, Shipsha e Persson (2004) são pertinentes e assim, podem melhorar a modelagem desses materiais, contudo tais procedimentos podem gerar erros experimentais, pois a identificação das frentes de plastificação nos corpos-deprova é muito irregular. O presente trabalho acredita que uma vez que a formação dessas frentes de plastificação ocorre somente em compressão, a implementação desse fenômeno somente é valida para abordagens analíticas com foco investigativo do comportamento da 
espuma polimérica. A contabilização numérica desse fenômeno requer uma representação realística geométrica e micro-mecânica da espuma polimérica, o que não é vantajoso computacionalmente, pois a análise requereria uma modelagem do material via RVE ou RUC juntamente com uma implementação das irregularidades na estrutura modelada a fim de gerar, e assim representar, as instabilidades a partir das micro-flambagens das estruturas celulares.

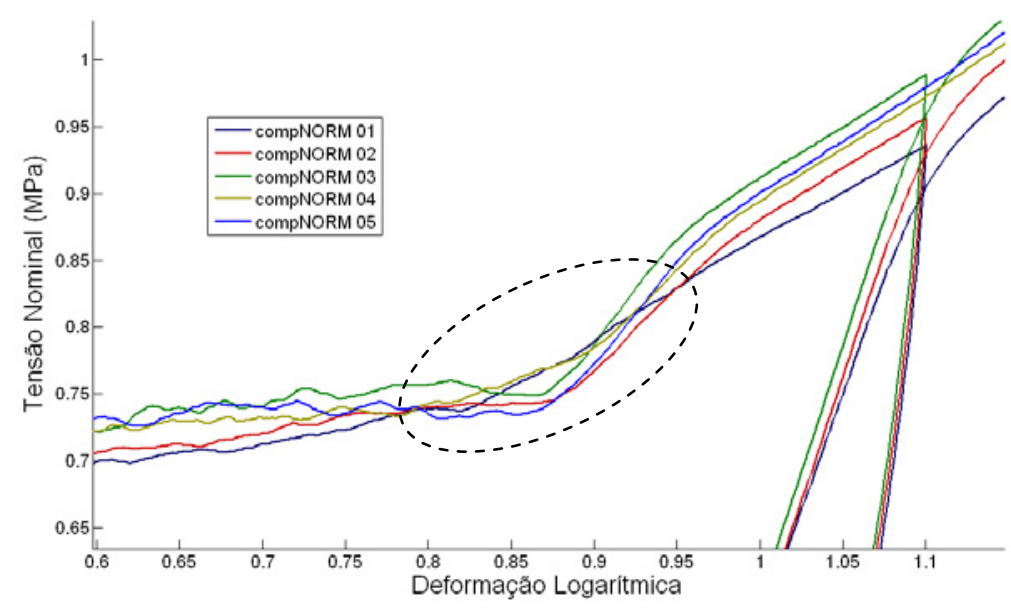

Figura 35. Encontro das frentes de plastificação para os ensaios de compressão na direção normal

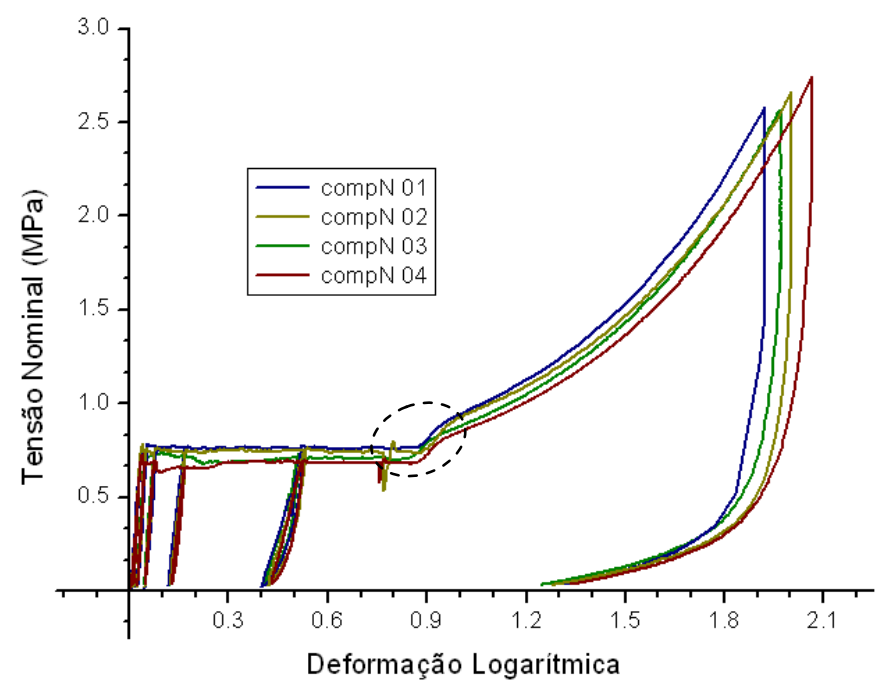

Figura 36. Tensão de escoamento para diferentes taxas de deformação para a direção normal. Em destaque vê-se a influência do encontro das frentes de plastificação

Em análises numéricas uma contabilização indireta e parcial desse fenômeno seria a implementação da viscosidade e, portanto, da sensibilidade a taxas de deformação da estrutura celular. Os efeitos viscosos discutidos anteriormente não estão implementados no modelo em análise, assim, não será avaliada a sensibilidade do material em função de taxas de deformação. Além disso, como visto na bibliografia estudada, a viscosidade deve ser implementada caso o usuário souber qual a faixa de variação das possíveis taxas de 
deformação sob as quais o material estará submetido em serviço. Ademais, ambos os ensaios quase estáticos e de impacto (altas velocidades) podem ser necessários para garantir o comportamento do material em toda faixa de aplicação. Sendo assim, extrapolações devem ser feitas com muita cautela.

A investigação sobre a sensibilidade do material sob diferentes taxas de deformação proposta para o presente trabalho é feita a partir das curvas mostradas na Figura 36.

Nas curvas da Figura 36, observa-se vários ciclos de carregamento e descarregamento para os diferentes níveis de tensão de escoamento para os quatro corpos-de-prova ensaiados. De acordo com a velocidade, o material apresenta diferentes taxas de deformação "média" e tensões de escoamento que estão na Tabela 11, com os erros estatíticos. Os valores foram calculados a partir de regressões lineares do nível de tensão do platô até $50 \%$ de deformação, enquanto as taxas foram obtidas de regressões lineares das curvas de deformação-tempo discutidas no Apêndice B.

Tabela 11 - Variação da Tensão de escoamento com as taxas de deformação calculadas

\begin{tabular}{|c|c|c|c|}
\hline $\begin{array}{c}\text { Corpo-de- } \\
\text { prova }\end{array}$ & Taxa de Deslocamento & Taxa de Deformação & Tensão de Escoamento \\
\hline 01 & $25 \mathrm{~mm} / \mathrm{min}$ & $1.82 \pm 0.02 \mathrm{E}-2 / \mathrm{s}$ & $0.765 \pm 0.001 \mathrm{MPa}$ \\
\hline 02 & $5 \mathrm{~mm} / \mathrm{min}$ & $3.92 \pm 0.03 \mathrm{E}-3 / \mathrm{s}$ & $0.746 \pm 0.001 \mathrm{MPa}$ \\
\hline 03 & $1 \mathrm{~mm} / \mathrm{min}$ & $7.28 \pm 0.02 \mathrm{E}-4 / \mathrm{s}$ & $0.705 \pm 0.001 \mathrm{MPa}$ \\
\hline 04 & $0.1 \mathrm{~mm} / \mathrm{min}$ & $7.94 \pm 0.02 \mathrm{E}-5 / \mathrm{s}$ & $0.672 \pm 0.001 \mathrm{MPa}$ \\
\hline
\end{tabular}

Um ajuste desses dados experimentais, semelhante ao apresentado no trabalho de $\mathrm{Li}$, Mines e Birch (2000), resulta na curva da Figura 37 e na expressão (114) apresentados a seguir.

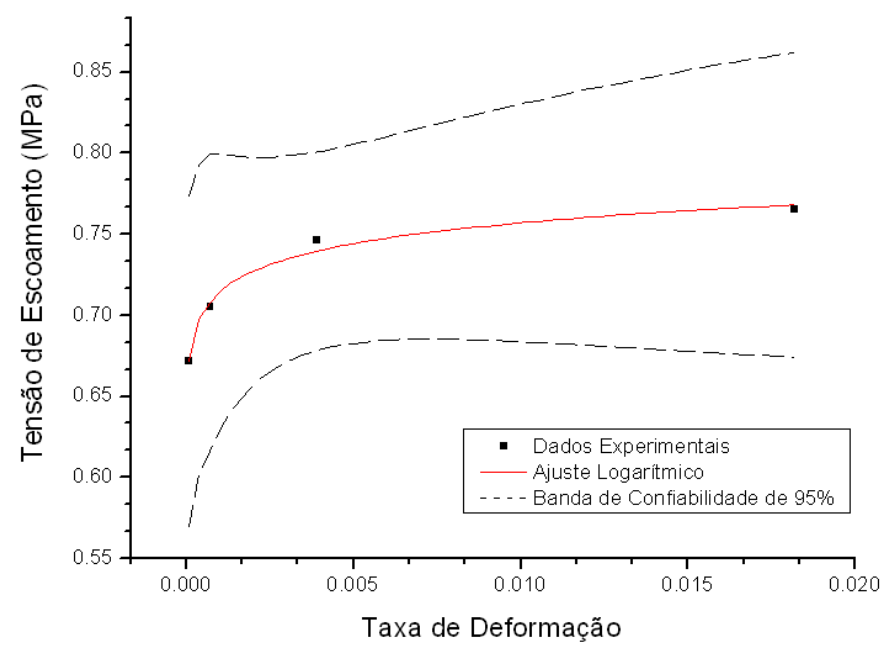

Figura 37. Ajuste exponencial para a variação da tensão de escoamento na direção normal com a taxa de deformação 
Novamente com base no trabalho de Ouellet, Cronin e Worswick (2006), supõe-se que o limite de para o qual tende a exponencial da expressão (114) seja prolongado por uma extensa faixa de taxa de deformação, voltando a aumentar sob altas taxas (igual ou superior a 500/s). Para estas taxas elevadas, a velocidade de carregamento é tão elevada (impacto) que a densificação do material dar-se-á muito rapidamente, quase de modo instantâneo, o que altera as tensões de escoamento de modo significativo.

Um último dado qualitativo obtido das compressões uniaxiais foi o comportamento global da estrutura celular referente ao colapso do material por flambagem. Assim como observado por Gong e Kyriakides e Jang (2005), a anisotropia do material também influência o colapso da espuma, fazendo com que as flambagens macroscópicas da estrutura ocorram com maior frequência para os ensaios na direção normal. Para uma direção no plano, não foi observado o fenômeno de flambagem global em nenhum dos ensaios realizados no presente trabalho, mostrando assim, um comportamento coerente com o observado por Gong e Kyriakides e Jang (2005). Na Figura 38, há uma foto de um corpo-de-prova comprimido na direção normal e o mesmo corpo-de-prova rotacionado, exibindo flambagem global no plano $3-2$
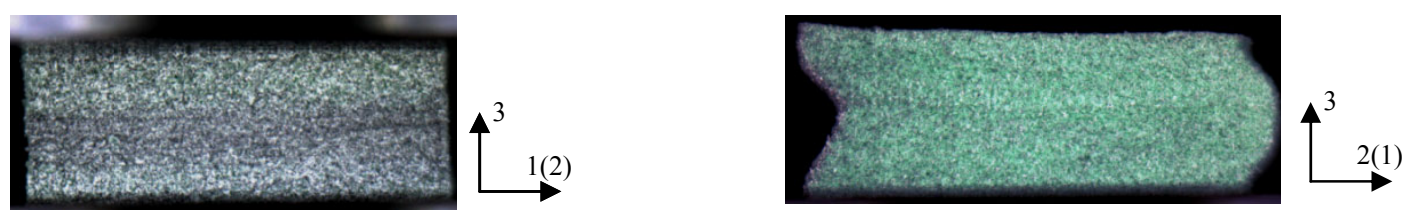

Figura 38. Flambagem macroscópica da espuma polimérica para a direção normal: a) Plano de um CDP, aparentemente, sem flambagem macroscópica; b) Mesmo CDP rotacionado mostrando a flambagem macroscópica

Explorando alguns artigos revistos no presente trabalho (GONG; KYRIAKIDES; TRIANTAFYLLIDIS, 2005, GONG; KYRIAKIDES; JANG, 2005, GONG; KYRIAKIDES, 2005), vale ressaltar que é possível realizar um procedimento semelhante ao contido nesses trabalhos e quantificar as flambagens macroscópicas e posteriormente aplicar esses resultados em modelos de material micro-mecânicos. 


\subsubsection{Tração Uniaxial}

Sob tração uniaxial, a espuma polimérica rígida H60 apresenta um comportamento mecânico frágil, se comparado ao comportamento sob compressão, que pode ser observado nas Figuras 39 e 40. Nessas figuras os primeiros dois corpos-de-prova representam os ensaios cíclicos. Com exceção do CDP04 para a direção normal ensaiado sob uma taxa de deslocamento de $1 \mathrm{~mm} / \mathrm{min}$, os demais foram ensaiados sob a taxa de $0.2 \mathrm{~mm} / \mathrm{min}$. A variação de resposta observada nos ensaios é atribuída à combinação da irregularidade da estrutura celular da espuma com as variações na geometria dos corpos-de-prova devido a sua usinagem manual juntamente com os erros experimentais advindos do método de fixação dos CDPs ao equipamento de ensaio. Os erros têm grande influência na resposta devido aos baixos níveis de deformação da espuma polimérica rígida em tração.

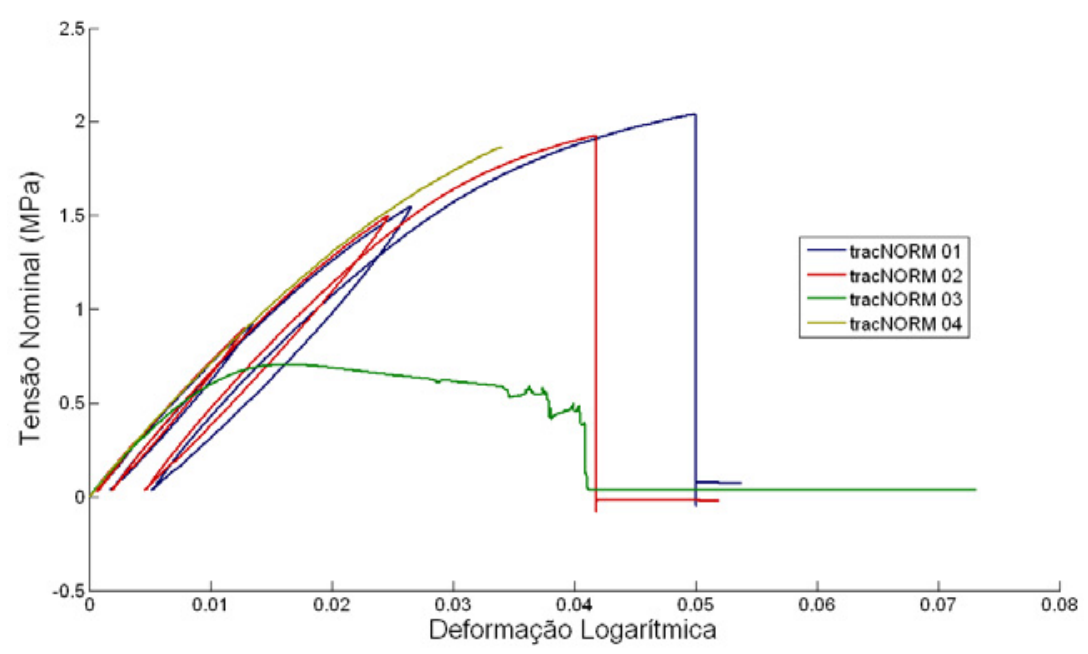

Figura 39. Curvas experimentais para os ensaios de tração uniaxial para a direção normal 3

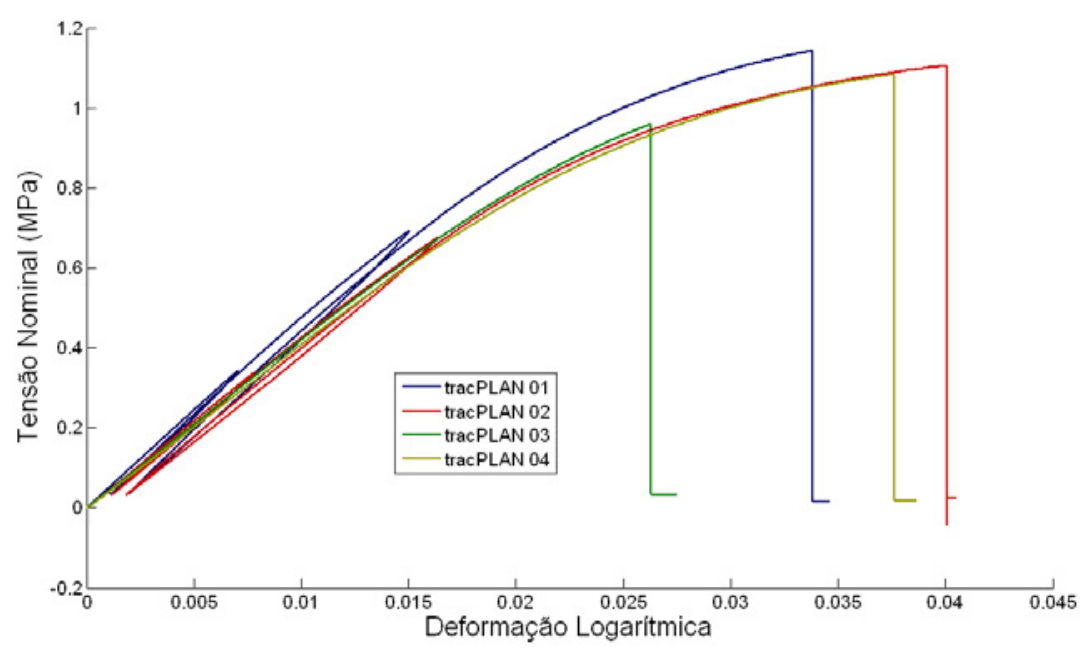

Figura 40. Curvas experimentais para os ensaios de tração uniaxial para uma direção no plano 1-2 
Mais uma vez, verifica-se que a anisotropia não é desprezível. Diferentemente dos ensaios de compressão, a espuma polimérica tem comportamento frágil e por isso a norma consultada ASTM D1623-03 não denota tensões de escoamento, mas apenas instrui o cálculo para as tensões de resistência do material, ou seja, a maior tensão observada no ensaio antes da ruptura do corpo-de-prova. No entanto, é importante rever os conceitos de Plasticidade e lembrar que as Superfícies de Escoamento evoluem e representam os incrementos plásticos. Essas superfícies são definidas através de tensões de escoamento e não através de tensões de resistência. Quando essas superfícies de escoamento são construídas para um material frágil tanto em compressão como em tração, é coerente observar que se trata de uma superfície de falha, definida com base nas tensões de resistência, como mostra o trabalho de Gdoutos, Daniel e Wang (2002). Através de ensaios sob tensões multiaxais e/ou combinadas em espumas poliméricas de PVC (Divinycell H100 e H250), semelhantes à do presente trabalho, estes pesquisadores identificaram a influência da anisotropia na resposta desse material. Para contabilizar as respostas mecânicas, incluindo diferentes resistências em tração e compressão para a direção normal e uma direção do plano, os dados experimentais foram calibrados com base no Critério de Tsai-Wu (eq. (31)), cuja Superfície de Falha mais se aproximou do comportamento da espuma. O critério foi calibrado em tração com tensões de resistência e em compressão com o valor máximo de pico de tensão observado.

Conclui-se, assim, que dependendo da aplicação para a espuma polimérica em questão, podem-se empregar Superfícies de Falha ou Superfícies de Escoamento e sua respectiva Lei de Evolução. Ficam assim diferenciadas as Superfícies de Falha das Superficies de Escoamento para o presente trabalho de acordo com o que foi supracitado.

Independente da abordagem é preciso obter as tensões de resistência e de escoamento do material. O cálculo para as tensões de resistência segue a norma ASTM D1623-03, porém se os conceitos de superfícies de falha são adotados, tem-se que um procedimento de cálculo mais conservador como o descrito por Deshpande e Fleck (2001) se faz necessário. No trabalho destes autores, os valores de resistência foram obtidos através da intersecção de duas retas extrapoladas a partir do limite elástico do material e da tensão de ruptura. Por outro lado, a definição da tensão de escoamento é realizada com base nos ensaios cíclicos para a direção normal (Fig. 39) que também são observados para uma direção do plano, porém com menor intensidade. Verifica-se que o material apresenta deformações permanentes para tensões com deformações acima de $1 \%$ e esta tensão é definida no presente trabalho como a tensão de escoamento em tração, sendo igualmente calculadas para ambas as direções. A Tabela 12 resume os resultados obtidos para os ensaios de tração com os respectivos erros estatísticos. 
Tabela 12 - Tensões médias de escoamento e resistência para os ensaios de tração

\begin{tabular}{|c|c|c|c|}
\hline Propriedade & Metodologia & Direção Normal & Direção no Plano \\
\hline Tensão de Resistência $\left(\sigma_{\mathrm{r}}\right)$ & Norma ASTM D1623-03 & $1.96 \pm 0.07 \mathrm{MPa}$ & $1.07 \pm 0.07 \mathrm{MPa}$ \\
\hline Tensão de Escoamento $\left(\sigma_{\mathrm{y}}\right)$ & $1 \%$ de deformação total & $0.714 \pm 0.005 \mathrm{MPa}$ & $0.43 \pm 0.03 \mathrm{MPa}$ \\
\hline
\end{tabular}

\subsubsection{Endentação}

Os ensaios de endentação foram utilizados para avaliação e principalmente, identificação das potencialidades e limitações dos modelos de material empregados, pois o carregamento, imediatamente, abaixo do endentador é multiaxial, o que simula uma aplicação de carregamentos de tração, de compressão e de cisalhamento em diferentes planos. Dessa forma, as curvas referentes a esses ensaios serão apresentadas em gráficos de forçadeslocamento.

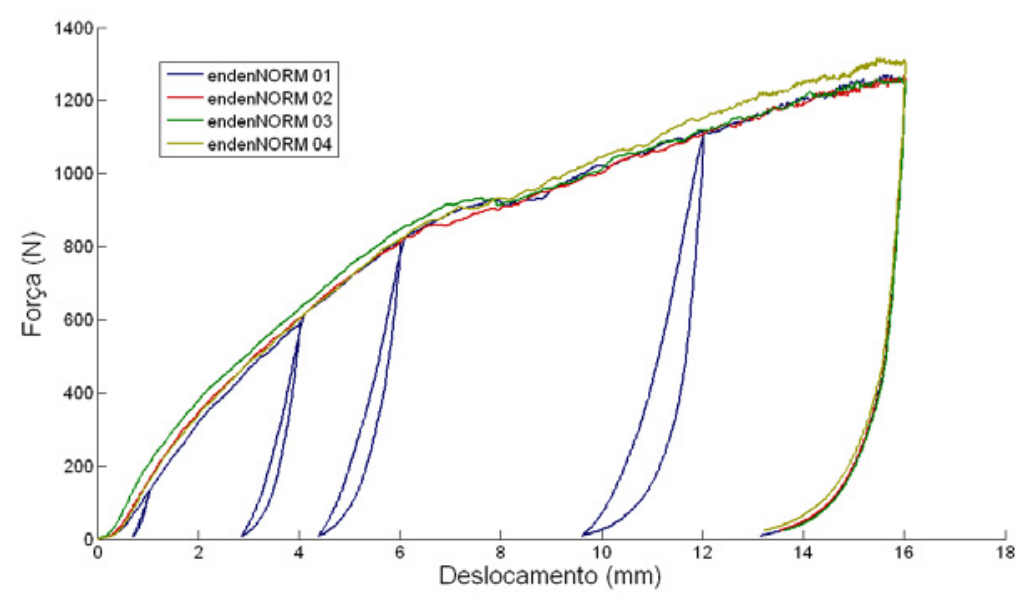

Figura 41. Curvas experimentais para os ensaios de endentação na direção normal 3

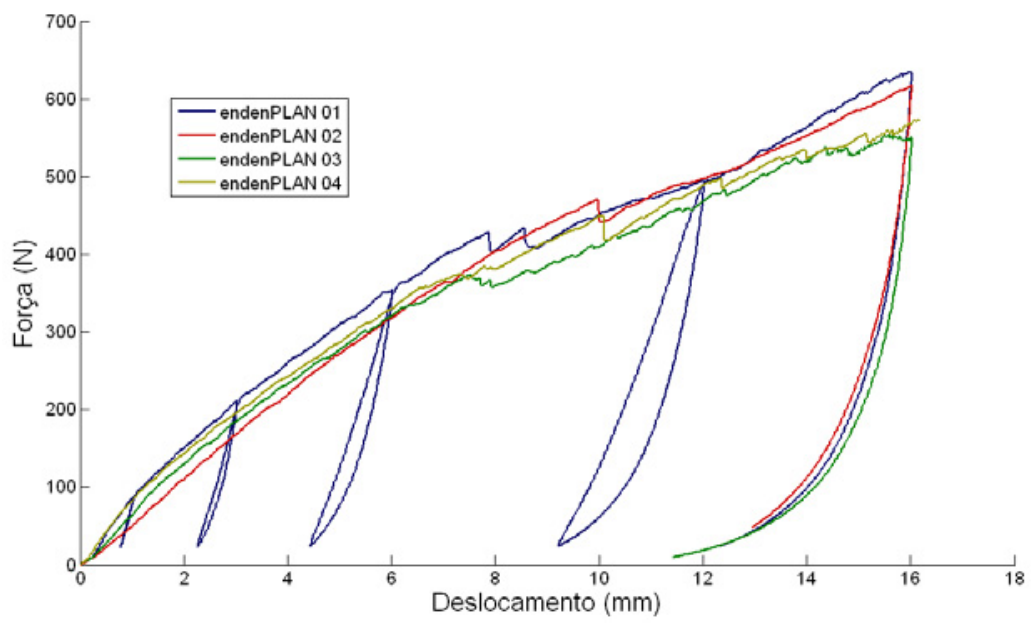

Figura 42. Curvas experimentais para os ensaios de endentação em uma direção no plano 1-2 
Ambas as direções de anisotropia foram avaliadas e as curvas de força-deslocamento estão evidenciadas nas Figuras 41 e 42, sendo que somente para o primeiro corpo-de-prova fez-se um teste cíclico.

Nas figuras 41 e 42, é possível observar para um deslocamento de 6-8mm, há uma ligeira redução da força, para ambas as direções de anisotropia, porém estas diminuições são mais acentuadas no plano 1-2. Essas oscilações no carregamento estão associadas com a ruptura do material durante o ensaio que pode ser vista na Figura 43.

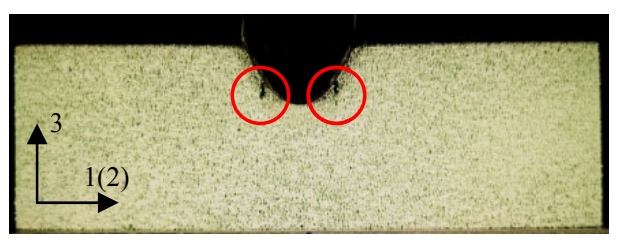

Figura 43. Ensaio de endentação da espuma polimérica na direção normal 3

Uma vez que ocorreu a ruptura do material, a Teoria da Mecânica do Contínuo deve ser revista e a investigação do modelo de material, portanto, foi realizada no presente trabalho até o momento em que o CDP ainda era íntegro, ou seja, para deslocamentos de até $6-8 \mathrm{~mm}$ em ambas as direções de anisotropia.

\subsubsection{Dados Experimentais via Técnica DIC}

No cálculo dos coeficientes de Poisson elástico e plástico para a espuma polimérica, o uso da técnica de correlação de imagens permitiu que os respectivos campos de deslocamento e deformação ficassem livres de alguns erros experimentais comuns em ensaios com uso de sensores eletro-mecânicos. Para cada tipo de carregamento e direção do material, os campos de deslocamento e deformação obtidos via Técnica DIC possibilitaram complementar e corrigir resultados provenientes de dispositivos acoplados ao equipamento de ensaios.

\subsubsection{Compressão Uniaxial}

Ao comprimir a espuma polimérica rígida acima da tensão de pico, surgem as frentes de plastificação no material que aparecem de maneira irregular como comentado. Com as imagens, que a técnica DIC gera, é possível identificar a formação das frentes de plastificação 
e a sua localização nos corpos-de-prova. Nas Figuras 44 e 45, os resultados via técnica DIC para os ensaios de compressão nas direções normal e no plano 1-2 são apresentados através da interface do programa Correli ${ }^{\mathrm{LMT}}$. Os resultados, para ambas as direções, compõem uma sequência de fotos cujo atual deslocamento do aplicador de carga, $u_{d}$, tem valor semelhante para ambas sequências de fotos nas direções normal e no plano para fins de comparação (ver Figuras 44 e 45).
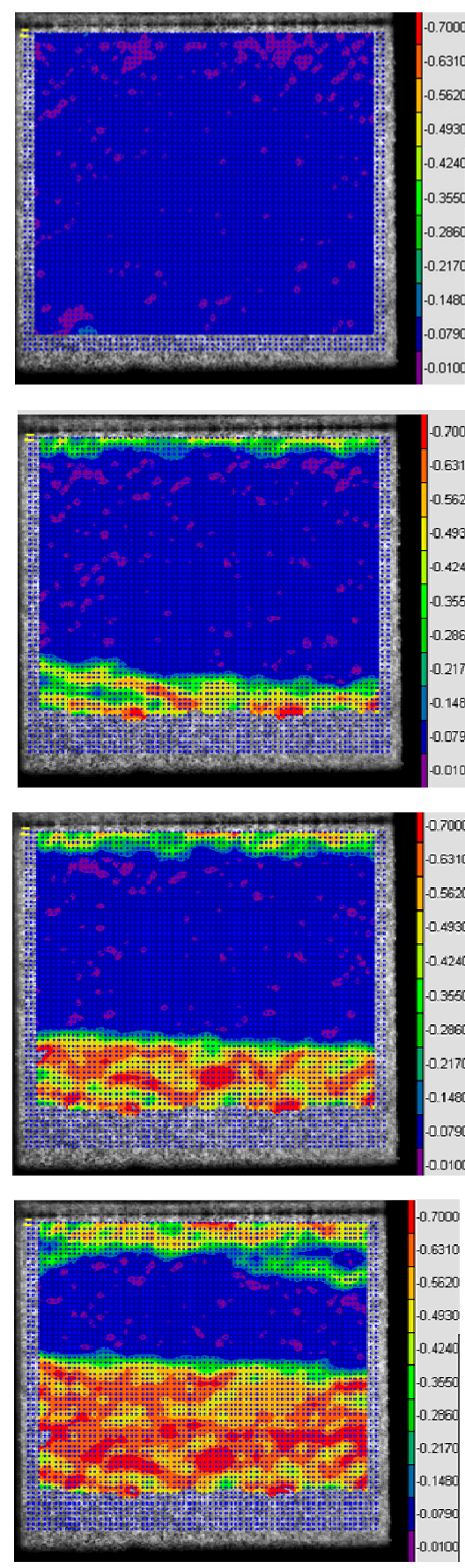

b) $u_{3}=7.5 \mathrm{~mm}$

$$
\text { c) } u_{3}=10.0 \mathrm{~mm}
$$

$$
\text { d) } u_{3}=15.0 \mathrm{~mm}
$$
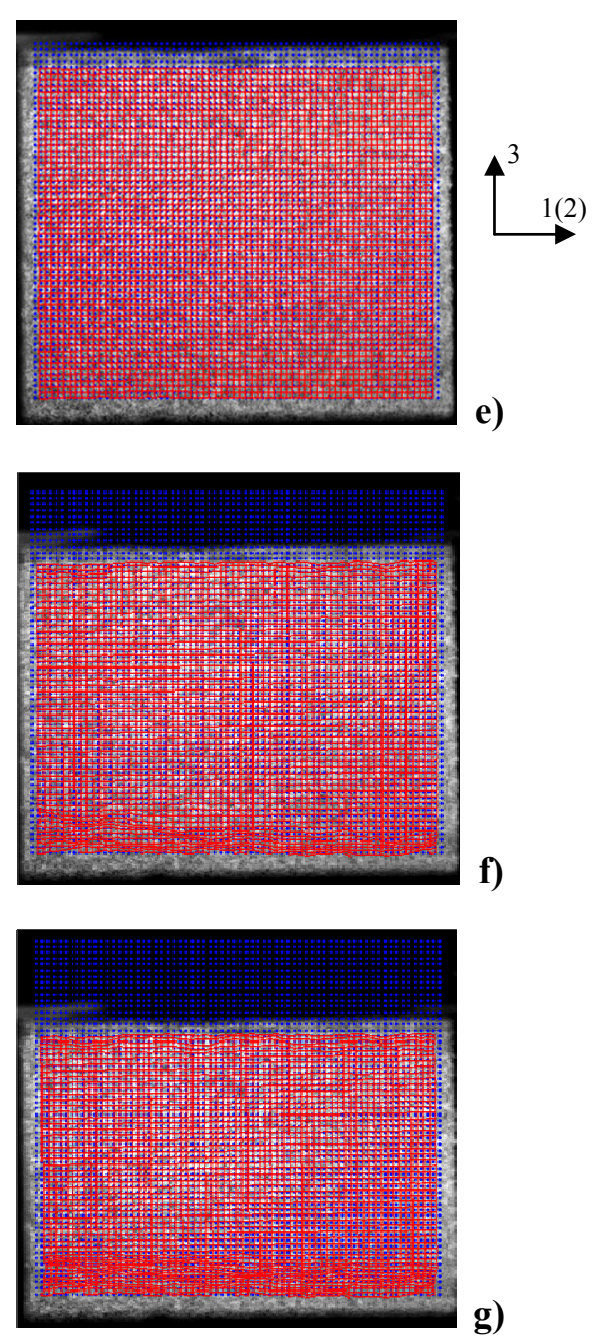

g)

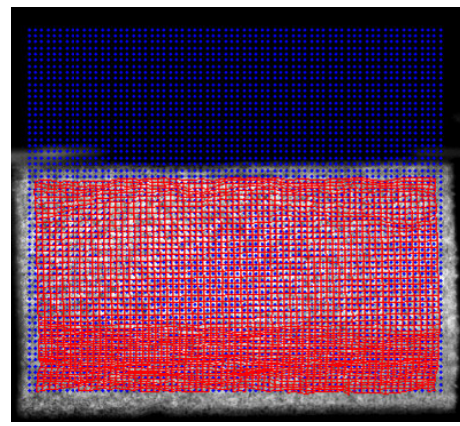

h)

Figura 44. Imagens do programa Correli ${ }^{\text {LMT }}$ para ensaio de compressão do CDP5 na direção normal 3: De a) à d) tem-se a evolução do campo de deformação nominal $\varepsilon_{33}$ e de e) à h) a evolução da malha virtual correspondente 

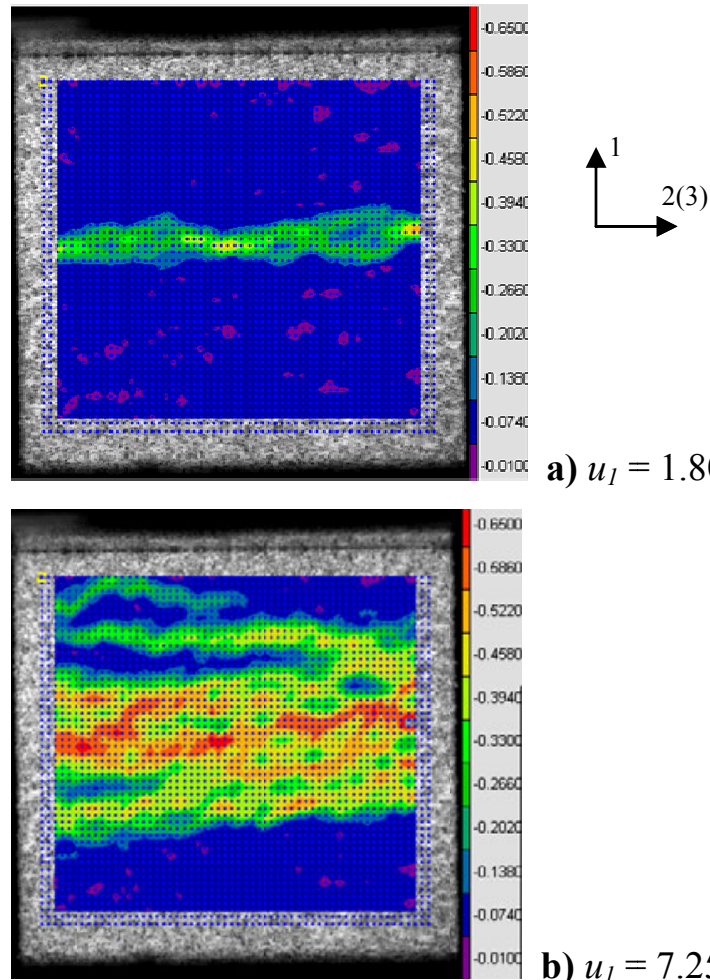

a) $u_{1}=1.80 \mathrm{~mm}$

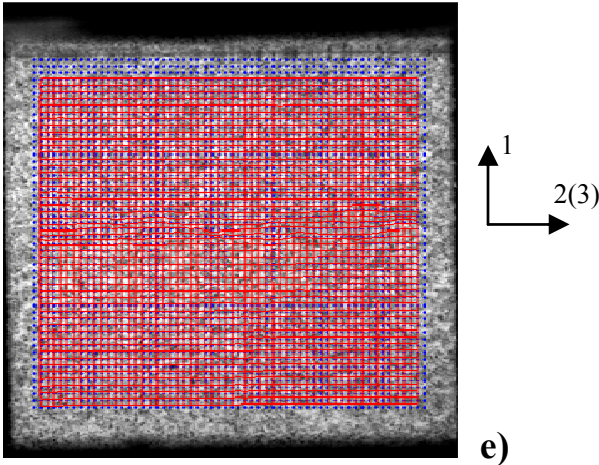

b) $u_{1}=7.25 \mathrm{~mm}$
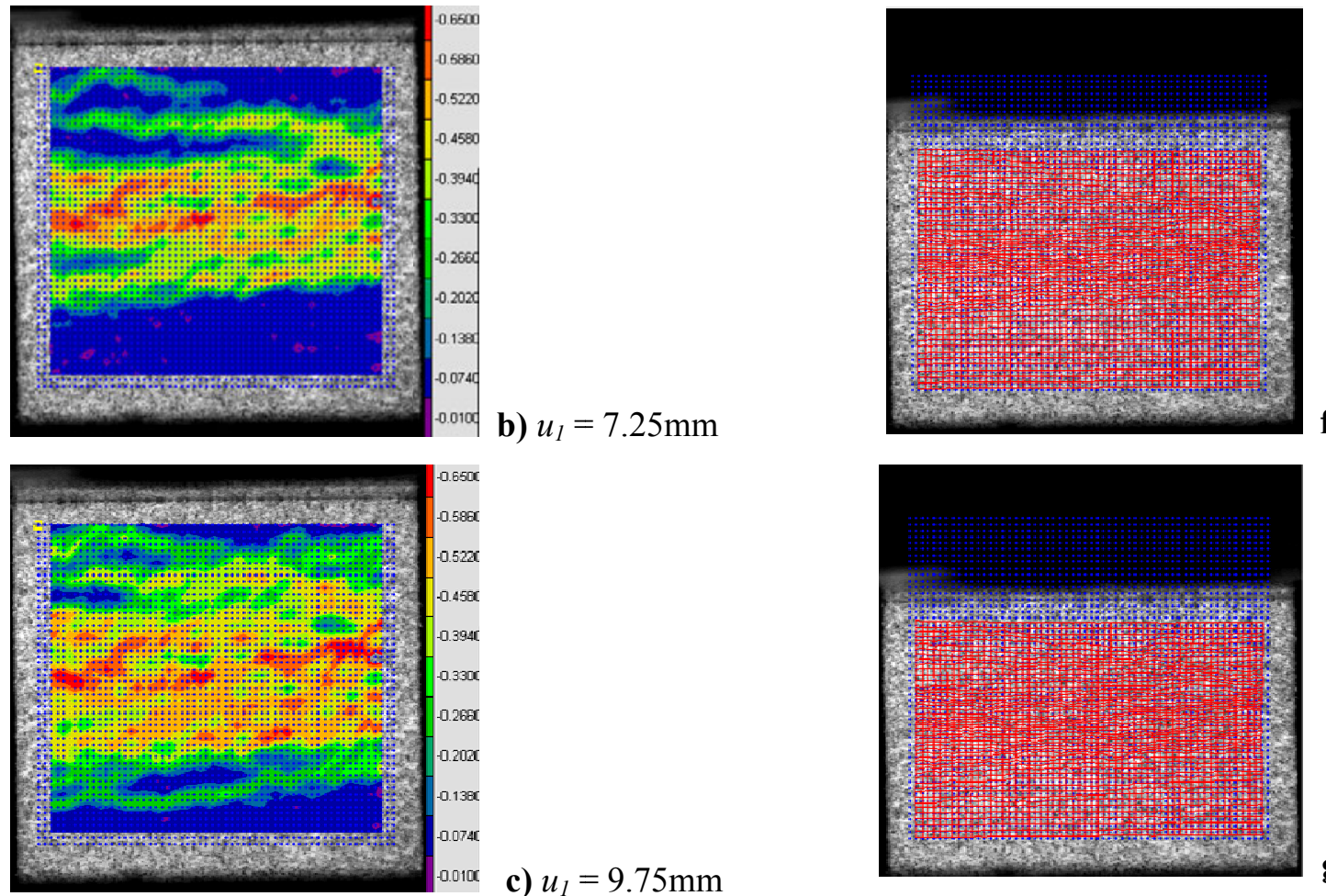

c) $u_{1}=9.75 \mathrm{~mm}$

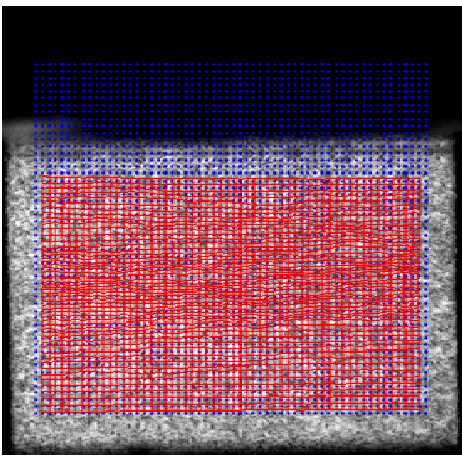

f)
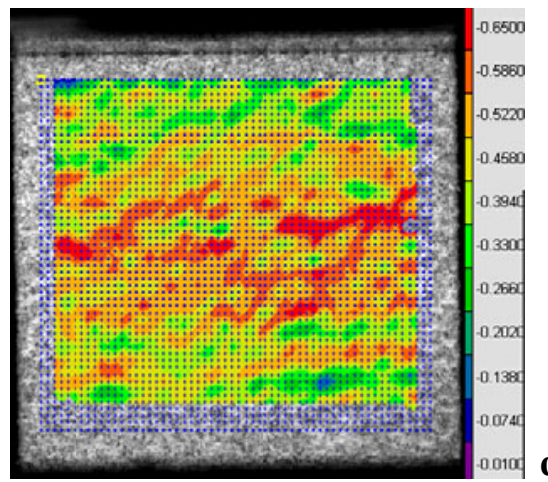

d) $u_{1}=14.75 \mathrm{~mm}$

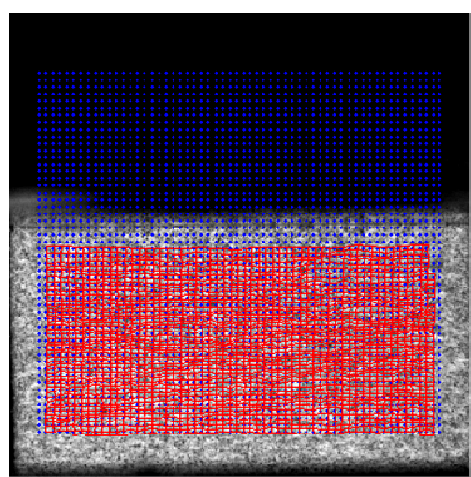

g)

Figura 45. Imagens do programa Correli ${ }^{\mathrm{LMT}}$ para ensaio de compressão do CDP5 na direção 1 no plano 12: De a) à d) tem-se a evolução do campo de deformação nominal $\varepsilon_{11}$ e de e) à h) a evolução da malha virtual correspondente

Da primeira sequência para a direção normal (Fig. 44), observa-se a formação de duas frentes de plastificação. Uma primeira frente mais intensa na região inferior e outra mais fraca na região superior. Devido à irregularidade da estrutura na direção normal, uma grande 
parcela do material se mantém sob regime elástico, indicado nas últimas fotografias pela cor azul (Figura 44). Isto ocorre até o momento em que as frentes de plastificação superior e inferior se encontrem, como evidenciado na curva tensão-deformação do material (Figs. 35 e 36).

Comparando os níveis de deformação da segunda sequência (Fig. 45) com a primeira (Fig. 44) observa-se que para níveis de deslocamento semelhantes, os campos de deformação gerados na direção normal e no plano variam. Das figuras 44a e 45a confirma-se o surgimento aleatório das frentes de plastificação, sendo que para a 44a são duas frentes de plastificação que surgem nas extremidades e para a 45a, apenas uma surge ao centro do corpo-de-prova. Caso sejam analisadas as demais fotografias, observa-se que a maior flexibilidade e homogeneidade do material na direção do plano faz com que a frente de plastificação evolua a partir de suas extremidades e se desfaça de maneira suave evitando o encontro das frentes de plastificação observados para a direção normal, pois mesmo sob grandes deslocamentos ainda há regiões em regime elástico de deformação.

\subsubsection{Tração Uniaxial}

Em particular para os ensaios de tração realizados no presente trabalho, a técnica DIC teve uma função de correção e validação da metodologia proposta, uma vez que apenas algumas dimensões do CDP da norma ASTM D1623-03 foram seguidas. De modo resumido, projetou-se uma seção de área mínima com pelo menos 1 polegada quadrada $\left(645 \mathrm{~mm}^{2}\right)$ e uma velocidade de carregamento que culminasse em uma ruptura do material em torno de aproximadamente 3 a 6 minutos, minimizando assim os efeitos viscosos inerentes ao material polimérico.

A geometria dos corpos-de-prova influenciou, principalmente, os ensaios para a direção normal, pois o comprimento de área mínima efetivo não foi suficiente para garantir um resultado satisfatório para as curvas de tensão-deformação calculadas com dados da célula de carga utilizada e partir dos deslocamentos da máquina de ensaios. Essa afirmação é confirmada com base nas Figuras 46a e 46b que exibem o campo de deslocamento paralelo à direção normal de carregamento no início e no final do ensaio. 


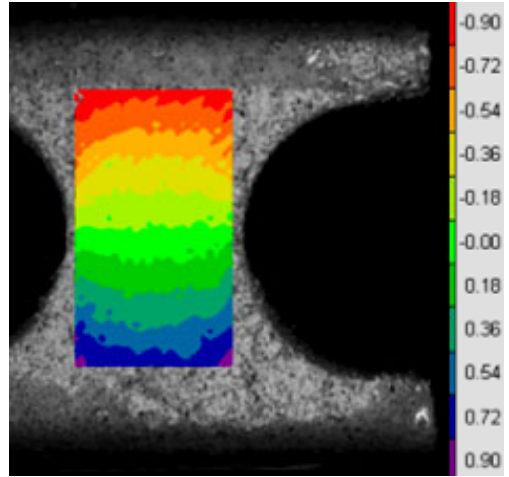

a)

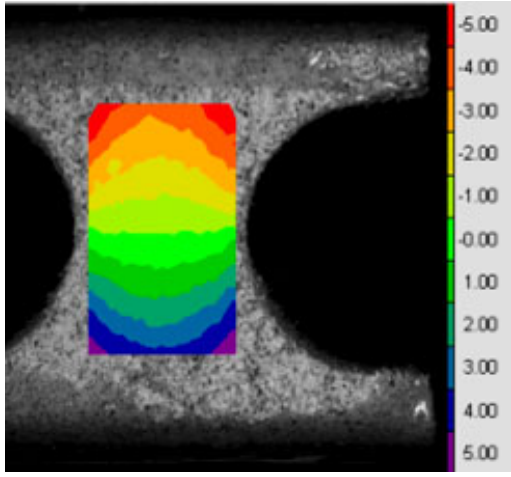

b)

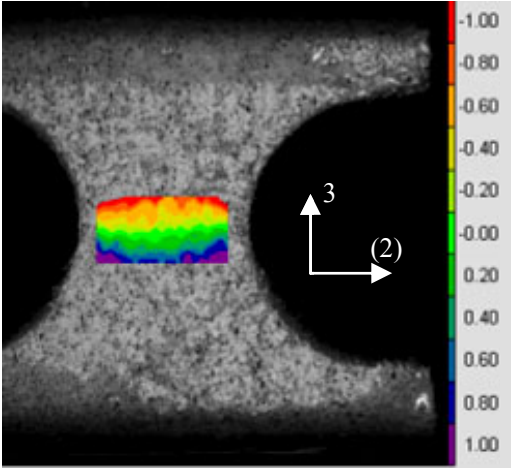

c)

Figura 46. Campos de deslocamento (medido em pixels) via Correli ${ }^{\text {LMT }}$ para a tração uniaxial do CDP2 na direção normal: a) Configuração inicial; b) Configuração pré ruptura; c) Região com carregamento próximo ao uniaxial

$\mathrm{Na}$ verdade, verifica-se que nem toda a região analisada do corpo-de-prova está somente sob estado uniaxial de tração, ou seja, há regiões do mesmo que estão sob um estado multiaxial, como esperado. Assim, o campo de deslocamento variável (indicando o aparecimento de grandes distorções no material) fez com que as análises via técnica DIC fossem realizadas para uma região localizada no centro do corpo-de-prova, próxima da seção de área mínima (Fig. 46c).

Por outro lado, na direção do plano 1-2, o campo de deslocamentos (Figs. 47 a e 47b) não variou tanto quanto na direção normal, contudo as análises também foram realizadas para uma região mais localizada (Fig. 47c).

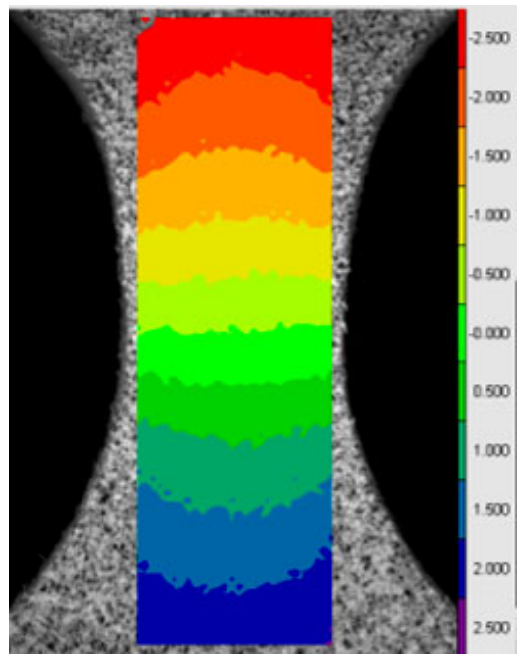

a)

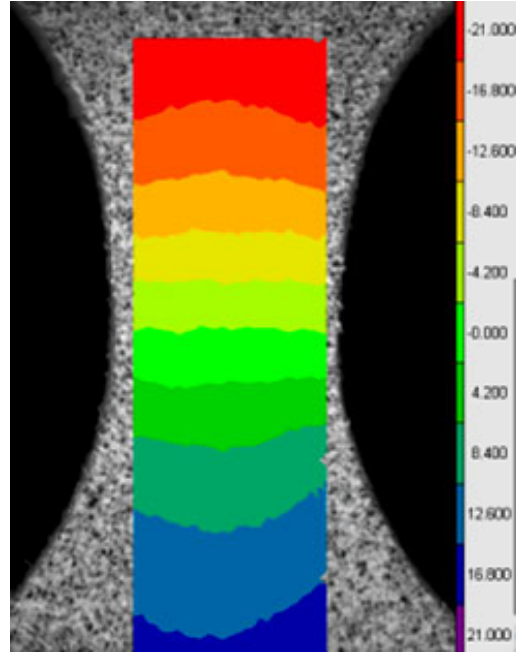

b)

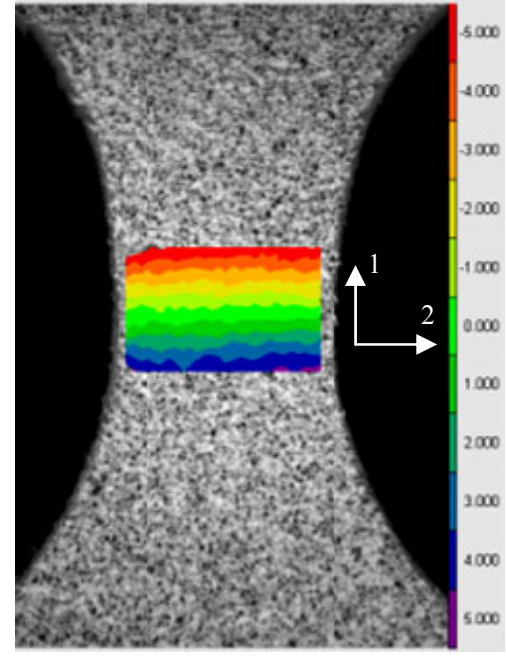

c)

Figura 47. Campos de deslocamento (medido em pixels) via Correli ${ }^{\text {LMT }}$ para a de tração uniaxial do CDP1 na direção do plano: a) Configuração inicial; b) Configuração pré ruptura; c) Região com carregamento próximo ao uniaxial 
Com esse procedimento, assegura-se que as propriedades do material obtidas com base nas medidas coletadas via técnica DIC, correspondam àquelas de um ensaio de tração uniaxial puro. Além disso, deve-se ressaltar que os dados obtidos são mais precisos que os determinados por dispositivos eletro-mecânicos, pois as medidas de deformação são feitas diretamente no material a partir dos campos de deslocamento virtual gerados.

\subsubsection{Endentação}

A técnica de correlação de imagens também foi utilizada nos ensaios de endentação para uma análise qualitativa e quantitativa. São discutidos nessa seção os resultados qualitativos sendo que os quantitativos serão abordados posteriormente. Dessa forma, seguem nas Figuras 48 e 49, os resultados para duas análises qualitativas referentes a dois corpos-deprova, um para cada direção de anisotropia.
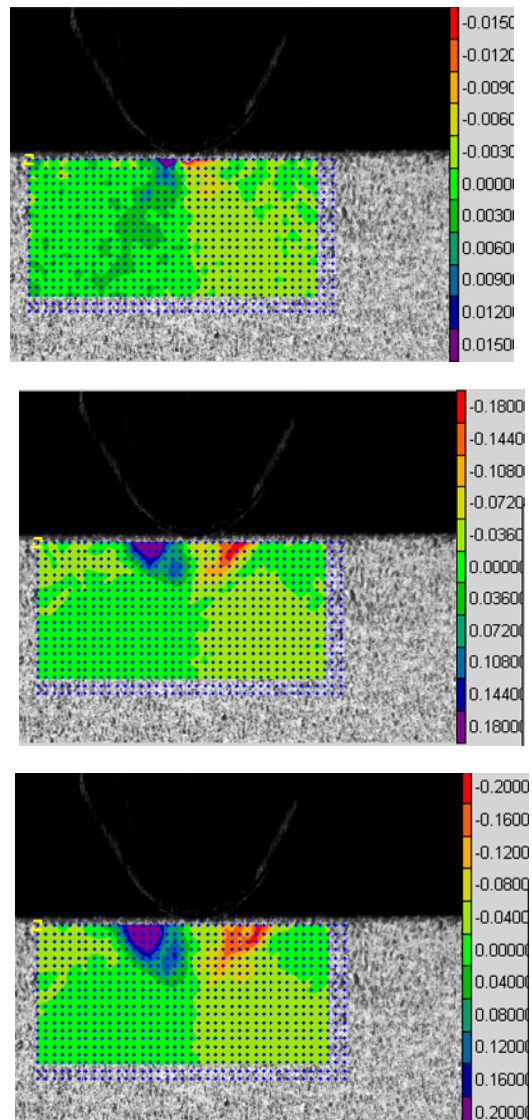

b) $u_{3}=4.8 \mathrm{~mm}$

c) $u_{3}=7.4 \mathrm{~mm}$
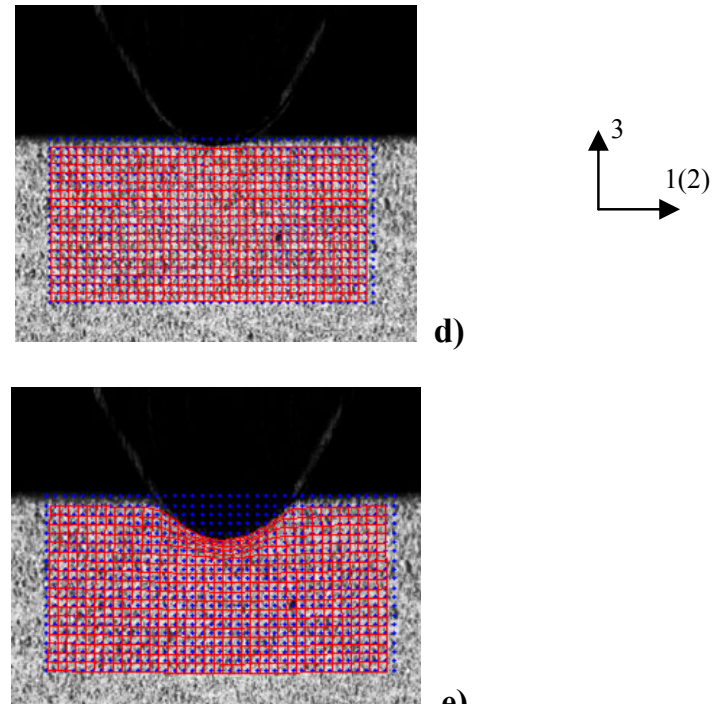

e)

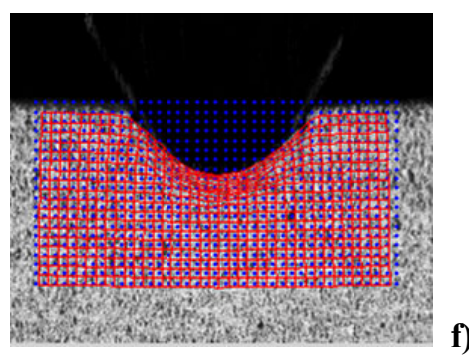

f)

Figura 48. Imagens do programa Correli ${ }^{\mathrm{LMT}}$ para a endentação do CDP2 na direção normal: De a) à c) tem-se a evolução do campo de deformação $\varepsilon_{13}$ e de d) à f) a evolução da malha virtual correspondente 
Os campos deformação $\varepsilon_{13}$, na Figura 48 , foram escolhidos para serem exibidos ao invés das deformações nas direções 3 ou 1, pois o material tem comportamento frágil em tração, o que influencia os resultados de endentação para grandes deformações.

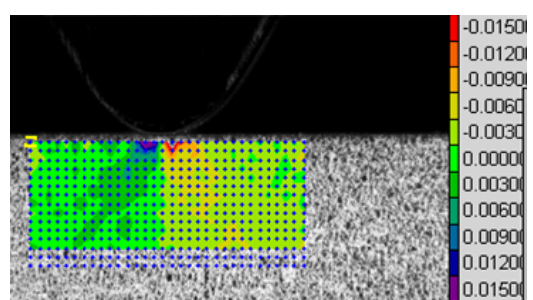

a) $u_{1}=1.8 \mathrm{~mm}$

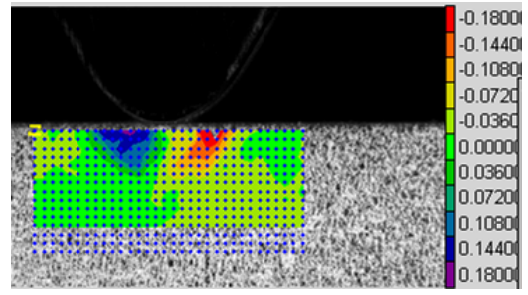

b) $u_{1}=4.8 \mathrm{~mm}$

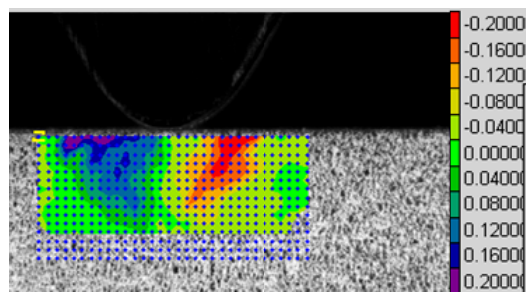

c) $u_{1}=7.9 \mathrm{~mm}$
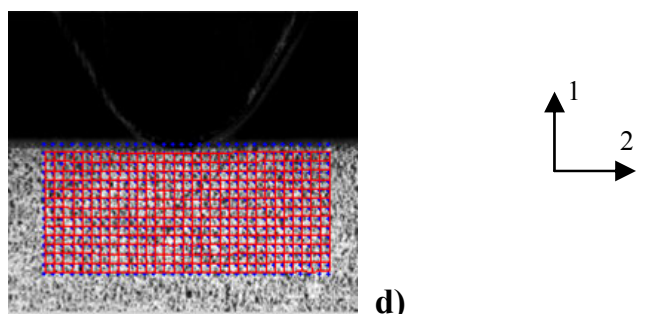

d)

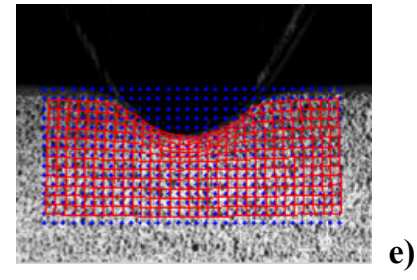

e)

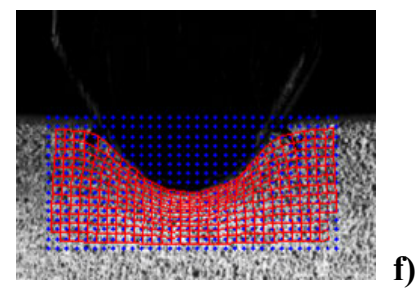

f)

Figura 49. Imagens do programa Correli ${ }^{\text {LMT }}$ para a endentação do CDP3 para uma direção no plano: De a) à c) tem-se a evolução do campo de deformação $\varepsilon_{12}$ e de d) à f) a evolução da malha virtual correspondente

Quando a espuma é submetida a cisalhamento, a fragilidade da espuma à tração é verificada com a ruptura dos corpos-de-prova nas extremidades do raio do endentador, onde ocorre a maior distorção no material (Fig. 48f). Na Figura 49, as últimas fotografias, 49c e 49f, representam um deslocamento em torno do $8 \mathrm{~mm}$ discutidos anteriormente e não são utilizáveis na avaliação direta do modelo de material. Entretanto essas imagens exibem claramente o carregamento multiaxial e as deformações associadas ao ensaio de endentação que representam em parte um dos modos de falha para o material do núcleo das estruturas sanduíche sob ensaios de flexão em três pontos.

Um comportamento muito semelhante é obtido para a direção no plano 1-2. Uma diferença notada entre os resultados é uma maior definição da região da espuma que se rompe (Fig. 50). Mais uma vez, acredita-se que essa diferença seja atribuída a irregularidade do material na direção normal e uma maior homogeneidade do mesmo para uma direção no plano. 


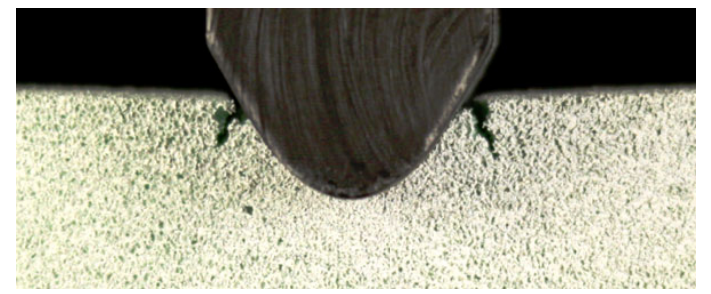

Figura 50. Detalhe da ruptura da espuma H60 no ensaio de endentação para a direção no plano

\subsubsection{Compressão Hidrostática e Curvas de Encruamento}

Por necessitar de um sistema de ensaios mais complexo, não foi possível utilizar a técnica DIC para os corpos-de-prova em questão e, assim, os dados foram somente obtidos de maneira convencional. Os dados de pressão foram coletados a partir de um manômetro e a deformação plástica foi tomada após a remoção e medição dos corpos-de-prova, que relaxaram durante o tempo em que o equipamento era desmontado (em torno de 10min), sendo que a aquisição das medidas foi efetuado com um paquímetro de forma padronizada. $\mathrm{O}$ uso da técnica DIC requer uma modificação ou um desenvolvimento de um equipamento especial, similar ao utilizado por Viot (2009), onde o material foi monitorado através de janelas de vidro.

Foram obtidas curvas de tensão-deformação volumétrica plástica (a partir de três corpos-de-prova) e curvas de relaxamento dadas pela deformação volumétrica plástica em função do tempo (a partir de dois outros corpos-de-prova), para quantificar efeitos viscosos do material. Como os efeitos viscosos não são utilizados nos modelos computacionais do presente trabalho, a curva de relaxamento construída é exibida no Apêndice $\mathrm{C}$ a título de ilustração.

O principal propósito do ensaio de compressão hidrostática foi o de obter o limite de escoamento da espuma H60 para que as superfícies de escoamento referentes ao modelo de material estudado fossem calibradas. Construiu-se também a curva de encruamento (tensãodeformação volumétrica plástica - Figura 51) para comparações qualitativas e quantitativas. Com base na dispersão dos dados experimentais, obteve-se a função exponencial dada pela equação (115) para a tensão hidrostática $\sigma_{m}$ exibida. O primeiro ponto experimental indica que a tensão de escoamento é um valor de aproximadamente $0.45 \mathrm{MPa}$. 


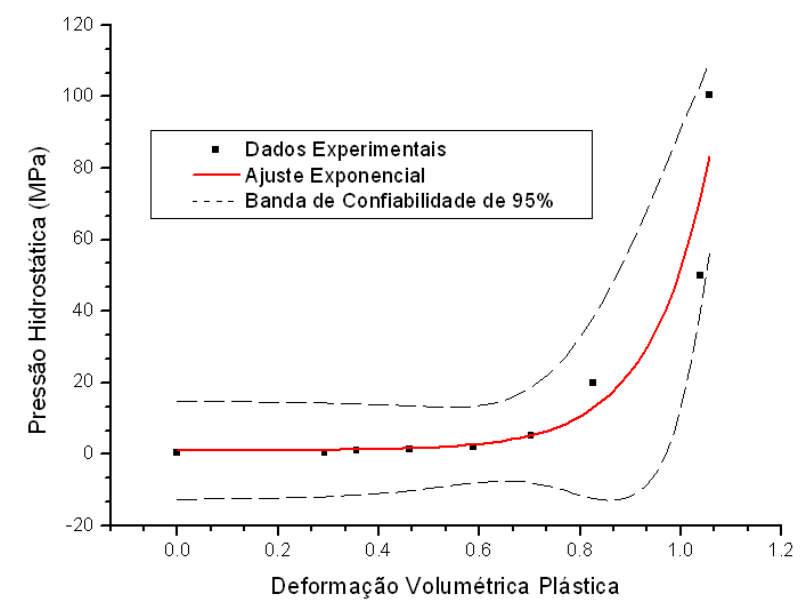

Figura 51. Compressão hidrostática: Deformação volumétrica plástica

$$
\sigma_{m}=1.10+0.0117 \exp \left(\varepsilon_{v o l} / 0.119\right)
$$

$\mathrm{Na}$ determinação desse valor, houve um erro associado à leitura do manômetro analógico que foi instalado. $\mathrm{O}$ manômetro instalado forneceu uma precisão suficiente para identificar as tensões de escoamento, mas durante a leitura das pressões uma dificuldade surgiu com a "instabilidade na leitura dos valores" quando o material atingia a tensão de escoamento. Nesse instante, os incrementos de pressão do equipamento eram muito elevado (mesmo em seu limite operacional mínimo), e assim, a cada novo incremento, o material era comprimido de forma acentuada, fazendo com que o volume da mistura água-óleo variasse muito, e, por consequência, surgia uma variação de pressão no manômetro analógico. Todavia essa perturbação foi minimizada com uma quantificação parcial dessa variação da pressão em torno da tensão de escoamento através do uso de três corpos-de-prova, sendo que dois desses CDPs tiveram a geometria similar à usada nos ensaios de compressão uniaxial (Tabela 5).

Esses corpos-de-prova com geometria diferente foram ensaiados para que o valor da tensão de escoamento de $0.45 \mathrm{MPa}$ (Fig. 51) fosse definido com maior precisão, através do monitoramento das variações da pressão do sistema.

Apesar da equação (115) fornecer a curva de encruamento para a espuma quando solicitada hidrostaticamente, não é essa a curva utilizada na equação (94) durante a calibração do modelo de material empregado. De acordo com o Capítulo III, as curvas de encruamento são aquelas obtidas a partir dos ensaios de compressão uniaxial. A expressão geral, segundo a teoria, para a determinação da curva de encruamento é obtida a partir da equação (116) que fornece a deformação plástica do material: 


$$
\varepsilon^{p l}\left(\varepsilon_{\log }\right)=\varepsilon_{\log }-\left[\sigma_{y}\left(\varepsilon_{\log }\right) / E\right]
$$

Todavia a expressão (116) não corresponde com a deformação plástica obtida das curvas de compressão uniaxial obtidas experimentalmente, pois o material é uma estrutura celular e não um material homogêneo. As curvas de encruamento real para a estrutura celular, são exibidas nas Figuras 52a e 52b e são obtidas diretamente das Figuras 31 e 30. Os respectivos ajustes são as equações (117) e (118).
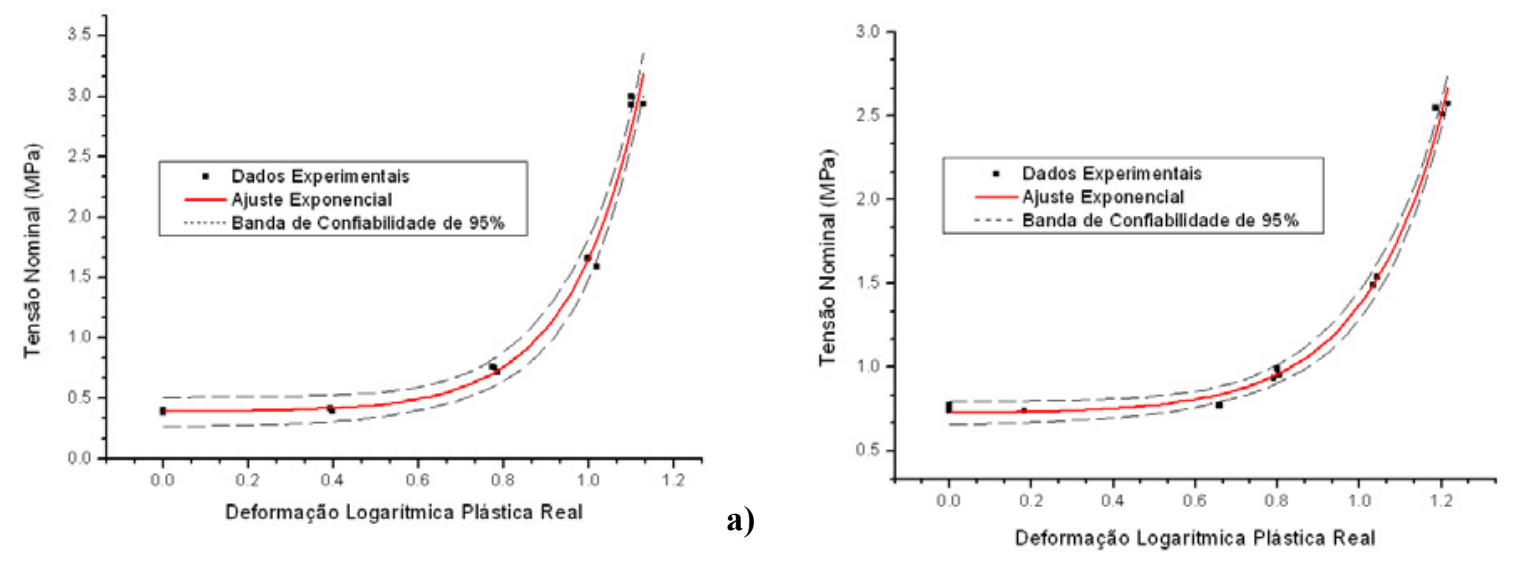

b)

Figura 52. Curvas de encruamento real para as compressões uniaxiais: a) Direção no plano; b) Direção normal

$$
\begin{aligned}
& \sigma_{y 11}^{p l}=0.387+0.00282 \exp \left(\varepsilon_{11}^{p l} / 0.163\right) \\
& \sigma_{y 33}^{p l}=0.723+0.00413 \exp \left(\varepsilon_{33}^{p l} / 0.197\right)
\end{aligned}
$$

Ao analisar o retorno elástico dos corpos-de-prova comprimidos, observa-se uma deformação elástica verdadeira maior que a deformação teórica que é obtida a partir da subtração da deformação elástica da curva de deformação logarítmica total (eq. (116)).

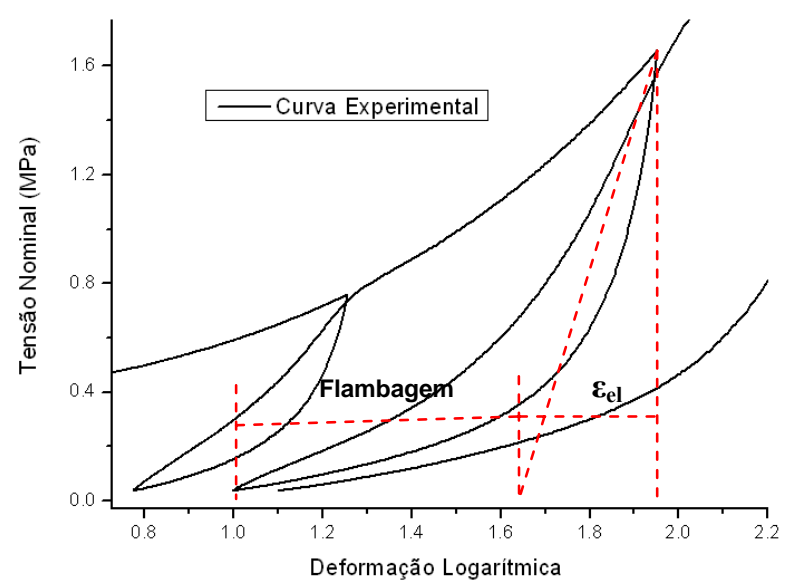

Figura 53. Composição da deformação elástica total em compressão para a espuma polimérica 
A aparente incoêrencia nos dados experimentais advém dos mecanismos de falha da espuma polimérica que é uma estrutura celular e não uma material homogêneo (sem vazios), como supõe a teoria para o respectivo cálculo. Como discutido, um dos mais influentes modos de falha da espuma é a micro flambagem das células. Essa flambagem faz com que haja grandes deslocamentos e uma deformação plástica associada (Fig. 53) menor que o valor teórico segundo a equação (116).

Pela teoria, uma curva de encruamento média pode ser obtida aplicando a equação (116) diretamente nos resultados das curvas nas Figuras 30 e $31 . \mathrm{O}$ resultado consiste nas equações (119) e (120) referentes às Figuras 54a e 54b respectivamente:

$$
\begin{gathered}
\sigma_{y 11}^{p l}=0.257+0.0732 \exp \left(\varepsilon_{11}^{p l} / 0.635\right) \\
\sigma_{y 33}^{p l}=0.624+0.0530 \exp \left(\varepsilon_{33}^{p l} / 0.554\right)
\end{gathered}
$$
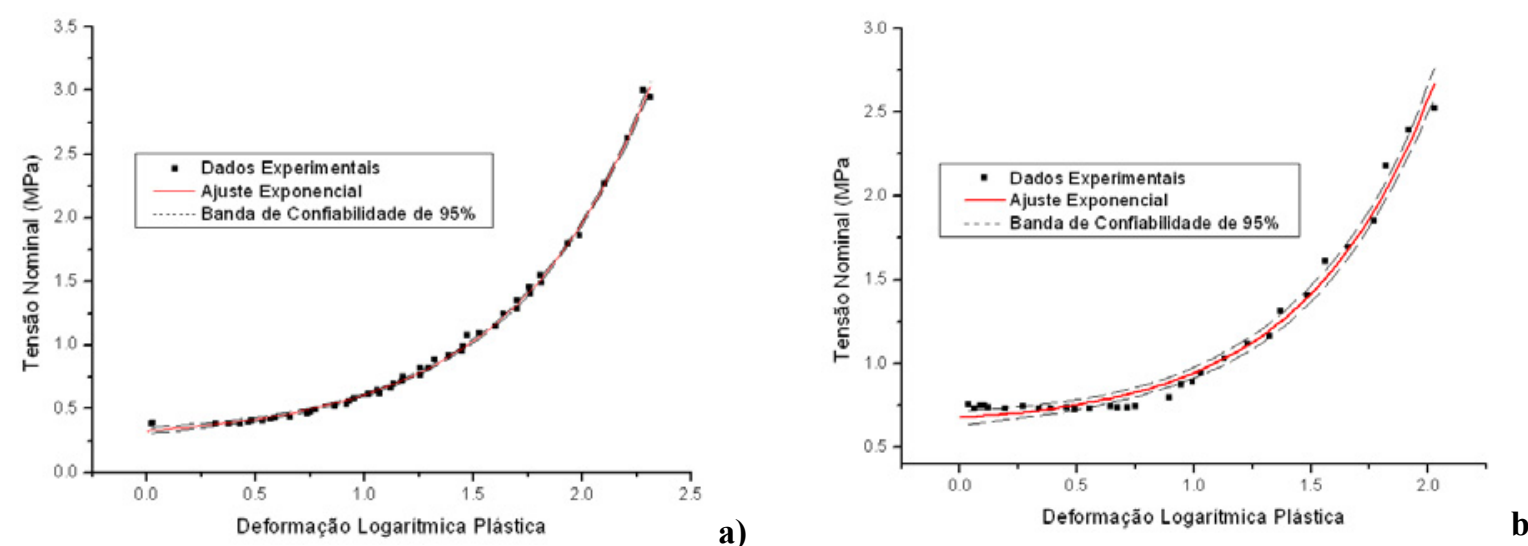

Figura 54. Curvas de encruamento teórico para as compressões uniaxiais: a) Direção no plano; b) Direção normal

Em tração, os mecanismos micro-mecânicos de falha não alteram significativamente os resultados e de maneira análoga, são construídas as curvas de encruamento médio para ambas as direções do material segundo as duas metodologias. A primeira utiliza os gráficos e valores reais das Figuras 39 e 40 para obter curvas lineares cujas inclinações estão na Figura 55. A partir da expressão (116), obtém-se as curvas na Fig. 56 cujo comportamento logarítmico é representado nas equações. (121) e (122).

$$
\begin{gathered}
\sigma_{y 11}^{p l}=2.134+0.289 \ln \left(\varepsilon_{11}^{p l}\right) \\
\sigma_{y 33}^{p l}=3.678+0.373 \ln \left(\varepsilon_{33}^{p l}\right)
\end{gathered}
$$




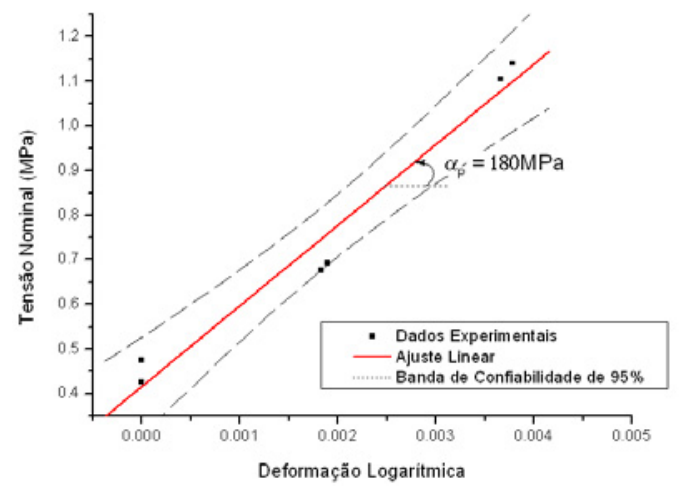

a)

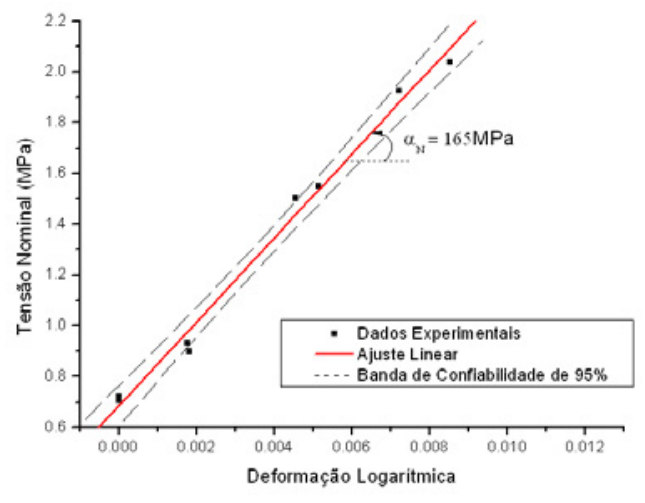

b)

Figura 55. Curvas de encruamento real para as trações uniaxiais: a) Direção no plano; b) Direção normal
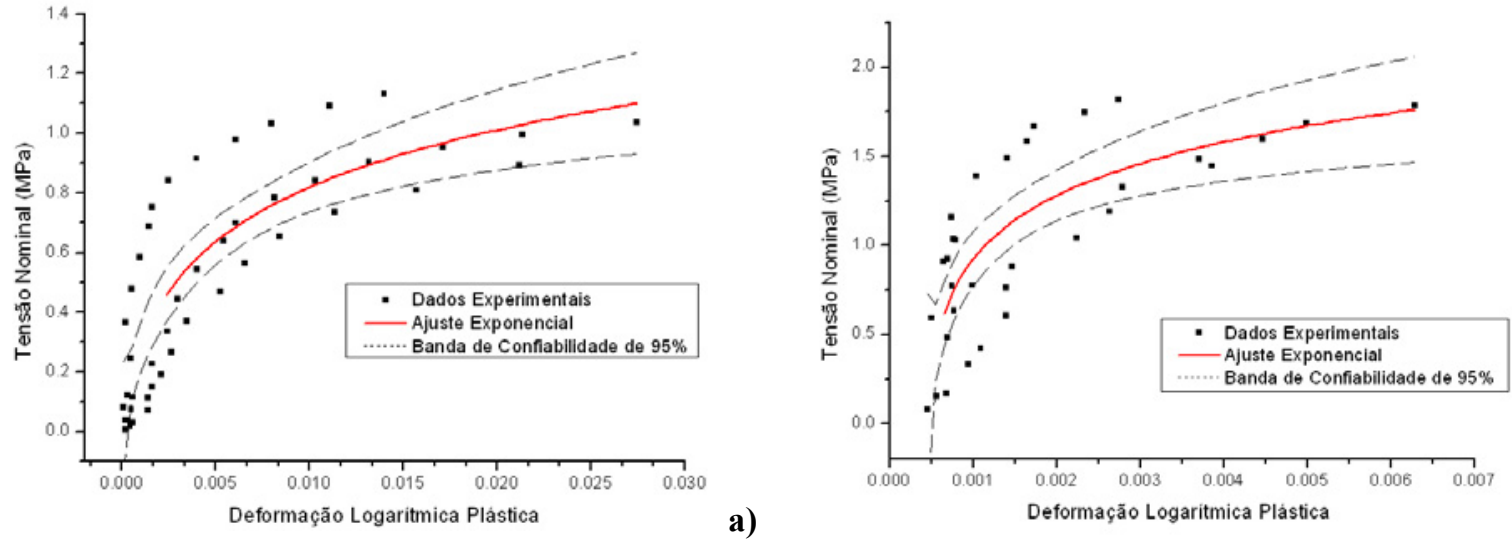

a)

b)

Figura 56. Curvas de encruamento teórico para as trações uniaxiais: a) Direção no plano; b) Direção normal

Comparando as Figuras 51 a 56, fica evidente que uma Lei de Encruamento que dependa do caminho de carregamento ou a utilização de um encruamento misto, bem como ambos associados a um potencial de escoamento específico (associativo ou não) é necessária para que os carregamentos multiaxiais sejam devidamente modelados. Existe ainda a questão da anisotropia do material que será melhor avaliada nas modelagens computacionais. De forma resumida e didática, cinco curvas de encruamento (Figs. 51, 54 e 56) foram agrupadas (Fig. 57) para exibir a dependência do encruamento do material com o tipo de carregamento e o grau de anisotropia.

Na Figura 57, a deformação plástica logarítmica apenas não é volumétrica para a tração uniaxial no plano, de acordo com o que foi discutido anteriormente sobre os coeficientes de Poisson identificados. Todavia, devido ao baixo nível de deformação, a contabilização da deformação no plano perpendicular ao carregamento para o respectivo ensaio, pode ser desprezada para as comparações da Figura 57. Nesta, observa-se a grande diferença entre as compressões uniaxiais e as hidrostáticas. Essa diferença é devido ao mecanismo de falha da espuma com caráter anisotrópico. 


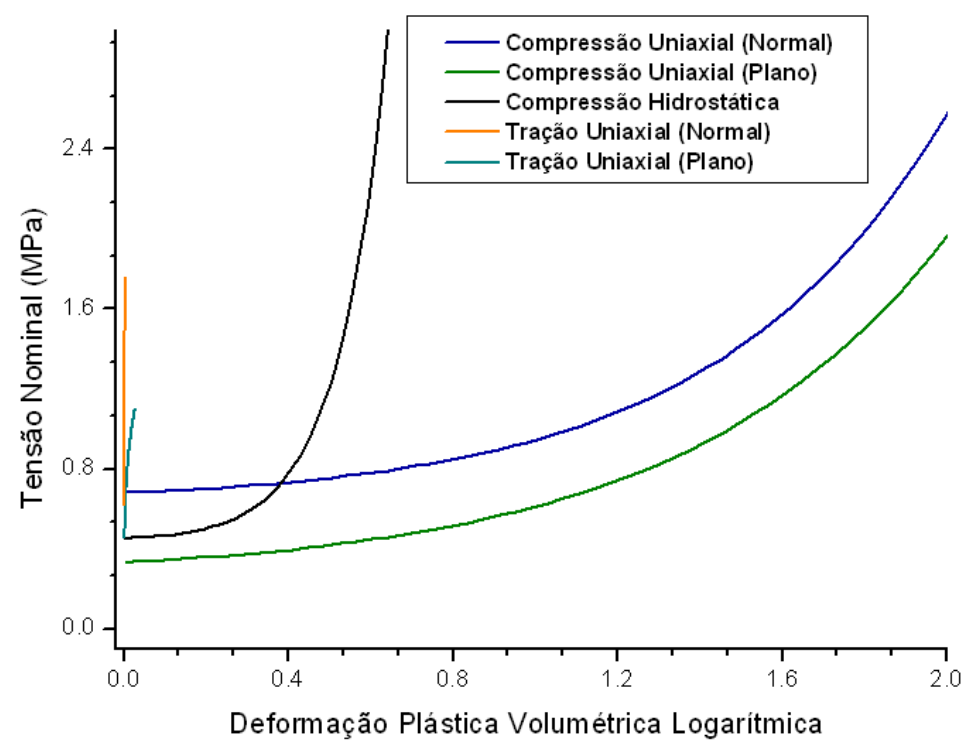

Figura 57. Sensibilidade da curva de encruamento com o tipo de carregamento para a espuma $\mathbf{H 6 0}$
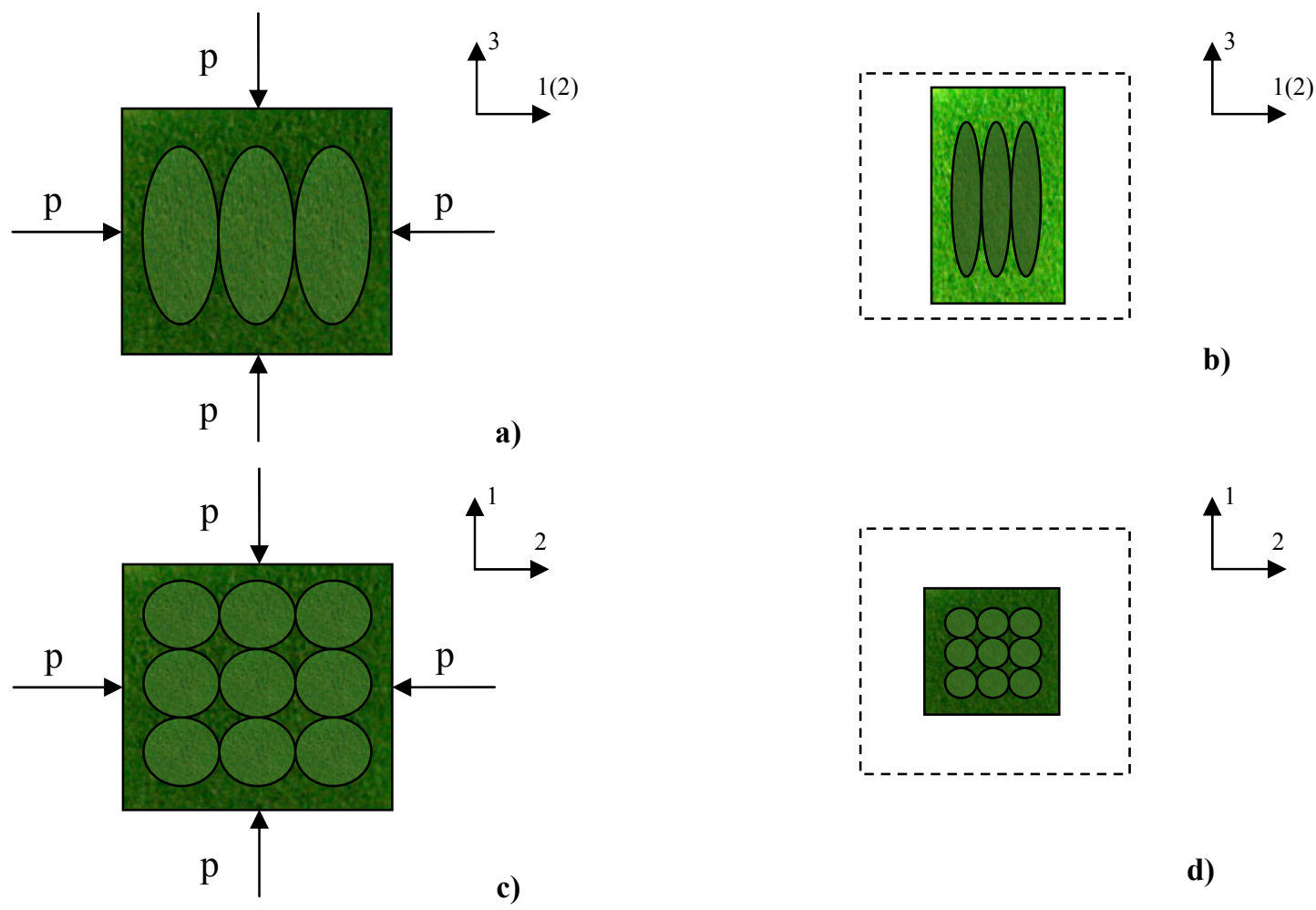

b)

c)

d)

Figura 58. Mecanismos de falha na espuma H60 sob compressão hidrostática: a) Carregamento no plano 3-1(2); b) Deformação plástica no plano 3-1(2); c) Carregamento no plano 1-2; b) Deformação plástica no plano 1-2

Uma vez que a direção normal tem maior tensão de escoamento, o material contido no plano perpendicular a esta direção escoa primeiro na direção 1(2). Esse fenômeno faz com que as células alongadas na direção normal 3 (Fig. 58) sejam comprimidas em sua seção transversal pertencente ao plano do material, o que resulta em um enrijecimento do material nessa direção adiantando o fenômeno de densificação do material. Logo, a deformação nas 
direções do plano 1-2 é maior que a na direção normal para essa solicitação. Na Figura 59, há uma sequência de corpos-de-prova que foram ensaios sob diferentes níveis de tensão hidrostática.
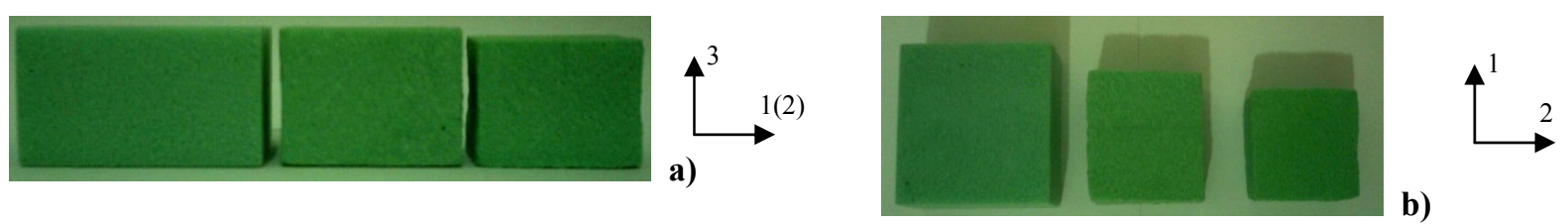

Figura 59. Deformação volumétrica real: Enrijecimento do material na direção normal: a) Plano 3-1(2); b) Plano 1-2

Por outro lado, constata-se que o encruamento e a respectiva tensão de escoamento para as solicitações de tração são superiores aos demais resultados obtidos nos carregamentos de compressão. Isso ocorre, pois a espuma H60 tem comportamento frágil sob tração e não apresenta fenômeno de micro-flambagem das células. Vale ressaltar que para um material frágil, existem geralmente duas abordagens. Na primeira, assume-se que o material não escoa e utiliza-se somente a tensão de resistência nas modelagens computacionais. Na segunda, considera-se que o material escoa, mas com um módulo de encruamento elevado. No caso, o presente trabalho investiga as duas abordagens e verifica qual delas é a melhor para prever o comportamento do material de acordo com a metodologia computacional proposta.

\subsubsection{Comparação e Discussão dos Resultados Experimentais}

Todas as medidas de força registradas nos ensaios experimentais do presente trabalho, exceto os dados para o ensaio hidrostático, foram obtidos através uma célula de carga de $10 \mathrm{kN}$. O cálculo das deformações para o material foi obtido através do método convencional (cálculos a partir do deslocamento do aplicador de carga) e também a partir da técnica DIC.

Para associar uma força aplicada no material ao seu respectivo deslocamento a partir da técnica DIC as duas técnicas são aplicadas ao mesmo tempo e o início da coleta de dados é sincronizado de modo que para cada foto obtida após o intervalo entre fotos $\Delta t$ seja associada à respectiva força medida pela célula de carga.

Como esperado, há uma diferença para os valores de deformações calculados pelas duas metodologias, resultando assim em valores de rigidez e/ou resistência diferentes. Para todos os corpos-de-prova ensaiados em tração e compressão uniaxial, foram construídas 
curvas comparativas de tensão-deformação e as propriedades elásticas e/ou plásticas para a espuma polimérica H60 foram calculadas.

\subsubsection{Compressão Uniaxial}

São apresentadas curvas comparativas, sendo uma figura para a direção normal (Fig. 60) e outra para a direção no plano (Fig. 61).

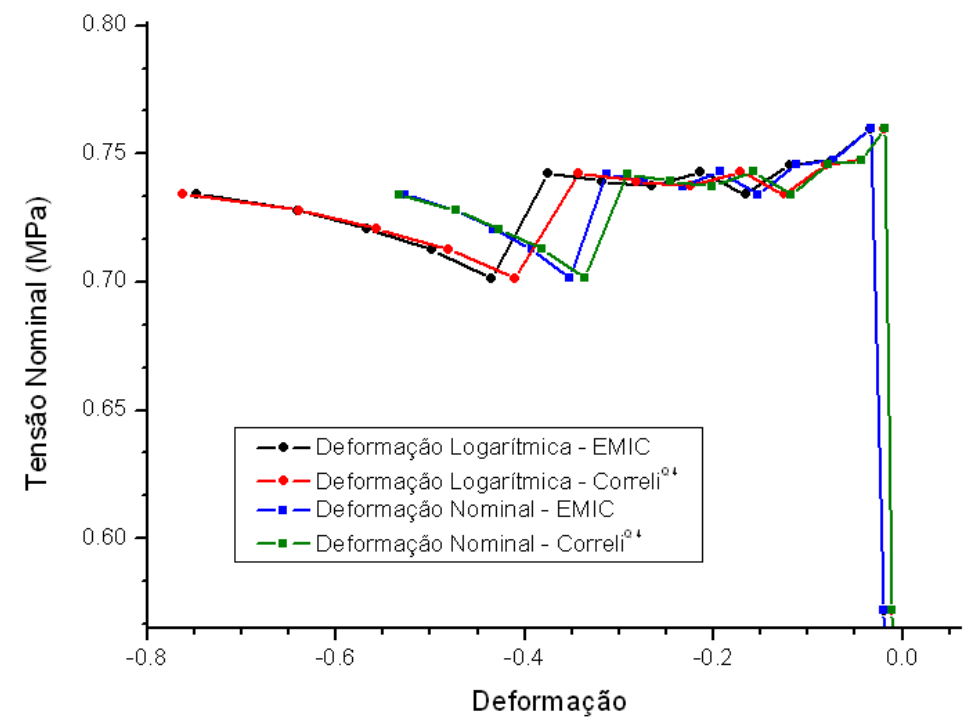

Figura 60. Comparações das deformações, para uma das compressões na direção normal, calculadas pelas duas metodologias adotadas

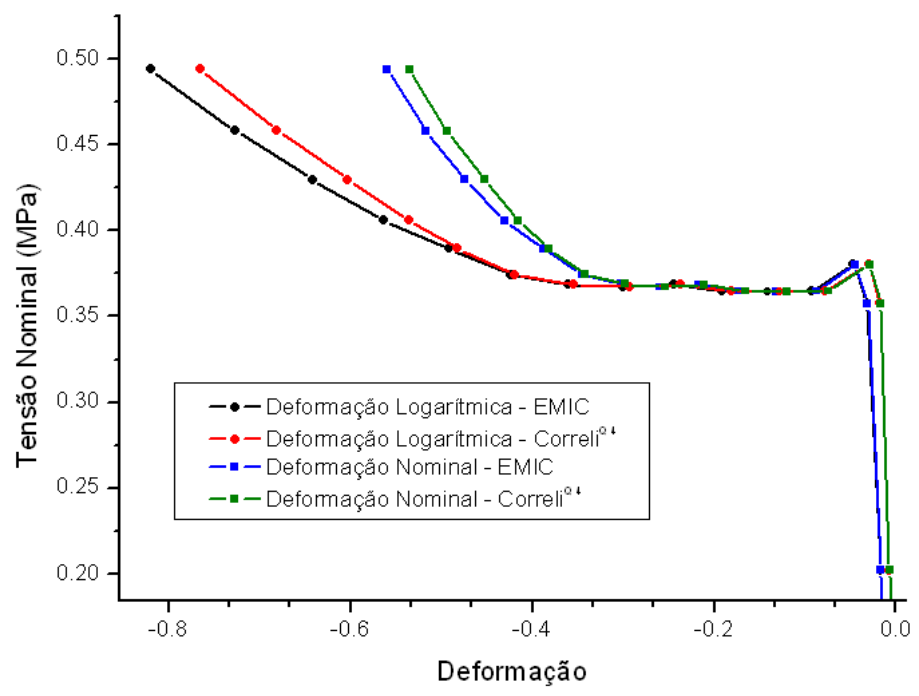

Figura 61. Comparações das deformações, para uma das compressões na direção do plano, calculadas pelas duas metodologias adotadas 
De modo geral, com base nos dados obtidos através das duas metodologias, conclui-se que para grandes deformações, os resultados são similares para compressão. Todavia verificase através da técnica DIC que o material é um pouco menos deformável, demonstrando ser mais rígido do que quando medido via técnica convencional. No entanto, vale ressaltar que até $30 \%$ de deformação, os resultados para a resistência da espuma são muito próximos.

Comparando as Figuras 60 e 61, observa-se variações para a tensão na direção normal e o encruamento não é tão evidente, porém, para a direção no plano, onde além de ocorrer uma consistente formação de um pico de tensão, o encruamento é evidenciado.

Deve-se ressaltar como foram calculadas as deformações logarítmicas a partir do programa Correli $^{\text {LMT }}$. Como visto, por exemplo, em uma das imagens na Figura 45, o programa fornece um campo de deformações, sendo que a comparação entre os resultados deve ser feita com valores médios para os campos de deformação obtidos pelo Correli ${ }^{\text {LMT }}$. Esses valores médios são fornecidos pelo programa tanto para deformações logarítmicas como para deformações de Green-Lagrange. Porém, o cálculo da média feita pelo programa deve ser tratado com cuidado, pois essas médias são aritméticas. Assim, o programa Correli $^{\text {LMT }}$ calcula uma média das deformações atuais (foto correspondente), sejam essas nominais ou logarítmicas. Ou seja, é feita uma média aritmética dos valores de deformação que compõem uma matriz de deformações correspondente. O problema nesse procedimento é que nem toda a área dos corpos-de-prova é representada por uma malha virtual que calcula esses deslocamentos. As extremidades quase sempre são excluídas nas análises. Logo, o comportamento dessas regiões não analisadas pelo programa, faz com que os resultados obtidos sejam estatisticamente favoráveis às deformações representadas. Ou seja, os resultados obtidos contêm um erro estatístico ao calcular um valor médio para os campos de deformações, por exemplo, pois assim estes valores deveriam ser maiores ou não dependentes do comportamento das regiões não representadas. Além disso, a existência das frentes de plastificação faz com que seja muito difícil analisar regiões com campos de deslocamento mais heterogêneos. Ademais, é importante lembrar que o cálculo logarítmico de deformações de compressão envolve valores negativos, e com isso a função logarítmica envolvida nas respectivas deformações aumenta exponencialmente para grandes deformações.

Visando contornar essas dificuldades, a deformação logarítmica média foi calculada a partir da deformação nominal fornecida pelo programa. Resumidamente, utilizou-se a expressão (123) para o cálculo das deformações logarítmicas médias $\bar{\varepsilon}_{l o g}$ a partir da matriz de deformação nominal (com dimensões $R \mathrm{x} S$ ) fornecida pelo programa Correli ${ }^{\mathrm{LMT}}$. E este, então, usa a expressão (124) para o mesmo cálculo: 


$$
\begin{gathered}
\bar{\varepsilon}_{\log }=\ln \left(1+\sum_{\substack{r=1 \\
S=1}}^{R, S}\left[\varepsilon_{n}\right]_{r s} / R S\right) \\
\left.\left(\bar{\varepsilon}_{\log }\right)_{\text {Cor }}=\left(\sum_{\substack{r=1 \\
S=1}}^{R, S} \ln \left(1+\varepsilon_{n}\right)\right]_{r s}\right) / R S
\end{gathered}
$$

Adotando esse procedimento, a influência da função logarítmica para deformações negativas elevadas é minimizada, restando assim, a variável estatística como fator de erro. Para evitar isto, procurou-se analisar uma maior área possível dos corpos-de-prova, como pôde ser visualizado nas malhas das Figuras 44 e 45.

Assim, pode-se afirmar que os dados observados nas Figuras 60 e 61 são consistentes e também coerentes, pois se espera que as deformações obtidas pelos dispositivos da máquina EMIC sejam um pouco maiores, haja vista que o equipamento de ensaio acoplado à máquina possui uma flexibilidade, influenciando os resultados, como observado.

\subsubsection{Tração Uniaxial}

Os ensaios de tração, também, possuem respostas que variam com a direção do material. De maneira similar aos ensaios de compressão, são apresentadas duas figuras (uma para cada direção do material) com uma comparação entre os resultados obtidos pela máquina EMIC e pela técnica DIC para um dos corpos-de-prova ensaiados em cada direção. Mostra-se apenas um CDP, pois houve também nos ensaios de tração, uma boa consistência nos resultados.

Nos ensaios de tração, as rigidezes do material, além de variar com a direção de anisotropia, apresentaram variação com a metodologia de aquisição de dados utilizada. Foi constatado que para a direção normal (Fig. 62) o material tem maior rigidez quando esta é calculada pela técnica DIC. Por outro lado, a rigidez na direção do plano (Fig. 63), é maior quando calculada pelo equipamento da máquina EMIC.

Parte dessa diferença pode ser explicada com base na resistência, para a direção normal, bem como com base na resistência do adesivo epóxi utilizado na fixação dos corposde-prova. 


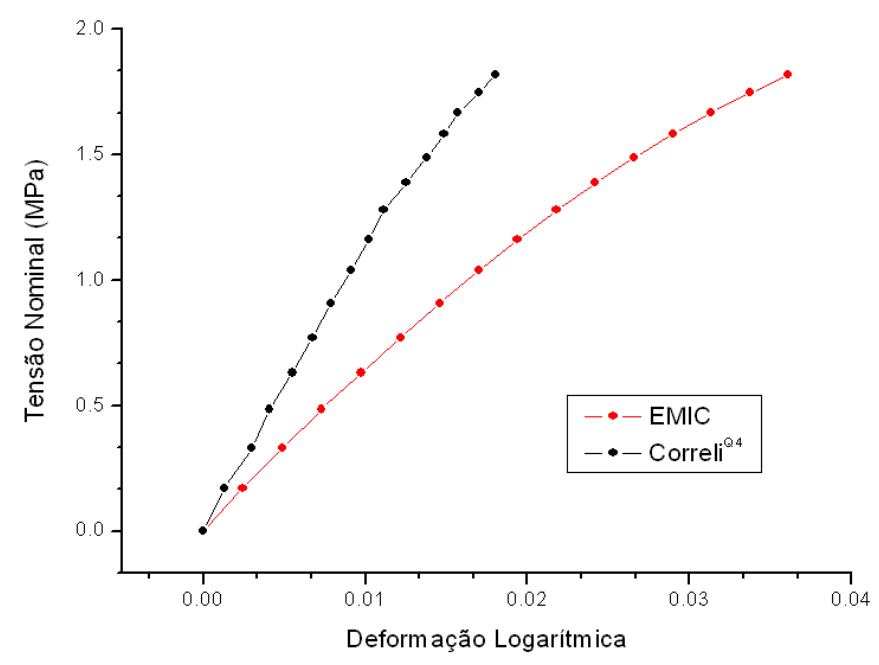

Figura 62. Comparações das deformações para tração na direção normal, calculadas pelas duas metodologias adotadas

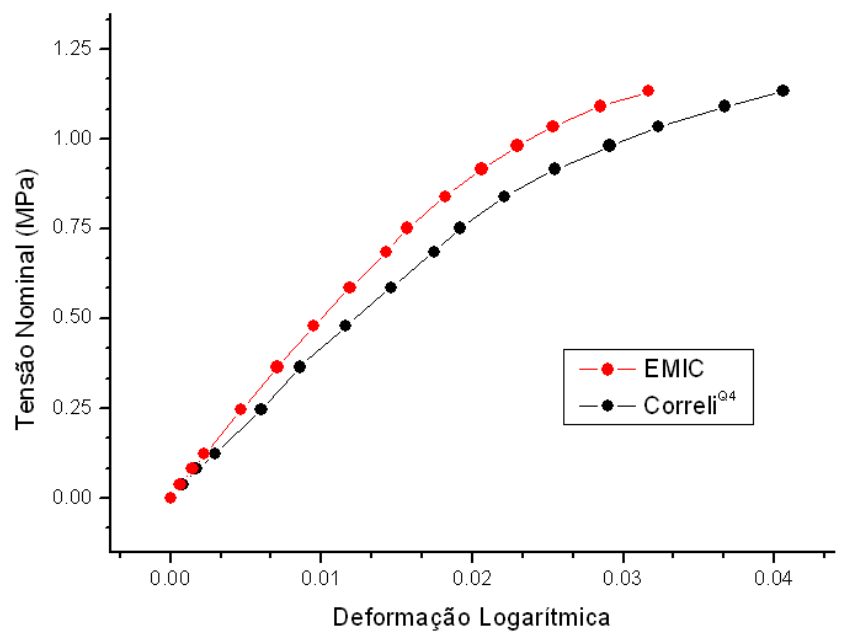

Figura 63. Comparações das deformações para tração na direção do plano, calculadas pelas duas metodologias adotadas

Pela bibliografia consultada, o adesivo comercial epóxi Araldite® tem uma resistência de aproximadamente $0.5 \mathrm{MPa}$. Isto explica a razão entre à área de seção mínima e a da base de fixação ser igual a 1/3. Assim, a tensão na base também foi um terço da registrada a partir da célula de carga. Para a direção normal, a tensão no momento de ruptura do CDP foi de aproximadamente $0.656 \mathrm{MPa}$ e para a direção no plano de $0.356 \mathrm{MPa}$. Comparando esses valores com o da resistência do adesivo, observa-se que no momento da ruptura, o adesivo poderia também se romper para o ensaio na direção normal, porém esse fato não ocorreu porque possivelmente o material tinha uma resistência um pouco superior ao da literatura. Porém, acredita-se que uma cura parcial (tempo de cura abaixo de 24 horas) do adesivo pode ter acarretado em escoamento do mesmo ao final do ensaio. Nesse ponto, a rigidez aparente 
do material, que é menor devido à flexibilidade do equipamento de ensaio, é reduzida um pouco mais devido a uma maior deformação.

$\mathrm{Na}$ direção do plano observou-se um comportamento inverso, pois, uma vez que as análises foram feitas para a região central dos corpos-de-prova (Fig. 47c), o resultado em questão advém do campo de deformações, que segundo o programa Correli ${ }^{\mathrm{LMT}}$, apresentam deformações puramente de tração uniaxial localizada na região central do CDP. Por outro lado, o equipamento da EMIC faz os cálculos utilizando todo o comprimento do corpo-deprova, considerando um campo de deformações uniaxial, uniforme e homogêneo. Todavia, o CDP como um todo apresenta outras componentes de deformação. Essa conclusão não é aplicada à direção normal, pois o campo de deformação ao longo da altura do respectivo corpo-de-prova pode ser considerado puramente uniaxial (Fig. 64).
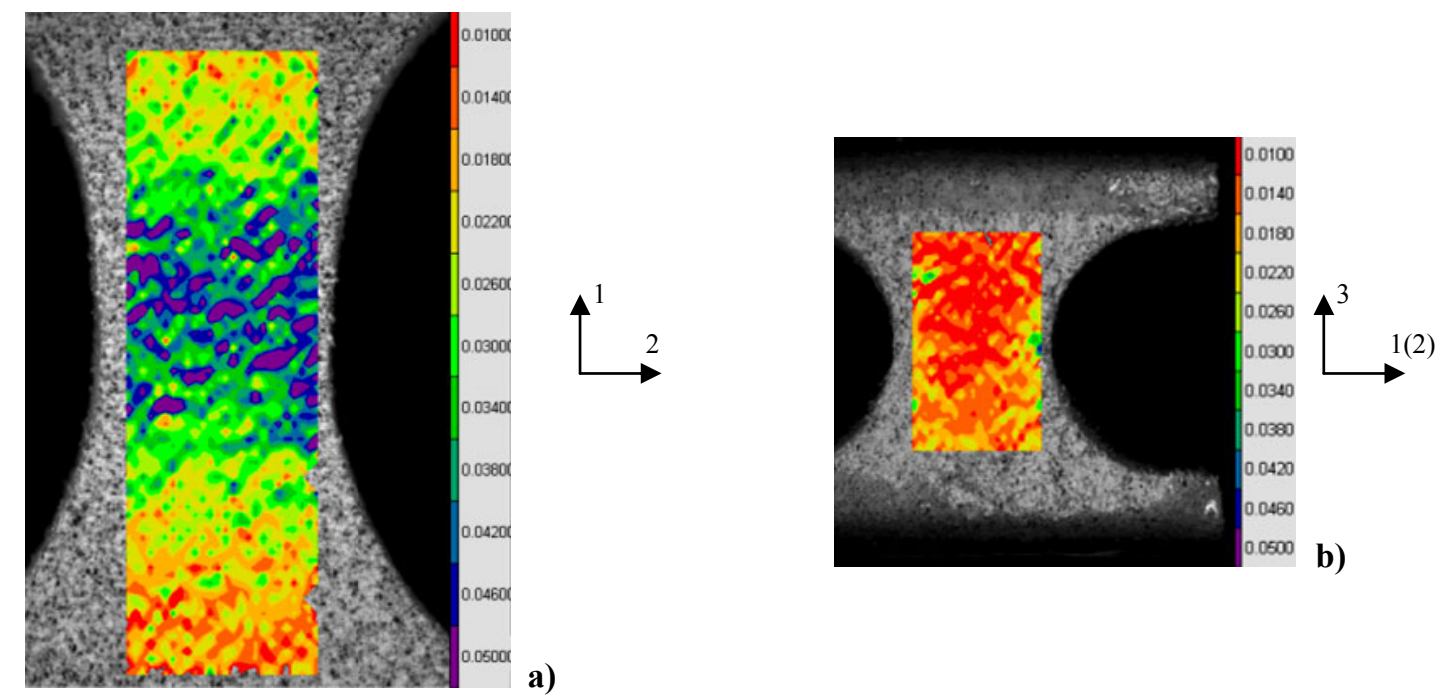

Figura 64. Comparação da variação dos campos de deformação (paralela à direção de carregamento) com a direção do material para os ensaios de tração: a) Direção no plano 1-2; b) Direção normal 3

Conclui-se que, independentemente da direção do ensaio, os resultados obtidos pela técnica de correlação de imagens são os mais próximos do comportamento real do material (apesar dos dados serem localizados) e da rigidez aparente da espuma. Contudo é importante lembrar que para realizar a avaliação criteriosa dos modelos empregados, as propriedades elásticas e/ou plásticas do material devem ser escolhidas com critérios quem nem sempre requerem as propriedades obtidas pela técnica DIC. 


\subsubsection{Propriedades Mecânicas da Espuma H60}

Discutidas as particularidades e resultados dos ensaios realizados, as propriedades elásticas da espuma polimérica material são obtidas criteriosamente a partir das curvas tesãodeformação. Além disso, deve-se monitorar a sensibilidade da estrutura celular e seus modos de falha com a precisão dos ensaios realizados. Pequenas variações na geometria dos corposde-prova ou ainda certos desalinhamentos dos mesmos com a base de apoio e o aplicador de carga acarretam em uma variação nas deformações iniciais que comprometem o cálculo das propriedades mecânicas no regime linear elástico. Nos ensaios cíclicos realizados, existe um ciclo de carregamento e descarregamento na fase linear elástica mostrados nas Figuras 30 e 31 e destacados na Figura 65.
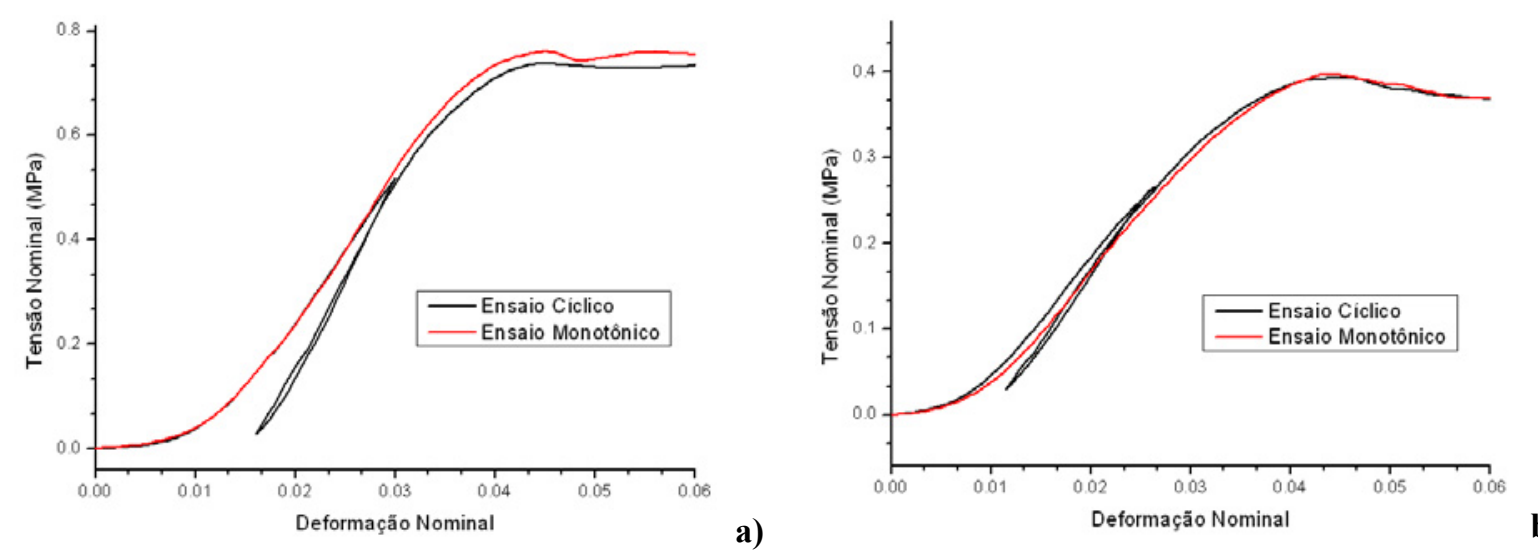

Figura 65. Ciclo de carregamento e descarregamento na fase linear elástica dos ensaios de compressão uniaxial via EMIC: a) Direção normal; b) Direção no plano

Os ensaios monotônicos seguem a linha externa vermelha das curvas na Figura 65 e por isso aparentam ser mais flexíveis devido às acomodações da estrutura celular. Por isso, as rigidezes obtidas a partir da máquina EMIC são aquelas calculadas com base nos ciclos dentro do regime linear elástico do material. Todavia, as rigidezes calculadas com as curvas dos ensaios monotônicos também serão listadas para comparações e validações.

Quanto aos dados para os ensaios de tração, as rigidezes foram calculadas através de uma regressão linear dos dados até $1 \%$ de deformação para ambas as direções normal e no plano.

Finalmente, os coeficientes de Poisson discutidos anteriormente, tanto para a fase elástica quanto plástica, foram determinados com os dados tratados com auxílio do programa Correli $^{\text {LMT }}$. Todos os dados discutidos estão registrados nas Tabelas 13 e 14 com seus 
respectivos erros estatísticos, para serem usados sob as devidas hipóteses nos modelos fenomenológicos investigados no presente trabalho.

Tabela 13 - Propriedades mecânicas para a espuma polimérica H60 de PVC obtidas pelo equipamento da máquina EMIC

\begin{tabular}{|c|c|c|c|c|c|}
\hline \multirow{2}{*}{ Propriedade } & \multirow{2}{*}{ Modo de Ensaio* } & \multicolumn{2}{|c|}{ Compressão } & \multicolumn{2}{|c|}{ Tração } \\
\hline & & Normal & Plano & Normal & Plano \\
\hline \multirow{3}{*}{ Módulo Elástico, E (MPa) } & $C$ & $35.1 \pm 0.1$ & $18 \pm 2$ & $72 \pm 6$ & $48 \pm 3$ \\
\hline & $M$ & $28.2 \pm 0.9$ & $13.5 \pm 0.5$ & $61 \pm 5$ & $41.2 \pm 0.7$ \\
\hline & Valor Médio & $32 \pm 1$ & $16 \pm 3$ & $67 \pm 11$ & $45 \pm 4$ \\
\hline Tensão de Escoamento, $\sigma_{y}(\mathrm{MPa})$ & $M / C$ & $0.75 \pm 0.02$ & $0.396 \pm 0.006$ & $0.714 \pm 0.005$ & $0.43 \pm 0.03$ \\
\hline Tensão de Resistência, $\sigma_{r}(\mathrm{MPa})$ & $M / C$ & $\mathrm{n} / \mathrm{d}$ & $\mathrm{n} / \mathrm{d}$ & $1.96 \pm 0.07$ & $1.07 \pm 0.07$ \\
\hline
\end{tabular}

*O modo de ensaio é representado pelos ensaios monotônicos $(M)$ ou cíclicos $(C)$

Tabela 14 - Propriedades mecânicas para a espuma polimérica H60 de PVC obtidas pela técnica de correlação de imagens e o programa Correli ${ }^{\mathrm{LMT}}$

\begin{tabular}{|c|c|c|c|c|c|}
\hline \multirow{2}{*}{ Propriedade } & \multirow{2}{*}{ Modo de Ensaio* } & \multicolumn{2}{|c|}{ Compressão } & \multicolumn{2}{c|}{ Tração } \\
\cline { 3 - 6 } & & Normal & Plano & Normal & Plano \\
\hline \multirow{2}{*}{ Módulo Elástico, E $(\mathrm{MPa})$} & $C$ & $56 \pm 3$ & $24.7 \pm 0.9$ & $107 \pm 5$ & $38 \pm 4$ \\
\cline { 2 - 6 } & $M$ & $49 \pm 3$ & $20 \pm 1$ & $116 \pm 3$ & $29 \pm 1$ \\
\cline { 2 - 6 } & Valor Médio & $53 \pm 6$ & $22 \pm 2$ & $112 \pm 8$ & $34 \pm 5$ \\
\hline Coeficiente de Poisson Elástico, $v_{e l}$ & $M / C$ & $0.35 \pm 0.01$ & $0.22 \pm 0.2$ & $0.1 \pm 0.2$ & $0.5 \pm 0.2$ \\
\hline Coeficiente de Poisson Plástico, $v_{p l}$ & $M / C$ & $0.05 \pm 0.03$ & $0.02 \pm 0.08$ & $0.04 \pm 0.05$ & $0.49 \pm 0.09$ \\
\hline
\end{tabular}

*O modo de ensaio é representado pelos ensaios monotônicos $(M)$ ou cíclicos $(C)$

Para completar os dados experimentais que serão utilizados nas modelagens computacionais, tem-se que o laminado compósito da estrutura sanduíche possui as propriedades mecânicas sob tração apresentadas na Tabela 15 (SOARES, 2009). Vale ressaltar que as propriedades da Tabela 15 são para um compósito de fibra de vidro e epóxi com tecido bidirecional $[0 / 90]_{\mathrm{T}}$. Sendo que na estrutura sanduíche, o laminado da face possui empilhamento $[0 / 90 / /+45 /-45 / / 0 / 90]_{\mathrm{T}}$.

Tabela 15 - Propriedades mecânicas para o material compósito da estrutura sanduíche investigada

\begin{tabular}{|c|c|c|c|c|}
\hline ASTM D3039/D3518 & $\mathbf{E}_{\mathbf{1 1}}(\mathbf{G P a})$ & $\boldsymbol{v}_{\mathbf{1 2}}$ & $\mathbf{G}_{\mathbf{1 2}}(\mathbf{G P a})$ & $\mathbf{X}_{\mathbf{T 1}}=\mathbf{X}_{\mathbf{T} 2}(\mathbf{M P a})$ \\
\hline Valores Médios & 26.5 & 0.16 & 4.25 & 419 \\
\hline
\end{tabular}




\subsection{Resultados Computacionais}

As modelagens computacionais foram divididas em 2 grandes grupos, ou seja, modelos para a espuma e para a estrutura sanduíche.

Com os primeiros modelos avaliam-se os parâmetros obtidos nos ensaios experimentais e verifica-se se o modelo calibrado com os parâmetros identificados produz resultados computacionais satisfatórios através de modelos de verificação. Depois de verificar estes modelos para os ensaios uniaxiais, uma validação final é feita com os ensaios de endentação.

Em um segundo momento, o modelo de material para espuma H60 devidamente calibrado é utilizado na modelagem de um ensaio de flexão em três pontos para a estrutura sanduíche das Figuras 15 e 16 cujos resultados experimentais foram obtidos de Oliveira (2007).

\subsubsection{Modelos Computacionais para a Espuma Polimérica}

Divididos de acordo com o tipo de ensaio, verificar-se-á o quanto os modelos computacionais se aproximam dos respectivos resultados experimentais em compressão e tração. Somente então, é possível modelar os ensaios de endentação. De acordo com os resultados dos ensaios realizados, foram feitos estudos sobre a convergência dos respectivos modelos, para se avaliar as potencialidades e limitações do emprego desses modelos implementados no programa ABAQUS.

No programa ABAQUS estão contidas duas formulações de modelo de material com encruamento para materiais celulares, sendo uma com encruamento isotrópico e a outra com encruamento misto. Vale ressaltar que as mesmas foram originalmente implementadas para espumas metálicas. Comparando-se as propriedades mecânicas da espuma H60 nas Tabelas 13 e 14 com as curvas de encruamento na Figura 57, nenhum dos modelos disponíveis no ABAQUS, representa idealmente o material estudado por motivos diferentes.

O modelo com encruamento isotrópico além de não retratar os diferentes valores para as tensões de escoamento em tração e compressão uniaxial, o potencial de escoamento associado faz com que o material produza encruamento igualmente sob qualquer solicitação 
mecânica, o que não ocorre com a espuma H60, como foi visto na Figura 57. Por outro lado, o modelo de material com encruamento volumétrico permite o ajuste da superfície inicial de escoamento de acordo com a superfície de escoamento inicial não isotrópica, bem como um encruamento volumétrico que mais se aproxima do encruamento observado na Figura 57. Todavia a implementação deste último modelo de material considera que em geral a tensão de escoamento do material em tração hidrostática é de $5 \%$ a $10 \%$ do valor para o limite em compressão hidrostática. Desse modo, tem-se que para carregamentos com somente tensões desviadoras e/ou com pressão hidrostática negativa (tração), o modelo apresenta comportamento perfeitamente plástico. Tal hipótese é valida, pois sendo o encruamento dado pela equação (94), a parcela da superfície para a qual se assume uma resposta sem encruamento se aproxima da resposta que seria obtida se a superfície como um todo evoluísse com a equação (94). Acredita-se que essa aproximação foi feita visando uma otimização do algoritmo associado à principal solicitação a qual são projetadas as espumas, ou seja, o carregamento de compressão. Contudo, nem sempre os materiais celulares estão submetidos somente a carregamentos compressivos, e como mencionado na bibliografia do presente trabalho, carregamentos concentrados como os observados em ensaios de flexão em três pontos produzem carregamentos multiaxiais localizados. Estes carregamentos associados à plastificação do material podem influenciar de maneira diferente os critérios de convergência do algoritmo implementado. Por isso, na respectiva implementação, impõe-se a restrição de que o modelo de material com encruamento volumétrico deva ser usado essencialmente para carregamentos monotônicos. Como o encruamento é governado pela tensão equivalente de von Mises, a variável que determina a convergência do modelo numérico é a tensão média (negativa). Quando os valores de tensão hidrostática negativa variam significativamente (oscilam) dentro de um dado elemento finito, tem-se que as forças internas do elemento passam a interferir de forma significativa nas equações de equilíbrio, o que ocasiona o travamento da solução numérica em modelos com carregamentos uniaxiais e/ou multiaxiais não-monotônicos localmente. Esses carregamentos produzem oscilações nos valores das tensões hidrostáticas negativas que se amplificam com erros numéricos do algoritmo de plastificação, que por sua vez busca a superfície de escoamento durante os incrementos da análise (com o método de retorno de Euler). Além disso, essas oscilações são maiores quanto mais próximo o elemento estiver de um estado de tensão desviador puro. Isso porque um incremento na tensão hidrostática próxima do eixo das ordenadas (ou eixo das tensões desviadoras) pode mudar o regime de plastificação dos pontos de integração do respectivo elemento o que gera maiores descontinuidades dentro do elemento. Essas observações estão 
fundamentadas nas análises de muitos modelos computacionais realizados para carregamentos uniaxiais e multiaxiais monotônicos ou não.

Para que se minimize essas oscilações, os carregamentos impostos ao material devem ser essencialmente monotônicos, e para carregamentos multiaxiais, quanto menor o módulo de encruamento do material menores serão as possibilidades de travamento do algoritmo. Felizmente, a espuma polimérica de PVC, assim como outros materiais celulares apresentam uma fase inicial de encruamento (Figs. 52 e 54) sob compressão uniaxial que se aproxima de um material perfeitamente plástico até aproximadamente $50 \%$ de deformação logarítmica. Acima desse valor de deformação, dependendo das propriedades do material, o uso do modelo deve ser mais cauteloso.

Uma vez que foram usadas técnica e metodologias de ensaio experimental apenas com base nos respectivos ensaios normalizados ou não, uma avaliação das propriedades obtidas juntamente com modelos de tração e compressão uniaxial é realizada, para então, posteriormente, realizar-se as análises com os ensaios de endentação.

São definidas inicialmente quatro superfícies de escoamento de acordo com os valores limites na Tabela 16 que serão utilizadas de acordo com o modelo computacional e o seu ensaio experimental. Os respectivos parâmetros de calibração $k, k_{t}$, e $v_{p l}$, estão definidos na Tabela 17. Para a determinação dessas quatro e das demais presentes nesse tópico, é utilizado o dado de compressão hidrostática ao invés da tensão de escoamento em cisalhamento. Isso porque a espuma H60 mostrou-se anisotrópica e como os modelos de material implementados assumem que o material é isotrópico, o uso dos resultados para a compressão hidrostática aumenta a representatividade das superfícies identificadas.

Tabela 16 - Parâmetros para a determinação das superfícies de escoamento iniciais

\begin{tabular}{|c|c|c|c|c|}
\hline Superfície & Direção & $\begin{array}{c}\text { Compressão } \\
\text { Uniaxial (MPa) }\end{array}$ & $\begin{array}{c}\text { Tração Uniaxial } \\
\text { (MPa) }\end{array}$ & $\begin{array}{c}\text { Compressão } \\
\text { Hidrostática (MPa) }\end{array}$ \\
\hline$I$ & Normal & 0.714 & 0.714 & 0.45 \\
\hline$I I$ & Plano & 0.43 & 0.43 & 0.45 \\
\hline$I I I$ & Normal & 0.75 & 1.96 & 0.45 \\
\hline$I V$ & Plano & 0.396 & 1.07 & 0.45 \\
\hline
\end{tabular}

Tabela 17 - Parâmetros $k$, $k_{\mathrm{t}}$ e $v_{\mathrm{pl}}$ para as superfícies de escoamento inicial

\begin{tabular}{|c|c|c|c|c|c|}
\hline Superfície & Direção & Encruamento & $\mathbf{k}$ & $\mathbf{v}_{\mathbf{p l}}$ & $\mathbf{k}_{\mathbf{t}}$ \\
\hline$I$ & Normal & Isotrópico & 1.5832 & 0.04 & $\mathrm{n} / \mathrm{d}$ \\
\hline$I I$ & Plano & Isotrópico & 0.9540 & 0.49 & $\mathrm{n} / \mathrm{d}$ \\
\hline$I I I$ & Normal & Volumétrico & 1.8852 & $\mathrm{n} / \mathrm{d}$ & 12.2965 \\
\hline$I V$ & Plano & Volumétrico & 1.9522 & $\mathrm{n} / \mathrm{d}$ & 5.1478 \\
\hline
\end{tabular}


Duas superfícies são isotrópicas ( $I$ e $I I)$, uma para cada direção das propriedades da espuma. Cada uma desta é definida com os respectivos limites de escoamento em tração para a construção dos modelos de tração. Outras duas superfícies volumétricas (III e $I V$ ) foram definidas com a tensão de escoamento em compressão uniaxial e a tensão de resistência em tração uniaxial. Estas superfícies são usadas nos modelos de compressão e tração uniaxiais.

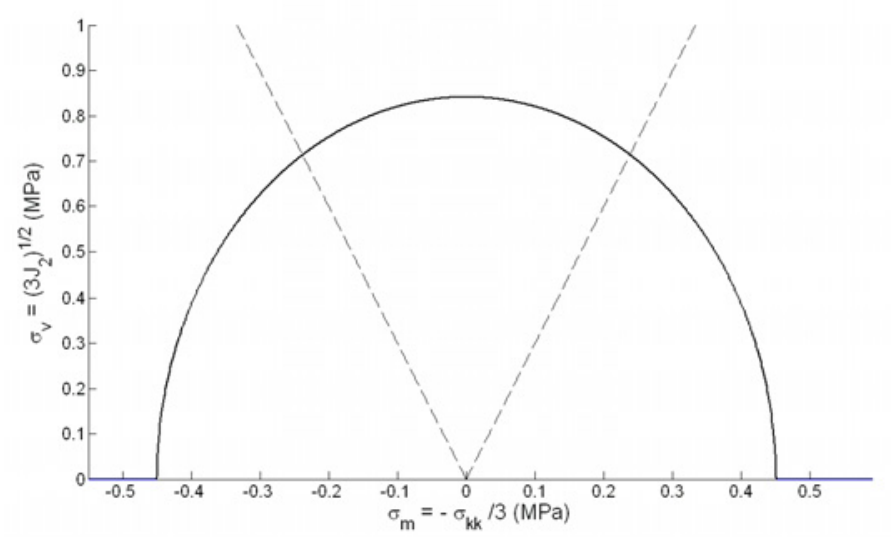

Figura 66. Superfície inicial de escoamento I

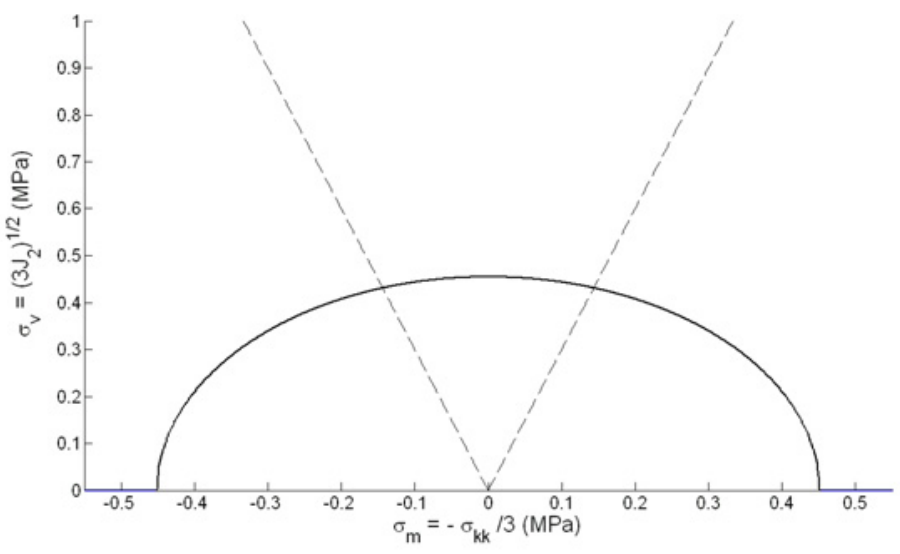

Figura 67. Superfície inicial de escoamento II

As Figuras 66 e 67 exibem as formas iniciais das superfícies I e II e as Figuras 68 e 69 trazem as superfícies III e IV bem como suas evoluções, que podem gerar complicações na convergência no algoritmo de plastificação do modelo de material com encruamento volumétrico. As evoluções das superfícies são expostas para uma avaliação de sua aplicabilidade na espuma polimérica H60 nos modelos computacionais e posterior calibração do modelo. As referidas figuras exibem as curvas de tensão $\left(\sigma_{\mathrm{v}}=-3 \sigma_{\mathrm{m}}\right)$ e compressão uniaxiais $\left(\sigma_{\mathrm{v}}=3 \sigma_{\mathrm{m}}\right)$ como referências.

Na Figura 68, a superfície verde corresponde a uma tensão de encruamento de $\sigma_{\mathrm{v}}=$ 1.8MPa. Pelas curvas de encrumanto do material (Fig. 57), esse nível de tensão corresponde a 
uma deformação de compressão acima de $50 \%$, sendo que acima deste valor, os problemas de convergência são mais frequentes em análises multiaxiais. Pode-se observar estes problemas de convergência analisando como as superfícies de escoamento deveriam evoluir e como acredita-se que as mesmas evoluam segundo o algorítmo implementado no programa ABAQUS. Portanto, tanto na Figura 68 como na 69, tem-se que o algoritmo implementado no programa ABAQUS irá evoluir a superfície de plastificação de forma similar à porção localizada à direita do eixo desviador, ou seja, com tensão hidrostática positiva (compressão). Por outro lado, para a porção localizada à esquerda do eixo desviador (tensão hidrostática negativa), a superfície de plasticação do programa ABAQUS não irá evoluir, e assim, não será similar à superfície mostrada nas Figuras 68 e 69.

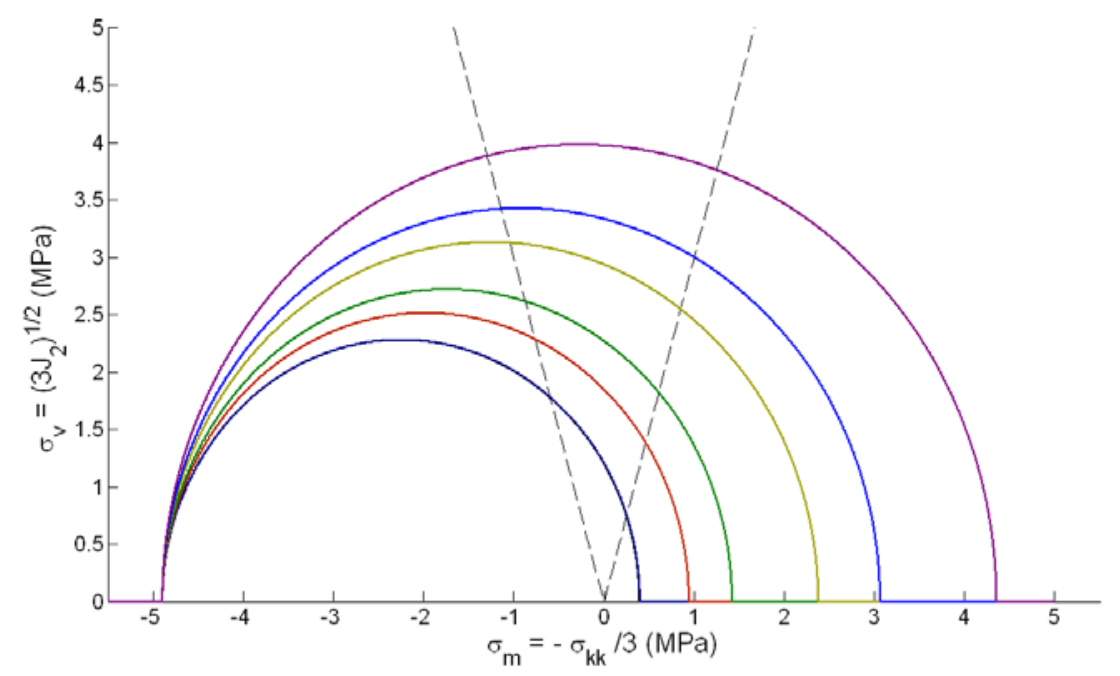

Figura 68. Evolução da superfície de falha III para a direção normal. A elipse mais interna corresponde à superfície de escoamento inicial

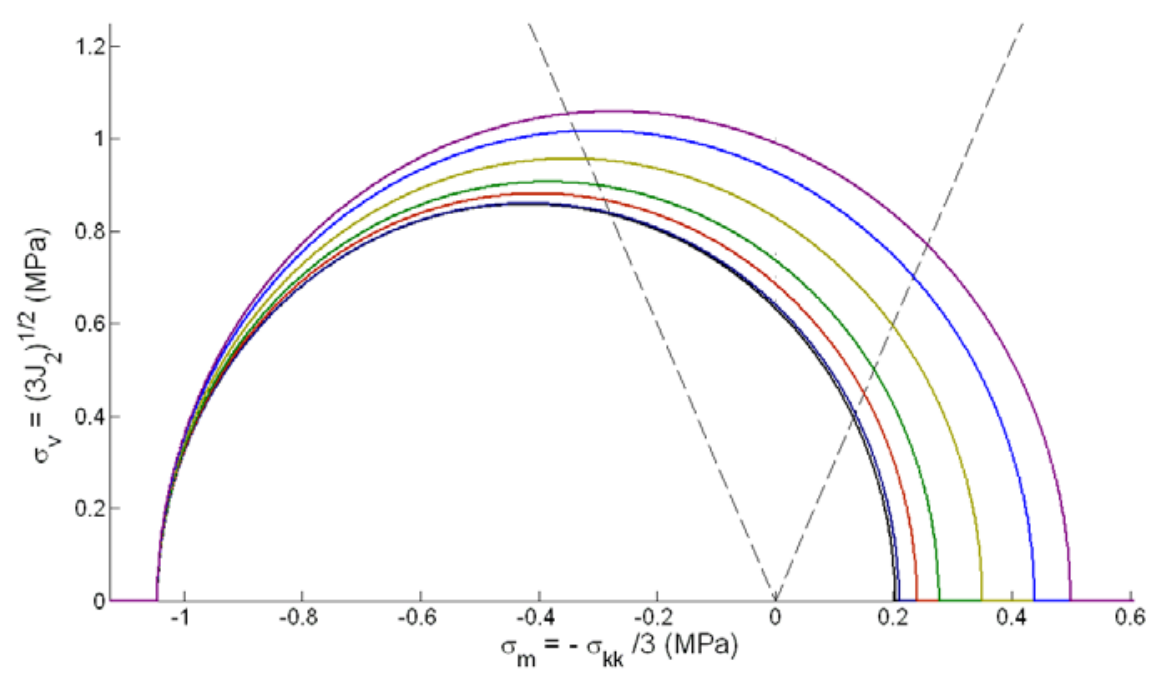

Figura 69. Evolução da superfície de falha IV para a direção no plano. A elipse mais interna corresponde à superfície de escoamento inicial 
Observa-se que para análises em elementos finitos no respectivo programa, os elementos que estão submetidos a tensões hidrostáticas próximas de zero, sob deformações logarítmicas acima de 50\% e dependendo das funções de forma do elemento, os problemas de convergência em relação ao algorítmo de plasticidade podem ser mais ou menos influentes na convergência da análise como um todo.

Na direção 1(2) no plano, a elipse em azul claro na Figura 69, corresponde a uma tensão equivalente de von Mises de $\sigma_{\mathrm{v}}=0.70 \mathrm{MPa}$ que também representa um nível de deformação acima de 50\%, logo esse modelo deve ser empregado também com cautela.

\subsubsection{Modelos Computacionais para Compressão Uniaxial}

As superfícies são construídas de acordo com os parâmetros da Tabela 17 e as propriedades elásticas utilizadas são os valores médios da Tabela 13 correspondente aos valores obtidos pela máquina EMIC. Apesar dos dados obtidos via técnica DIC serem mais representativos para o material, sabe-se que os resultados computacionais são mais rígidos, pois são livres de flexibilidades do equipamento de ensaio. Com isso, visando uma melhor representação computacional do ensaio específico, as rigidezes utilizadas são as obtidas via EMIC. Os modelos computacionais para os ensaios de compressão utilizaram as curvas de encruamento das equações (119) e (120) para as direções no plano e normal respectivamente. É importante lembrar que os valores iniciais para as curvas de encruamento devem ser ajustados de tal forma que as curvas iniciem com os valores de tensões de escoamento em compressão uniaxial. Para fins comparativos, os modelos computacionais são realizados também para os ensaios de compressão uniaxial, tomando as curvas de encruamento real dada nas equações (117) e (118).

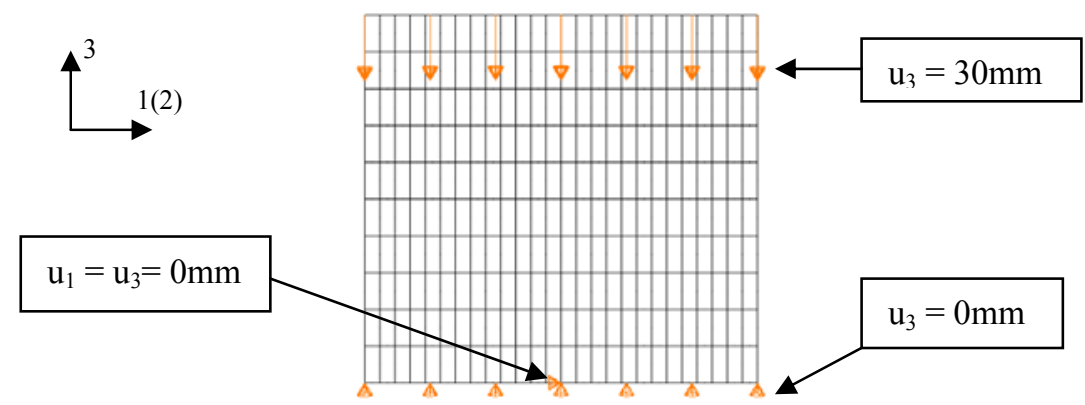

Figura 70. Modelo computacional para compressão uniaxial na direção normal: malha e condições de contorno 
A geometria foi modelada de acordo com a Tabela 5 e a malha e as respectivas condições de contorno estão exibidas na Figura 70 para a direção normal. Para a direção no plano a análise é análoga.

Para essas análises mais simples, os elementos escolhidos são quadriláteros com interpolação quadrática para um estado plano de deformação, designados no programa ABAQUS por CPE8 (quadriláteros com 8 nós). Os resultados obtidos para ambas as direções são exibidos nas Figuras 71 e 72.

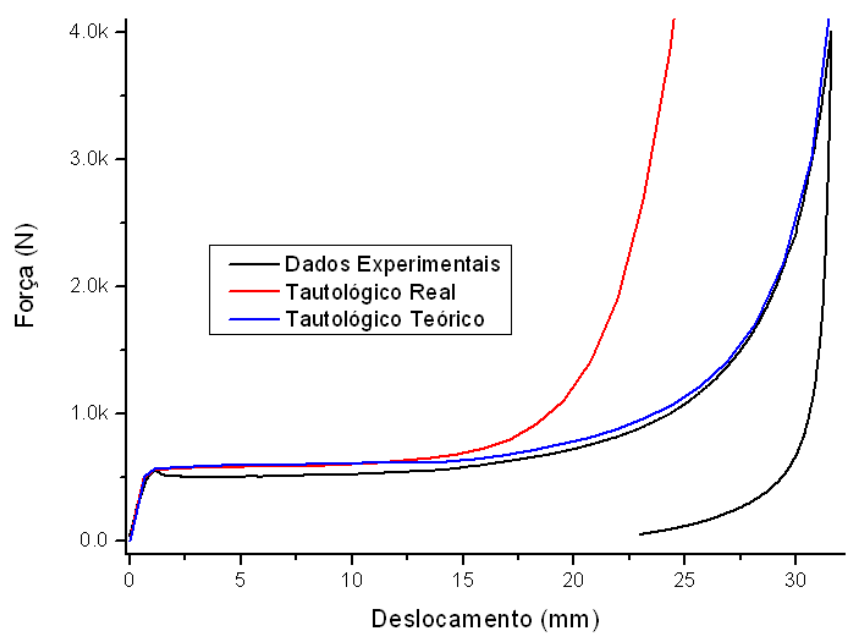

Figura 71. Comparação entre resultado experimental e modelo computacional de compressão com curvas de encruamento teórica e real para uma direção no plano

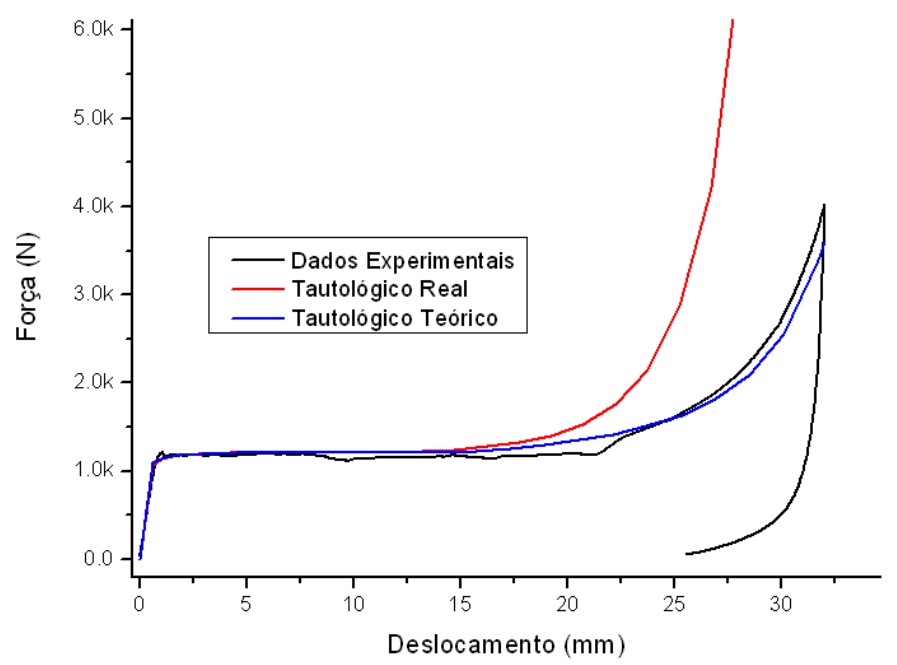

Figura 72. Comparação entre resultado experimental e modelo computacional de compressão com curvas de encruamento teórica e real para a direção normal

Observa-se que a utilização da metodologia teórica na obtenção da curva de encruamento, resulta em um comportamento do modelo computacional que mais se aproxima da curva experimental obtida. Isso porque, como foi discutido anteriormente, os mecanismos 
de falha micro-mecânicos de flambagem sofrem grandes deslocamentos sem necessariamente serem deformados proporcionalmente a estes deslocamentos. Por isso a curva de encruamento real fornece uma densificação antecipada através do modelo computacional, o que não ocorre na realidade, evidenciando uma limitação do modelo de material. Todavia as curvas de encruamento teórico serão utilizadas, mas com a ressalva de que os modelos constam apenas de carregamentos monotônicos, pois o retorno elástico do material proveniente das micro flambagens não é contabilizado.

Outra diferença nas Figuras 71 e 72 é o nível de tensão do platô. Para a direção normal existem apenas pequenas variações decorrentes da formação e evolução das frentes de plastificação (Figs. 10 e 34). Na direção 1(2) no plano, a superfície de escoamento inicia com o valor da tensão de pico, pois, como já mencionado anteriormente, esse pico de tensão tem forte reincidência e seu valor não pode ser desconsiderado, de tal forma a assumir o nível de tensão do platô como o limite de escoamento do material. Todavia, essa metodologia será questionada quando a calibração do modelo for realizada com os ensaios de endentação devido à concentração de carga na estrutura celular e seus mecanismos de falha micro e macroscópicos.

\subsubsection{Modelos Computacionais para Tração Uniaxial}

Em tração as análises são razoavelmente mais complicadas. Os modelos computacionais são divididos em modelos via EMIC e modelos via Correli ${ }^{\text {LMT }}$. A diferença está na geometria que foi modelada no programa ABAQUS e no uso das respectivas propriedades elásticas. Essa abordagem foi realizada para que os dados obtidos com a técnica EMIC fossem investigados quanto à influência do equipamento, metodologia de ensaio e com o perfil dog bone utilizados para os corpos-de-prova de tração. Além disso, dado o perfil estrutural destes corpos-de-prova, um estudo sobre a influência do uso de modelos isotrópicos para um material com forte anisotropia foi realizado. Por outro lado, os perfis retangulares foram construídos para a verificação das propriedades obtidas via técnica DIC que são tidos como mais representativos. Dessa forma, as quatro geometrias diferentes abordadas estão de acordo com as Figuras 73 e 74. Novamente as malhas utilizam o elemento CPE8.

Vale ressaltar que a utilização de dados dos corpos-de-prova com perfil parcialmente normalizado tornou-se viável devido à utilização da técnica de correlação de imagens. Através desta foi possível analisar somente as regiões centrais dos corpos-de-prova, região na qual, 
como comentado, contém a menor influência do cisalhamento presente nos corpo-de-prova. Portanto, são regiões que apresentam carregamento puro de tração o que possibilita a verificação de parâmetros.

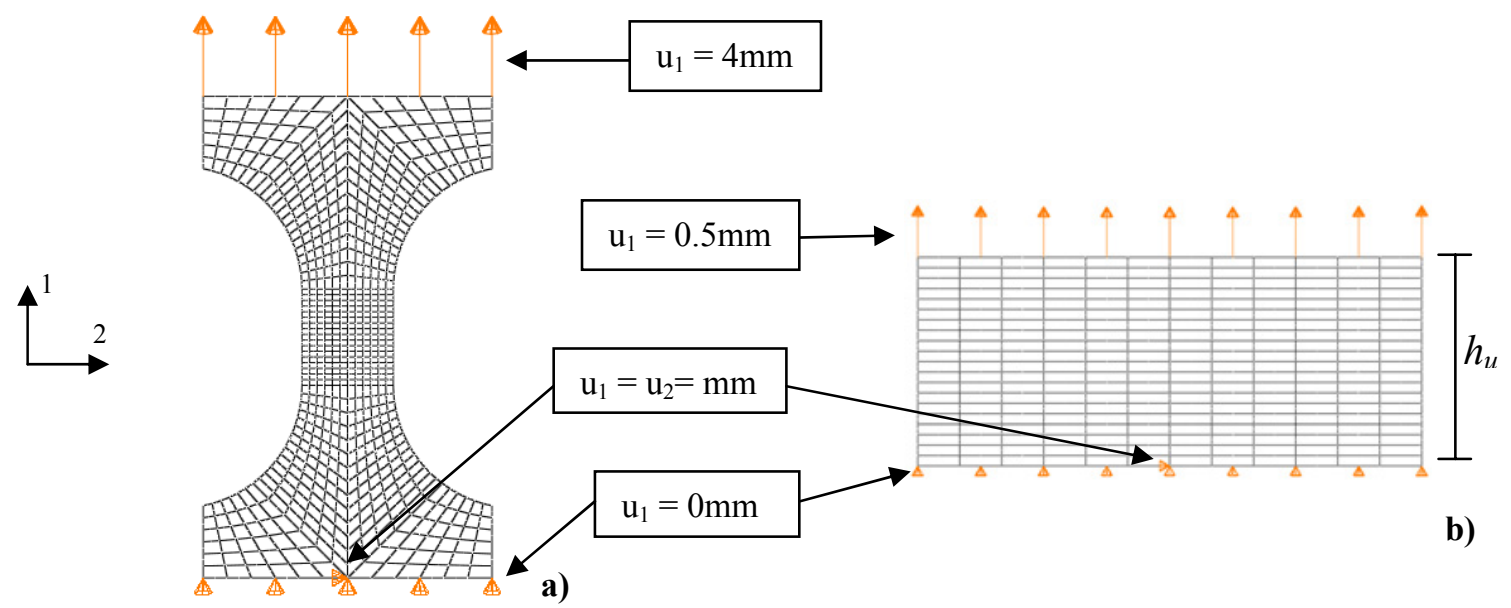

Figura 73. Geometrias para a direção no plano: a) Análise com dados da EMIC; b) Análise com dados via Correli $^{\text {LMT }}$

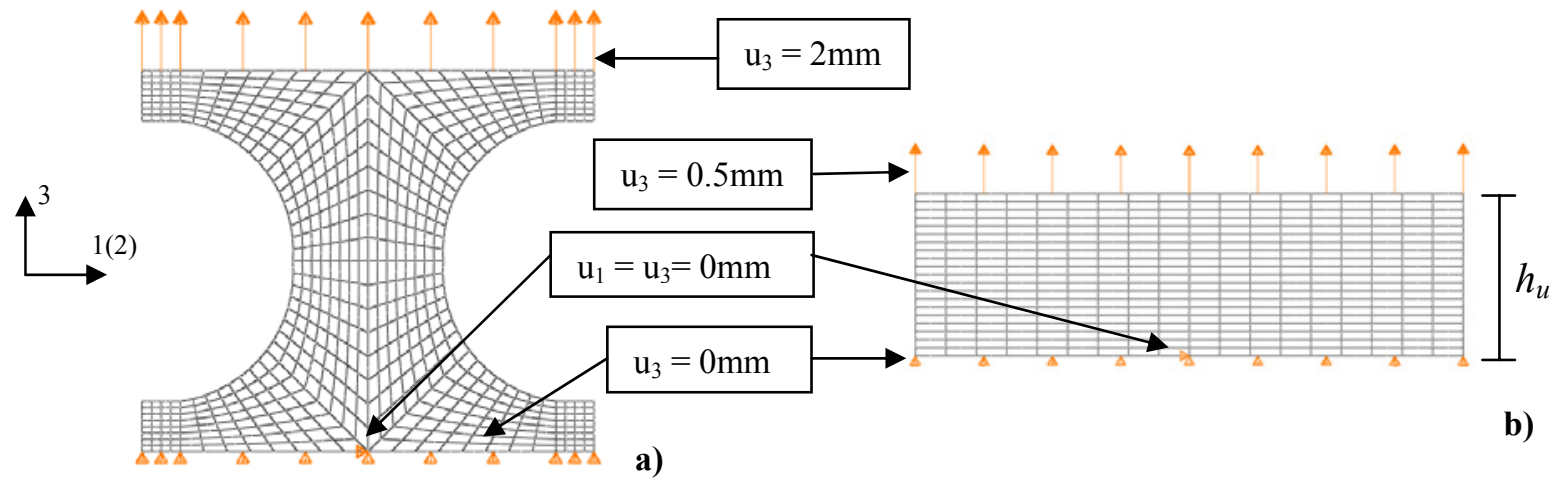

Figura 74. Geometrias para a direção normal: a) Análise com dados da EMIC; b) Análise com dados via Correli $^{\text {LMT }}$

Para cada corpo-de-prova existe uma escala de $\mathrm{mm} /$ pixel a partir da qual é possível obter os campos de deslocamento no CDP através do programa Correli ${ }^{\mathrm{LMT}}$, campos estes que são utilizados na determinação da altura útil $\left(h_{u}\right)$ dos perfis retangulares para modelos de verificação de parâmetros (Figs. 73b e 74b). Há uma complicação na obtenção desse campo de deslocamento que pode ser melhor identificada com auxílio da Figura 75.

$\mathrm{Na}$ Figura 75, observa-se que conforme a análise das imagens avança, a malha do programa Correli $^{\text {LMT }}$ torna-se insuficiente. Isso porque previamente às análises, é definida a região sobre a qual serão realizados os cálculos de deslocamento e deformação. 

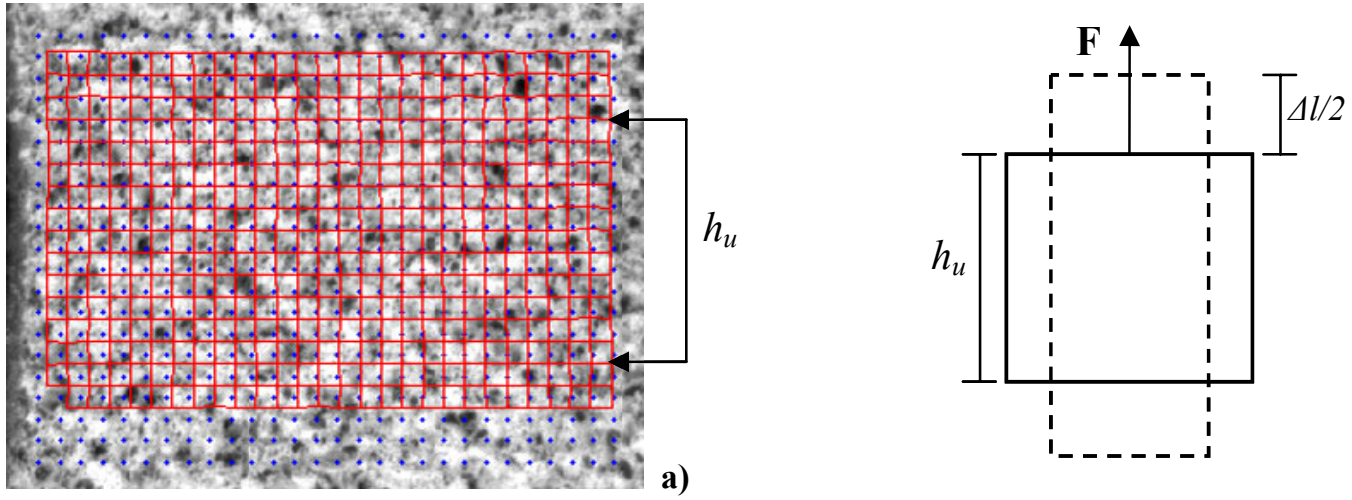

b)

Figura 75. Identificação ilustrativa da malha útil em a) e da respectiva altura $h_{u}$ e o deslocamento $\Delta l$ em b)

Contudo sob tração, toda a região em destaque na Figura 75 se desloca, e, portanto, é necessário identificar a região na malha com altura máxima útil $\left(h_{u}\right)$, sendo essa utilizada na determinação das geometrias das Figuras 73 b e 74b. Identificada esta altura, utiliza-se um valor médio do deslocamento dos elementos das regiões limites inferior e superior para determinar o deslocamento total $(\Delta l)$ da região central. Isto visa compatibilizar as análises via Elementos Finitos com as análises via Correli ${ }^{\text {LMT }}$ para os resultados da região central dos corpos-de-prova (Figs. 46 e 47).

Construiu-se assim, oito modelos computacionais no programa ABAQUS cujos resultados estão agrupados na Figura 76 para a direção 1(2) no plano e na Figura 77 para a direção normal. Foram empregadas, as rigidezes médias das Tabelas 13 e 14 de acordo com a origem dos dados experimentais. Existem, contudo, algumas particularidades que devem ser realçadas. Primeiro, para o plano 1-2, o coeficiente Poisson é próximo a 0.5 o que caracteriza um material hiperelástico, porém o baixo nível de deformação envolvido não requisita o emprego de modelos e/ou elementos específicos para este tipo de solução numérica específica. Outro ponto a ser destacado, é a anisotropia do material que não é modelada no programa ABAQUS por imposição da implementação dos respectivos algoritmos de plastificação. Com isso, os modelos estruturais bidimensionais ou modelos estruturais tridimensionais são parcialmente comprometidos quando o comportamento da seção perpendicular ao carregamento é modelado isotropicamente, pois, a anisotropia da espuma H60 produz variações em torno de $50 \%$, tanto em resistência quanto em rigidez.

Considerando que a espuma polimérica seja transversalmente isotrópica, para o carregamento na direção normal, a influência da anisotropia é mínima. Isto se explica através do equacionamento ortotrópico aplicado ao material (eq. (125), que supõe a direção 3 normal ao plano). Nota-se que as deformações na direção normal praticamente não são influenciadas pelas propriedades transversais. Por outro lado, na direção 1(2) no plano, um equacionamento 
semelhante indica que a anisotropia do material não pode ser desconsiderada (eq. (126)), pois afeta diretamente as propriedades elásticas de ambas as direções.

$$
\begin{aligned}
& \varepsilon_{3}=\frac{1}{E_{3}}\left[\sigma_{3}-v_{31}\left(\sigma_{1}+\sigma_{2}\right)\right] \\
& \varepsilon_{2}=\frac{\sigma_{2}}{E_{1}}-\left(\frac{\nu_{12}}{E_{1}} \sigma_{1}+\frac{v_{31}}{E_{3}} \sigma_{3}\right)
\end{aligned}
$$

Supondo um módulo de elasticidade e um coeficiente de Poisson menores para o modelo computacional no plano $1-2$, o primeiro $\left(v_{12} / E_{1}\right)$ e o segundo $\left(v_{31} / E_{3}\right)$ termos entre parênteses na equação (126), são, respectivamente, 6.5E-3 $\mathrm{MPa}^{-1}$ e $3.1 \mathrm{E}-3 \mathrm{MPa}^{-1}$ para os dados coletados via Correli ${ }^{\mathrm{LMT}}$ e em torno de $4.9 \mathrm{E}-3 \mathrm{MPa}^{-1}$ e $5.2 \mathrm{E}-3 \mathrm{MPa}^{-1}$ para os dados via EMIC (Tabelas 13 e 14). Assim, para carregamentos de tração, os modelos computacionais com resultados do programa Correli ${ }^{\mathrm{LMT}}$ apresentam comportamento menos rígido que os experimentais (Figura 76). Por outro lado, os modelos representativos da metodologia empregada (corpo-de-prova com perfil de validação), que utilizam os dados coletados via EMIC, apresentam comportamento mais rígido que os dados experimentais, como pode ser visto na Figura 76. Ademais, os níveis de distorção angular do material para essa geometria são da mesma ordem que as deformações nas respectivas direções de carregamento (Fig. 78), confirmando que o corpo-de-prova como um todo está sob um estado multiaxial de carregamento. Isto faz com que a razão $v_{31} / E_{3}$ tenha maior influência nos resultados macroscópicos dos modelos de validação, do que a referida razão no modelo computacional.

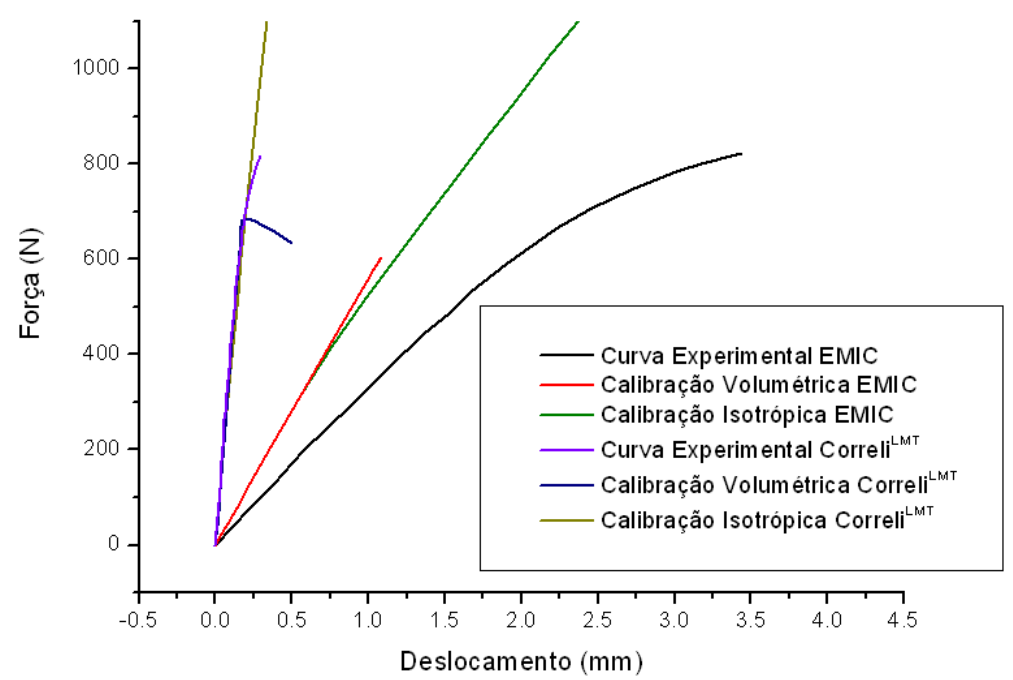

Figura 76. Comparação entre resultado experimental e modelo computacional de tração na direção no plano 


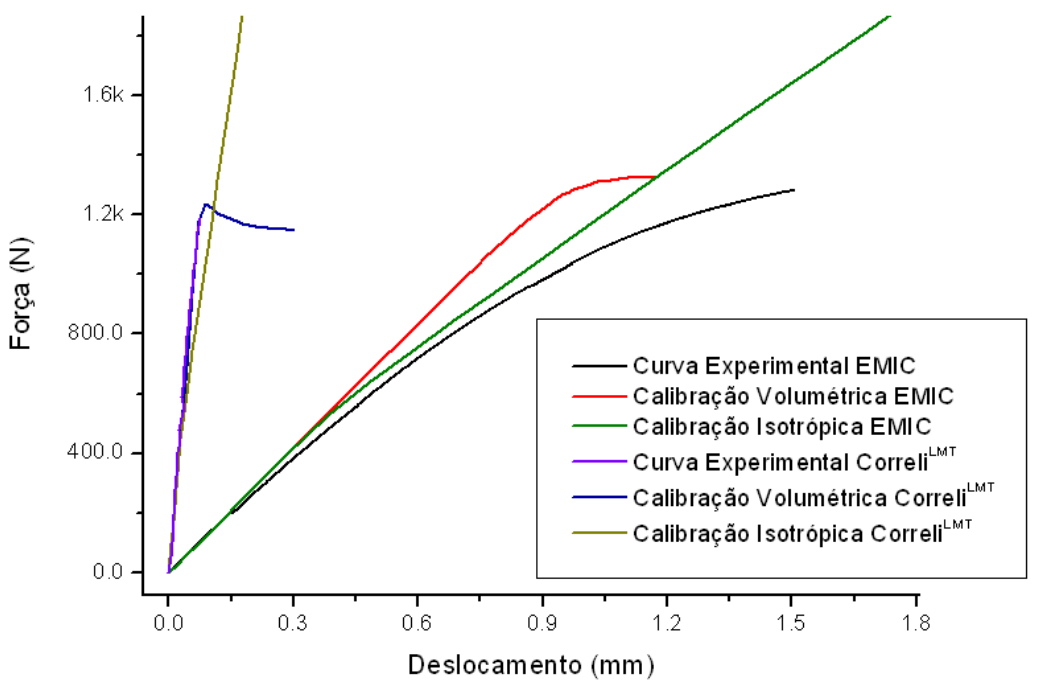

Figura 77. Comparação entre resultado experimental e modelo computacional de tração na direção normal

Além disso, os resultados dos modelos computacionais da EMIC são no geral mais rígidos que os experimentais devido à característica de falha micro-mecânica do material, que depende fortemente da regularidade da estrutura celular. No presente trabalho buscou-se utilizar as dimensões para os corpos-de-prova de acordo com as respectivas normas, contudo, no caso dos ensaios de tração, acredita-se que corpos-de-prova em maior escala proporcionariam um resultado mais próximo de uma abordagem macroscópica.

Dessa forma, os resultados das Figuras 76 e 77 estão coerentes devido à simplificação dos modelos de material implementados que assumem um material isotrópico para a espuma H60, cujas propriedades elásticas possuem as variações nas Tabelas 13 e 14. Pode-se melhorar o resultado da Figura 76, utilizando os valores máximos e mínimos de acordo com o modelo numérico em questão. Todavia esses desvios estatísticos são relativamente grandes e um estudo mais focado em ensaios experimentais deve ser realizado para que se possa aplicar as propriedades elásticas dentro de seus desvios. Dessa forma, uma alternativa seria a implementação de um modelo anisotrópico.

Com base na figura 78, bem como, em muitas análises computacionais, conclui-se que a utilização do modelo de material com encruamento volumétrico gera erros numéricos (Figs. 68 e 69) nas análises quando elementos com grande distorção encruam. Isto pode ser explicado devido à simplificação da respectiva implementação discutida, que impede a convergência da análise numérica. Logo, o modelo de material com encruamento volumétrico mostra-se insuficiente para análises multiaxiais cujos principais carregamentos estão associados a uma tensão hidrostática positiva (tração) ou próxima de zero. 

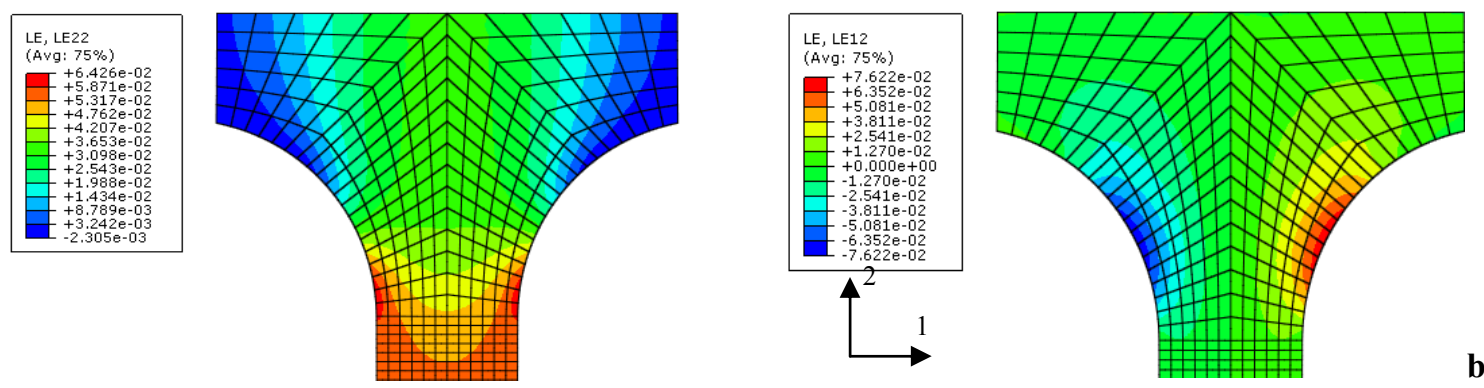

b)

a)

Figura 78. Resultados para uma análise de tração com modelo de material isotrópico: a) Deformação logarítmica na direção do carregamento; b) Distorção no plano 1-2

Por fim, as análises computacionais também demonstraram que o modelo de material é limitado para representar situações de carregamentos uniaxiais não-monotônicos.

\subsubsection{Calibração dos Modelos de Material via Endentação}

Como mencionado, dois modelos de material serão calibrados com os dados experimentais obtidos e seus resultados comparados para investigar a sensibilidade do modelo de material em questão com o comportamento mecânico da espuma polimérica. As superfícies volumétricas das Tabelas 15 e 16 serão utilizadas, todavia as isotrópicas serão modificadas, pois foram calculadas para as modelagens em tração. Sendo a compressão, a principal solicitação do material sob endentação, duas novas superfícies isotrópicas serão definidas a partir dos limites de escoamento do material.

Além dessas duas novas superfícies, outra superfície será definida a partir de uma média dos valores para as tensões de escoamento em compressão, bem como, para as tensões de resistência sob tração. Esta abordagem é semelhante ao que foi proposto no trabalho de Gibson et al. (1989) para a utilização do respectivo critério de GAZT em materiais anisotrópicos (eq. (18)). Esse procedimento tem o propósito de gerar uma superfície de "escoamento média" para que os carregamentos multiaxiais nos planos 3-1 e/ou 3-2 sejam melhor representados devido à anisotropia mais evidente nesses planos. Vale lembrar também que é preciso criar uma curva de "encruamento média" a partir das equações (119) e (120). Os valores com os quais as novas superfícies são calculadas bem como os parâmetros das novas superfícies estão para ambas às direções nas Tabelas 18 e 19. As quatro novas superfícies estão exibidas na Figura 79. 
Tabela 18 - Parâmetros para a determinação das novas superfícies de escoamento iniciais

\begin{tabular}{|c|c|c|c|c|}
\hline Superfície & Direção & $\begin{array}{c}\text { Compressão } \\
\text { Uniaxial (MPa) }\end{array}$ & $\begin{array}{c}\text { Tração Uniaxial } \\
\text { (MPa) }\end{array}$ & $\begin{array}{c}\text { Compressão } \\
\text { Hidrostática (MPa) }\end{array}$ \\
\hline$V$ & Normal & 0.75 & 0.75 & 0.45 \\
\hline$V I$ & Plano & 0.396 & 0.396 & 0.45 \\
\hline$V I I$ & Normal/Plano & 0.57 & 0.57 & 0.45 \\
\hline$V I I I$ & Normal/Plano & 0.57 & 1.52 & 0.45 \\
\hline
\end{tabular}

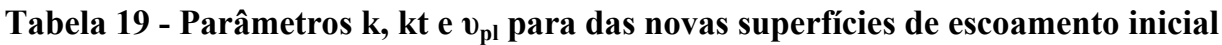

\begin{tabular}{|c|c|c|c|c|c|c|c|}
\hline Superfície & Direção & Encruamento & $\mathbf{E}(\mathbf{M P a})$ & $\mathbf{v}_{\mathbf{e l}}$ & $\mathbf{k}$ & $\mathbf{v}_{\mathbf{p l}}$ & $\mathbf{k}_{\mathbf{t}}$ \\
\hline$V$ & Normal & Isotrópico & 32 & 0.35 & 1.6656 & 0.04 & $\mathrm{n} / \mathrm{d}$ \\
\hline$V I$ & Plano & Isotrópico & 16 & 0.22 & 0.8801 & 0.02 & $\mathrm{n} / \mathrm{d}$ \\
\hline VII & Normal/Plano & Isotrópico & 24 & 0.285 & 1.2664 & 0.03 & $\mathrm{n} / \mathrm{d}$ \\
\hline VIII & Normal/Plano & Volumétrico & 24 & 0.285 & 1.9418 & $\mathrm{n} / \mathrm{d}$ & 5.6858 \\
\hline
\end{tabular}

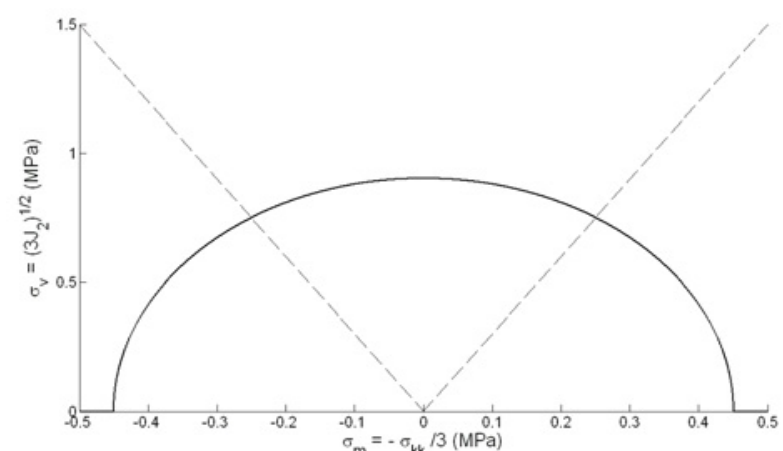

a) $\mathbf{V}$

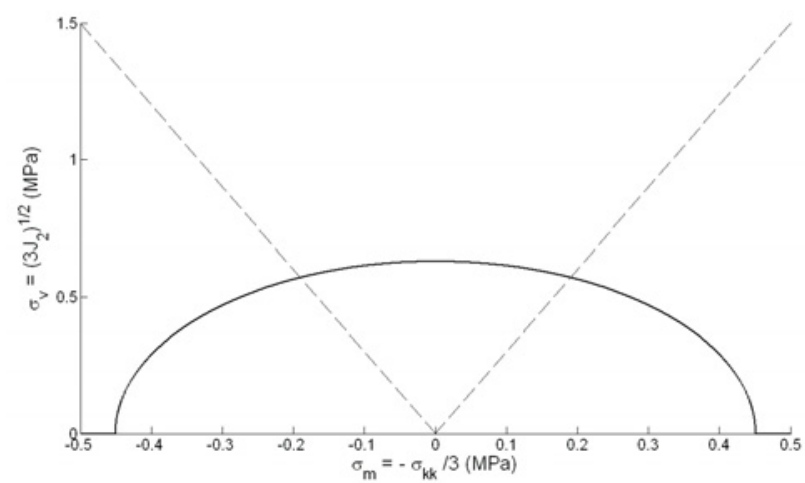

c) VII

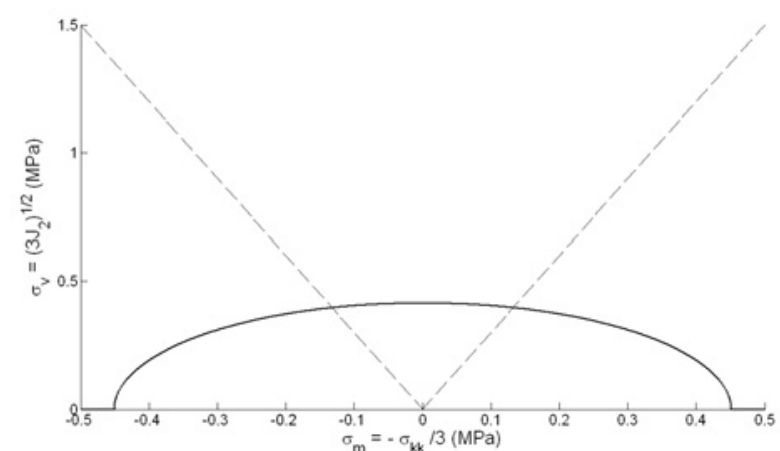

b) VI

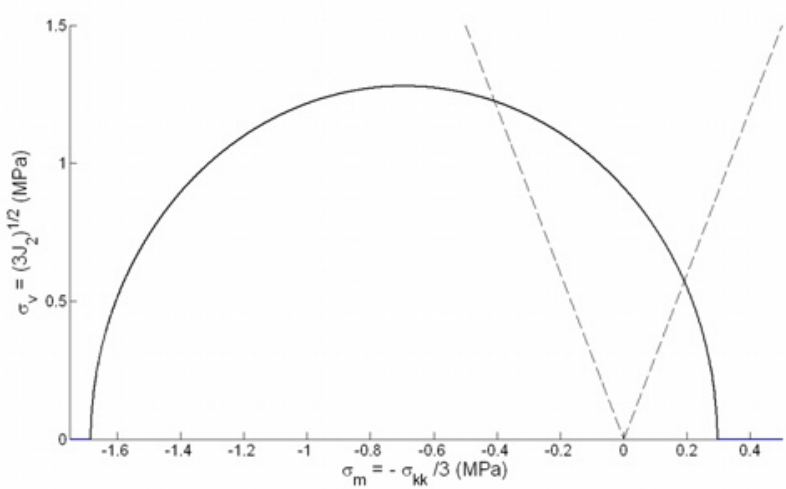

d) VIII

Figura 79. Superfícies de escoamento inicial para a Tabela 19: a) V; b) VI; c) VII; d) VIII

Os modelos computacionais foram construídos buscando uma maior representatividade dos ensaios realizados. Para isso um modelo bidimensional com as dimensões dos CDPs foi gerado (a simetria do carregamento foi parcialmente explorada) e os contatos entre base-espuma e endentador-espuma também foram modelados. Tanto a base como o endentador são modelados como superfícies rígidas. As condições de contorno bem 
como a discretização utilizada estão exibidas na Figura 80 para a direção 1-2 no plano, sendo que para a direção normal a análise é análoga.

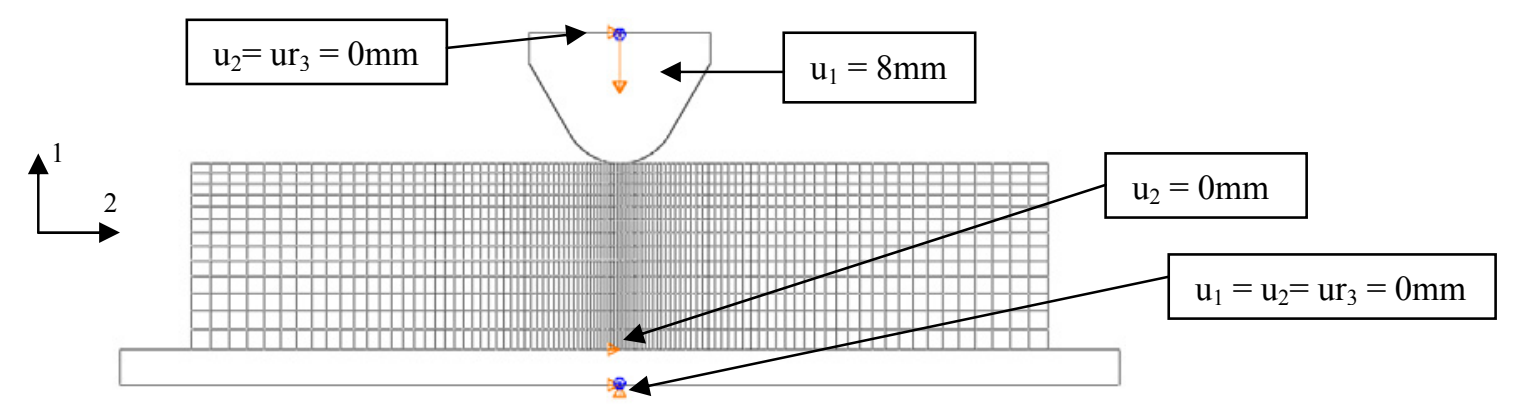

Figura 80. Modelos de endentação: Condições de contorno e discretização

Nos modelos para a endentação, o tipo de elemento escolhido influencia fortemente na convergência do algoritmo de plasticidade. Além disso, o tipo de superfície, a lei de encruamento, e um carregamento multiaxial localizado podem produzir diferentes complicações numéricas referente à convergência do algoritmo.

Primeiramente, deve-se lembrar que elementos isoparamétricos com integração completa de todos os pontos de Gauss, os quais são necessários para uma integração exata da função de forma polinomial em elementos quadriláteros, torna-os assim, muito rígidos para solicitações de flexão. Essa rigidez faz com que os elementos não se deformem como deveriam e a análise gera resultados não confiáveis quando a convergência é obtida, pois geralmente a solução não avança. Esse fenômeno é conhecido como travamento volumétrico devido ao surgimento de um cisalhamento parasita (parasitic shear) na malha proveniente da rigidez excessiva dos elementos com integração completa. Para contornar esse problema, pode-se empregar elementos com integração reduzida cujos pontos são conhecidos como pontos de Barlow (1976), onde as deformações são calculadas com maior precisão. Todavia, o uso do recurso de integração reduzida faz com que ocorra uma degeneração nas energias de deformação para elementos com interpolação linear (ex. CPE4R, nos quais há apenas um ponto de integração), possibilitando a geração de modos de deformação nula que acarreta em distorções excessivas (modos de deformação incompatíveis) que se propagam pela malha gerando outro fenômeno conhecido como hourglassing. Para evitar esse comportamento da malha, é comum inserir uma rigidez artificial na malha.

Além da integração reduzida, é possível utilizar elementos com um grau de liberdade a mais para suprir a deficiência dos elementos regulares. O novo grau de liberdade é inserido para controlar a rigidez excessiva que surge na malha forçando uma variação linear da pressão 
hidrostática nesses elementos (CPE4I - Incompatible Modes), evitando assim os modos de deformação incompatíveis.

Logo, verifica-se que a modelagem computacional para o ensaio de endentação apresenta maiores complicações que os demais modelos. Ademais, deve-se lembrar que as superfícies de escoamento volumétrico apresentam uma grande sensibilidade a carregamentos puramente desviadores para deformações acima de 50\%, pois como discutido, os elementos sob tais solicitações apresentam maiores problemas de convergência no algoritmo de plasticidade que geralmente culmina em um travamento antecipado da análise. Existe ainda uma sensibilidade ao travamento volumétrico, devido ao cisalhamento parasita, com o modelo de material em questão. O modelo isotrópico mostra-se mais sensível, pois ocorre encruamento do material em tensão hidrostática negativa com ou sem tensões desviadoras e, diferentemente, o modelo volumétrico para os mesmos carregamentos não apresenta evolução da superfície de escoamento, tornando o de certa forma mais robusto para a análise de endentação. De modo geral, há uma sensibilidade nas análises numéricas quanto à robustez do modelo computacional, incluindo modelo de material escolhido, grau de refinamento da malha e tipos de elementos utilizados para modelar carregamentos multiaxiais localizados. Além disso, cabe ressaltar que problemas referentes a carregamentos não-monotônicos pontuais, também podem ocorrer, ocasionando o travamento das análises.

Essas particularidades numéricas podem também ser evitadas utilizando elementos com interpolação quadrática e integração completa (CPE8). Todavia, devido aos diversos fatores que influenciam a convergência das análises associados ao refinamento localizado da malha abaixo do endentador (Fig. 80), esses elementos tornam as análises mais sensíveis ao travamento volumétrico, aos erros no algoritmo de plastificação, além do aumento de custo computacional envolvido.

Existem ainda outros fatores que influenciam na convergência do algoritmo de plasticidade, como a influência numérica da curva de encruamento fornecida de maneira tabular, mas tais empecilhos são de solução menos complicada.

Desse modo, o presente trabalho opta por uma realização de análises com elementos do tipo CPE4, e quando necessário e de acordo com as propriedades do material, os elementos com integração reduzida, CPE4R, são utilizados, juntamente com um controle de distorção (hourglassing) padrão.

Prosseguindo com a modelagem dos ensaios de endentação, para a direção no plano 12 serão realizadas duas análises referentes às superfícies IV e VI para comparação dos modelos. Para a endentação do plano 3-1(2), o carregamento multiaxial é aplicado em um 
plano com anisotropia, diferente da endentação no plano 1-2 onde as propriedades do material são as mesmas para a solicitação em questão. Por isso, serão avaliadas, também as superfícies médias VII e VIII bem como as superfícies III e V para a direção normal. O regime elástico é novamente modelado como sendo isotrópico devido a uma imposição da implementação do algoritmo. Os respectivos valores utilizados são os valores médios em compressão (principal carregamento imposto), que estão na Tabela 13.
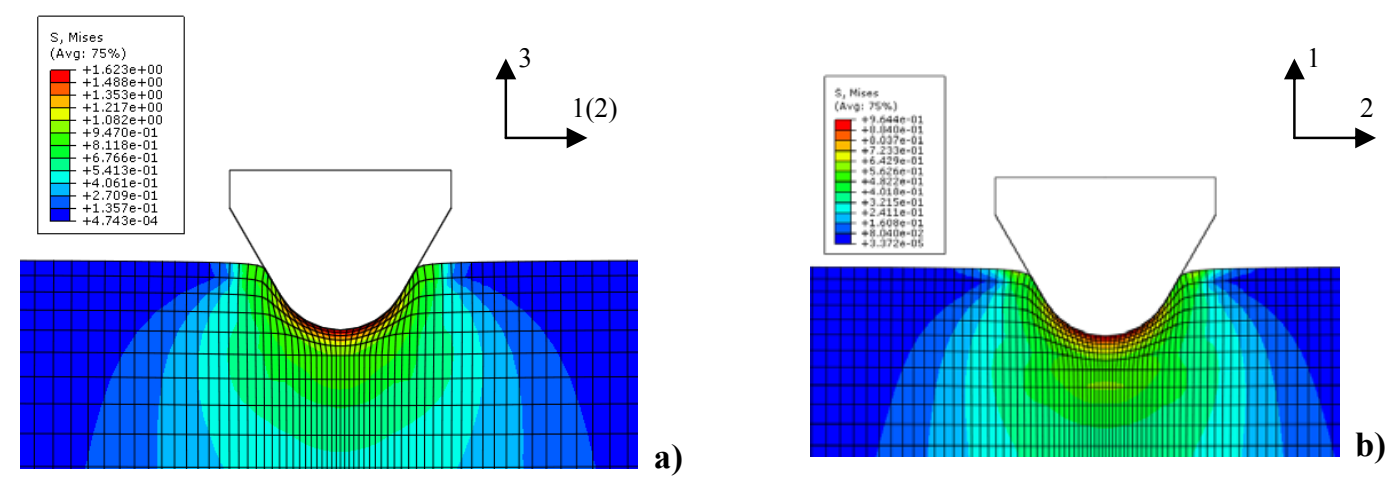

Figura 81. Tensão equivalente de von Mises (MPa): a) Superfície III para o plano 3-1(2); b) Superfície IV para o plano 1-2

Uma malha deformada para cada uma das direções é mostrada na Figura 81, e, nas Figuras 82 e 83 estão as curvas de carga-deslocamento para o plano 1-2 e 3-1(2) respectivamente.

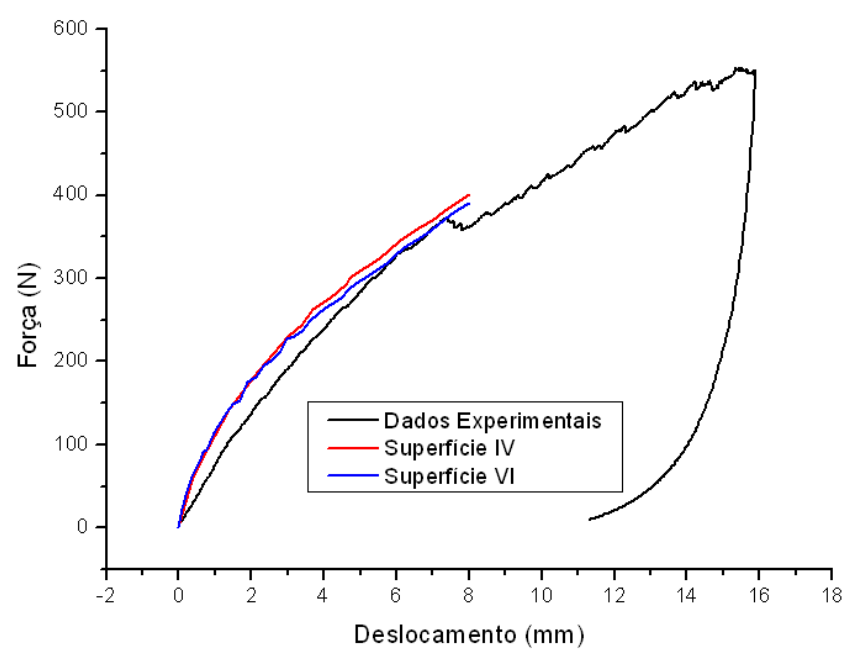

Figura 82. Modelo de endentação para o plano 1-2

$\mathrm{Na}$ Figura 82, observa-se que o modelo computacional é mais rígido no início da análise, mas tende ao valor da curva experimental para o deslocamento próximo de $8 \mathrm{~mm}$. Esse comportamento é resultado do mecanismo de falha localizado da espuma nos ensaios 
experimentais. Observa-se que a aplicação direta de cargas localizadas através do endentador na espuma torna a resposta do material mais sensível aos mecanismos de falha micromecânicos e, portanto, a resposta experimental é mais influenciada por esses mecanismos. No caso, como a falha da espuma é por flambagem das células, a concentração de cargas do endentador danifica a mesma sob cargas menores que as observadas nos ensaios uniaxiais, onde as áreas transversais mínimas garantem uma resposta macroscópica do material. Conforme o endentador avança na espuma, o esmagamento das células aumenta a resistência local do material, resultando na convergência das curvas experimentais e numéricas. Por outro lado, o modelo numérico é homogêneo e, portanto, exibe menor sensibilidade às cargas concentradas que fragilizam a espuma polimérica localmente.

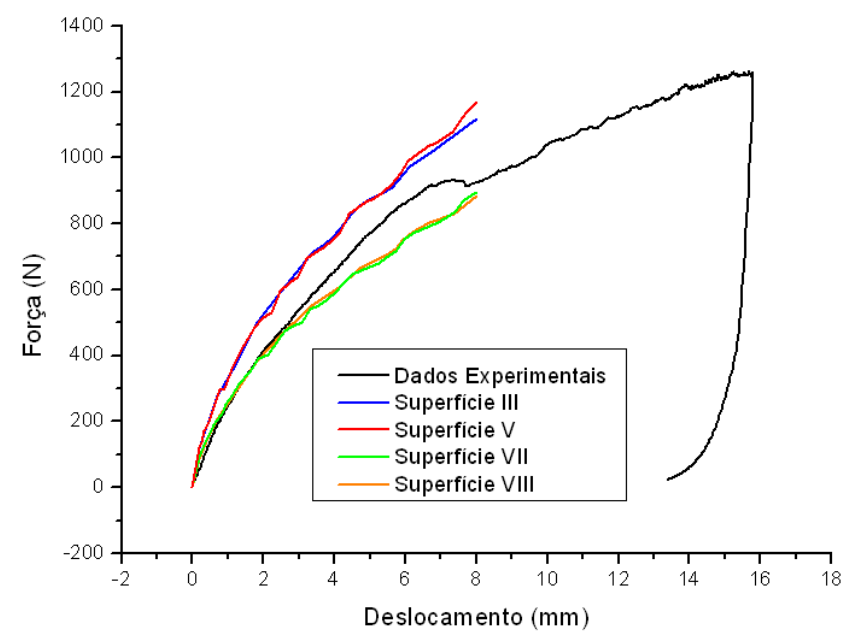

Figura 83. Modelo de endentação para o plano 3-1(2)

Para o plano 3-1(2) (Fig. 83), a análise é similar no sentido da fragilização do material com a aplicação direta de cargas localizadas na espuma, entretanto como neste plano há uma combinação de respostas das direções 3 e 1(2), a densificação do material é controlada pela maior resistência do material na direção 3. Isso porque as cargas aplicadas são significativamente superiores à resistência nas direções 1 e 2 e desse modo a resposta numérica (curvas azul e vermelha) segue mais resistente que o resultado experimental. Pois, o material é modelado isotropicamente, sendo esta abordagem mais representativa para o plano 1-2. Lembrando que o material é transversalmente isotrópico, possuindo certo grau de anisotropia e os modelos numéricos compõem uma análise em estado plano de deformação.

Em ambas as Figuras 82 e 83, percebem-se que os modelos de material não influenciam as respostas numéricas significativamente. Tanto o modelo isotrópico como o 
volumétrico produzem resultados praticamente iguais devido ao fato de que o principal carregamento no ensaio de endentação é a compressão e, assim, as superfícies evoluem de modo muito semelhante. Vale lembrar também que para ambos os modelos, as curvas de encruamento são as mesmas. Os parâmetros que mais influenciam na resposta do material são as superfícies de escoamento em função dos limites de resistência, pois sob endentação quase toda a análise é dominada pela plastificação do material. Essa influência pode ser constatada na Figura 83 (curvas verde e amarela), onde os valores médios para as resistências geram uma superfície que produz um comportamento combinado das duas direções, sendo o início da curva bem representativo, mas com um final mais flexível, característica da baixa resistência na direção $1(2)$.

Dessa forma constata-se que a calibração dos modelos de material em questão é altamente sensível ao tipo de carregamento. Quanto maior a área solicitada, mais o comportamento do material se aproxima de uma resposta macroscópica e, portanto, torna-se mais representativo de modo geral. Se o carregamento for localizado, a resposta do material sofre grande influência dos mecanismos microscópicos e, portanto, de modo geral, os modelos numéricos super estimam, principalmente, a resistência estrutural.

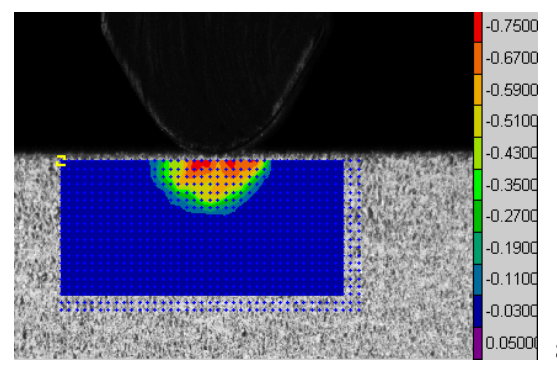

a) $u_{3}=4.8 \mathrm{~mm}$
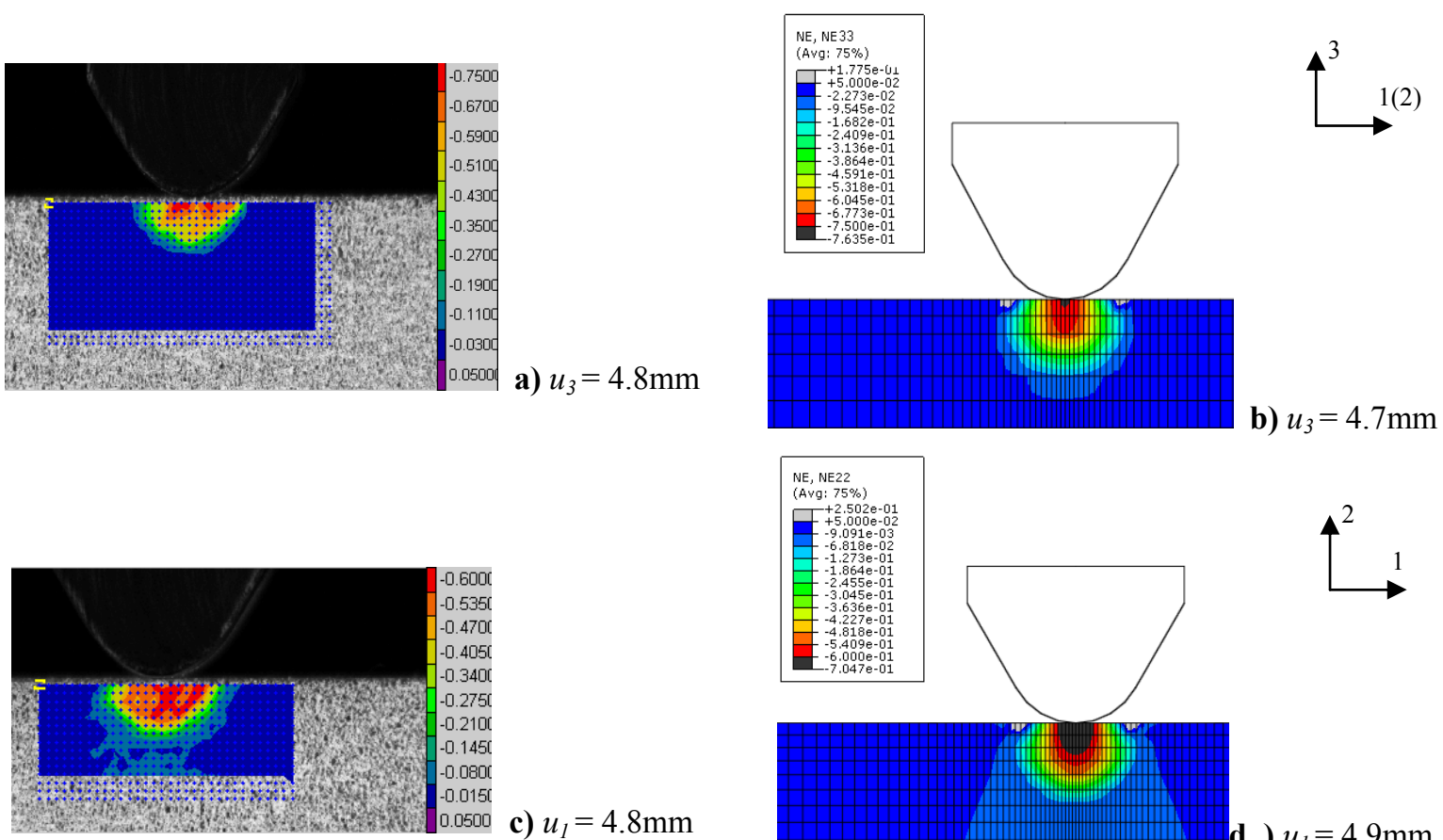

c) $u_{1}=4.8 \mathrm{~mm}$

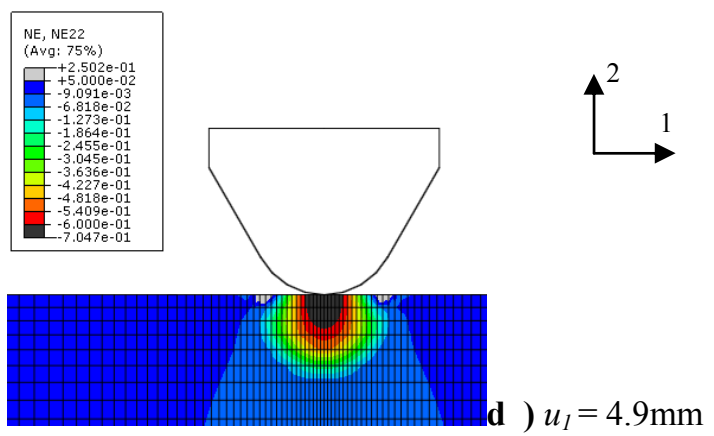

Figura 84. Comparação da deformação nominal na direção do carregamento via Correli ${ }^{\mathrm{LMT}}$ e EF: a) e b) Resultados para o plano 3-1(2); c) e d) Resultados para o plano 1-2 
Outra base quantitativa de comparações é obtida das análises via Correli ${ }^{\mathrm{LMT}}$. Na Figura 84, as deformações nominais para as respectivas direções de carregamento obtidas via técnica DIC são comparadas com os respectivos modelos numéricos.

Na Figura 84, as escalas de deformação são as mesmas em relação à origem dos resultados, para uma comparação direta via gradiente de cores. Constata-se uma boa concordância dos resultados das deformações nominais para ambos os planos. Para as deformações logo abaixo do endentador, os resultados via MEF são um pouco superiores aos resultados de deformação via Correli ${ }^{\mathrm{LMT}}$ devido à maior precisão dos resultados via MEF. Na região da endentação ocorrem grandes distorções e a precisão das malhas utilizadas que foram geradas nas fotografias pela técnica DIC, não são suficientes para garantir resultados com maior concordância para altos níveis de deformação.

É importante ressaltar que esse comportamento da espuma H60 para o carregamento local de endentação, de um modo geral, representa uma resposta para aplicações de carga diretamente no material. Contudo, quando a espuma é utilizada em estruturas sanduíche, a influência da rigidez e resistência das faces tende a minimizar a diferença observada nos resultados experimentais devido à minimização da influência dos mecanismos de falha micromecânicos envolvidos.

\subsubsection{Modelos Computacionais para a Estrutura Sanduíche}

Para a estrutura sanduíche com as dimensões da Tabela 3 e uma distância entre apoios (span) de 100mm, tem-se que os modelos de material avaliados para o núcleo na seção anterior serão utilizados juntamente com as propriedades das faces laminadas em material compósito (descritas na Tabela 15) investigada por Oliveira (2007). As propriedades de material que estão nas Tabelas 13 a 19, obtidas experimentalmente para a espuma H60, são utilizadas para avaliar a representatividade dos modelos de material na resposta da estrutura sanduíche. $\mathrm{O}$ carregamento na estrutura é imposto através de um deslocamento prescrito de $12 \mathrm{~mm}$ do endentador.

O modelo computacional construído para representar a estrutura sanduíche foi um modelo tridimensional, sendo que a espuma foi modelada com paralelepípedos com interpolação linear e integração completa dos oito pontos de integração (C3D8). Os skins (faces) foram modelados com elementos de casca com interpolação linear e integração completa dos 4 pontos de integração (S4). Novamente os elementos e a malha são 
determinados visando contornar os problemas relativos às convergências das análises discutidos anteriormente. Nas Figuras 85 e 86 são exibidas as condições de contorno e à discretização da estrutura sanduíche definidas para a modelagem de um ensaio de flexão em três pontos.

Tanto os apoios quanto o endentador são modelados como superfícies rígidas e a geometrias são as dos equipamentos utilizados por Oliveira (2007) e Soares (2008). O contato entre as superfícies supõe que não há atrito longitudinal entre as respectivas superfícies, o que é coerente com os ensaios realizados, onde a estrutura é apoiada diretamente sobre os suportes cuja rugosidade superficial pode ser considerada desprezível para o respectivo experimento. Da Figura 85, observa-se que os apoios estão fixos e que o endentador só pode deslocar-se na direção 3 de aplicação de carga. Há também uma condição aplicada no centro da estrutura sanduíche (aresta na região inferior), que garante o posicionamento teórico e experimental da estrutura sanduíche na configuração do ensaio de flexão em três pontos.

Para essa modelagem, é escolhido o modelo de material com encruamento volumétrico, pois a utilização deste torna as análises significativamente mais rápidas, sendo o resultado teórico para a espuma praticamente igual, como visto nas Figuras 82 e 83. Todavia, alguns erros experimentais inevitáveis acompanham os resultados numéricos devido às complicações do uso desse modelo de material.

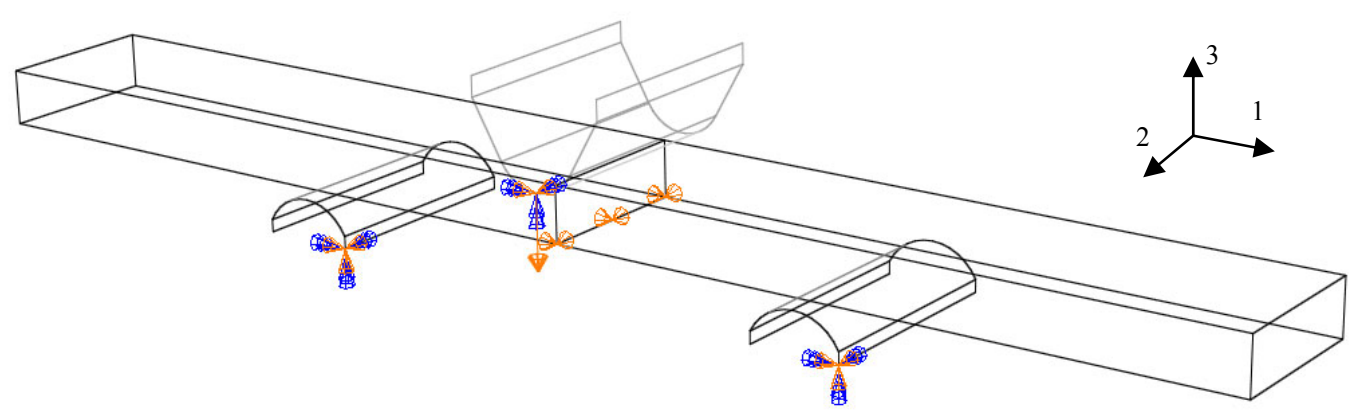

Figura 85. Condições de contorno e deslocamento aplicado à estrutura sanduíche sob flexão em 3 pontos

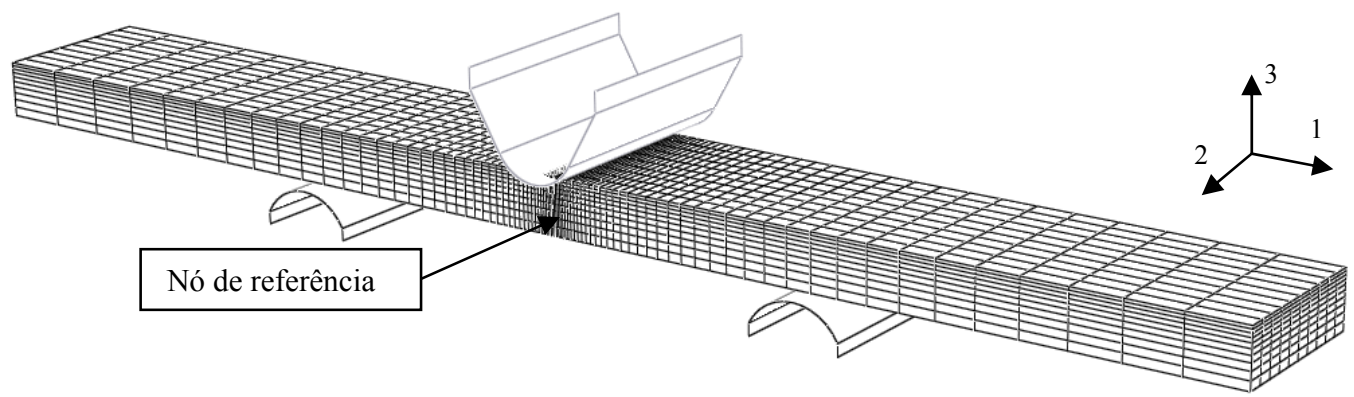

Figura 86. Discretização da estrutura sanduíche e configuração do ensaio de flexão em três pontos 
Com esse modelo de material são avaliadas as influências da geometria dos componentes da estrutura sanduíche (mais especificadamente as faces), as superfícies de escoamento (bem como suas curvas de encruamento) e as propriedades elásticas e plásticas da espuma polimérica.

Na Tabela 3 verifica-se que o valor de espessura das faces relatado por Oliveira (2007) é de $0.22 \mathrm{~mm}$. Entretanto, uma medida experimental da mesma grandeza, mostra que o valor real é em torno de $0.27 \mathrm{~mm}$ a $0.36 \mathrm{~mm}$. Uma das principais variáveis dessa medida é a variação da espessura do laminado das faces devido à impregnação da matriz nos tecidos de fibra de vidro, preparados manualmente (hand lay-up). Posteriormente, estes skins são colados às superfícies superior e inferior da espuma, sendo o adesivo uma segunda variável na definição da espessura do skin da estrutura sanduíche. Essa atenção à espessura das faces é muito importante para a modelagem computacional, pois como pode ser constatado da equação (4), a espessura da face influencia a rigidez da estrutura sanduíche. Além disso, a espessura da face influencia também na resistência transversal (eqs. (5) e (6)).

Para o processo de laminação por hand lay-up, a espessura de camada é relativamente difícil de ser determinada, principalmente, após a cura do laminado (TITA, 2003). Dessa forma, algumas análises para espessuras diferentes foram realizadas. Ademais, como a estrutura sanduíche foi fabricada com a direção 3 normal da espuma polimérica paralela à direção do carregamento, a superfície III será avaliada, bem como o uso da superfície média VIII, pois o plano de aplicação de carga é o 3-1(2). É importante ressaltar que as propriedades elásticas utilizadas são para ensaios de compressão do material e o módulo utilizado é o obtido via Correli ${ }^{\text {LMT }}$. O módulo de elasticidade obtido via EMIC, é analisado para a avaliação da rigidez e da resistência da estrutura modelada. Os diferentes dados de entrada estão agrupados na Tabela 20.

Tabela 20 - Propriedades mecânicas e geometrias para os modelos computacionais da estrutura sanduíche

\begin{tabular}{|c|c|c|c|c|c|c|}
\hline Superfície (Direção) & E (MPa) & $v_{\text {el }}$ & $\mathbf{k}$ & $\mathbf{k}_{\mathbf{t}}$ & $\mathbf{t}_{\text {face }}(\mathbf{m m})$ & Modelo \\
\hline \multirow{3}{*}{$\begin{array}{c}\text { III } \\
\text { (Normal) }\end{array}$} & 32 & 0.35 & 1.8852 & 12.2965 & 0.27 & $\bar{i}$ \\
\hline & \multirow[b]{2}{*}{53} & \multirow[b]{2}{*}{0.35} & \multirow[b]{2}{*}{1.8852} & \multirow[b]{2}{*}{12.2965} & 0.27 & $i i$ \\
\hline & & & & & 0.22 & $i i i$ \\
\hline \multirow{5}{*}{$\begin{array}{c}\text { VIII } \\
\text { (Normal/Plano) }\end{array}$} & \multirow{5}{*}{53} & \multirow{5}{*}{0.35} & \multirow{5}{*}{1.9418} & \multirow{5}{*}{5.6858} & 0.22 & $i v$ \\
\hline & & & & & 0.27 & $v$ \\
\hline & & & & & 0.30 & $v i$ \\
\hline & & & & & 0.33 & $v i i$ \\
\hline & & & & & 0.36 & viii \\
\hline
\end{tabular}


Como a endentação configura um carregamento localizado na face superior da estrutura, o comportamento da outra face é monitorado para obter uma resposta de características mais globais da mesma. Para a comparação do comportamento macroscópico da estrutura, um nó no centro e na face inferior da mesma é escolhido (nó de referência - Fig 86), sendo que a reação é obtida a partir da força no endentador.

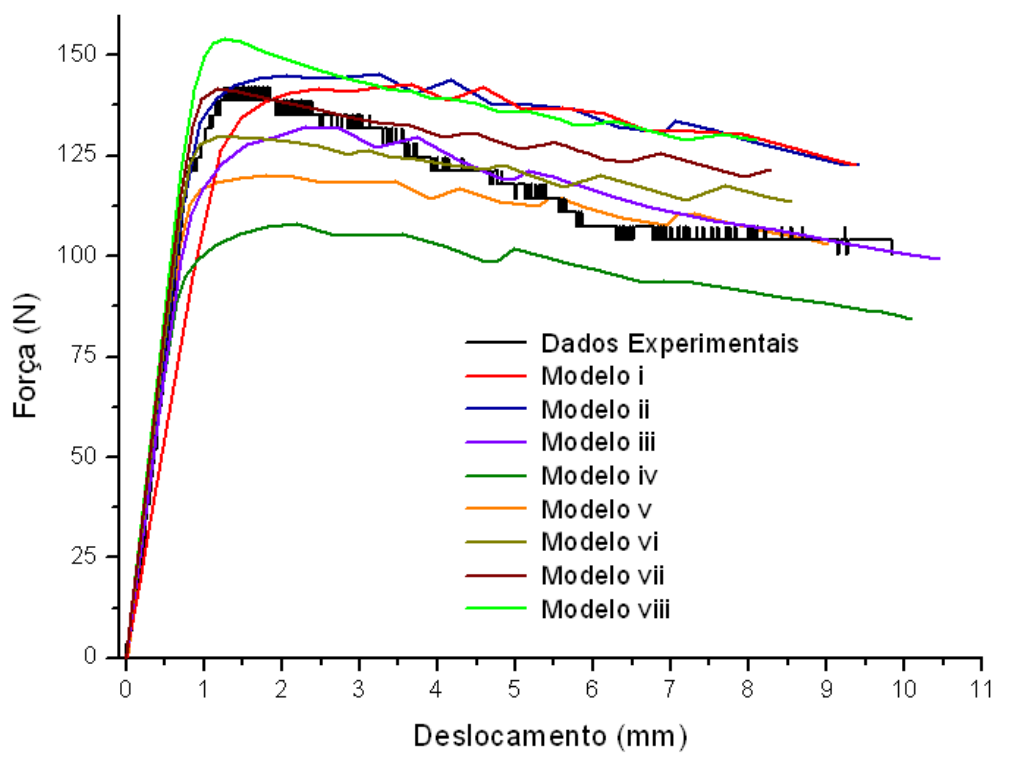

Figura 87. Curvas força-deslocamento para os 8 modelos computacionais da estrutura sanduíche estudada

De acordo com as especificações das Figuras 85 e 86 e da Tabela 20, as curvas de força-deslocamento são construídas e agrupadas na Figura 87.

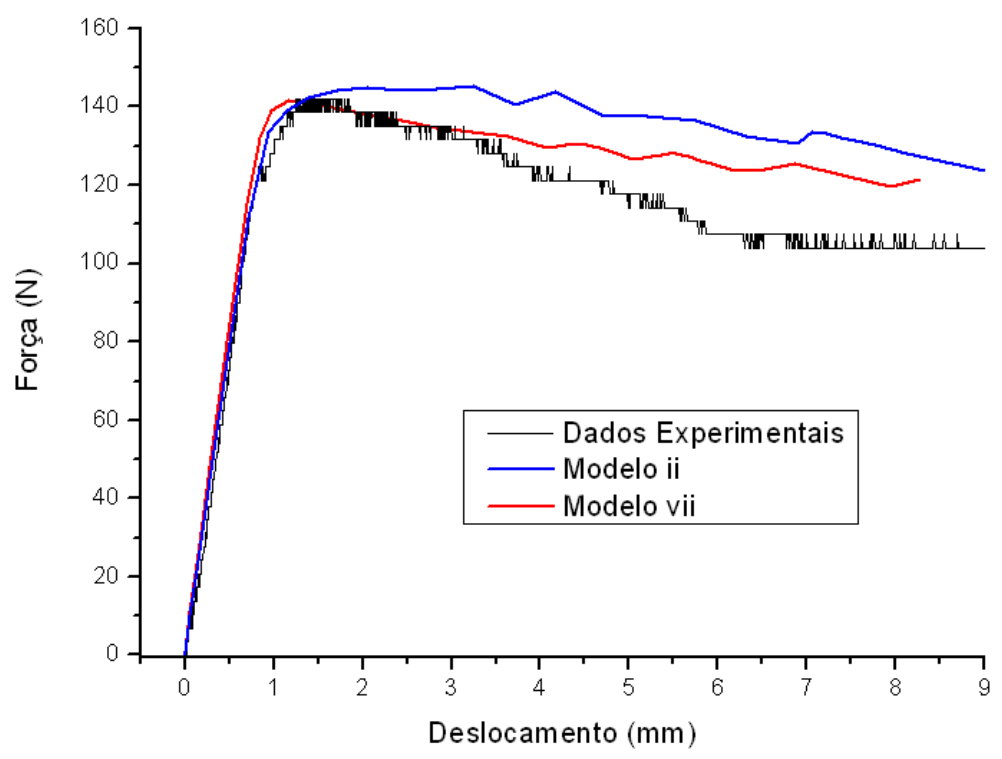

Figura 88. Curvas força-deslocamento para os modelos ii e vii 
Das Figuras 87 e 88, verifica-se que a rigidez do material é pouco sensível às variações na espessura das faces, contudo a resistência é muito sensível a este mesmo parâmetro. Outro fator demonstrado nessas figuras é que uma variação na rigidez da espuma tem forte influência na rigidez da estrutura, pois a razão entre a espessura do núcleo e da face é de aproximadamente $0.3 / 10=0.03$. Dessa forma, uma variação de aproximadamente $40 \%$ na rigidez da espuma, correspondente à diferença nas rigidezes obtidas via EMIC (32MPa) ou Correli $^{\text {LMT }}(53 \mathrm{MPa})$, influencia fortemente no valor final da rigidez da estrutura. O modelo $i$ exemplifica o quanto a rigidez da estrutura pode mudar com variações na rigidez da espuma. Dessa forma, podem-se associar, essencialmente, as pequenas diferenças (Fig. 87) na rigidez da estrutura ensaiada com os modelos computacionais, ao erro experimental na determinação da rigidez da espuma polimérica (módulo de elasticidade).

Há ainda a questão da superfície de escoamento utilizada. Como esperado, a superfície III fornece um estrutura mais resistente que a superfície VIII, que é uma superfície média. Contudo, existe um efeito combinado da superfície escolhida com a espessura do laminado, que alteram a curva de força-deslocamento após o pico de força verificado. De modo geral, pela Figura 88, verifica-se que resultados semelhantes podem ser obtidos para diferentes valores para a espessura das faces e a superfície de escoamento, de tal forma que um parâmetro pode vir a compensar o outro. Porém, após um deslocamento de aproximadamente $1.5 \mathrm{~mm}$, após a força máxima, a curva apresenta uma perda de resistência com maior intensidade para a superfície VIII (parâmetros identificados com valores médios). Assim, o modelo vii apresenta-se mais representativo frente aos ensaios experimentais que o modelo $i$, como observado na Figura 88. Essa perda de resistência das Figuras 87 e 88 é resultado da plastificação do núcleo que altera o ângulo de contado da estrutura sanduíche com os apoios, alterando a força de reação dos mesmos. As variações nas curvas, para deslocamentos do endentador acima de $1.5 \mathrm{~mm}$, são erros numéricos advindos da implementação do algoritmo associado aos passos e incrementos da solução. Quanto mais localizada a plastificação, maiores são os erros e, portanto, mais variações são observadas na curvas de forçadeslocamento. A solução viii, na Figura 87, ratifica essas considerações, pois a respectiva curva apresenta redução da resistência de maneira suave com erros mínimos devido à maior resistência das faces ao carregamento transversal.

Logo, acredita-se que o modelo de material calibrado com a superfície média VIII, e um laminado com espessura de aproximadamente $0.33 \mathrm{~mm}$ é a combinação de parâmetros que melhor representa a estrutura, ou seja, o modelo vii. Isso ocorre, pois a superfície média compensa a resistência excessiva definida para as direções 1 e 2 através do uso de um modelo 
isotrópico com propriedades plásticas para a direção normal 3. A rigidez, contudo é proveniente do ensaio em compressão, pois no regime elástico na endentação, a direção normal é a que domina a contribuição da espuma na resposta da estrutura. E por fim, a espessura dos laminados de $0.33 \mathrm{~mm}$ está mais próxima de um valor médio com um erro significativo $(0.3 \pm 0.1 \mathrm{~mm})$, dado que o processo de fabricação do laminado e da estrutura sanduíche é manual.

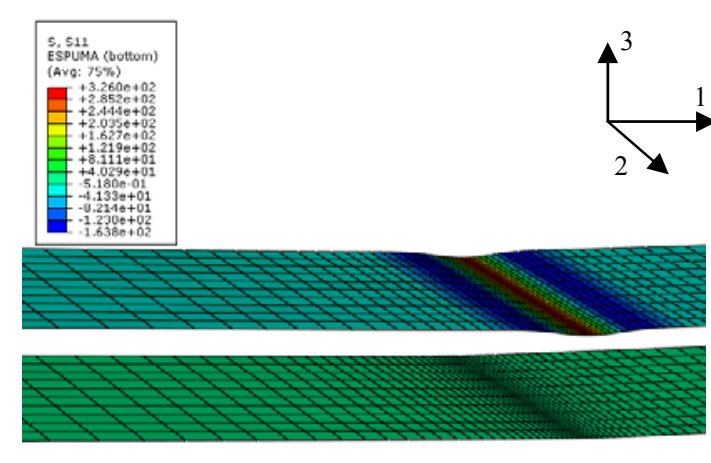

a)

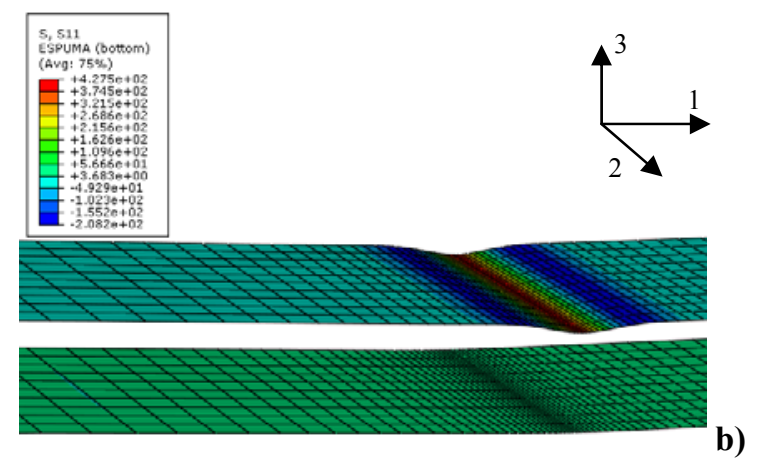

Figura 89. Tensão equivalente de von Mises para as lâminas mais próximas da espuma (modelo vii): a) Deslocamento de $1.6 \mathrm{~mm}$ do endentador; b) Deslocamento de $2.0 \mathrm{~mm}$ do endentador

Na Figura 89, os resultados da tensão normal na direção 1, para o modelo vii são exibidos para as faces da estrutura sanduíche, considerando um nível de deslocamento do endentador de $1.6 \mathrm{~mm}$ e $2.0 \mathrm{~mm}$. Os apoios, o endentador e o núcleo são suprimidos para melhor visualização das tensões nas lâminas da face superior e inferior que estão aderidas ao núcleo (Fig. 89).

De acordo com a Tabela 15, a resistência de uma lâmina das faces, é de aproximadamente $419 \mathrm{MPa}$. Entre 1.5 e $2.0 \mathrm{~mm}$, a tensão $\mathrm{S}_{11}$ para as lâminas indica uma possível falha das mesmas. Existe também a resistência da matriz, que sendo epóxi, tem resistência à flexão que pode variar de 40 à 460MPa (MATWEB, 2009). Dessa forma, as curvas computacionais superestimam os valores das experimentais, a partir de $1.5 \mathrm{~mm}$, pois as faces foram modeladas como sendo elásticas e nenhum modelo de falha foi utilizado (não se aplicou nenhum modelo de falha para as faces laminadas, pois o presente trabalho além de não ensaiar essas estruturas; a utilização desses modelos influencia a resposta não-linear da estrutura sanduíche como um todo, e dessa forma o estudo dos modelos de material para a espuma polimérica não seria possível de forma exclusiva). Acredita-se então, que a partir de $2.0 \mathrm{~mm}$ de deslocamento do endentador, a estrutura já apresente falha nas lâmina mais internas à estrutura (junto ao núcleo). Como a lâmina é bidirecional, as resistências locais $\mathrm{X}_{\mathrm{T} 1} \mathrm{e} \mathrm{X}_{\mathrm{T} 2}$ são aproximadamente iguais, assim, a lâmina da face superior mais próxima ao núcleo e a 
lâmina central rotacionada em $45^{\circ}$ são as que apresentam as primerias falhas para deslocamentos maiores de $2.0 \mathrm{~mm}$ do endentador.

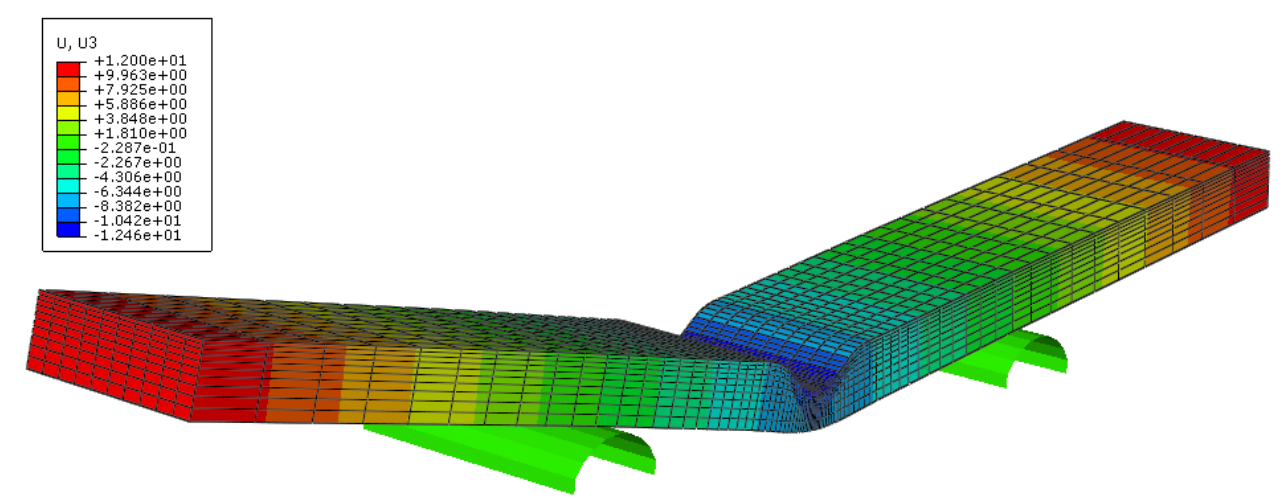

Figura 90. Deslocamento máximo (na direção 3) do endentador (12mm) para a estrutura sanduíche

As análises dos 8 modelos para a estrutura sanduíche, são para um deslocamento de $12 \mathrm{~mm}$ do endentador (Figura 90).
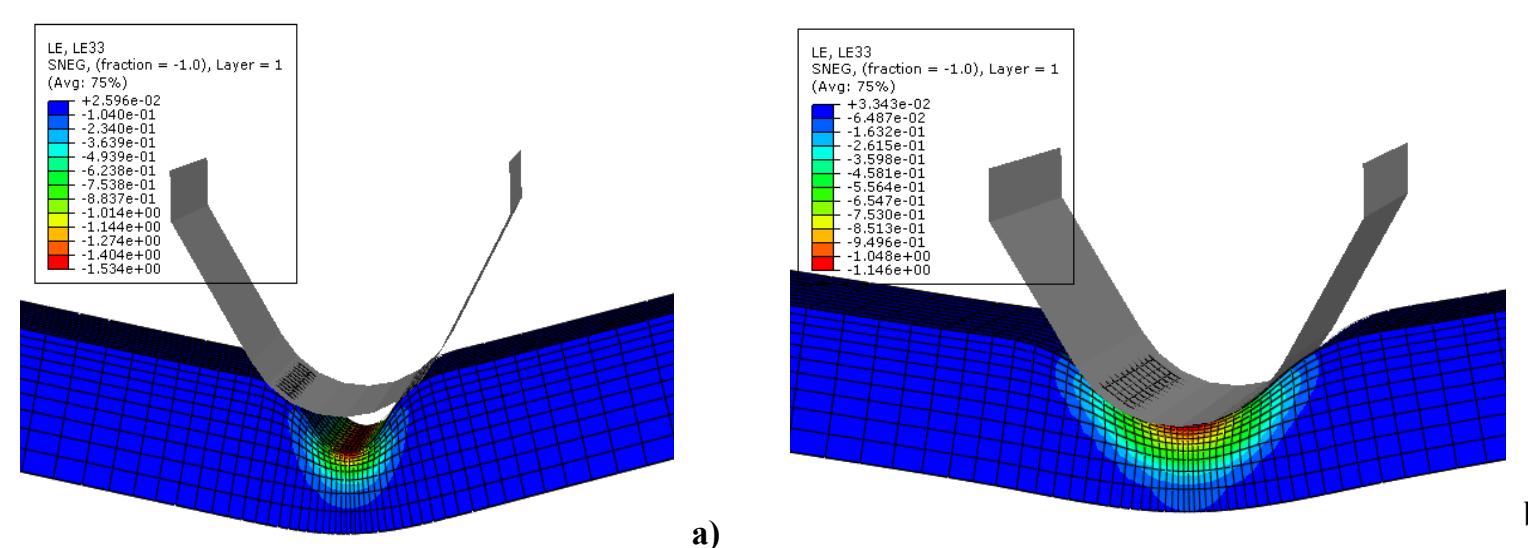

a)

b)

Figura 91. Deformação logarítmica para a estrutura sanduíche para deslocamento máximo do endentador: a) Modelo iii; b) Modelo viii

De acordo com o modelo computacional, para a aplicação desse deslocamento, a plastificação localizada na espuma varia significativamente. Quanto maior a espessura das faces e/ou mais resistente é a espuma, menor é a localização da falha (Figura 91), como esperado.

Contudo, o comportamento observado tende a ser modificado na prática, pois as faces são consideradas como corpos elásticos e sua falha não é modelada. Mesmo assim, o comportamento do núcleo tende ao que foi observado no presente trabalho, com a diferença de que, com a falha da face superior, a danificação da estrutura seria ainda mais localizada formando um vinco agudo na região abaixo do endentador e não um perfil suave (Fig. 92). A 
evolução da plastificação do núcleo e a falha do material, observados experimentalmente, reforçam a escolha do presente trabalho pelo modelo vii como o mais representativo, pois sua resposta sob deslocamento máximo do endentador é muito semelhante à Figura 91b. Por outro lado, nota-se pelo modelo iii que há perda significativa de contato do endentador com o laminado superior ao contrário do que ocorre no modelo viii e vii.
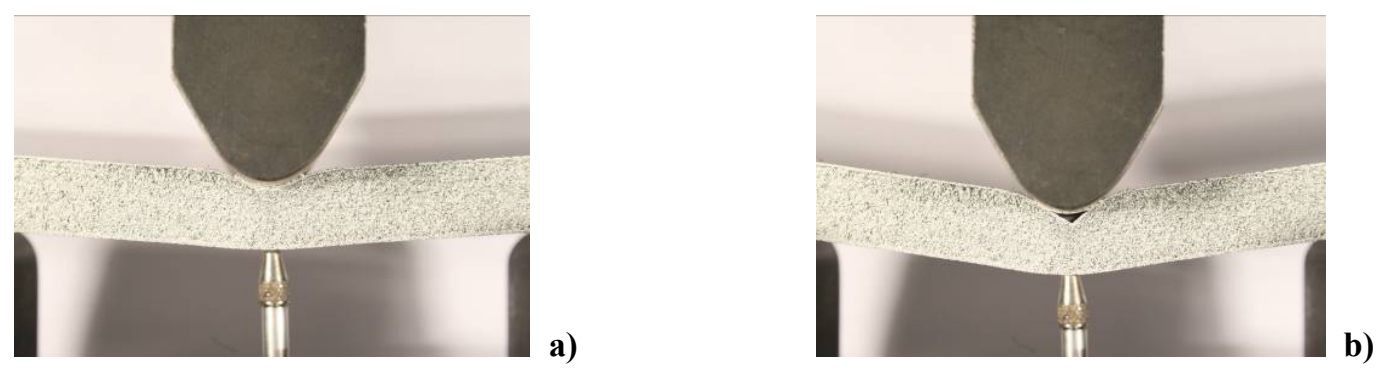

Figura 92. Ensaio de flexão em três pontos: a) Deslocamento $u_{3} \sim 3 \mathrm{~mm}$; b) Deslocamento $u_{3} \sim 5-6 \mathrm{~mm}$

Assim, constata-se que a redução da resistência nas curvas das Figuras 87 e 88 é devido em grande parte à plastificação localizada do núcleo que altera o ângulo de contato nos apoios, diminuindo a força de reação observada o que caracteriza em parte um descarregamento na estrutura, tanto nos ensaios experimentais como no modelo computacional. Entretanto, para os ensaios experimentais tem-se ainda a contribuição da falha da face superior como evidencia a Figura 92b. Essa falha também contribui para a redução da resistência nas curvas experimentais, sendo que nestas sempre observou-se uma redução mais acentuada da curva em torno de 5-6mm. Valor este para o nó de referência o qual caracteriza a falha total da face superior e a formação de um vinco agudo (Figura 92b). Com relação ao descarregamento, surgem as complicações computacionais referentes ao respectivo modelo de material que foi implementado no programa ABAQUS para carregamentos essencialmente monotônicos.

Para uma melhor modelagem da respectiva estrutura sanduíche, com os modelos de material em questão, é necessário que um modelo de falha progressivo para as faces laminadas com boa representatividade seja utilizado. Também é preciso contabilizar a influência do adesivo na resistência da estrutura, pois o material é uma estrutura celular e assim, a espessura efetiva da camada de adesivo é maior que a medida a partir da superfície da espuma. Pois, acredita-se que uma quantidade significativa de adesivo acumula-se nas células das superfícies da espuma nas quais as faces laminadas são coladas. Deve-se lembrar, que os bons resultados obtidos na Figura 88, foram obtidos com propriedades elásticas e plásticas da espuma polimérica que são mais relevantes para o carregamento em questão e 
levando em consideração a direção da espuma que foi solicitada. A influência do adeviso foi inserida no modelo com o aumento no valor da espessura das faces laminadas.

\subsection{Metodologia de Seleção e Calibração de Modelos de Material}

Com base nos primeiros quatro capítulos do presente trabalho, é possível definir uma metodologia para a construção de modelos computacionais estruturais onde um material com estrutura celular é utilizado. Apesar do presente texto conter apenas uma discussão sobre materiais celulares com material base sendo um polímero, é possível extrapolar muitas das conclusões para materiais celulares metálicos ou cerâmicos de acordo com a revisão bibliográfica do Capítulo II.

Apresenta-se na Figura 93, um fluxograma com a metodologia proposta para a escolha e calibração de modelos de material para materiais celulares utilizados em estruturas sob qualquer tipo de carregamento, desde que a geometria da estrutura e uma localização aproximada dos principais pontos com concentração de carga sejam conhecidos. Este tipo de abordagem ocorre na prática para se minimizar o tempo computacional da solução. Para análises amplas e independentes do tipo de carregamento e geometria da estrutura, é necessário que modelos de material com alta parametrização, e consequentemente alto custo computacional, em tempo de solução, sejam implementados.

O diagrama inicia com a determinação da estrutura na qual o material celular está presente, bem como o tipo de carregamento e sua localização. Isso é necessário, pois, como comentado acima, modelos independentes dessas variáveis iniciais aumentam muito o tempo de solução, que pode ser praticamente a mesma que a obtida em modelos implementados já conhecendo o principal carregamento na estrutura. No caso, o modelo de material com encruamento volumétrico contido no programa ABAQUS supõe um limite de escoamento em compressão muito maior que em tração, e com isso a hipótese para os casos em que o material não escoa sob tensão hidrostática trativa é válida. Todavia para a espuma polimérica H60 estudada, observou-se que apesar de seu comportamento frágil em tração, a mesma apresenta os limites de escoamento relativamente próximos aos de compressão (Ex.: Figs. 68 e 69). Isto torna a implementação em questão muito dependente da modelagem e calibração numérica devido às dificuldades e limitações discutidas anteriormente. 


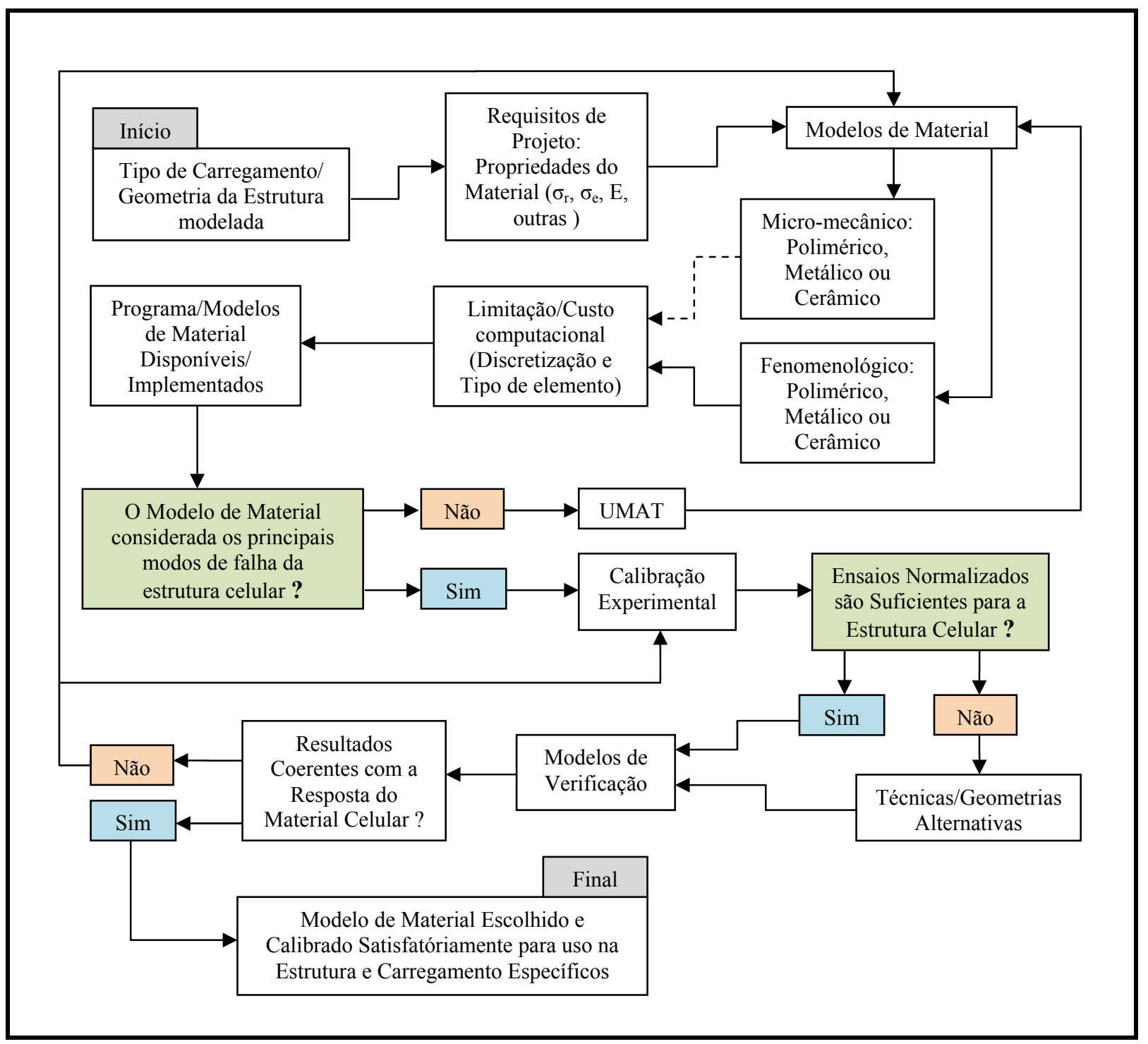

Figura 93. Metodologia de seleção e calibração de modelos de material para análises computacionais

É importante também saber o tipo do material, pois a falha da respectiva estrutura celular é altamente dependente do material base que define os principais modos de falha da mesma (falha frágil, elástica e/ou plástica). Também, define-se, com o tipo de material base, quais parâmetros o modelo de material deve ter para que este seja representativo.

Com essas duas informações (tipo de material e de carregamento), é possível selecionar o modelo de material a ser empregado. Naturalmente, a melhor opção seria uma modelagem computacional da estrutura celular, contabilizando as variações na seção das arestas, bem como nas faces, e os erros e imperfeições no material advindos de seu processo de fabricação, para que os modos de falha fossem representativos. Porém, fica claro que este tipo de modelagem contém muitos parâmetros a serem monitorados desde a fabricação da espuma à modelagem computacional. Mesmo que grande parte ou todos esses parâmetros 
fossem conhecidos, o custo computacional seria simplesmente inviável atualmente para aplicações correntes. Por isso na Figura 93, o uso de modelos micro-mecânicos é indicado por linhas tracejadas. A melhor opção continua sendo o uso de modelos fenomenológicos que, como visto no presente trabalho, são capazes de gerar resultados satisfatórios para aplicações específicas.

Os modelos fenomenológicos também possuem seu custo computacional atrelado à discretização da geometria em função do carregamento específico, bem como ao tipo de elemento utilizado. Ademais, existe a complicação de se empregar um modelo de material elastoplástico para carregamentos multiaxiais e/ou não-monotônicos (descarregamento), devido, além da dificuldade matemática, aos mecanismos micro-mecânicos do material que alteram significativamente a resposta do material sob descarregamento. Por isso, muitos programas de análises em elementos finitos trazem modelos de material com certas limitações, pois estes programas procuram sempre oferecer modelos de material que retratam a maior parte das aplicações com estes materiais. Todavia, independentemente do programa escolhido ou disponível, é quase sempre possível utilizar um modelo de material mais representativo com o uso de sub-rotinas de material (UMAT, no caso do ABAQUS). O custo computacional tende a aumentar com o uso de UMATs, pois o programa de elementos finitos fica sujeito à implementação do usuário. Sendo assim, aconselha-se, sempre que possível, utilizar um modelo de material escrito no programa de elementos finitos.

Com as dificuldades computacionais superadas, e o modelo de material e programa definidos, a representatividade da modelagem computacional fica dependente da calibração do modelo de material com a identificação de parâmetros como a rigidez e a resistência do material. Uma vez que as estruturas celulares nem sempre exibem uma resposta macroscópica, os mecanismos de falha e a coleta de dados para o cálculo das propriedades elásticas e plásticas do material podem requerer técnicas e geometrias específicas, como comentado nas seções experimentais do presente trabalho.

Para verificar os dados experimentais, é válido realizar modelos computacionais para avaliar os respectivos resultados. Geralmente são modelos simples de serem construídos e analisados. Para a espuma polimérica H60, observou-se, através de modelos computacionais, a limitação dos modelos de material em questão quanto ao encruamento da espuma (Figs. 71 e 72), mas, como comentado, essas limitações foram contornadas. Se realizados os modelos computacionais para verificação de parâmetros, e uma deficiência no modelo de material não possa ser contornada com uma utilização coerente dos dados experimentais ou então, com uma calibração mais eficiente, novos modelos de material devem ser considerados. No 
presente trabalho, a forte característica anisotrópica da espuma H60, mostrou-se uma grande complicação nas modelagens computacionais que, por imposição do programa utilizado e por opção do presente autor, são modelados isotropicamente. Para a endentação estudada, verificou-se que a localização do carregamento influencia mais a resposta macroscópica da estrutura do que a anisotropia do material. Contudo, a mesma anisotropia pode também apresentar forte influência de acordo com o modelo de material e carregamento aplicado na estrutura (Figs. 76 e 77). Porém, se as técnicas e procedimentos experimentais forem bem consolidados, assim como a falha da estrutura celular em questão, os modelos computacionais para verificação podem ser evitados. De modo geral, o modelo computacional é altamente dependente das propriedades do material, e no caso de modelagens com laminados em material compósito, a precisão na geometria tem também forte influência nas estruturas modeladas, pois, basicamente, esses materiais são muito mais rígidos que os demais materiais na estrutura em foco.

Enfim, obteve-se, pelo diagrama da Figura 93, uma proposta de modelagem computacional relativamente otimizada, em relação ao tempo de solução computacional, e uma metodologia de seleção e calibração de modelos de material utilizados nessas modelagens, que fornecem soluções representativas e satisfatórias. 


\section{Capítulo $V$}

\section{CONCLUSÕES E PERSPECTIVAS}

Com base nos resultados experimentais e computacionais obtidos no presente trabalho, tem-se a seguir algumas conclusões, bem como, perspectivas de trabalhos futuros sobre a utilização de modelos de material para espumas poliméricas aplicadas ou não, a estruturas aeronáuticas em material compósito sanduíche.

\section{i. Quanto aos modelos de material}

Ratificou-se a potencialidade da abordagem fenomenológica no presente trabalho. Mesmo sem representação teórica significativa, uma calibração dos respectivos modelos de material realizada criteriosamente, mostrou-se capaz de superar algumas limitações do modelo e assim, obter resultados satisfatórios. As principais dificuldades encontradas e superadas referentes a esta abordagem macro-mecânica foram:

a) Determinação da superfície inicial de escoamento com a utilização de dados experimentais reais (sem supor um comportamento específico para o material sob tração ou compressão) para a espuma H60 e estudo da evolução efetiva das respectivas superfícies, partindo das superfícies de escoamento inicial real calculadas para a espuma polimérica com auxílio de uma rotina em código MATLAB;

b) Utilização dos modelos de material implementados no programa ABAQUS para estruturas celulares com uma calibração de parâmetros e modelagem computacional, que geraram resultados satisfatórios. Lembrando das complicações que surgem ao se utilizar as implementações dos modelos de material em questão para carregamentos multiaxiais e não monotônicos em estruturas, especialmente quando o modelo de material com encruamento volumétrico é utilizado. 
O uso prático de modelos micro-mecânicos para espumas poliméricas não é aconselhável de modo geral. Há modelos que representam muito bem os regimes elásticos e lineares ou não, contudo o regime plástico é difícil de ser modelado devido ao mecanismo de falha que varia muito de acordo com o material, sua densidade relativa e estrutura celular. Em tese, uma análise micrográfica e estatística deve ser feita para que sejam identificadas as dimensões base da estrutura celular em questão. Somente então, é aconselhável, por exemplo, modelar estruturas anisotrópicas e com geometrias variáveis, tais como seção de arestas e vértices das células da espuma.

Para o material utilizado no presente trabalho, um modelo micro-mecânico requer a seleção ou determinação de um modelo de material para o polímero base, para somente então determinar se a modelagem será feita com elementos de viga, ou sólidos. Independentemente do tipo de elemento, as faces devem ser modeladas, pois estima-se que mais de $85 \%$ do material da espuma H60 está na parede das células, sendo que essa modelagem traz novas complicações. Lembrando ainda da dependência com a taxa de deformação, temperatura e o tempo que os polímeros e as respectivas estruturas possuem e toda a questão de estabilidade e flambagem micro e macro das espumas. Em suma, os modelos micro-mecânicos constituem uma abordagem com foco na criação de novos materiais. Uma vez que estes já são comercializados, os modelos fenomenológicos surgem como a melhor opção de abordagem em questão de representatividade, tempo de implementação e desempenho computacional.

\section{ii. Quanto aos ensaios experimentais}

Os ensaios mostraram que a anisotropia da espuma (transversalmente isotrópica) não pode ser desconsiderada para a espuma polimérica H60. A seguir, têm-se as principais observações de acordo com o tipo de ensaio:

a) De modo geral, com base nos resultados dos ensaios de compressão, foi possível observar a maior precisão dos dados coletados via técnica DIC, pois toda a acomodação inicial do material é desconsiderada, uma vez que a medida de deformação é feita localmente. Pode-se melhorar os resultados obtidos a partir da máquina EMIC, utilizando ensaios cíclicos, contudo a fragilidade e flexibilidade da espuma H60 tornam os resultados obtidos via técnica DIC mais precisos e coerentes com as informações do fabricante;

b) Os resultados gerados a partir dos ensaios de tração não normalizados trouxeram muitas complicações cujos resultados foram discutidos juntamente com as análises 
computacionais. Devido à geometria adotada para os corpos-de-prova, os resultados obtidos pelas duas técnicas diferiram razoavelmente, mas todas as particularidades foram explicadas. Os dados obtidos via técnica DIC possibilitaram a utilização dos corpos-de-prova não normalizados em tração, na medida em que, os dados provenientes desses ensaios foram divididos e analisados de acordo com a técnica de obtenção de dados. Retomando as dificuldades na realização desses ensaios, juntamente com a variação nos dados experimentais e a anisotropia marcante da espuma, uma boa concordância foi atingida;

c) Como a espuma estudada, apresenta uma forte anisotropia, para que as superfícies de escoamento iniciais fossem definidas com maior representatividade, foram feitos alguns ensaios hidrostáticos com a espuma H60, para estimar o limite de escoamento do material sob compressão hidrostática. Novamente, devido às complicações encontradas nesse tipo de ensaio e à característica celular do material (estrutura celular), os resultados obtidos são suficientes para a determinação da superfície inicial de escoamento;

d) Visando uma verificação da representatividade e dos modelos de material estudados, os ensaios de endentação exibiram a dependência do material com a superfície de escoamento e lei de encruamento associados às falhas localizadas. Os ensaios mostraram que quanto maior for a anisotropia do plano analisado, mais os mecanismos micro-mecânicos presentes nos resultados experimentais influenciam na resposta macroscópica computacional. Em geral, estas são mais rígidas e resistentes em comparação aos resultados experimentais.

Sobre o uso de uma técnica DIC, este não é obrigatório na calibração de modelos de material, mesmo porque essas técnicas requerem equipamento específico, bem como um programa computacional para tratar essas imagens. O uso dessas técnicas torna a análise mais confiável e consequentemente também mais precisa. Porém, como discutido neste trabalho, as espumas poliméricas apresentam irregularidades em sua estrutura celular, que gera uma variação nos resultados experimentais, principalmente no valor das rigidezes. Isto torna aconselhável, o uso dessas técnicas no estudo de estruturas celulares relativamente flexíveis. 


\section{iii. Quanto à identificação e calibração de parâmetros}

Demonstrou-se neste trabalho como proceder com a calibração e validação de modelos de material fenomenológicos. Os resultados obtidos são satisfatórios, entretanto uma maior atenção com valores experimentais encontrados foi necessária devido à dispersão obtida para os mesmos, principalmente no valor das rigidezes. Essa variação indica que as calibrações de modelos de material devem seguir uma sequência de passos pré-determinados, como indicado na Figura 93, para que a dispersão nos resultados seja minimizada. Primeiro, uma identificação do grau de anisotropia do material deve ser realizada para que os modelos de material sejam escolhidos, e caso seja necessário propor novos modelos. Em seguida deve-se escolher uma metodologia de análise, seja ela uma técnica DIC ou não, e fabricar uma quantidade significativa e suficiente de corpos-de-prova. A proposta é que os ensaios sejam otimizados com o emprego de uma metodologia.

Constatou-se de uma forma geral, que os dados experimentais não podem apresentar uma variação superior a um valor em torno de $10 \%$. Acima deste valor, os modelos computacionais são muito comprometidos. A influência desse erro é tal que a obtenção de dados experimentais e as respectivas quantificações dos parâmetros dos modelos de material e das geometrias nas modelagens computacionais torna-se mais relevante em aplicações específicas, frente à implementação de um modelo de material com maior parametrização, que busca uma maior representação do material. Entretanto, para modelagens mais abrangentes e genéricas, os modelos de material mais elaborados podem também ser necessários, o que implica em uma abordagem experimental e posterior calibração de parâmetros muito mais trabalhosa.

\section{iv. Quanto aos modelos computacionais}

Todas as respostas obtidas dos modelos computacionais são coerentes com o esperado segundo a teoria e as considerações impostas. Separando de acordo com o tipo de carregamento ou estrutura, conclui que:

a) Para os ensaios de compressão foram feitos alguns modelos computacionais para ratificar os dados experimentais. Os resultados são satisfatórios de acordo com as hipóteses feitas, com destaque para a curva de encruamento. Devido ao mecanismo de falha micro-mecânico de flambagem das células, as deformações reais da espuma e os respectivos deslocamentos aplicados não são diretamente proporcionais; 
b) Os modelos computacionais em tração exibiram resultados esperados, contudo a determinação dos parâmetros e geometrias envolvidas, devido ao uso de uma geometria não completamente normalizada, resultou em diversas complicações discutidas ao longo dos resultados do presente trabalho;

c) Nos modelos computacionais para as endentações, os resultados numéricos apresentaram algumas variações relativamente inerentes à precisão dos dados experimentais, pois, como mencionado, neste carregamento há uma interação direta do endentador com a espuma. Isto resulta em uma maior fragilização do material devido à influência dos mecanismos de falha micro-mecânicos mais evidenciados em carregamentos localizados, que também variam de acordo com o plano de anisotropia do material. Observou-se também que as modelagens computacionais exibem uma maior sensibilidade a variações na resistência do material, uma vez que a plastificação da espuma está presente praticamente em toda a análise;

d) As análises da estrutura sanduíche em questão mostraram que os erros numéricos associados às dimensões dos laminados e nas propriedades elástica e plástica do núcleo, são responsáveis por grandes variações nos resultados macroscópicos nas curvas de força-deslocamento. A influência da anisotropia deve ser contabilizada, pois, como visto nas Figuras 82, 83 e 88, as respostas macroscópicas da estrutura podem ser muito próximas até certo ponto, mas podendo exibir um comportamento com variações na resistência e/ou na rigidez. O uso de um modelo mais refinado, que considere a anisotropia ou falhas micro-mecânicas ou uma calibração mais coerente e estratégica de modelos existentes (como por exemplo, a utilização de uma superfície de "escoamento médio" proposta no presente trabalho) pode aproximar ainda mais os resultados. Quanto melhor a representação do material celular, melhor podem ser os resultados obtidos em uma futura implementação da mesma estrutura sanduíche, mas com um modelo de falha para os laminados.

\section{v. Perspectivas para trabalhos futuros}

Um avanço nessa área de estruturas celulares seria a implementação de um modelo de material que fosse avaliado para carregamentos multiaxiais e cíclicos. Somado a isso, um maior controle sobre o tipo de encruamento e sua variação com o tipo de solicitação são as propostas mais significativas. Ensaios para determinar a dependência da espuma polimérica com as taxas de deformação (principalmente impacto) e com temperatura também são 
avanços importantes e necessários na criação e validação de modelos, principalmente para espumas fabricadas a partir de polímeros, para aplicações mais genéricas. Essas propostas já foram abordadas por vários pesquisadores, alguns utilizam um ou mais conceitos, outros utilizam uma combinação dessas propostas. Porém, de modo geral na literatura encontrada, muito pouco é voltado ao confronto desses modelos com dados experimentais. A maior parte dos pesquisadores não realiza essa abordagem, pois nem sempre os equipamentos necessários estão disponíveis. Este trabalho de mestrado esteve focado na calibração de modelos de material para espumas poliméricas com o intuito de explicitar todas as particularidades da calibração dos modelos de material trabalhados, contudo as conclusões obtidas podem ser extrapoladas para outros modelos de material. Dessa forma, outros modelos e outros materiais podem ser calibrados sem que haja a necessidade, num primeiro momento, de se criar e implementar uma UMATs para cada novo material. Eventualmente um modelo de material precisa ser substituído por outro mais representativo ou mais refinado, mas isto não deve ser efetuado antes dos modelos de material mais acessíveis serem completamente explorados.

Nesse ponto, algumas avaliações mais criteriosas sobre aplicação dos modelos de material devem ser realizadas, pois, independentemente do modelo de material escolhido, as modelagens numéricas passam pela identificação de parâmetros via ensaios experimentais. Dependendo da recorrência na utilização de um material em específico e fazendo uma análise a longo prazo, é possível que a implementação direta de uma sub-rotina com um modelo de material fenomenológico mais representativo, seja mais estratégica. A metodologia proposta para a escolha e calibração de modelos de material, não releva a frequência de uso do modelo de material como variável, para que a mesma permaneça o mais genérica possível e dessa forma, esta pode sempre ser utilizada. 


\section{REFERÊNCIAS}

ABAQUS/CAE User's Manual. ABAQUS version 6.7 - documentation. (C) Dassault Systèmes, 2007.

ABRATE, S. Criteria for yielding or failure of cellular materials. Journal of Sandwich Structures and Materials, v. 10, p. 5, 2008.

ANAND, L.; AMES, N. M. On modeling the micro-indentation response of an amorphous polymer. International Journal of Plasticity, v. 22, p. 1123, 2006.

ANGÉLICO, R. A. Avaliação de modelos de falhas progressivas para estruturas em material compósito. 62 f. Dissertação (Mestrado) - Escola de Engenharia de São Carlos, Universidade de São Paulo, São Carlos, 2009.

ARRUDA, E. M.; BOYCE, M. C.; JAYACHANDRAN, R. Effects of strain rate, temperature and thermomechanical coupling on the finite strain deformation of glassy polymers. Mechanics of Materials, v. 19, p. 193, 1995.

AMERICAN SOCIETY FOR TESTING AND MATERIALS. ASTM D 1621 - 04a: Standard Test Method for Compressive Properties of Rigid Cellular Plastics. 2004.

ASTM D 1623 - 03: Standard Test Method for Tensile and Tensile Adhesion Properties of Rigid Cellular Plastics. 2003.

ASTM D 3574 - 08: Standard Test Methods for Flexible Cellular Materials - Slab, Bonded, and Molded Urethane Foams. 2005.

BARLOW, J. Optimal Stress Locations in Finite Element Models. International Journal for Numerical Methods in Engineering, v. 10, p. 243, 1976.

BESNARD, G.; HILD, F.; ROUX, S. "Finite-Element" displacement fields analysis from digital images: Application to Portevin-Le Châtelier bands. Experimental Mechanics, v. 46, p. 789, 2006.

BERTHELOT, J. M.; LOLIVE, E. Non-linear behaviour of foam cores and sandwich materials, Part 1: Materials and modelling. Journal of Sandwich Structures and Materials, v. 4, p. 219, 2002a. 
. Non-linear behaviour of foam cores and sandwich materials, Part 2: Indentation and three-point bending. Journal of Sandwich Structures and Materials, v. 4, p. 297, 2002b.

BRYDON, A. D. et al. Simulation of the densification of real open-celled foam microstructures. Journal of the Mechanics and Physics of Solids, v. 53, p. 2638, 2005.

BUCKLEY, C. P.; JONES, D. C. Glass-rubber constitutive model for amorphous polymers near the glass transition. Polymer, v. 36, n. 17, p. 3301, 1995.

CHEN, C.; LU, T. J.; FLECK, N. A. Effect of imperfections on the yielding of twodimensional foams. Journal of the Mechanics and Physics of Solids, v. 47, p. 2235, 1999.

CHEN, W.F.; HAN, D.J. Plasticity for structural engineers. New York: Springer-Verlag, 1988.

CHRISTENSEN, R. M. Mechanics of cellular and other low-density materials. International Journal of Solids and Structures, v. 37, p. 93, 2000.

CIBA Especialidades Químicas Ltda. Disponível em: $<$ http://www.hobbys.com.br/centraldeveleiros/araldite-epoxi.htm>. Acesso em: 25 abr. 2010.

CRISFIELD, M. A. Non-linear finite element analysis of solids and structures: advanced topics. New York: John Wiley \& Sons, 1997.

CUNDA, L. A. B. et al. Numerical simulation of the mechanical behaviour of metallic hollow spheres structures. In: CONGRESSO IBERO LATINO AMERICANO DE MÉTODOS COMPUTACIONAIS EM ENGENHARIA - CILAMCE, 29., 2008, Maceió, Anais... Maceió: UFAL/ABMEC/AMC, 2008.

DANIEL, I. M.; GDOUTOS, E. E.; WANG, K. -A.; ABOT, J. L. Failure modes of composite sandwich beams. International Journal of Damage Mechanics, v. 11, p. 309, 2002.

DESHPANDE, V.S.; FLECK, N.A. Isotropic constitutive models for metallic foams. Journal of the Mechanics and Physics of Solids, v. 48, p. 1253, 2000.

Multi-axial yield behaviour of polymer foams. Acta materialia, v. 49, p.1859, 2001. 
DIAB Literature - Manuals. Technical Manual: Divinycell H. Disponível em: < http://www.diabgroup.com/europe/literature/e_lit_man.html >. Acesso em: 2 mar. 2010.

FAN, X. et al. Four-point bending evaluation of sandwich materials with strain mapping system. In: EUROPEAN CONFERENCE ON COMPOSITE MATERIALS - ECCM. 10., June, 2002, Brugge, Belgium. Proceedings... Belgium: ECCM, 2002.

FERRANTE, M. Seleção de materiais. 2. ed. SãoCarlos: EDUFSCar, 2002.

GDOUTOS, E. E.; DANIEL, I. M.; WANG, K.A. Failure of cellular foams under multiaxial loading. Composites: part A, v. 33, p. 163, 2002.

GHORBEL, E. A viscoplastic constitutive model for polymeric materials. International Journal of Plasticity, v. 24, p. 2032, 2008.

GIBSON, L. J.; ASHBY, M. Cellular solids: structures \& properties. England: Pergamon Press-Headington Hill Hall, 1988.

GIBSON, L. J. et al. Failure surfaces for cellular materials under multiaxial loads -I. Modelling. International Journal of Mechanical Sciences, v. 31, n. 9, p. 635, 1989.

GIMENEZ, I. et al. M. Experimental Analysis of mechanical behaviour and damage development mechanisms of PVC foams in static tests. Materials Science (Medžiagotyra), v. 10, n. 1, 2004.

GIOUX, G.; MCCORMACK, T.M.; GIBSON, L.J. Failure of aluminum foams under multiaxial loads. International Journal of Mechanical Sciences, v. 42, p.1097, 2000.

GONG, L.; KYRIAKIDES, S.; JANG, W. -Y. Compressive response of open-cell foams. Part I: Morphology and elastic properties. International Journal of Solids and Structures, v. 42, p. 1355, 2005.

GONG, L.; KYRIAKIDES, S. Compressive response of open cell foams Part II: Initiation and evolution of crushing. International Journal of Solids and Structures, v. 42, p. 1381, 2005.

GONG, L.; KYRIAKIDES, S.; TRIANTAFYLLIDIS, N. On the stability of Kelvin cell foams under compressive loads. Journal of the Mechanics and Physics of solids, v. 53, p. $771,2005$. 
GRÉDIAC, M. The use of full-field measurement methods in composite material characterization: Interest and limitations. Composites: Part A, v. 35, p. 751, 2004.

GRÉDIAC, M.; TOUSSAINT, E.; PIERRON, F. Special virtual fields for the direct determination of material parameters with the virtual fields method. 1- Principle and definition. International Journal of Solids and Structures, v. 39, p. 2691, 2002a.

Special virtual fields for the direct determination of material parameters with the virtual fields method. 2- Application to in-plane properties. International Journal of Solids and Structures, v. 39, p. 2707, 2002b.

Special virtual fields for the direct determination of material parameters with the virtual fields method. 3. Application to the bending rigidities of anisotropic plates. International Journal of Solids and Structures, v. 40, p. 2401, 2003.

HILD, F.; ROUX, S. CORRELI ${ }^{\mathrm{Q4}}$ : A Software for "finite-element" displacement field measurements by digital image correlation. Paris: Université Paris/LMT-Cachan. 2008, 55p. (Relatório interno sobre correlação de imagem digital - ENS de Cachan/CNRS-UMR 8535/PRES).

HUČKO, B.; FARIA, L. Material model of metallic cellular solids. Computers \& Structures, v. 62, n. 6, p. 1049, 1997.

JIN, H. et al. Full-field characterization of mechanical behavior of polyurethane foams. International Journal of Solids and Structures, v. 44, p. 6930, 2007.

JUNTIKKA, R; HALLSTRÖM, S. Shear characterization of sandwich core materials using four-point bending. Journal of Sandwich Structures and Materials, v. 9, p. 67, 2007.

LI, H. X.; BUCKLEY, C. P. Evolution of strain localization in glassy polymers: A numerical study. International Journal of Solids and Structures, v. 46, p. 1607, 2009.

LI, Q. M.; MINES, R. A. W. Strain measures for rigid crushable foam in uniaxial compression. Strain, v. 38, p. 132, 2002.

LI, Q. M.; MINES, R. A. W.; BIRCH, R. S. The crush behaviour of Rohacell-51WF structural foam. International Journal of Solids and Structures, v. 37, p. 6321, 2000. 
LINN, R. V.; OLIVEIRA, B. F. Finite element simulation of compression behavior of cellular metals. In: CONGRESSO IBERO LATINO AMERICANO DE MÉTODOS COMPUTACIONAIS EM ENGENHARIA - CILAMCE, 29., 2008, Maceió, Anais... Maceió: UFAL/ABMEC/AMC, 2008.

LIU, Q; SUBHASH, G.; GAO, X. -L. A parametric study on crushability of open-cell structural polymeric foams. Journal of Porous Materials, v. 12, p. 233, 2005.

LIU, Y. et al. Thermomechanics of shape memory polymers: Uniaxial experiments and constitutive modeling. International Journal of Plasticity, v. 22, p. 279, 2006.

MATWEB - Material property data. Disponível em: <www.matweb.com>. Acesso em: 16 mar. 2009.

MENDONÇA, P.T.R. Materiais compostos e estruturas sanduíche: projeto e análise. Barueri: Manole, 2005.

MILLER, R. E. A continuum plasticity model for the constitutive and indentation behaviour of foamed metals. International Journal of Mechanical Sciences, v. 42, p.729, 2000.

MILLS, N. J.; ZHU, H. X. The high strain compression of closed-cell polymer foams. Journal of the Mechanics and Physics of Solids, v. 47, p. 669, 1999.

OLIVEIRA, G. P. Evaluation de modèles de matériaux des structures sandwiches aéronautiques. São Carlos: EESC/France: Dép. Génie Mécanique - Université Pierre et Marie Curie, 2007. 49 p. (Relatório de Estágio Internacional).

OLIVEIRA, G. P. et al. An investigation of material model parameters for foams of composite sandwich structures. In: CONGRESSO NACIONAL DE ENGENHARIA MECÂNICA. 5., 2008. Salvador. Anais... Salvador: ABCM, 2008.

OUELLET, S.; CRONIN, D.; WORSWICK, M. Compressive response of polymeric foams under quasi-static, medium and high strain rate conditions. Polymer Testing, v. 25, p. 731, 2006.

PÉREZ, M. A. R.; SAJA, J. A. Dynamic mechanical analysis applied to the characterization of closed cell polyolefin foams. Polymer Testing, v. 19, p. 831, 2000. 
PFLUG, J.; VERPOEST, I. Sandwich materials selection charts. Journal of Sandwich Structures and Materials, v. 8, p. 407, 2006.

QUÍMICA e Tecnologia dos Poliuretanos. Disponível em: <http://www.poliuretanos.net/>. Acesso em: 5 jan. 2010.

RIBEIRO, M. L. (2009). Programa para análise de juntas coladas: compósito-compósito e metal-compósito. 163 f. Dissertação (Mestrado) - Escola de Engenharia de São Carlos, Universidade de São Paulo, São Carlos, 2009.

RIZOV, V. I. Non-linear indentation behavior of foam core sandwich composite materials - A 2D approach. Computational Materials Science, v. 35, p. 107, 2006 a.

Elastic-plastic response of structural foams subjected to localized static loads. Materials and Design, v. 27, p. 947, 2006 b.

ROMERO, P. A.; ZHENG, S. F.; CUITIÑO, A. M. Modeling the dynamic response of viscoelastic open-cell foams. Journal of the Mechanics and Physics of Solids, v. 56, p. 1916, 2008.

RUSSO, A.; ZUCCARELLO, B. Experimental and numerical evaluation of the mechanical behaviour of GFRP sandwich panels. Composite Structures, v. 81, p. 575, 2007.

SADIGHI, M.; POURIAYEVALI, H.; SAADATI, M. A study of indentation energy in three points bending of sandwich beams with composite laminated faces and foam core. World Academy of Science, Engineering and Technology, v. 36, p. 214, 2007.

SCHUBEL, P. M.; LUO, J. -J.; DANIEL, I. M. Impact and post impact behavior of composite sandwich panels. Composites: Part A, v. 38, p. 1051, 2007.

SEGERSTAD, P. H.; TOLL, S. Open-cell cellular solids: A constitutive equation for hyperelasticity with deformation induced anisotropy. International Journal of Solids and Structures, v. 45, p. 1978, 2008.

SHIPSHA, A.; HALLSTRÖM, S.; ZENKERT, D. Failure mechanisms and modelling of impact damage in sandwich beams - A 2D Approach: Part I - Experimental investigation. Journal of Sandwich Structures and Materials, v. 5, p. 7, 2003. 
SOARES, G. P. Ferramenta computacional de análise de estruturas em material compósito sanduíche. São Carlos: EESC, 2009. 59 p. (Relatório científico para FAPESP 2007/07795-8).

SODEN, P. D. Indentation of composite sandwich beams. Journal of Strain Analysis, v. 31, n. 5, p. 353, 1996.

SOKOLINSKY, V. S. et al. Experimental and analytical study of nonlinear bending response of sandwich beams. Composite Structures, v. 60, p. 219, 2003.

STEEVES, C. A.; FLECK, N. A. Collapse mechanisms of sandwich beams with composite faces and a foam core, loaded in three-point bending. Part I: Analytical models and minimum weight design. International Journal of Mechanical Sciences, v. 46, p. 561, 2004a.

Collapse mechanisms of sandwich beams with composite faces and a foam core, loaded in three-point bending. Part II: Experimental investigation and numerical modelling. International Journal of Mechanical Sciences, v. 46, p. 585, 2004 b.

SUBHASH, G.; LIU, Q. Crushability maps for structural polymeric foams in uniaxial loading under rigid confinement. Experimental Mechanics, v. 44, n. 3, p. 289, 2004.

SWANSON, S. R.; KIM, J. Optimization of sandwich beams for concentrated loads. Journal of Sandwich Structures and Materials, v. 4, p. 273, 2002.

TAGARIELLI, V.L.; FLECK, N.A.; DESHPANDE, V.S. Collapse of clamped and simply supported composite sandwich beams in three-point bending. Composites: part B, v. 35, p. 523, 2004.

TITA, V. Contribuição ao estudo de danos e falhas progressivas em estruturas de material compósito polimérico. 193 f. Tese (Doutorado) - Escola de Engenharia de São Carlos, Universidade de São Paulo, São Carlos, 2003.

TRIANTAFILLOU, T. C. et al. Failure surfaces for cellular materials under multiaxial loads II. Comparison of models with experiment. International Journal of Mechanical Sciences, v. 31, n. 9 , p. $665,1989$.

VIANA, G. M.; CARLSSON, L. A. Mechanical properties and fracture characterization of cross-linked PVC foams. Journal of Sandwich Structures and Materials, v. 4, p. 99, 2002. 
VIOT, P. Hydrostatic compression on polypropylene foam. International Journal of Impact Engineering, v. 36, p. 975, 2009.

WANG, D. -A.; PAN, J. A non-quadratic yield function for polymeric foams. International Journal of Plasticity, v. 22, p. 434, 2006.

WANG, Y.; CUITIÑO, A. M. Three-dimensional nonlinear open-cell foams with large deformations. Journal of the Mechanics and Physics of Solids, v. 48, p. 961, 2000.

WARREN, W. E.; KRAYNIK, A. M. Foam mechanics: the linear elastic response of twodimensional spatiallly periodic cellular materials. Mechanics of Materials, v. 6, p. 27, 1987.

WARREN, W. E.; KRAYNIK, A. M.; STONE, C. M. A constitutive model for twodimensional nonlinear elastic foams. Journal of the Mechanics and Physics of Solids, v. 37, no. 6, p. $717,1989$.

WEAIRE, D.; HUTZLER, S. The physics of foams. New York: Oxford University Press, 1999.

YANG, J.; SHEN, H. -S.; ZHANG, L. Nonlinear local response of foam-filled sandwich plates with laminated faces under combined transverse and in-plane loads. Composite Structures, v. 52, p. 137, 2001.

ZENKERT, D.; SHIPSHA, A.; PERSSON, K. Static indentation and unloading response of sandwich beams. Composites: Part B, v. 35, p. 511, 2004.

ZHANG, J. et al. Constitutive modeling of polymeric foam material subjected to dynamic crash loading. International Journal of Impact Engineering, v. 21, n. 5, p. 369, 1998

ZHANG, T. A general constitutive relation for linear elastic foams. International Journal of Mechanical Sciences, v. 50, p.1123, 2008.

ZHU, H. X.; MILLS, N. J. Modelling the creep of open-cell polymer foams. Journal of the Mechanics and Physics of Solids, v. 47, p. 1437, 1999. 


\section{APÊNDICE A}

Com base na equação (87), observa-se que a equação possui três parâmetros: $\sigma_{y} ; \alpha$; e $\sigma_{0}$. Adotando três caminhos (tipos) de carregamento no espaço das tensões $\sigma_{\chi} x \sigma_{m}$, pode-se realizar os ensaios referentes à esses três caminhos de carregamento, de tal forma que se obtenha o valor das tensões desviadoras ou hidrostáticas de escoamento do material. Assim, 3 pontos nas superfícies (87) são conhecidos, e um sistema de 3 equações e 3 incógnitas é construído para que os parâmetros da superfície sejam calculados, e os consequência os parâmetros $k$ e $k_{t}$.

A exemplo do que foi utilizado, os ensaios de compressão hidrostática, tração uniaxial e compressão uniaxial configuram um possível sistema não-linear (eq. (127)).

$$
\begin{aligned}
\sigma_{y}{ }^{2} & =\left(x_{1}{ }^{2}+\alpha^{2}\left(\frac{x_{1}}{3}-\sigma_{c}\right)^{2}\right) \\
\sigma_{y}{ }^{2} & =\left(x_{2}{ }^{2}+\alpha^{2}\left(\frac{x_{2}}{3}+\sigma_{c}\right)^{2}\right) \\
{\sigma_{y}}^{2} & =\left(0+\alpha^{2}\left(x_{3}-\sigma_{c}\right)^{2}\right)
\end{aligned}
$$

No sistema (127), os índices 1, 2 e 3 nas componentes de tensão $x$, são os respectivos valores para os carregamentos em compressão uniaxial, tração uniaxial e compressão hidrostática respectivamente. Na terceira equação, o número zero é mantido por completeza.

A solução desse sistema deve ser realizada com muita atenção, pois os parâmetros obtidos são números irracionais que resultam em uma superfície de falha, cujos limites de escoamento, referentes ao três caminhos de carga escolhidos, tendem a ser inferiores aos valores de entrada. Logo os resultados precisam ser corrigidos. Uma das possíveis soluções é uma incrementação do parâmetro $\sigma_{y}$ para que toda a superfície aumente, o que caracteriza um um aumento das tensões de escoamento definidas por esta superfície. 


\section{APÊNDICE B}

As taxas de deformação para as direções normal e no plano, para ambas as direções e trações e compressões uniaxiais foram estimadas a partir das Figuras 94 a 97.

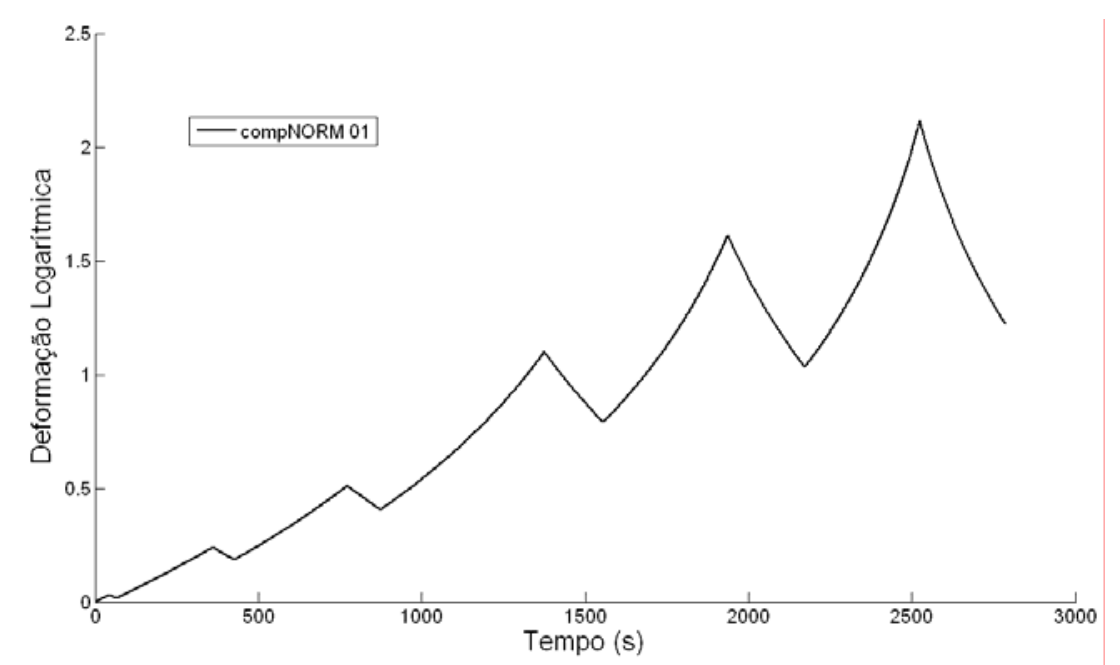

Figura 94. Variação da deformação logarítmica de compressão na direção normal com o tempo

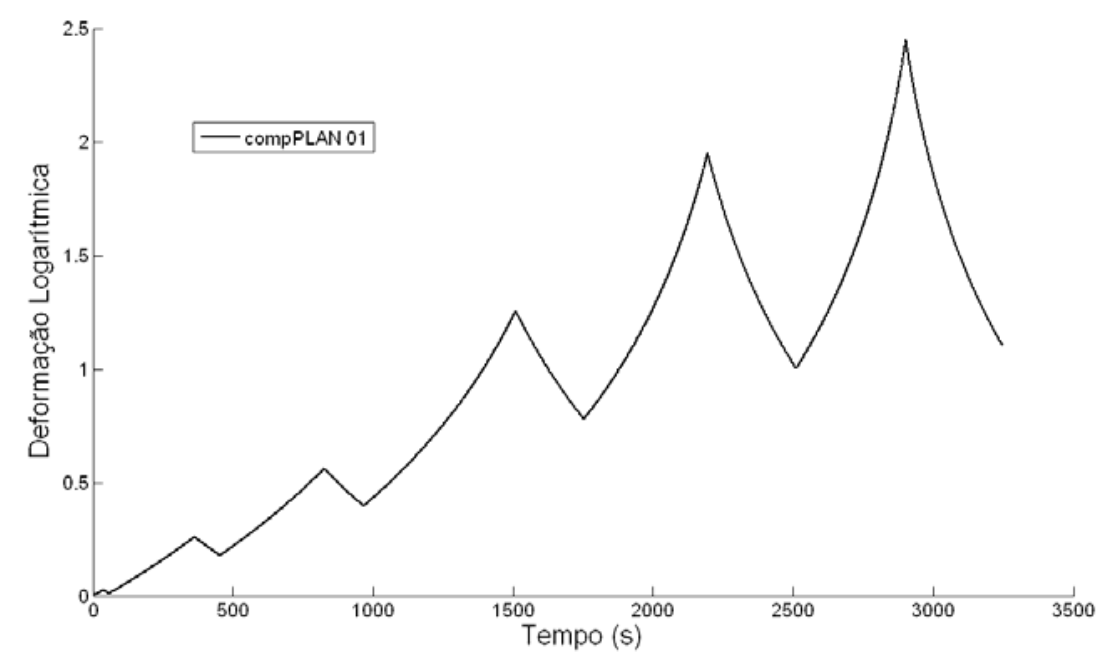

Figura 95. Variação da deformação logarítmica de compressão na direção do plano com o tempo

Em compressão a taxa de deformação não é constante durante todo o carregamento cíclico exibido nas Figuras 94 e 95 como nas Figuras 96 e 97 referentes aos ensaios de tração. Essa variação na taxa de deformação é devido à densificação do material em compressão. As taxas de deformação em compressão foram calculadas através de uma média das taxas de deformação para os 3 ciclos intermediários. 


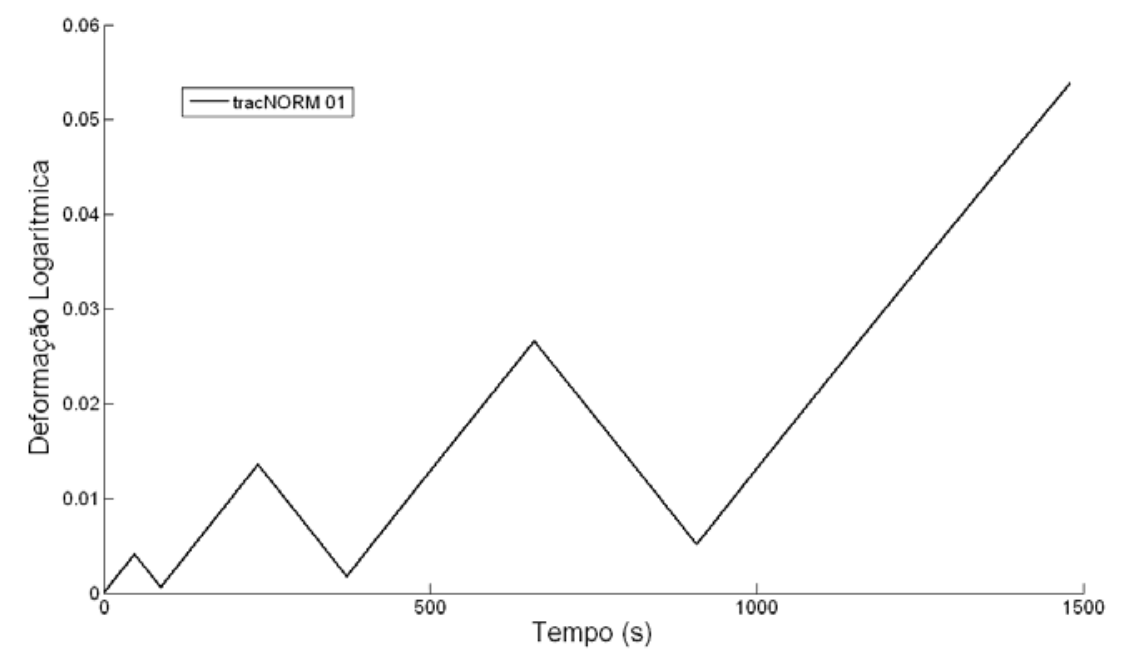

Figura 96. Variação da deformação logarítmica de tração na direção normal com o tempo

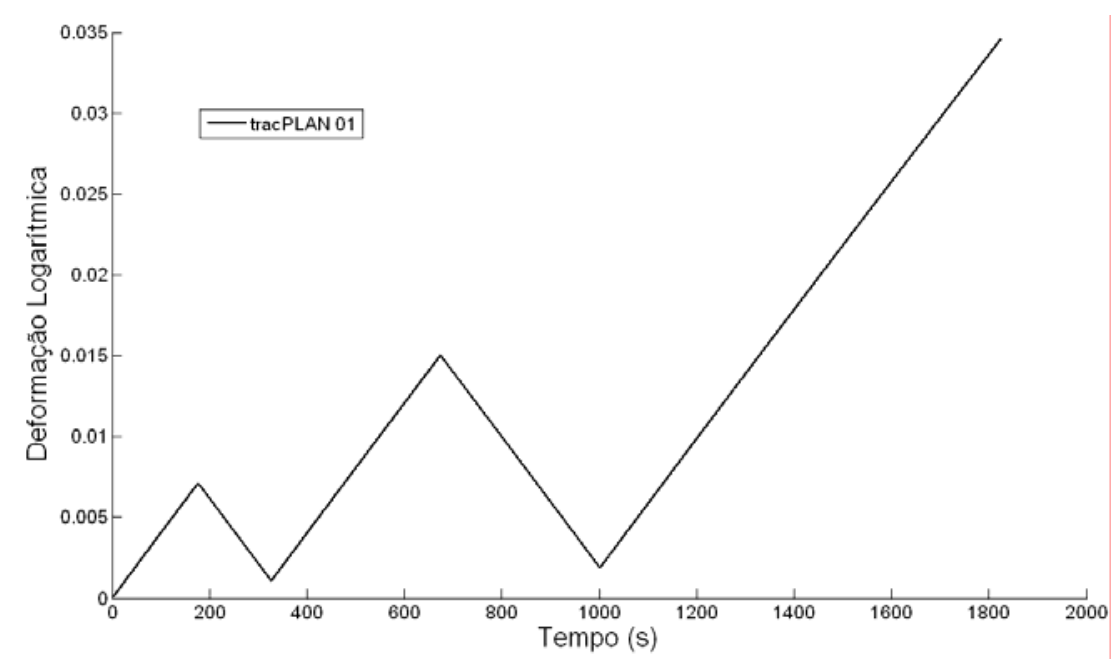

Figura 97. Variação da deformação logarítmica de tração na direção do plano com o tempo 


\section{APÊNDICE C}

Dos ensaios hidrostáticos, também foi obtida uma curva de recuperação para a espuma polimérica (Fig. 98) submetida a uma pressão de aproximadamente 220psi ( 1.5MPa). Dois corpos-de-prova foram ensaios e monitorados por aproximadamente 65 horas. Um ajuste exponencial foi adotado para os dados obtidos e a respectiva equação é a expressão (128).

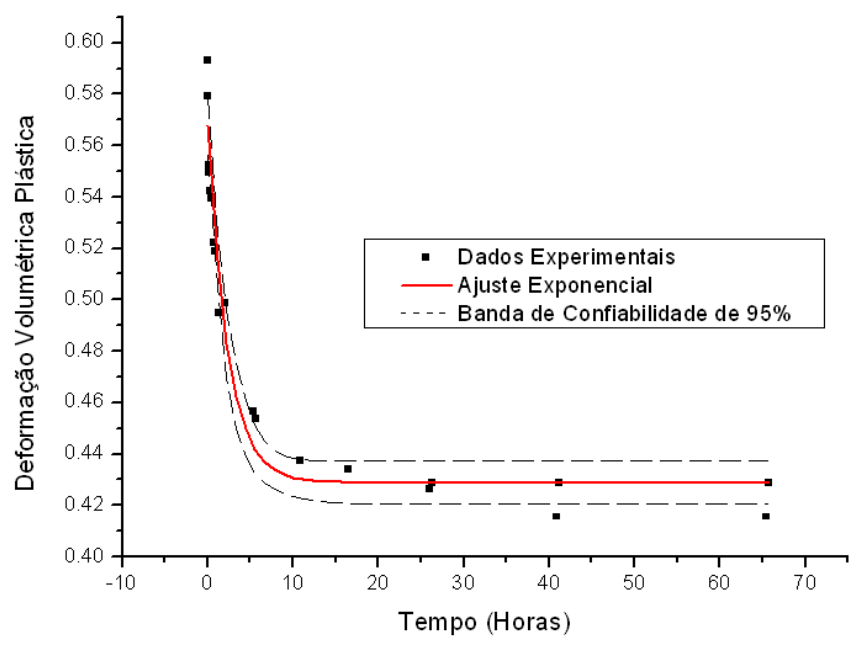

Figura 98. Relaxamento da espuma polimérica H60

$$
\varepsilon_{v o l}=0.429+0.139 e^{-(t / 2.359)}
$$

